

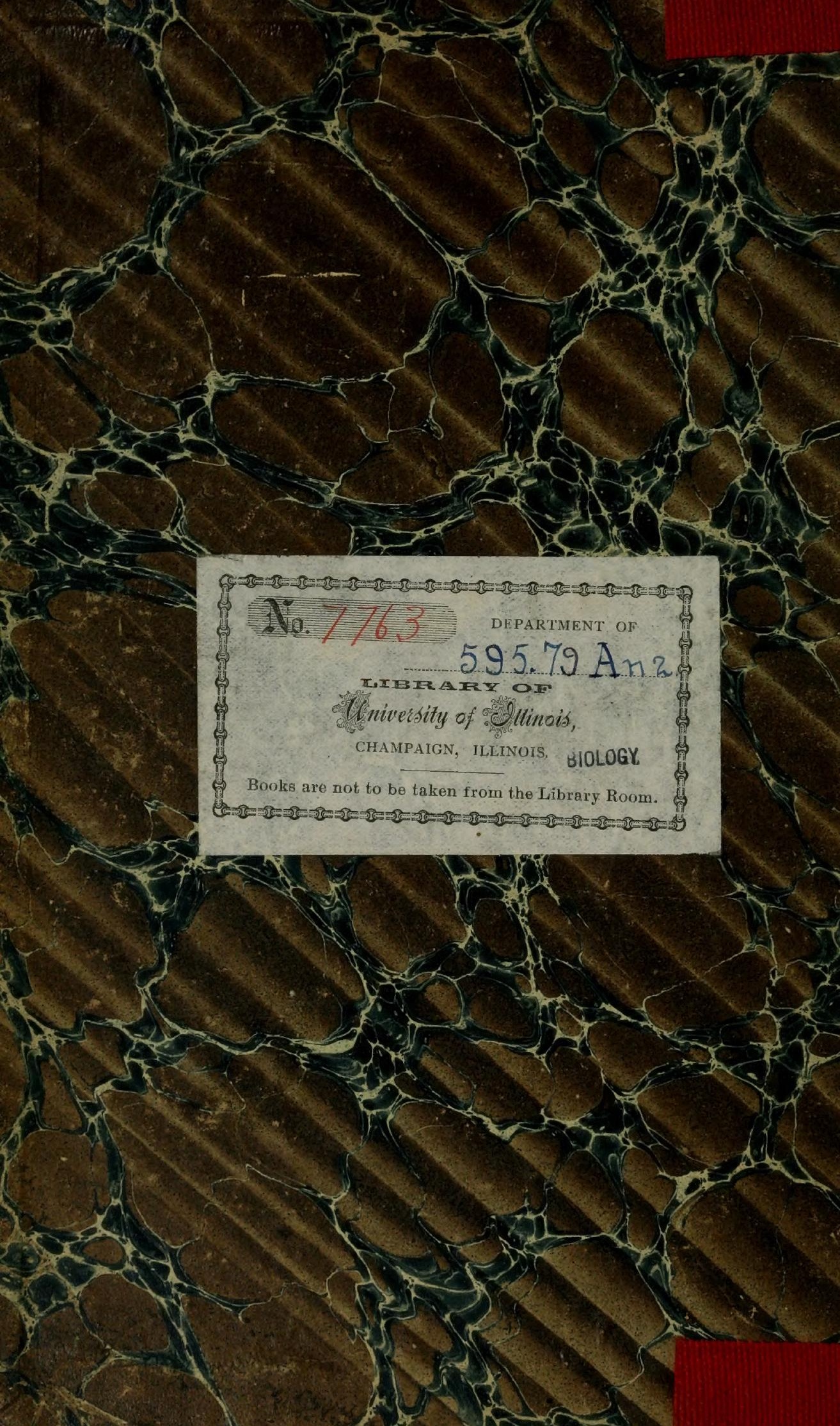




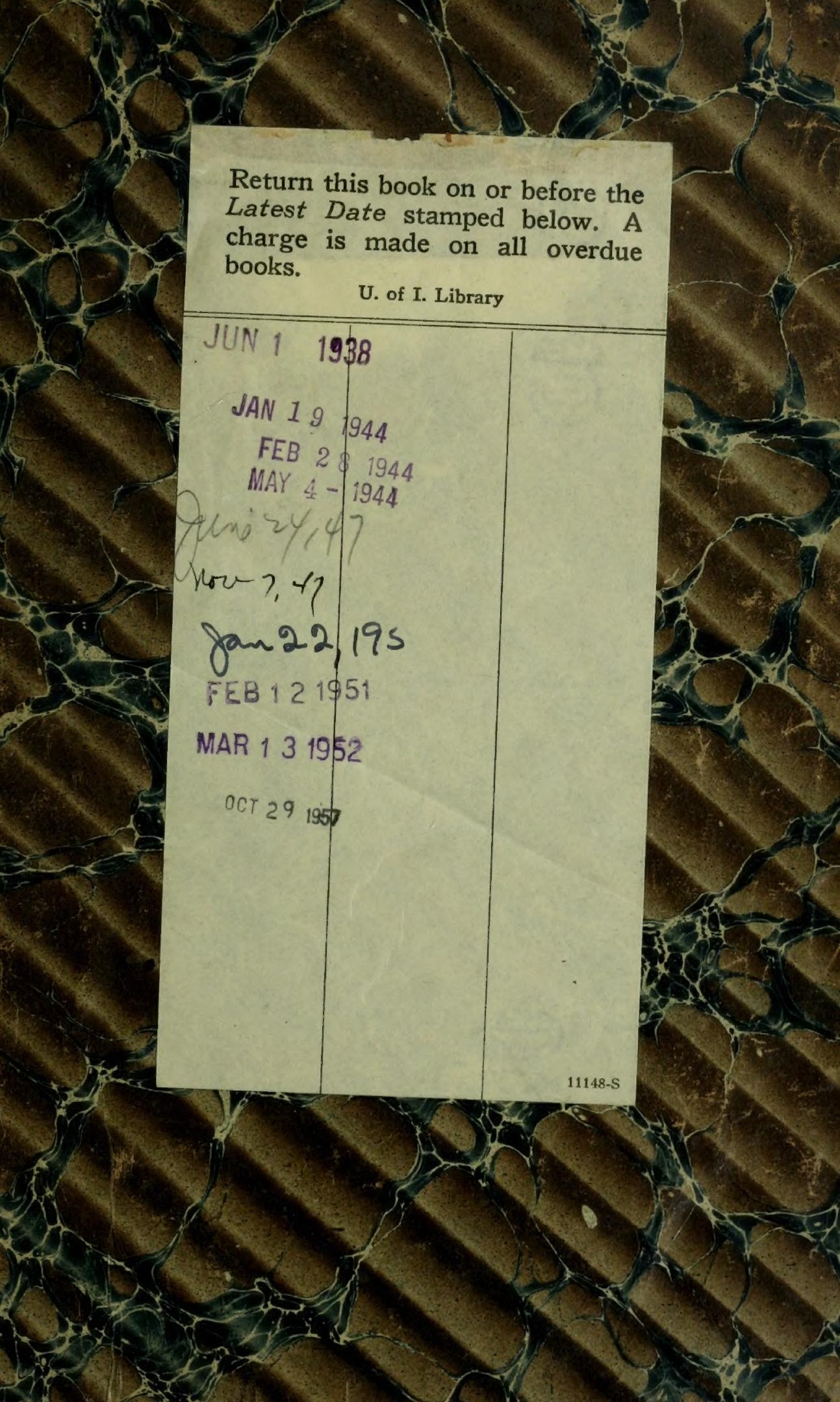





LA STRUCTURE \& LA BIOLOGIE

\section{DES INSECTES}




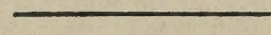

Extrair du Species des Hyménoptères d'Europe et d'Algérie. 


\section{LA STRLCTLRR \& LA BIOLOCIR}

ans

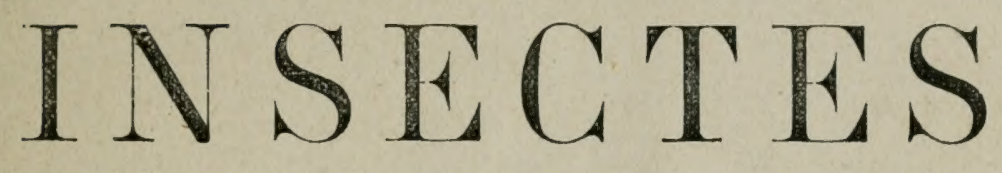

et particulièrement de ceux appartenant à l'ordre

DES H Y M É N O P T E R E S

(MOUCHES A SCIE, ICHNEUMONS, GUEPPES, ABEILLES, FOURMIS)

PAR

ED. ÁNDRÉ

Membre des Sociétés entomologiques de France, Londres, Berlin, Stettín, etc. Membre correspondant de la Société des Sciences historiques et naturelles de Semur, Membre correspondant de la Société d'Etudes scientifiques de Paris, de l'Association scientifigue de la Gironde, Ingénieur des Arts et Manufactures, etc. Enginear

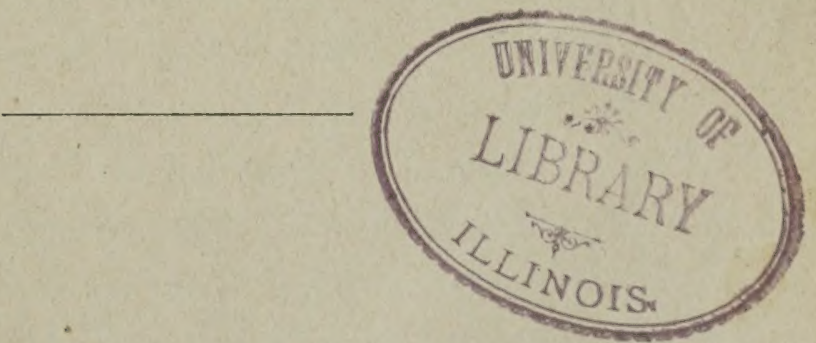

CHEz L'AUTEUr, A BEAUNE (CÔTE-D'Ori) 1882

Tous droits réservés 
595.7

$$
\text { An }
$$




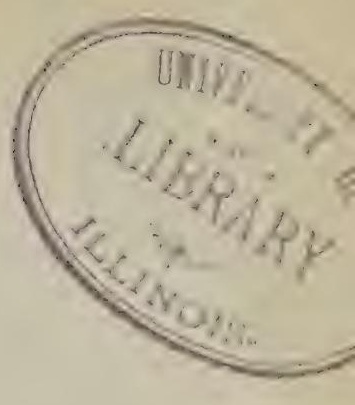

\section{AVANT-PROPOS}

L'ouvrage que je présente aujourd'hui au public a déjà passé sous les yeux de quelques entomologistes, comme introduction à mon grand travail sur les hỵménoptères (1). C'est sur la demande d'un grand nombre de personnes que leurs goùts ne poussent pas vers l'étude détaillée des insectes, ou qui n'ont pas les loisirs nécessaires pour s'y adonner, mais qui désirent toutefois avoir des notions générales aussi cxactes que possible sur ces petits itres si intéressants, que je me suis décidé à faire une édition sé-

(1) Species des IIymenopteres d'Europe et d'Algérie. 
parée de cette introduciion. J'y ai apporté les moditications nécessaires pour en faire un livre tout à fait indépendant.

Les pages qui suivent ne sont pas, comme cela n'arrive que trop souvent dans les travaux mis au jour dans un but de vulgarisation, la répétition banale de tout ce qui a été dit mille fois précédemment, mais elles constituent, au contraire, une œuvre complètement inédite dans toutes ses parties, et où les travailieurs, comme les gens du monde désireux de s'instruire, trouveront amplement à se satisfaire.

A l'époque où nous vivons, époque fiévreuse s'il en fût, et oủ les progrès de la science et de l'industrie se précipitent au point de lasser l'intelligence la mieux trempée, à cette époque où la vapeur nous donne mille fois la force des géants de l'antiquité, ou l'électricité laisse bien loin derrière elle toutes les conceptions les plus hardies des esprits les plus avertureux, à cette époque où l'instruction tient en tout lieu la première place, il serait indigne d'un esprit, même peu cultivé, d'ignorer les notions les plus générales des sciences dont il entend parler et dontil parle lui-même à chaque instant, malgré son ignorance.

La nature, au milieu de laquelle nous vivons et dont nous faisons partie nous-mêmes, renferme une population si nombreuse d'ètres différents, que les spécialistes peuvent seuls esperer en scruter tous les détails; mais si telle ne peut être l'ambition de chacun de nous, au moins devons-nous tâcher d'acquérir des notions générales assez précises 
pour nous permettre de comprendie le iesultat de leurs recherches, et, par suite, d'en apprécier toutel'imprtance.

C'est le but que je me suis proposé de remphir', et je serai satisfait s'il m'est donné d'être utile à quelques-uns.

\author{
ED. ANDRÉ.
}

Beaunè, 25 Avril 1882. 

veux sculement, en quelques mols, montrer la meilleure manière de cultiver cette science pour y trouver l'intérêt le plus grand, les plaisirs les plus réels, et, en mème temps, pour arriver à la faire progresser le plus rapidement.

Il y'a, en effet, plusieurs manières de comprendre et d'étudier l'entomologie; par suite plusicurs catígories d'entomologistes pouvant se classer en deux séries principales: les collectionneurs et les observateurs.

Parmi les premiers se placent déjà de simples amateurs, ramassant des insectes sans but bien détcrminé, et sans résultat autre que de remplir des cadres d'espèces plus ou moins brillantes. Ceux-là ne méritent aucun intérêt.

Sur un échelon plus élevé so trouvent ceux qui cherchent à réunir chez eux la faune d'un pays; ils adaptent quelquefois des noms aux espèces, mais n'ont aussi, le plus souvent, qu'un but assez restreint et ne méritent pas mème le nom d'entomologistes.

Enfin nous arrirons aux collectionneurs sérieux, bornant parfois aussi leur ambition à étudier les insectes d'une localité,mais ne faisant que de la science systématique, ne s'inquiétant absolument que de classification sans s'occuper ni des mours, ni des métamorphoses. Ces savarits, parmi lesquels on compte les hommes les plus éminents, sontaussi les plus nombreux, et on leur doit des travaux d'autant plus recommandables, que la partie systématique de la science est l'un des principaux outils dont a besoin de se servir le naturaliste, dans la véritable acception du mot. Mais ce n'est qu'un outil, et réduire l'entomologic à ce point de vue, c'est en fuire une science trop abstraite, c'est lui enlever, avec son utilité pratique qui est incontestable, toute sa grâce, toute sa poésie et les sources des principales jouissances qu'elle peut procurer.

Tout autre est le travail du naturaliste proprement dit. Il ácepte les résultats de ses collégues, se réservant de les vérifier par ses propres observations; mais il a des vues plus larges. Chez lui, peu de cartons méthodiquement arrangés; ses insectes sont souvent brisés pan le fait même de ses études. Il n'a rien dans son. cabinet qui prisse attirer les yeux, sinon un désordre apparent de flacons, de plantes clesscehées, de boites de toutes grandeurs et des papiers portant en tous sene des notes et des éroquis. Tout son tra. 
Vail se troure ì peu pres confiné dans le registre de ses observations ; mais lì s'etalent de véritables trésors, inappréciablespour le public et formant les matíriaux des ourrages importants (ju'il médite, et yui doirent repousser d'un pas les bornes des connaissances lumaines.

De nos jours, la science ne peut plus s'étudier comme on le lisisail encore dans la premiere moitié de ce siècle, où les savants sévertuaient presque uni fuement a trouver lessystè mes de classitication les meilleui's et les plus rationnels, car c'est en effet par là qu’il fillait commencer. Leursétudescomprenaient, non seulement lit totalité des insectes, mais encore les crustacés, les annélides, ctc.

Aujourd hui, l'entomologie s'est tellement étendue, les savants en ont si bien reculé les limites, qu'une vie d'homme serait tout a lait insullisante pourembrasser l'étude detant d'êtres différents. Il faut maintenant, de toute nécessité, nous restreindre, non seulement aux insectes seuls, mais encore, parmi eux, choisir un ordíc ou même une famille, pour lui consacrer nos soins. L'analyse d'un scul genre suffit souvent mème à occuper un naturaliste. Nous ne devons donc pas calquer les travaux trop vastes de nos devanciers, mais nous résigner à n'apporter chacun qu'une petite pierre à l’édifice de la science, si nous voulons qu'ellę soit parlatite, laissant seulement ì l'érudition, plutót qu'au mérite de yuelques-uns, le soin de réunir tous ces fragments épar's et de les c-ordonner. Le róle de l'entomologiste est, aujourd hui, d'arriver ¿ connaitro les secretis les plus intimes de la vie des insectesqu'il éludie. C'est là que la science présente les plus grandes lacunes et qu'clle appelle le plus de recrues.

Aussi, pour répondre aux questions étonnćes de beaucoup de gens sur ce (que peut avoir de séricux l'étudedeces petits êtres, et encore pour montrer aux débutimts la marche genérale à suivre, ne sera-t-il pas hois de propos d'indiquer ici les conditions que doit remplir un travailleur serieux, désireux d'artiver à un résultat, si minime qu'il soit, et d'en doter la science.

Le nalturaliste oul'entomologiste observateur, tel que je le comprends, doit ête assez au,courant destravaux systematiques pour connaitre parfaitement l'ordre qu il a pris a tiche d'étudier et pouvoir rectifier les erreurs qui se seraient grissées dans les catalo- 
gues; il doit, de plus, en raison des relations intimes qui relient tous les insectes entre eux, avoir une connaissance générale.mais moins approfondic, de tous les autres ordres: Il doit être assez bo. taniste pour pouvoir nommer les plantes qui servent de nourriture ou. d'habilat aux insectes (qu'il recherche; il doit enfin avoir des notions de géologie suffisantes pour pouvoir distinguer la nature des régions qu'il parcourt et où vivent ces mêmes insectes.

Chaque individu qu'il possède a ainsi déjà un petit dossier qui lui est spécial, et où se trouvent relatéès les conditions les plus générales de son existence. Mais là ne se borne pas le travail du naturaliste. Il faut qu'il cherche à profiter de toutes les circonstances pouvant lui réréler les mours de ses captures. Il doit voir si ses victimes sont parasites, herbivores, carnassières, etc. ; il doit les observer dans toutes les phases de leur vie, il doit faire tout son possible, au besoin, pour conduire à bien des élevages longs et difficiles, pour être témoin de l'éclosion de l'œuf, suivre la vie et les mues de la larve, voir sa transformation en nymphe, puis en insecte parfait ; il toit noter les dates de toutes cescirconstances, cxaminer les conditions de l'accouplement et de la ponte, etc., etc.

I! doit encore recueillir et conserve: les galles et autres prodúc. tions spéciales qui sont l'aure des insectes; il doit aussi réunir les notes publiées un peu, partout sur le sujet qu'il examine, entirer? des conséquences pour la dispersion géographique, les variations dans la nourriture, etc

Il y a déjà là matière à des recherches si multipliées et si longues que beaucoup se contenteront de ces renseignements qui forment un tout complet.

Ce n'est encore cependant ıqu'un côté de l'étude de l'insecte, et lorganisation intérieure peut aussi occuper le naturaliste et lui révèler de nouvelles merveilles, s'il entreprend ce travail. Il doit alors être, outre ce que j'ai déjà énuméré, micrographe et préparateur aussi parfait (que possible; il doit pouvoir disséquer etanalyser ses insectes dans les plus petits détails, conserver tous les faits observés dans des notes et des croquis nombreux, correspondant à despréparations microscopiques, qui forment une seconde collection parallèle à celle que nous faisons habituellement, et qui n'est pas la moins intéressante. 
Le naturaliste, enfin, doit être dessinaleur et coloriste aussi habile (fue possible, pour pouvoir rendre par le crayon et le pinceau tous les détails que lui a révélés sa loupe ou son microseope, écrivain expérimenté pour fixer dans des ouvrages bien faits les résultats nombreux de ses observations, de façon à les rendre exactement, complètement, et cependant sams longueurs ni ariılité. Car ce serait crime à lui de conserver clans ses cartons toutes ces notes si précieuses, et il doit se résigner it les soumellre, toujours sans retard, il l'appréciation et aussi à la critique de ses collógues.

Si nous ajoutons des éléments d'optique assez élendus, la connaissance de cing ou six lanģues étranģères è des langues morles classiques, nous aurons parcouru, à peu près, le cercle de ce que doit savoir l'entomologiste observateur réellement digne de ce nom.

D'après ce portrait, il semblerait qu'il est impossible d'arriver à réunir une pareille somme de connaissances. Il est certain (jue beatucoup d'entre elles feront le plus souvent défaut; mais l'amour véritable de la science y supplénra toujours, et suggérela des mojens de tourner les difficuliés qui peuvent se présenter, la pratique de l'observation en apprenant toujours beaucoup plus que toutes les leçons, même d'un maître.

M'objectera-t-on que le temps nécessaire à des études poursuivies d'une façon si complète doit empêcher d'y prétendre tous ceux qui n'ont pas une position indépendante. Ici, l'expérience a toujour's prouvé le contraire, et les travaux les plus importints sont souvent sortis de la plume des savants los plus empêchés par les obligations de la vie journalière. J'ai dit que l'entomolorie devenait une passion pour quelques uns, et j'en trouve précisćment la preuve dans ces travailleurs infatigables qui, aprés avoir satisfait, pendant de longues heures, aux charges de leur état, trourent encore le temps de faire les observations les plus longrues, les plus patientes et les plus minutieuses. Il faut, d'ailleurs, bien se persuader que l'élude consciencieuse, même d'un seul insecte, peut constituer un travail des plus utiles et du plus grand mérite.

Si l'on compare le portrait (qui précède, et qui est celui à la ressemblance duquel dloivent aspirer, sans jamais désespérer d'y pallvenir, les jeunes gens zélés et passionnés pour la science, avec ce que sont la plupart de ceux qui se disent entomologistes, il y a 
loin. Aussi est-il des degrés, et, sans atteindre la perfection, on peut, en se restreignant à des recherches plus modestes, rendre c'e réels services à l'histoire naturelle.

Mais il est, par dessus tout, une qualité qui est indispensableà tout entomologiste sérieux, petit ou grand, c'est la patience. Avec elle, on vaincra des difficultés qui pourraient, tout d'abord,paraitre insurmontables; sans elle, ces difficultés s'accroîtront, au contraire, à chaque pas, et finiront par devenir inextricables.

Je ne parlerai pas d'une troisième sorte de savant, que j'appellerai le naturaliste philosophe. Celui-ci se sert des résultats obtenus par les autres, pour en tirer de hautes conséquences, en déduire des vues générales sur l'organisation et le but de la création, toutes choses d'un intérêt considérable, mais qui sortent tout à fait du cadre de cet ouvrage.

En résumé, nous voyons que l'entomologie est une science sérieuse, et qu'il faut l'étudier sérieusement. Ses résultats pour l'agriculture, et par conséquent pour la richesse nationale, sont immenses, si l'on considère les pertes énormes que celle-ci subit, chaque année, par le fait des insectes nuisibles. Elle est tout aussi utile à d'autres points de vue, et son influence bienfaisante n'est pas moins manifeste quand on la voit procurer un aliment, agréable à tous égards, à l'activité des jeunes gens, donner un but à leurs promenades, une occupation à leurs loisirs; quand aussi c'est le refuge où viennent puiser la consolation ceux qu'a éprouvés le malheur et que les chagrins accableraient, si notre science n'arrivait à leur secours, en les meitant en présence des splendeurs de la création jusque dans les êtres les plus humbles et les plus dédaignés.

2. - La Nomenclature entomologique. - Étant donné le nombre immense d'êtres divers qui composent l'ordre des insecles, il était indispensable de désigner chacun d'eux par un nom différent, si l'on voulait pouvoir les distinguer les uns des autres dans les ouvrages spéciaux. Il fallait, en outre, que ces noms si multipliés fussent soumis à certaines règles pour soulager la mémoire et ne pas la charger inutilement d'appellations sans liens et trop nombreuses.

D'autre part, la science étant cosmopolite, et ne reconnaissant 
d'autres frontières que celles que lui donne naturellement, notre ignorance, il devenait nécessaire que tous ces noms fussent aussi cosmopolites et ne pussent varier d'un peuple à un autre.

Pour répondre à ces divers besoins, on a dù passer par une série de titlonnements plus ou moins heureux, el ce n'est que lorsque l'immorlel Linné eûl doté la science de ce que nous appellerons la nomenclature binominale, que celle-ci pût faire de sérieux progrès. Les noms de tous les ètres composant les séries naturelles de tous ordres ont, dès lors, été formés de deux mots distincls, corres. pondant à peu près ì ce que, pour nous-mêmes, nous désignons par les expressions de nom et de prénom.

Tout d'abord nous pouvons faire un premier partage dans la série de tous les insectes et les diviser en un petit nombre de groupes, comprenant chacun tous les individus qui ont les mêmes orģanes essenticls (nutrition, reproduction, elc.) conformés de la méme manière et dont les premiers états (larve, nymphe) ont des rapports et des ressemblances non équivoques. Ces premiers grroupes sont désignés, chez les insectes, sous le nom d'ordres. On distingue actuellement huit ordres, mais cette première classification ne s'est établie que très progressivement, comme nous le verrons.

Si nous prenons chacun des ordres, dont nous venons de parler, nous pouvons partager les insectes qui le composent en séries comprenant chacune tous ceux qui, par leurs mœurs à tous lours états et leur conformation générale, semblent concourir à un mème but dans les vues de la nature et ont, par conséquent, des affinités indiscutables. Ces réunions d'insectes forment les diverses familles.

A leur tour, ces familles, par l'examen plus approfondi des caractères et des formes des êtres qu'elles renferment, peuvent se classer en diverses catérories réunissant chacune tous les individus les plus semblables sous le rapport des formes extérieures. Ces catégories ont reçu le nom de genres, et sont désignées par un substantif qui appartient, il la fois, i tous les insectes compris dans un même genre.

Mais ceux-ci sont encore loin d'ètre identiques el se divisent en groupes composés d'individus seuls capalbles d'ètre reproduits les uns par les autres. Chacune de ces réunions d'individus, parfois très dissemblables entro cux, est unc espèce, ot à chaquo espèce a 
été imposé un adjectif ou un qualificatif qui, joint au substantif désignant le genre, forme le nom de l'insecte.

Pour ramener un insecte donné à l'espèce à laquelle il appartient. nous sommes réduits, le plus souvent, à invoquer seulement les ressemblances extćrieures, et je dois dire que ce n'est qu'exceptiorınellement que cette méthode est en défaut. Mais il y a des cas, que les progrès de l'entomologie rendent chaque jour plus nombreux, où des dissemblances extérieures considérables existent entre les individus d'une même espèce, comme nous le verrons. Les éludes biologiques seules permettent alors d'arriver à dévoiler la vraie nature de l'insecte.

Les grandes divisions primaires de la famille et du genre peuventquelquefois, selon les besoins, se subdiviser en coupes secondaires, ce sont: les tribusou sous-familles et les sous-genres dontle nom seul dispense de toute explication.

Il semble donc qu'une définition exacte et rigoureuse de l'ordre, de la famille, du genre, et de l'espèce soit seule indispensable pour éviter toute confusion, et que ces divisions doivent être parfaitement délimitées. Il n'en est malheureusement rien, et si, dans la plupart des cas, ces conditions se trouvent remplics, il y a, presque toujours aussi, quelques types intermédiaires servant de transition entre un groupe et ses voisins, et donnant lieu à d'interminables discussions entre les savants. Les espèces ellesmêmes qui paraissent devoir être tout-ì-fait distinctes les unes des autres par les conditions de la reproduction, se trouvent parfois présenter des motifs de confusion parsuite des hyloridations trop frérjuentes et aussi des conditions spéciales de cette reproduction. Darwin, avec'sa théorie d'un type originel unique ou presque unique, est venu encore jeter le doute dans beaucoup d'esprits sur la nature de l'espèce, et indiquer l'hypothèse que tous les êtres sont plus ou moins parents.

Je sortirais complètement des bornes où je veux renfermer mon travail, si j'effleurais seulement les discussions auxquelles ont donné licu toutes ces questions. De nouvelles définitions, outre qu'elles ne pourraient être plus exactes que celles qui ont été émises par la plupart des auteurs, n'auraient pour nous aucune utilité pratique et ne serviraient qu'à grossir le dossier de ces problemes scientifiques sans leur faire faire le moindre pas vers une solution. 
C'est par la vue des insectes, par l'habitudo que l'on aura de les étudier, de suivre leur's érolutions el les conditions de leurvie, que chacun se fera une idẻe plus ou moins nette de ces divisions; mais, dan ielat actuel de la science, toute définition précise est prématuréc et même impossible.

Etant donnés tous les individus d'une espèce cntomologique, possédant les conditions nécessaires de reproduction muluelle, nous sommes encore amenés à y faire entrer et à réunir par conséquent, sous un même nom, des individus de grandeur ét de couleur souvent très differrentes. Ces variations constituent alors ce que l'on nomme des variélés; celles-ci se retrourent souvent, d'une fieçon constante, dans un même pays ou sous une mime latitude, formant alors des races. On est convenu de leur donnerle nom de l'espèce ì lafuelle elles se rapportent, en y' ajoutimt soit un numéro, soit un nom supplémentaire, soit un signe distinctif quelconque.

J'ai dit que chaque espèce est désignée par la réunion du nom générique et du qualificatif qui lui est spécial.Ces deux mots sont toujours empruntés ì la langue latine, considérée comme lanı̧ue universelle adoptée par tous les savants.

Chaque espèce, quelle qu'elle soit, a été nécessairement décrite, pour la première fois, par un entomologiste quelconque. C'est celui-ci qui devient, alor's de droit, son parrain, et lui impose le nom spćcifique qui lui plaît; il est tenu seulement d'adopter le nom générique qui revient à l'insecte, d'après ses caractères.

Il peut arriver aussi que plusicur's savants découvrent le même insecte en mème temps, et en fassent des descriptionssimultanćes, ou que, un insecte étant déjii valablement décril par quelqu'un, se trouve décrit à nouveau plus tard par un second inventeur qui n'aurait pas eu communication de la première description, ou qui l'aurait méconnue. De là deux, trois noms, ou même davantage, appliqués à un méme insecte. Quand l'erreur se trouve reconnue, et que ces différentes descriptions se rapportent certainement à une même espèce, on est convenu d'adopter, comme nom définitif, celui qui a été donné le plus anciennemont, pourvu (que la description venant it l'appui se trouve ditre assez explicite pour permettre de reconnititre l'espéce ì coup sủr. Les autres noms sont inscrits ì la suile comme synonymes, pour assurer la concordance 
des divers ouvrages, et le nom de l'auteur de chacune de ces descriptions est placé ì la suite des synonymes el du nom définitive. ment adopté.

Il n'est pas besoin de montrer combien ces descriptions multipliées, pour un même insecte, jettent de confusion dans la science; les rectifications, en effet, n'arriventensuite que bien lentement, et les catalogues se trouvent chargés, de cette façon, d'espèces purement nominales. Aussi est-ce toujours avec la plus grande circonspiection que les savants doivent indiquer les insectes qu'ils considèrent comme nouveaux, et ils n'ont le droit de le faire qu'après s'être entourés de tous les renseignements désirables.

Le choix du nom spécifique, appliqué à un insecte, est laissé tout entier à la volonté de l'inventeur, pourvu que celui-ci se conforme aux règles grammaticales de la langue latine. Aussi y a-t-il des abus, qu'il n'est peut-ĉtre pas inutile de signaler ici. En thèse générale, le meilleur nom est celui qui donnera, sur l'insecte décrit, un renseignement essentiel se rapportant à son habitat, à sa forme, si elle est extraordinaire, à sa couleur, si elle est remarquable. On donne quelquefois le nom d'un entomologiste connu ou ami, dont on veut ainsi honorer le grand savoir. Rion de mieux quand il n'y a pas quelque chose de particulièrement remarquable i signaler dans l'insecte en question, mais je suis d'avis que les noms propres, qui ne donnent aucun renseignement utile, doivent être employés avec la plus grande modération, et c'est là précisément l'objet du premier abus que je veux signaler. On voit, en effet, se multiplier, chaque jour, ces noms sans aucun rapport avec l'insecte décrit, et je crois que cette tendance ne peut que gagner à être enrayée.

Unsecond abus consiste dans l'emploi, pour les noms spécificues, de mots sans signification aucune, tirés soit de la mythologie, soit d'une source plus difficile encore ì reconnaître. Nous avons des ouvrages où ces noms, incompréhensibles et rebelles à la mémoire, se montrent trop sourent et je ne peux que condamner ce procédé pour les raisons déjà énoncées. En résumé, je crois que les noms les meilleurs sont ceux qui donnent une indication quelconque et aussi importante que possible sur l'insecte.

Dans toute description d'insecte, il est essentiel, outre le nom latin, de donner, dans la même langue, un abrégé des caractères 
principaux, suffisant pour distinguer l'espèce déerite de toutes celles qui en seraient roisines. C'est ce que l'on nomme la cliagnose. Elle ne doit rien contenir que d'utile, afin d'être aussi courle (que possible, mais aussi ne rien omettre d'essentiel, pour qu'elle ne puisse être confondue avec une autre. On peut mémo recommander d'y inscrire les caractères dont se sont servis les monographes spécialistes dans la division de leur's espèces, afin de pouvoir facilement y faire entrer le nouveau venu.

Cetle diagnose constitue, avec le nom spécifique, l'état civil de l'insecte. On peut la faire suivre d'une description détaillée en langue vulgaire, mais celle-ci n'a plus le caractère officiel de lia diagnose. Cette description doit surlout être comparative, et donner les dissemblances les plus frappantes qui ont obligé it sćparer l'insecte décrit de tous coux qui lui ressemblent le plus. Si ces différences sont peu importantes, comme cela atrive souveni, il ne faut se résoudre à donner la nouvelle description que si l'on a pu examiner un grand nombre d'exemplaires des deux sexes; les nouveautés décrites trop souvent sur un seul ou sur deux individus étant la source principale du fléau des synonymies.

En dehors de la nomenclature proprement dite, nous devons nous occuper aussi de savoir ce qu'on entend par classification.

Les insectes, considérés dans leur ensemble, oni entre cux des rapports qui sont plus ou moins étroils ou plus ou moins éloignés. Si l'on veut les ranger dans un ordre rationnel,il est évident que l'on placera, les uns vers les autres, ceux qui ont le plus de caractères communs, et dont les mours seront aussi scmblables que possible. En procédant ainsi, on peut arriver it renfermer les insectes dans une série ininterrompuc, dont chaque terme est plus semblable à celui qui le précède el à celui qui le suil qu'à tout autre. Les transitions sont même, le plus souvent, assez insensibles pour que les coupes qu'il faut faire nécessairement, afin de former les genres et les familles, soient quelquefois inclécises. Celte classification, comprise comme je viens de le montrer, est ce (qu'on appelle une classification naturelle.C'est lia seulo parfitite, celle vers la réalisation de laquelle doivent tendre toutes nos investigations.

Mais, comme cette classification naturelle s'appuic sur l'ensemble des caractères de chaque insecte, il serail fort difficile, 
étnnt donné un sujet quelconque, de trouver sa place exacle dans la série, et, par suite, le nom qui lui a été assigné.Aussi,dans ce but spécial, et dans l'impuissance où nous sommes de faire mieux, a-t-on imaginé des classifications dites artificielles, fondées non plus sur l'ensemble des caractères, mais sur l'un deux seulement ou au moins sur un petit nombre d'entre eux. Ainsi une classification, qui diviscrait seulement les insectes en insectes ailés et en insectes aptères, s'appuierait sur le caractère unique résultant de la présence ou de l'absence des ailes, sans s'inquiéter des autres. Evidemment cette division sera insuffisante, puisque nous réunirons ainsi des êtres éminemment distincts. Cette classification serait artificielle, mais elle permettrait à notre esprit de trouver de suite ì quelle classe appartient un insecte donnć. Si nous divisons successivement chacune de ces classes en plusieurs autres s'appuyant aussi,chaque fois. sur un caractère unique, nous arriverons à connaître assez facilement le nom cherché; mais cette méthode est toute mécanique et ne tient aucun compte des affinités naturelles des espèces entre elles, affinités résultant, non de la présence ou de l'absence d'un certain caractère différentiel, mais bien de la réunion de tous les faits essentiels pouvant influer sur le rôle assignné à l'insecte.

Les classifications artificielles, bien plus à notre portée, par suite de l'ignorance où nous sommes de la plupartdes faits se rattachant à l'existence intime de chaque insecte, ont été aussi les premières qui aient pris naissance, et aujourd'hui encore, nous en sommes réduits à des systèmes, non plus tout-ì-fait artificiels, mais qui ne se rapprochent que bien peu d'une classification complètement naturelle, telle que la nature l'a conçue. On peut même dire que, plus nos connaissances s'accroîtront, plus nous approcherons de ce desideratum, mais que nous ne pouvons espérer d'y parvenir avant bien longtemps, puisque, pour cela, tous les secrets de la vie des insectes devraient nous être dévoilés et que nous avons encore malheureusement beaucoup à faire avant d'y arriver. Chaque jour amène son progrès et nous rapproche de la perfection, que l'homme n'atteindra jamais, car alors il cesserait d'être l'homme. 


\section{3. - Aperçu historique sur la classification des} insectes en général. - L'entomologic remonte déjà haut, puisque Aristote (384-322 av. J.-C.) en fil une science spéciale; en distinguant les articulés des autres animaux, et en en faisant une classe particulière sous le nom d'entoma.

Après lui, nous passons directement it Pline (23-79 ap. J.-C.) qui, dans ses compilations, reproduisit it peu près ce que disait son devancier.

Nous ne devons pas considérer comme entomologistes Ovide ni Virgile, pas plus que Collumelle et Varron, bien cu'ils se soient occupés plus que tous les auteurs de leur temps, à propos des abeilles, de l'ordre que nous étudions.

Pendant de longues années, l'entomologie sommeilla, et jusqu'au $x_{m}{ }^{e}$ siècle, rien de nouveau n'apparait dans son histoire.

Albert de Bollstad, plus connu sous le nom d'Albert-le-Grand (né en Souabe entre 1193 et 1205) ne fit, à celte époque, que mentionner les insectes. Encore ne trouve-t-on dans ses ćcrits que ce qu'en avait dit Aristote.

Longtemps après, au $\mathrm{xvI}^{\mathrm{e}}$ siècle, Rondelet (1507-1565) et Belon (1517-1564) remirent la zoologie en honneur, et IIarway accorda enfin aux insectes un fluide nourricicr analogue au sang des animaux supéricurs, dont il renaitde découvrir les phénomènes circulaloires.Dans son traité de differentiis animalium, E. Wolton ébauchail une première classification bien imparraite, tandis que Jean Bauhin (1598) et Conrad Gesner (1516-1558) faisaient connaître de nouvelles observations.

Après eux, Aldrovande, en Italie (1522-1605), Johnston (1633) en Angleterre,terminent avec Goëilart (1662), cette première scirie de savants cherchant avec ardeur, sans trop le découvrir, le fil qui les quidera dans le dédale de celte multitude d'étres divers vivant sous leurs yeux.

Le $\mathrm{xvu}^{\mathrm{e}}$ siècle ne devait pas cependant se terminer sans voir s'accomplir un progrès récl dans l'entomolowic. Un hollandiais, Jean Swammerdam (1637-1680), appliquant it notre science les ressources nouvelles que venaient de procurer au monde sarant Janssen et Dobbel (1620) par l’incention du microscope, iente une premiere classification raisonnce de tous les animaux. qu'il range patrmi les insectes; il les divise en quatre ordres, dont les 
caractères ressortent de leurs différents modes de métamorphose.

Après lui, mettant à profit ses récentes découvertes, deux anglais, Ray de concert avec Willughby, firent connaitre une méthode de classement fondée aussi sur les métamorphoses, mais confondant encore, arec les insectes, toutes sortes d'invertébrés disparates.

Réaumur (1683-1757), cet observalcur inimitable, dont on ne peut encore aujourd'hui négliger les ouvrages, puis son continua. teur de Geer (1720-1778), Bonnet, de Genève (1720-1793), Røsel, de Nuremberg. (1746), viennent ensuite, dans leurs mémoires si remarquables, jeter un jour tout nouveau et inattendu sur les mours de beaucoup d'insectes, préparant ainsi la voie au véritable lẻgislateur de l'histoire naturelle.

Vers la même époque, en effet, paraît en Suède un homme qui devait donner définitivement it l'étude de la nature le rangr d'une science véritable. Linné (né en 1707 à Roshult, mort à Upsal en 1778), lui consacra toule son existence, et l'entomologie lui doit, en particulier, d'avoir été enfin dotée d'une méthode, il est vrai, tout artificielle, mais qui, facilitant son étude, fut le point de départ de travaux nombreux, dont la série ne s'est plus interrompue jusqu'à nos jours. Cette méthode, basće presque uniquement sur la présence ou l'absence et sur la nature des ailes, distinguail sept ordres encore presque tous adoptés aujourd'hui.

A dater de cette époque, l'essor était donné, et il ne faut plus chercher, ì travers la suite des temps, les rares auteurs s'occupant, le plus souvent accidentellement, des insectes, on est, au contraire, obligé de négliger la plupart de ceux, trop nombreux, qui se produisent, et d'y faire un choix.

Nous voyons, en 1762, Geoffroy mettre au jour son Histoire abrégée des Insectes des environs de Paris, tandis qu'en Allemagne Fabricius (1778), se basant sur des caractères tout autres que Linné, donnait son nom à une nouvelle classification tirée uniquement de la conformation diverse des organes buccaux.

Je passe sous silence les travaux de Schæefer (1764), Scopoli (1777), Illiger (1798), Clairville (1798), Fourcroy (1785), Schranck 1781), Rossi (1790), Pallas (178?), Olivier (18'0), les deux Huber (1810 et 1814), et bien d'autres, malgré leur importance, parce qu'ils font moins époque dans l'histoire de l'entomologie, et j'arrive à Latreille (176?-1833.) 
Celui-ci, mettant en œurre tous les résultats obtenus par ses devanciers, leur adjoignant le fruit de ses immenses travaux et de ses nombreuses observations, vint enfin asscoir l'entomologie sur une base définitive. Sa méthode, la plus naturelle jusqu’a lui, partagreait les insectes en douze ordres, et elle a à peine été modifiée do nos jours.

Après lui Leach (1817), Kirby (1818), Burmeister (1832) ot d'autres ont fait connaitre diverses classifications qui n'ont pu être généralement adoptées comme celle de Latreille. Je veux citer encore, commo mérilant toute notre admiration, les travaux de Lamark, Drury, Newport, Jurine, Savigny, de Saussure, Dufour, Perris, Costa, Blanchard, ete. J'aurai à en énumérer bien d'autres dans le cours de cet ouvrage; mais je ne puis insister sur ce sujet, et je renverrai le lecteur désircux de l'approfondir à l'excellent historique donné par M. Lacordaire dans son Introduction à l'Entomologic, ainsi ([u'aux renseignements bibliogrraphiques que je ferai connaître plus loin.

De nos jour's, on a sépare des insectes un certain nombre d'ar. ticulés qui ne peuvent y trouver place, comme les crustacés, les myriapodes, les aptères, les arachnides, et on n'y a laissé subsister que huit ordres, pouvant se caractériser comme suit :

Ils renferment, dans leur ensemble, tous les animaux ayant un squelelte extérieur divisé en segments ou anneaux, pourvus, à l'ètat parfail, de six pattes, et, le plus souvent, d'ailes, à respiration trachéenne, présentant une tête, un thorax et un abdomen distincts, enfin subissant des métamorphoses.

Comprise de cette façon, la classe des insectes peut se diviser, comme je l'ai dit, en huit ordres, de la manière suivante:

I. Métamorphoses complètes. - Ailes inégales.

$t$ Bouche munie de mandibules. -4 ailes.

* Ailes antérieures cornées ...... Colíoptínes.

* Les 1 ailes membraneuses, veinces. - . HYMénoptéres.

+ Bouche munie d'un sucoir.

* 4 ailes membraneuses, couvertes d'é-

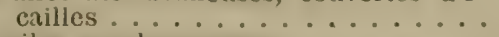

tit Bouche présentant des organes a la fois suceurs el broyeurs. . . . . . . .

II. Métamorphoses tantôt complètes, tantót incomplètes.

'1 ailes égales, membrancuses, reticulées .

III. Métamorphoses incomplètes. - i ailes, les supérieures DIRTERES.

RHIPIPTEHES.

Nívroptìres. rieures membraneuses.

† Bouche munie de mandibules. ........ Orthoptìnes.

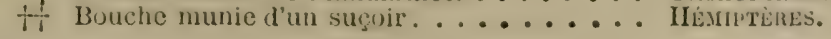


Les caractéres généraux inscrits dans le tableau qui précède ne laissent pas que de subir de nombreuses exceptions et je ne me dissimule pas ses grandes imperfections. Lo caractère emprunté aux ailes, laisse, en effet, particulièrement à désirer, bien des espèces des divers ordres en étant dépourvues. Lorsque nous aurons étudié successivement toutes les familles d'hyménoptères, je me réserve de donner, comme conclusion à cetouvrage, une définition plus exacte et plusscientifique de ces insectes et les comprenant lous sans exception. Qu'il me suffise de dire aujourd'hui que les individus aptères se reconnaîtront,presque toujours facilement, à la présence des mandibules et d'une tarière ou d'un aiguillon. Dans tous les cas, la conformation spéciale des mâchoires et de la lèvre, disposées pour la succion, conformation que nous apprendrons à connaître plus tard, sera un caractère peut-être moins facile à vérifier, mais décisif. 


\section{II}

\section{ÉTUDE PARTICULIÈRE DES INSECTES HYMÉNOPTÈRES. (1)}

\section{$\S 1^{\mathrm{er}}$ - FORMATION DES COLLECTIONS}

Avant de songer à étudier les hyménoptères, comme tous les insectes en général, il faut d'abord se préoccuper de savoir les recueillir et les préparer. C'est ç gue je vais tàcher d'enseigner dans les chapitres suivants.

1. - Ghasse aux hyménoptères. - L'habilat des hyménoptères étant d'une nature plus restreinte que celui des colćoptìres, lour récolte semble devoir en être simplifiée. Il n'en est rien cependant, et la difficultó plus grande de leur capture, à cause de la rapidité de leur vol, m’oblige à entrer dans des détails plus minutieux. La connaissance générale de leurs mours aidera aussi beaucoup à les rencontrer.

Pendant les journées chaudes de l'été, un procédé général et qui procurera un grand nombre d'espèces de toutes les familles, consistera ì explorer les plantes fleuries qui se trourent sur le bord des chemins, vers la lisière des bois, dans les clairic̀res, dans les champs, etc. La vipérine, les chardons, les ombellifères, en général, les mille-feuilles, les ronces, les hiẻbles, et mille autres fourniront, d'avril à octobre, de nombreux spécimens pourant se

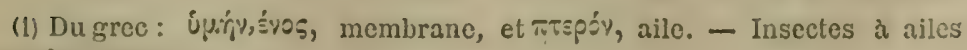
membranouses. 
répartir dans chacune des familles. Pour cette chasse qui est la plus habituelle, il suffira de se munir d'un filet à papillons, en forte gaze. Quelques entomologistes trouvent commode de se servir, dans certaines circonstances, d'une réduction de ce même filet auquel ils ne donnent que 10 à 15 centimètres de diamètre, avec un manche de 50 à 60 centimètres. Ce petit instrument permet de saisir facilement les insectes posés sur les fleurs. Quand il s'agit de fleurs de ronces ou d'autres plantes dures ou épineuses, . notre gaze serait vite déchirée, et il faut alors, ou bien arrêter au vol les hyménoptères dans leur fuite, ou se servir du filet en forte tóle des coléoptéristes.

Si l'on a enfermé un ou plusieurs individus dans l'un ou l'autre de ces filets, il reste à les faire entrer dans le flacon sans leur permettre d'user contre nous de leur aiguillon. Dans ce but, j'emploie un flacon à large embouchure et, enfermant, avec une main, l'insecte dans la partie extrême du filet, j'introduis le goulot dans cette prison dont je réduis, peu à peu, les dimensions, jusqu'à ce que ma capture, refoulée vers l'extrémité, se trouve forcée de pénétrer dans le flacon. Appuyant alors, par dessus la gaze, le doigt sur l'ouverture,ce, qui se fait sans danger, quelle que soit la fureur du prisonnier, on peut retirer le flacon du filet, et on n'a plus qu'a le boucher rapidement, en profitant d'un instant où l'insecte se trouve au fond.

Mais, pour continuer la chasse, il est essentiel que cet insecte meure de suite. Voici, pour cela, un moyen facile, réussissant parfaitement et ne présentant aucun danger, tout en conservant les produits de la chasse parfaitement frais, co qui est une condition indispensable. Je prends, comme je l'ai dit, un flacon à large ouverture, je le remplis à moitić de sciure de bois, grosse, lavée et bien séche. Je choisis un bouchon saillant suffisamment pour pouvoir être bouché et débouché rapidement et sans efforts. Enfin j'introduis, dans l'intérieur, un fragment de tuyau de plume long de trois centimètres environ, fermé à chaque extrémité par un tampon de coton, et contenant dans l'intérieur quelques grains de cyanure de polassium. Ce cyanure est, comme l'on sait, $u^{n}$ poison violent et l'on ne saurait trop prendre de précautions dans son usage. Aussi est-il prudent de faire préparer à l'arance, par un droguiste, une petite provision de ces tubes. Si, par suite d'une 
chûte ou d'un autre accident, le flacon vient à se briser dans le vêtement, à entamer même la chair du chasseur avec ses débris, le tuyau de plume qui est élastique, ne cédera jamais, et la blessure restera inoffensive, ce qui n'arrive pas avec les autres systemes. Le eyanure ainsi employé dure assez longtemps, et le même tube servira plusicurs jours de suile, pourvu qu'on évile d'introduire dans le flacon toule cause d'humidité, comme des fragments de plante, ou des insectes mouillés et écrasés. Les hyménoptères, à peine le flacon est-il fermé, tombent suffoqués sous l'influence cles vapeurs dégagées par le cyanure à travers les tampons de coton. Ils ne sont cependant pas morts, et ils reviendraient à la vie, si on les meltait de suite au grand air. Ils doivent au moins sćjournor dans le flacon de vingt a trente minutes pour que l'effet soit complet.

Pour les insectes dont nous nous occupons, il faut éviler de se servir de tout poison liquide, qui mouillerait leurs ailes et leur's poils et les rendrait méconnaissables. On doit donc proscrire l'alcool, la benzine, etc.

Pour les très-petits insectes qui se perdraient dans la sciure, de petits flacons spéciaux seront nécessaires.

Je neveux parler, que pour le condamner, d'un procédé incliqué dans quelques ouvrages et qui consiste à piquer les gros insectes vivants, it travers la gaze du filet, et à les placer ainsi dans une boîte de chasse. Outre le sentiment pénible que fait naîlre une parcille opération, les mouvements désordonnés auxquels ils se livrent ne peuvent qne les détériorer.

Enfin on a préconisé (voyez : Entom. monthly Mag. 1875) un mode d'asphyxie qui consiste à faire entrer, dans le flacon de chasse, les vapeurs d'une allumette soufrée. Ce procédé, certainement efficace, me semble moins simple, (quoique bon à recommander dans le cas ou l'on ne voudrait ou ne pourrait se servir de cyanure.

Outre le procédé général de chasse dont j’ai parlé, il faut encore connaître diverses méthodes plus particulières ì certaines familles.

Si l'on sort le matin, lorsquelesoleil est encore près de l'horizon, en avril ou mai, on trouvera souvent les fleurs peuplées d'hyménoptères divers engourdis par le froid et, par conséquent, trèsfaciles a prendre. Ces excursions matinales ont encore l'avantage 
de procurer, à coup sûr, certaines espèces, si l'on connait leur plante de prédilection. Quand le soleil les a réchauffées, elles reprennent leur vivacité et, devenant beaucoup plus volages, quittent volontiers ces mêmes fleurs pour aller butiner au loin.

Si l'on rencontre des chemins peu fréquentés, pierreux, des talus sablonneux, on pourra les voir souvent criblés de trous où entrent et sortent une foule d'hyménoptères fouisseurs, mellifères, ou leurs parasites. Le filet de gaze les atteindra sûrement dans leurs évolutions.

Il faut encore surveiller les murs exposés au midi ; ceux en pisé sont particulièrement favorables.

Sur les tas de pierres ou de bois bien ensoleillés, d'autres espèces viennent s'abattre pour pénétrer dans les interstices et $\mathrm{y}$ trouver un abri pour leur progéniture. Beaucoup de représentants de la belle famille des chrysides ne se prennent que là. Mais la surface inégale de ces monceaux rend les captures avec le filet assez difficiles. M. Abeille de Perrin nous apprend (Feuille des J. Nat. mars 1877) qu'il tourne la difficulté en plantant, dans les trous, des fleurs coupées d'euphorbe ou de carotle. Les volages insectes s'y arrêtent bien, un instant, dans leur course vagabonde et un adroit coup de filet peut alors faucher en même temps fleur et insecte.

Enfin des recherches spéciales sont nécessaires pour découvrir d'autres espèces. Les fourmis, par exemple, se cachent sous les pierres, dans les vieux troncs, ou élèvent des nids volumineux au milieu des broussailles. Si l'on se livre à leur chasse, on peut, en quelques heures, recueillir un grand nombre d'espèces représentées chacune par beaucoup d'individus. Leur détermination subséquente étant assez laborieuse, il est indispensable de se munir, pour ce cas spécial, d'un grand nombre de tubes fermés à un bout, et de ne mettre, dans chacun d'eux, que le produit d'une même fourmilière. Si la saison est favorable, on trouvera, en même temps, les sexes ailés et on les joindra aux ouvrières. Si l'on possède déjż celles-ci et qu'on ne veuille se procurer que des mâles ou des femelles, il faut cependant prendre toujours quelques ouvrières avec eux, car la détermination de ces dernières est beaucoup plus facile, celle des mâles et des femelles isolés étant quelquefois impossible. 
Il ne faut pas oublier encore que, sous les pierres très profonciémeni enfoncées ou ì l'extrémité de pieux fiches en terre. on peut, pendant la belle saison, rencontrer des espéces de fourmis aveugles très-rares, et qu'on aura même beaucoup plus de chince, lit (qu'ailleurs, de trouver des insectes non encore connus. L'exploration des grottes ne doit pas être négligée, car rien n’empêche que cet habitat spécial ne nous livre des hyménoplères, comme il a donné déjả des coléoptères, des arachnicless, ete.

- Par ces diverses méthodes, on arrivera à réunir un très grand nombre d'espèces, mais on ne pourra jamais ou presque jamais trouver toutes celles qui habitent lia localité qu'on explore. P'our les hyménoptères, plus peut-être que pour les autres ordres, il faut, concurremment avec les chasses actives, avoir recours aux éducations. Pour des familles entières et extrêmement nombreuses, celles des Ichneumonides, des Chalcidites, et, en général, des hyménoptères parasites, celle des Cynipides el d'autres, beaucoup de raisons militent en laveur du système des éducations. Ces insectes sourent fort petits, présentent, dans leur étude et leur détermination, des difficultés spéciales résultant de leur ressemblance souvent désespérante, de leur nombre immense, et aussi, il faut bien le dire, de notre ignorance à leur égard. Les nombreuses espèces encore inédites ou non connues créent ì l'entomologiste des diflicultés particulières. Sins les détruire complètement, les données. que l'on a sur l'habital ot le parasilisme d'un individu, sont souvent un précicux jalon pour arriver it son identité. Mrais ce n'est lì encore que l'avantage le moins séricux; le principal est (qu'on obticnt ainsi, du méme coup, la connaissiance dés mour's de l'insecte, et que c'est lì précisément le desideratum final du naturaliste. Enfin, en ayant recours aux éclosions, on se procure ces espèces avec facilite et șouvent en nombre, tandis que les ballues les plus consciencieuses dans la campagne ne parviendraient pas à les donner, ou ne le feraient que par individus isolés; chacun de coux-ci nécessiterait lout un travail de détermination, au lieu que le nom do toute la nichée est comu par une seule étude. Ces petites bestioles sont souvent si délicales, qu'on ne saurait s'attacher i les avoir trop fraîches, et c'est un rocu réalisé complétement par les élucatiuns. Itat coninaissance exacte de l'habitat d'une espèce permet aussi de la rechercher 
plus tard et de la retrouver facilement, quand le besoin de nouveaux exemplaires se fait sentir. Je veux encore citer l'avantage qui consiste à pouvoir, d'une part, sćparer des espèces très-voisines, dont la différence d'habitat fait micux soupçonner aussi la différence spécifitque, d'autre part, s'assurer de l'identification des deux sexes d'une même espèce; ceux-ci sont assez différents, dans bien des cas, pour qu'on les ait décrits, maintes fois, comme espèces distinctes.

Ces ćducations ne prósentent, d'ailleurs, aucune difficulté et peuvent réussir sans beaucoup de soin. En effet, tandis que certains insectes gallicoles, lignicoles, etc., ne peuvent parvenir à l'ćlat parfait dans nos flacons, parce qu'ils n'y trouvent pas des conditions hygiéniques convenables, leur's parasiles réussissent, au contraire, la plupart du temps; ils sont bien moins sensibles aux influences morbifiques de la sécheresse ou de la moisissure que leurs hôtes eux-mômes, ce qui se comprend, puisqu'ils vivent, le plus souvent, dans le corps même de leurs victirnes, et que ce milieu ne subit que très indirectement les influences extérieures.

Le matériel nécessaire consiste simplement en petits flacons de dimensions variées, généralement à larges goulots, en une collection de tubes, de petit diamètre pour la plupart, fermés à un bout et longs seulement d'environ 4 à 5 centimètres. Ces tuljes et ces flacons seront fermés, les uns avec des bouchons de liége, les autres avec des capuchons de papier ou de gaze fixés par un fil ; on n'a jamais assez de ces petits ustensiles. Il faut aussi quelques grands bocaux, des boites de carton à fermeture exacte, et enfin des boîtes à couvercle garni de gaze, pour l'élevage des diverses chenilles. Des pots à fleurs à demi remplis de terre et recouverts d'un papier qui les ferme complètement; sont aussi fort utiles; la toile métallique doit ĉtre proscrite, car elle ne serait pas une barrière pour nos minuscules espèces. Les tubes fermés, dontj'ai parlé tout-à-l'heure, peuvent se remplacer, souvent avec avantage, par de simples tronçons d'un tube de verre ordinaire, à chaque extrémité desquels on adaple un bouchion ou un papier. Cestubes, ouverts aux deux bouts, permettent un neltoyage commode, rapide et complet, outre lá facilité que l'on a de se les procurer partout.

C'est dans ces tubes, flacons ou bocaux que l'on renferme les 
galles diverses, les petites branches habitées par des larres, cte. Ces matériaux peuvent se recucillir en tous temps, el leur recherche permet d'utiliser même les belles journées d'hiver. Quint it lour nature, elle est infiniment variée, et il ne serait pas possible de les énumérer même en partie. Pour s'en rendre compte un peu complètement, il faut parcourir les indications biologiques des catalogues, et l'on y verra tous les habitats connus, ce qui n'est encore que la plus minime partio de ce qui est à connaître.

Il faut recueillir toules les galles, excroissances ou renflements des différentes plantes; peu importe d'ailleurs que ces difformités soient produites par des hyménoptères, des diptères, des homoptères, ctc. Il laut prendre les graines habitcen, les feuilles minces, les rameaux percés, les tiges sèches de ronce, d'ćglantier, de sureau, elc., il faut élerer les chienilles que l'on rencontre et ne pas se regarder comme battu, si elles se transforment on chrysalides, car elles arrivent souvent it cette forme, mais ne peuvent aller au-deli; quelquefois il en sort des myriades de Braconides ou d'Ichneumonides, des Microgaster qui se construisent en dehors de pelits cocons. Là encore rien n'est définitif, car ces cocons de parasites peuvent donner naissance it quelque Chalcidile parasite au deuxic̀mo degré. Il faut avoir soin de reconnaître les larves qui s'enfoncent en terre, et, alors, placer une certaine épaisseur de colle-ci au fond du flacon; les parasites écloront plus tard.

Il faut recueillir avec soin les eocuilles vides, souvent habitées par diverses larves, les nids d'hyménoptires, les cocons, less chrysalides, les fourreaux de P'syché, les puccrons gonflés el désséchés, fixés aux feuilles de diverses plantes, les pupes de diplères, que l'on trouvera dans la terre, sous les feuilles mortes. On peut encore délerrer avec soin les larves des insecles coprophages, sous les crottins, ou fungivores, sous les champignons, yui se sont ensevelies pour se transformer, celles des nécrophores et autres insectes, sous les cadarres des petits animiax, dans la campanne. En les replaçant elans la terre un peu humide, au fond iles llacons, on peut arriver, sinon à mener à bien ces lar'ves elles-mêmes, du moins à obtenir les parasites qu'elles contiendratent. Les nymphes des coccinelles, sur les feuillos, donnent aussi diverses espèces. . Ye laissez pas non plus échapper les oculs des lépidoptères, des hé- 
miptères, etc. fixés aux feuilles, aux tiges, aux murailles, sous les pierres; ils vous donneront de minuscules espèces spéciales, souvent impossibles à trouver autrement. Les oothèques des Mantides, les nids et les coques d'araignées trouveront leur place dans nos tubes.

Recueillons encore les capitules ou les calathides des composécs, carduacćes, clc., les siliques ou les gousses des crucifères et des légumincuses; tout cela abrite une nombreuse population

Dans les détritus, les fumiers, les plaies des arbres, vivent une multitude de larves qu'il faut prendre et placer, avec une certaine quantité de la matière qu'elles habitent, dans un flacon, dont la moitié a ćté remplie de terre humide. On doit alors avoir soin de ne pas fermer avec un bouchon, mais simplement avec un papier ou une gaze fine, et de donner de l'air, plusieurs fois par jour, pour éviter la moisissure. Quelques-unes au moins, de ces larves donneront certainement naissance à des parasites.

Vous pouvez aussi, en juillet ou août, chercher les entonnoirs des larves de Formica-Leo, les installer dans une boîte, et les nourrir jusqu'à leur transformation en coque, qui ne tardera pas. Vous aurez peut-être, en enfermant ensuite ces cofjues dans un flacon, des parasiles.intéressants.

Jusqu'en avril, il est meilleur de ne pas fermer les flacons ou les boîtes, et de laisser à l'air libre les fagots de branchages altaqués. Il n'y a pas à craindre d'évasion jusqu'à cette époque, et on évitera ainsi deux fléaux des éducations artificielles, la sécheresse et la moisissure. Il faut, d'ailleurs on tout temps, se tenir en garde contre elles, soit en humectant légèrement l'intérieur des flacons quand il en est besoin, soit en détruisant, au moyen d'un petit pinceau imbibé d'acide phénique, les moindres traces de champignons parasites dès qu'il s'en produit.

Je n'en finirais pas, si je voulais énumérer toutes les sources qui peuvent procurer des hyménoptères. Je vais me borner aux quelques indications qui précèdent, pour aborder un sujet auxiliaire, mais cependant non moins important.

Quand tous les flacons sont garnis, on doit les surveiller et les visiter chaque jour un à un, avec les plus grandes précautions pour ne pas faire subir des chocs trop considérables aux prisonniers contre les parois de leur habitation. Ces visites auront lieu 
surtout le matin, car c'est pendant la nuit que se fait en fiénéral la transformation. Elles permettront, presque toujours, de constater (puelque éclosion nouvelle; il est important de recueillir les insectes, pendant qu'ils sont très frais et de ne pas attendre fu'ils meurent el se dessechent au fond du flacon. On doil, au contraire, consiacrer chaque jour un instant à leur préparation et à leur étiquelasce, qui feront l'objet d'un chipitre spécial. Il est cependant ulile de dire ici que chaque flacon, boîte ou tube, doit porter une éliquelle indiquant la nature de ce qui y est introduit avec le lieu d'origine.

Il est préférable encore de les numéroter simplement; sur un pelit registre spécial, où chaque page porte un numćro correspondant i ceux des flacons, on inserit les renseignements que je. réclamais toul-it-l'heure. On peut aussi le faire moins brièvement, et ajouter, au fur et à mesure des ćclosions, le nom des parasites obtenus. C'cst ce que j'appellerai le livre des éducalions.

Irais l’ mese bornera pas notre comptabilité. A chaque éclosion, les insectes étant préparés, comme je le montrerai, on doit tenir nole exacte du flacon d'où ils sont sortis, et, parsulte, deleur habital et de la date de leur naissance. Ces indications seraient cncombrantes sur une étiquelle enfiléc dans l'épingle. Il vaut infiniment mieux adopter un deuxième registre, que je nommerai: livro d'éclosion. Chacune de ses pages sera divisce en quatre colonnes rle largeur approprice à ce que l'on doit y inscrire ot portant comme entête : $\mathrm{n}^{0 \mathrm{~s}}$ d'ordre - clales d'éclosion - noms observations.

Lit premicre colonne n $^{\text {ns }}$ d'ordrei donne les nombres tels (qu'ils se suivent naturellement.

La deuxième colonne (dates d'éclosion) indique ces dates avec cxiclitude.

La troisième colonne (noms) restera tout d'abord en blanc, et sera remplic au fur et à mesure des déterminations.

La quatrième, enfin, (observations) domnera lous les détails utiles sur l'habitat, le lieu d'origine, (plaine montane, endroits sees ou humides, ete.) et les notes particulicres auxquelles peut donner lieu l'insecte considéré.

A l'épingle, qui supporte eet insecle, est fixé seulement un numéro correspondant au numéro d'ordre de ce registre. 
Les deux registres dont je viens de parler peuvent même être mis en relation l'un avec l'autre, les numéros des individus éclos étant reportés sur la note d'éducation de chaque flacon.

Cette petite tenue de livres est excessivement simple; en méme temps qu'elle évite l'encombrement des boîter par des étiquettes trop nombreuses ou trop volumineuses, elle supprime toute erreur, et elle constitue, en fin de compte, une sorte de répertoire d'éclosion fort instructif et fort intéressant. L'idée première en revient à M. Lichtenstein, qui l'a indiquée dans les Petites Nouvelles entomologiques-1877, $\mathrm{n}^{\circ} 170$.

J'ai encore, avant de terminer, à faire une dernière recommandation. Quand une éclosion importante se produit, il s'y trouve, en même temps, et des parasites, et des victimes épargnées. Il faut recueillir ces dernières, les piquer avec soin, les déterminer ou les faire déterminer, si elles appartiennent à un ordre d'in. sectes que l'on ne connaît pas; et porter leur nom sur le livre d'éclosion au numéro du parasite; réciproquement porter au numéro de la victime, si elle est elle-mème un hyménoptère, l'indication des parasites. C'est, en effet, un renseignement important à conserver. Souvent on ne pourra connaître cette victime; mais l'aspect de la larve, de lit chrysalide, etc. donnera une idée du genre d'insectes auquel elle peut appartenir, et il faut le noter, de façon à garder au moins celte indication approchée.

Il sera bon enfin de joindre dans la collection, aux hyménoptères leurs parasites, aux parasites leurs victimes d'ordre quelconque, quand on le peut, puis les coques, les galles, chrysalides, etc. d'où ils sont sortis. Cet ensemble forme, avec les renseignements que l'on a notés, un véritable monument scientifique, un fait acquis.

2. - Préparation. - Dès que la chasse est termince, on doit s'occuper de préparer les insectes recueillis, et si on ne le fait lo jour même, on ne doit pas attendre plus tard que le lendemain, car ils se dessèchent et deviennent cassants. Les antemnes tombent sous les doigts, et les pattes ou les ailes conservent les positions anormales qu'olles ont prises dans les dernières convulsions qui ont amené la mort. Les insectes frais se manient, au contraire, avec facilitć et sans qu'on ait à craindre de les briser. 
Il n'y a pas, pour les hyménoptères en général, de procédé pariiculier de préparation. Tous ceux qui sont assez gros ifuatre millimètres el au-dessus), doivent ètre traversés pat une ępin gle à insectes qui perce le thorax à peu près ver's son milieu.

Avec un pinceau fin, on débarrasse le sujet des poussières yui pourraient y adhérer; on ramène les antennes en avant de fiagon à les rendre bien visiblés; on place les pattes d'une mauićre symétrique, sans les écarter du corps, car elles deviendraient embarrassantes; on likche enfin de ramener les ailes dans une position normale, mais de façon que l'abdomen ne soil pas roilé parr elles, el que leur observation qui est essenticlle, soit rendue facile.

$\mathrm{Si}$, comme cela arrive très-souvent, l'abdomen tend i tomber et it former un angle droit arec le thorax, ce qui donne it l'insecte un aspect disgracieux, contre nature, et en rend l'etude malaisée, on le relève en enfilant dans l'épingle une petite bande de carton bristol assez rigide pour le soutenir; quand l'insecte est sec, on enlève ce carton et l'abdomen garde la position qu'on lui a donnéc. Si l'on veut apporter encore plus de soin it cette préparation, on peut étaler les ailes, comme font les lépidoptéristes pour les papillons; mais ce travail, qui donne beaucoup de cachet is une collection, n'ajoute que bien peu ì sa valeur scientifique, et si l'on mel en balance, d'un còté, le temps énorme que coùtent ces soins minutieux, de l'autre, le peu d'utilité réelle du résultat oblenu, on verra que l'entomologiste fera beaucoup micux d'éviter ces précautions superflues, pour reporter son zèle et ses loisirs dians l'étude plus approfondie des caracteres de l'insecte. Il y a, dans tout cela, tant a faire, qu'une minute perdue inutilement ne peut se regagner. Aussi ne veux-je pas ici décrire de procédé pour cet étalage inutile.

Les insectes qui ne sont pas encore trés-petits, mais ont cependant une taille inférieure à quatre millimètres, peuvent, si l'on ne veut pas employer d'épingle, qui détruirait une partie du thorax, ctre collés sur des petites bandes de carton, comme on fait pour les colcoptères. Dans ce cas, je conseillerai de coller deux males et deux femeljes, un des exemplaires de chaque sexe l'étant sur le dos. La colle à employer doit être composce de gomme arabique bien blanche, additionnée d'un peu de sucre qui lui donne du liant, el d'acide phénique qui assure sa conservation. Les pro- 
poriions suivantes indiquées déjả dans d'autres ouvrages, et que j’ai expérimentées, sont très-recommandables.

Gomme arabique pure en morceaux
Sucre blanc
Acide phénique cristallisable

S'il s'agit d'insectes très exigus, par exemple les Chalcidites, les Proctotrupiens, les petits Ichneumonides, etc., il faut suivre d'autres procédés. C'est, le plus souvent, par éclosion qu'on les oblient.

Si done vous avez recueilli dans une chasse, ou si quelques uns de vos flacons à élèves laissent voir, le matin, sur leur paroi, un insccte, un Chalcidite, par exemple, nouvellement ćclos, cherchant le jour et la lumière avec autant d'avidité que leurs larves mettaient d'obstination à les fuir, demandant surtout une issue à tous les interstices, il ne faut pas lui laisser le temps de déflorer la fraîcheur de ses ailes, et, si l'action de la lumièro a suffisamment raffermi ses organes, vous devez procéder de suite à sa préparation, qu'il est toujours mauvais de remettre au lendemain.

Pour cela, vous ouvrez le flacon d'éducation, vous faites passer adroitement l'insecte ou les insectes dans un petit tube que vous fermez incomplètement avec un très-léger tampon do coton, puis vous l'introduisez dans un flacon spécial, contenant un de nos tubes à cyanure. Les petiles bestioles ne tárdent pas à subir son influence délétère et perdent, peu à peu, leurs mouvements. On ne doit pas trop se hâter de les remettre à l'air libre, car l'asphyxie ne sorait pas complèto; il faut attendre quinze à vingt minutes au moins.

Quelquefois, pour tuer ces petits insectes, on a recours à la chaleur; mais, bien que ce moyen soit simple et efficace, il faut éviter de l'employer, car on risque toujours de brûler ou de racornir les ailes, quoiqu'un simple passage du tube dans une flamme d'alcool suffise pour les faire mourir.

Nos captures étant sans vie, nous arrivons à la préparation proprement dite. Ici se présentent plusieurs méthodes dont deux - surtout méritent notre attention, à cause de leur emploi le plus général. L'exiguité de la taille de ces insectes étant souvent très- 
grande, beaucoup de collectionneurs se contentent d'acir, comme avec les coléoptères, les hémiptères, otc., c'est-à-dire qu'ils les fixent sur un petit rectangle de carton au moyen d'une gouttelette de gonme. Ce procédé est trop employé, car il détériore, le plus souvent, les individus sur lesquels on opère en engluant leurs ailes et les rendant méconnaissables.

Le second procédé, employé surtout en Allemaguc, est de beaucoup préférable. Aussi le recommanderai-je d'une faģon spéciale et donnerai-je tous les détails nécessaires pour sa boune exécution. Des insectes bien préparés et bien disposés pour l'élude, sans (fu'il soit besoin cependant d'un étalaģe complet, présentent un intérêt et une valeur bien plus considérables que s'ils ćtaient massacrés ou plongés dans un océan de colle.

Ce procédé, employé pour les microlépidoptères, est celui du piçuage au moyen de fragments de fil arģenté excessivement fin. Ce fil se rend à bas prix sous forme de bobines. Au moyen d'un ciseau ordinaire, on le coupe en tronçons de 15 millimètres environ, en ayant soin de faire la section obliquement, afin que les extrémités soient aussi aigües que possible. Puis, au moyen de pinces à bec très-fin, on saisit, avec la main droite, un de ces fils, à environ deux millimètres d'une des extrémités. Sur un doigt de la main gauche, on maintient l'insecte couché sur le côté, et un peu d'habitude aidant, au besoin même avec le secours d'une grosse loupe montée, on arrive facilement à percer, avec l'extrémitè du fil argenté, la poitrine de l'insecte du cóté inféricur ou sternal. Ceci fait, on pose le dos sur un morceau de moelle de sureau, et appuyant sur celui-ci, le fil traverse le thorax; on le pousse de fagon it ce qu'il fasse saillie d'un inillimétre onviron.

Celte opération, sans cloute assez délicate à cause de la petitesse souvent excessive des individus ì préparer, devient cependant très-facile et très-rapide avec un peu d'habitude, quelle que soit celte petitesse, à condition que l'insecte soit frais.

On pique ensuite l'autre pointe du fil argenté vers l'une des extrémités d'un parallellipipède découpé, aussi nettement (que possible avec une lame bien tranchante, dans de la moclle de sureau parffitementblanche. A l'autre extrémité de cette moelle, on fait passer une épingle à insectes ordinaire, $n^{\circ} 3$ ou 4 , qui sert de support ì tout l'appareil. Un seul fragment de sureau pout porler plusicurs insectes, pourvu qu'ils appartiennent ì la même espèce. 
Il ne reste plus qu'ì faire traverser par l'épingle le signe indiquant le sexe, quand on. le peut, et le numéro correspondant à celui accordé sur le livre d'éclosions à l'insecte considéré, puis à le placer dans une boîte de dépôt, en attendant son examen définitif.

Si l'objet n'est pas trop volumineux, on enfile encore dans l'épingle un petil rectangle de carton sur lequel sera collé, avec soin, l'œuf, la galle. ou la coque d'où est sorti l'hyménoptère. Si cet objet est trop gros, on lui consacre une épingle spéciale munie du même numéro que l'insecte, et portant en oulı'e, si cela est possible, et s'il s'agit d'un parasite, un exemplaire de la victime.

Quant au rangement en collection, il n'y a rien de spécial à en dire, si non qu'il ne faut pas se fier sur ce que l'on a affaire souvent à de très-petits hyménoptères, pour leur ménager la place. Ceux-ci étant presque toujours parasites, il faut que chaque espèce présente un grand nombre d'exemplaires mâles et femolles avec leurs victimes. Comme ces dernières peuvent souvent se rapporter à plusieurs insectes différents, chaque liabitat constaté doit être représenté avec les parasites qui en sont sortis, pour bien étudier les variétés possibles.

La mise en collection des autres hyménoptères, de taille plus considérable, n'exige pas d'autre précaution que celle qui consiste à placer, autant que possible, dans l'épingle, l'indication du sexe et de la patrie. Chaque nom doit laisser, entre le suivant et lui-même, assez de place pour qu'on puisse y mettre des individus de toutes les grandeurs, surtout les plus grands et les plus petits, ainsi que les variétés, puis tout ce qui se rattache ì cet insecte, galles, nids, dégats, parasites, préparation des parties délicates, œufs, larves, nymphes, si on le peut, préparées comme nous le verrons, etc.

Tout cet ensemble constituera, à chaque espèce pour laquelle on pourra le réunir, un résumé de toutes les conditions de sa vie.

Pour quelques unes, (les Tenthrédines), les larves sont très-semblables aux chenilles de lépidoptères, et toutes les fois qu'on le pourra, il sera bon de les joindre aux insectes parfaits, en les préparant comme on fait des chenilles. On les fend un peu par dessous, du côté de l'anus, puis on les presse légèrement soit 
entre les doigts, soit en passant sur le corps, de la tête ì l'extrémitć, une surface arrondie comme un manche de porte-plume, de façon it faire sortir, par l'ouverture pratiquée, tous les organes intéricurs. On introduit ensuite, dans la même ouverture, l'extrémité d'un brin de paille non écrasé, formant tube, dans lequel on souffle. La penu se distend, reprend sa forme arrondie, et si on la passe légèrement, tout en soufflant, au-dessus de quelques charbons ardents, olle se dessèche, et conserve la forme que l'air lui a donnce. Il ne reste plus qu'it couper le brin de paille au ras du corps, ì coller la larve préparée, soit sur un carton, soit sur un fragment de l'arbuste cuui lui sert de nourriture, et à la fixer, à sa place, au moyen d'une épingle, dans la collection.

On agira de même pour les chenilles ou larves ayant servi de victimes aux hyménoptères parasites, et que llon joint à ceux-ci, dans les boîtès, comme pièces de conviction.

Dans les autres familles d'hyménoptères, les larves sont toujours molles, blanches, inertes, et il est préférable de les conscrver dans de très-petits tubes remplis d'alcool. Une ou deux épingles les fixent aussi à leur place dans la collection.

Si l'on fait une étude sérieuse et complète, il est de grande utilité de pouvoir examiner facilement les parties les plus délicates et les plus eachées, comme les pièces de la bouche, les pattes, les antennes, les tarières, les aiguillons, les organes génitaux mâles, etc. Il est très-commode, pour épargner du temps et augmenter la valeur d'une collection, de faire de tous ces objets de véritables préparations microscopiques, que l'on peut ensuite étudier tout à loisir.

Pour y arriver, il y a deux opérations successives à exécuter, la dissection et la préparation.

Pour les insectes d'assez grande taille, la dissection ne présente pas de difficulté. S'il s'argit des pièces de la bouche, on sépare d'abord la tête du thorax, puis, avec un ciseau très-fin dont une branche pénètre dans le trou occipital, on fond la tête sur les cótés jusqu'it l'anorle des mandibules. La tête se trouve divisée en deux calottes, contenant, chacune, une partic de ces pieces de la bouche. $\Lambda u$ moyen d'une aiquille emminchée et d'une aiguille it cataracte, on sépare facilement, en s'aidant d'une loupe montice, s'il le faut, toutes ces différentes parties. 
Pour la tarière et l'aiguillon, on fend l'abdomen à son extrémité en dessus ou en dessous, et on retire ensuite facilement ces organes, ainsi que les parties plus intérieures qui y sont adhérentes.

Une simple pression à l'extrémité de l'abdomen fait, le plus souvent, saillir complètement à l'extérieur, les organes génitaux mâles, et il est facile de les séparer.

L'extraction des pattes, des antennes ou des ailes ne demande que du soin, sans qu'il soit besoin d'explication spéciale.

A l'égard des très-petites espèces, pour lesquelles ces préparations ont surtout de l'intérêt, les difficultés sont bien plus grandes. On commence par se procurer une petite plaque de cire bien blanche, des pinces très-fines, des aiguilles emmanchées et une aiguille dile à calaracte. On sćpare d'abord la tête du thorax, on la place sur la plaquette de cire où elle adhère un peu, on la couvre d'une goulte d'eau; puis on relève les antennes qui pourraient se trouver couchées sur la tête, et on les appuie sur la cire. Avec l'aiguille à cataracte, on fait ensuite deux sections dans la tête, allant du trou occipital à l'insertion de chacune des mandibules. On obtient ainsi quatre fragments, dont deux contiennent chacun quelques pièces de la bouche, qu'il est alors facile do séparer. Pour la tarière, les pattes, les antennes, il n'y a rien ì ajouter à ce que j'en ai dit. Pour les ailes, il est bon d'enlever d'abord, avec les ciseaux ou les aiguilles, l'écaillette qui en recouvre la base. Ensuite, avec l'aiguille dans la main droite, une pince fine dans la main gauche, on tâche de les désarticuler, de façon à conserver intactes les pièces de cette articulation.

Ces dissections ćtant terminées à souhait (et on y arrivera trèsfacilement avec un peu d'adresse, de patience et surtout de pratique), il faut procéder à la préparation proprement dite.

Pour les grosses espèces, on colle simplement et avec soin les parlies disséquées sur des rectangles de carton bien blanc.

Pour les petites, on doil faire de véritables préparations microscopiques, ce qui d'ailleurs est bien simple. On se procure des lames de verre bien pur, des lamolles minces et du baume du Canada. On commence par bien laisser sécher les piéces que l'on veut conserver, en les étalant sur un papier blanc, puis on les place entre deux lames de verre, avec une goutte d'essence de térébenthine, le tout étant attaché avec un fil. 
On netloie, d'autre part parfaitement, ì l'acide, une lame de reire, et on y dépose une goutte du baume du Canada, qu'on ramollit en passint rapidement, au moyen de pinces, la lame sur une flamme d'alcool. Le baume se liquéfie, s'élend sur le verre, et, quand sa surface est bien unie, on y dépose, avec le plus grand soin, les petits fragments que l'on retire de la térébenthine, en les pliçant arec ordre, de façon ì pouvoir les recomnaitre et les étiqueter convenablement. On chauffe de nouveau légèrement, puis on recouvre le tout aree une lamelle mince, bien propre. Il faut prendre de grandes précautions pour éviter que des bulles d'air, si pelites (qu'elles soient, séjournent entre les deux verres. Elles produiraient autant de taches qui empêcheraient de voir les objets préparés. Pour y arriver, on a soin de chauffer très-légèment le baume contenant les objets de façon à le rendre bien liquide; on saisit avec des pinces fines, la petite lamelle, on l'appuie, par un des bords, sur la lame de verre et on la couche doucement sur le baume, de façon que tout l'air soit chassć. Il faut agir assez rapidement, quoique sans précipitation. La praticque, ou les ourrages spéciaux, indiqueront à chacun tous les détails et les tours de main impossibles à décrire ici. Quand ces opérations sont terminées, on presse légèrement sur la lamelle pour chasser l'excédant de baume, et on laisse la préparation baume séeher et se durcir pendant quelques jours. Lorsqu'il n'y a plus ì craindre que la lamelle se déplace, on onleve avec un peu d'alcool le baume qui dépasse celle-ci, puis on colle, sur l'extrćmité de la lame de verre, une étiquette indiquant la nature de la préparation. On n'a plus qu'i la placer dans une boîte à ratinures, où elle vient prendre son rang pour constituer une collection des plus utiles pour l'étude.

Il est encore fort intéressant de conserrer les oryanes intérieurs, les alppareils de respiration, de circulation, de digestion, de reproduction, de secrétion, etc. Mais les préparations de cette nature nécessitent des connaissances spéciales pour les(quelles je ne pais que renvoyer aux traités de micrographie.

En règle générale, lout insecte qui est entré dans la collection, muni de tous les documents et renseignements qui y sont relittifs, ne doit plus en sortir. Il faut mettre on collection assez d'individus pour aroir ì peu près toutes les dégradations de taille 
pour les deux sexes, puis ceux provenant de pays très-différents, enfin toutes les variétés. Il est donc nécessaire, si l'on veut y ajouter tous les renseignements que j'ai indiqués, de donner à chaque espèce un grand espace dans les boîtes. Les noms de fitmille, de genre et d'espèce seront sur des papiers de teintes différentes, en ayant soin, si l'on s'occupe aussi de réunir les espèces exotiques, de consacrer, pour leurs ćtiquettes spécifiques spéciales, les couleurs suivantes :

Bleu, aux insectes provenant d'Afrique.

$\begin{array}{llll}\text { Jaune, } & - & - & \text { d'Asie, } \\ \text { Vert, } & - & - & \text { d'Amérique, } \\ \text { Rose, } & - & - & \text { d'Océanie. }\end{array}$

Les étiquettes blanches étant réservées à tous les insectes d'Europe. Si une espèce se rencontre en môme temps en Europe et en Afrique, par exemple, le nom spécifique sera sur papier blanc, mais l'individu provenant d'Afrique portera, sur un petit papier bleu enfilé dans l'épingle, le nom exact du pays d'origine : Algérie, Egypte, Gabon, elc.

Le goût de chacun doit, avant tout, présider l'arrangement de sa collection, cependant les points que je viens de traiter doivent rester uniformes pour tout le monde, afin de faciliter les relations d'échange.

A côté de la collection, on a nécessairement, d'abord des boîtes renfermant les doubles déterminés, dont on a pas l'usage pour soi-même, et qui servent aux échanges ; puis d'autres boîtes, servant de magasin, où l'on enferme les insectes provenant des chasses ou des éclosions, à mesure qu'on les obtient, et en attendant qu'on ait le temps de les examiner. Si parmi eux, il en est dont on ne puisse reconnaître le nom spécifique avec sûreté àu moyen des ouvrages, on fera bien de les placer dans la collection, avec des étiquettes sans nom, à la fin du gुenre auquel ils appartiennent. On les a de cette manière souvent sous les yeux, et il est facile de les comparer avec leur congénères; leur place, de plus, se trouve ainsi réservée.

3. - Gonservation des Collections. - Une collection contenant un grand nombre de types el renfermant de nombreux renseignements, comme j'ai indiqué que cela doit avoir lien, 
représente, pour celui (qui l'a réunie, une somme de travail souvunt très-considérable. C'est, de plus, une propriélé pouvant avoir de lai valeur, el enfin surtout, un monument seientifigue qui mérite les soins les plus assichus. Aussi la question de conservation de ces collections est-clle tris-importante et l'on ne saurail trop s'en préoccuper. La premiere précaution ì prendre est de se servir de boîles ì fermeture aussi hermélique que possible. Mais, en grénéral, il ne faut pas trop compter sur leur perfection el on doit toujours surveiller minuticusement leur contenu. Celte attention continue, l'ouverture fréquente des cartons est une des meilleures conditions de conservation.

Les collections entomologiques ont a craindre plusieurs sortes d'ennemis, d'abord les insectes rongeurs, puis la moisissure et l'humidité. Contre le premier, la bonne installation des boîtes et leur ouverture fréyuente sont les meilleures garanties. Quelques entomologistes piquent dans un des coins une éponge ou un tampon de coton nu ou enfermé dans un petit récipient de verre el fortement imbibé d'acide phénique. D'autres emploient du mercure, du camphre, de l'essence de thym, elc., dins ces derniers temps, on a préconisé la naphtaline purifice, et l'essence d'amandes amères du commerce; la plupart se contentent de fréquentes visites.

Quand un peu de poussière au fond d'une boîte signale l'invasion d'un insecte destructeur, il faut, en frappant sur le fond, cn examinant de près les individus que l'on suppose attaqués, le rechercher avec ardeur et ne se donner de repos que lorsqu'on l'a trouvé. Les larves d'anthrènes se laissent facilement tomber sous l'influence d'une secousse un peu vive. Point de pitié alors pour ce terrible ravageur, il faut l'écraser sans attendre; de même pour les acarus et les mites que l'on voit souvent courir avec agilité au fond des boîtes.

Enfin, chaque fois (que l'on regoit pall culnange de notreaux in. sectes, il est tre's-prudent de leur faire subir une quarantaine dans un carton spécial, el ce ne sera que lorsqu'on aura la cerlitude qu'ils ne recélent aucun ennemi, (qu'on les admettra dans la collection elle-même. On a recommandé encore, pour ce cas, l'emploi de l'alcool arsenié, qui se prépare en plaģant simplement un fragment d'acide assenieuxau fond d'un flacon d'esprit devin. 
On y plonge et on y laisse séjourner un certain temps les insectes qui ne craignent pas d'être mouillés. Pour les autres, on est rédluit à porter, avec un pinceau, un peu de cet alcool dans toutes les parties où l'on peut craindre la présence d'œufs ou de larves.

La moisissure est tout aussi terrible et plus difficile encore à déloger. Si vous avez une armoire ou un local sensiblement humide, il faut les abandonner de suite et employer un autre eridroit. Si cette humidité n'est que très-faible, on peut la combattre, souvent avec succès, en s'assurant d'abord que les fermetures de l'armoire sont bonnes, et en mettant, sur quelques-uns des rayons, des soucoupes contenant du chlorure de calcium. Celte substance, très-avide d'eau, absorbe toutes les vapeurs aqueuses qui se trouvent dans le meuble en même temps qu'elle. Enfin une très-bonne condition est de placersa colleclion dans une chambre habitucllement chauffée en hiver.

$\mathrm{Si}$, malgré les précautions prises, on s'aperçoit que quelques cartons sont atteints de moisissure, on peut les en débarrasser en passant, sur les individus endommagés, un pinceau doux imbibé de benzine ou d'éther. Ce procédé si simple suffit pour rendre, ì des insectes en fort mauvais état, un aspect tout autre.

Dans le cas où des têtes, pattes ou antennes seraient brisécs ou tombées, on peut les recoller à leur place, si le sujet est précicux, et on arrive à de bons résultats avec du soin et de la patience. Mais il ne faut absolument le faire que si l'on est tout à fait sûr de rapporter les parties brisées à l'insecle même auquel elles appartiennent. Toute erreur dans cette circonstance serait très-regrettable, et il vaudrait micux le garder incomplet que de lui adjoindre des organes qui laisseraient le moindre doute sur leur prorenance.

4. - Rédaction du Catalogue. - Le catalogue d'une collection on est la clef véritable, et sa rédaction, bien comprise, est fort importante et moins simple qu'on ne pourraitle supposer.

Un système, fort employé, consiste à prendre un catalogue im. primé et ì pointer simplement les espèces que l'on possède. Ceite méthode praticable encore avec les coléoptères, les lépidoptìres, même les hémiptères, le devient beaucoup moins quand il s'agit d'hyménoplères, dont de nombreuses espèces nouvelles ipparaissent sourent, qui ne peuvent exister sur des catalogues plus 
ou moins anciennement edités. Celui de Kirschner, qui est ì peu près le seul employable, contient forcément beaucoup de lateunes, puis(pue, depuis son apparition, des travaux assez nombreux ont été mis au jour.

Il est done bien préférable de rédiger soi-même son catalowne. Si l'on prend celte peine, il n'en coùte guère plus de lui fitire comprendre des renseignements un peu plus détaillés. l'our celit, chacun doit suivre son inspiration et noter les circonstances qui l'intéressent le plus.

Le plan général consistera eependant toujours it avoir un registre portatif et contenant environ is it 700 pages. On divisera. ce nombre de pages, en s'aidant des indications du catalozue de Kirschner, en parties proportionnelles à l'importanco des familles, et on inscrira, en tête de chacune d'elles, le nom de ces familles. Le nombre de pages assigné à celles-ci sera, à son tour, partagé proportionnellement à l'élondue de chacun des grenres qu'elles contiennent, et leur nom sera inscrit à sa place. Il sera très. commode de n'employer, pour tout cela, (que le verso des parces (à gauche du lecteur), le recto étant laissé en blane et destinć à recevoir, en face de chacun des noms, les indications que l'on. désirera y inscrire, soit la localité où l'on trouve habituellement I'insecte, avec sa date d'apparition, la partie de l'Europe yu'il affectionne, soit une nole rapide sur ses mocur's, soit la nomenclature des variétés que l'on posséde, des patasiles qui lui sont adjoints dans la collection, soit tes synonymies, soit toute autre chose, suivant le goul de chacun. En agrissant ainsi, on se crée un repertoire plein de notes intire-sintes, que l'on peut potter partoút arec soi, et qui est un véritable résumé de la collection.

\section{5. - Détermination des insectes et usage des ta- bleaux dichotomiques. - Pour li détermination, ou la recherche du nom assigné it un insecte, une simple loupe avec plusieurs grossissements doil, le plus souvent, suffire. Les prépa- rations des parties délicates, que j'ai conseillé d'exécuter, seront aussi d'un grand secours. D'ailleur's les caractères employés dans les tables dichotomiques scront toujours, autant que possible, choisis parmi les plus faciles a constater, el indipendants dessexes.}


Tes systime dicholomique a été imaginé, it la suite d'une espèce de défi, par lo chevalier de Lamarck (né à Bazentin en 1744, mort it Paris, membre de l'Institut el professeur au Jardin des Plantes, en 18:9). Par son application, les êtres sont loin de se tronver rangés convonablement, eu égard à ce que doit être une classification. Celle (que l'on obtient ainsi est complètement artificiclle; mais celte methode donne une si grande facilité pour arriver à connaitre le nom d'une espèce, qu'on doit la choisir toules les fois que l'on veut déterminer, quitte ensuile à placer convenablement l'animal, ou la plante, dans la sćrie naturelle des êtres. Aussi a-t-clle étẻ adoptée de nos jours, soit sous sal forme primitive, soit sous la forme dite analytique, pour tous les ouvrages d'histoire naturelle ayant pour but principal de conduire rapidement à des noms exacts.

Lat base de ce système consiste à placer toujours le lecteur en face de deux hypothèses contraires. Le sujet considéré doit forcément, par sa nature, rentrer dans l'une ou dans l'autre. De là ressisort une première division des êtres étudiés, des insectes pour ce qui nous regarde, en deux parlies. Recommençant pour la première de ces parties, comme on a fait pour la totalité, on a encore deux subdivisions : chacune d'elles peut aussi, de la méme mánière, so partager en doux autres et ainsi de suite, jusqu'à ce qu'on arrivo à n'avoir plus à choisir qu'entre dęux noms. Un dernier groupe de deux hypothèses contraires les différencie, à lour tour, et indique, en dernière analyse, celui-là même qui - convient à l'insecte que l'on examine.

T'oute la difficulté consiste a choisir, pour ces phrases opposées, des caractères convenant on même temps à toute une série d'insecies, assez simples pour être vérifiés, facilement et assez constants pour qu'on ne soit jamais induit en erreur.

Ceci posé, la marehe ì suive pour employer les tableaux dichotomiques en découle facilement.

Etant donnó un insecte, uno guêpe, par exemple, on commence par lire attentivoment les phrases caractéristiques contenues dans le paratgraphe marequé 1 du tableau des familles, et à voir lanuelle des deux phrases convient it l'insecte. On lit alors le numéro qui suit la phrase adoptée, et on se reporte au paragraphe indiqué par ce numéro. On y retrouve deux autres phrases, avec 


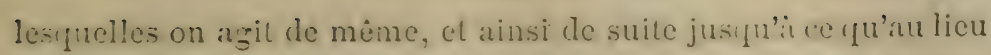
d'arriver à un numéro de renvoi, on trouve, à lạ suite de la dẹrnitre hypothese adoplee, le nom d'une famille. C'est ecile qui est cherchée.

On passe alor's au tableau spécial des genres de celte famille, et on opére de méme jusqu'i ce qu'on obtienne le nom du genre de l'insecte qu'il s'agit de déterminer.

Dn cherche enfin le tableau des espèces de ce genre, et on arrive aussi facilement au nom spécifique.

(quelle que soit lit perfection d'un tableau dichotomique, il peut se faire que deux phrases contraires laissent un peu dans l'indécision pour un insecte petit ou mal caractérisé. On doit alor's poursuivre l'une des phráses, ef si l'on parvient à un résultat impossible, par exemple qu'elle conduise à des insectes noirs ou jaunes, tandis qu'on en a examinć un bleu, on revient au point où l'on a hésité, et on reprend la seconde phrase, qui conviendra, alors très-probablement, à l'insecte en question.

Pour toute determination, l'habitude, la connaissance des facies aident beaucoup, et les débutants feront toujour's bien, soit de se procurer une petite collection typique bien déterminée qui leur. donnera une ídée générale des diverses formes, soit de consulter de bonnes planchés. Ils distingueront ainsi presçue toujours, à première rue, au moins la famille, sourent le genred'un insecte.

Les déterminations nécessitent beaucoup de soins et de patience, car un nom inexact, dans une collection, est comme une tache, diautant plus a craindre qu'elle peut rester inaperçue fort longtemps et occasionner beaucoup d'autres erreurs.

\section{§2. - STRUCTURE EXTERNE}

Le corps de tout hyménoptère, à l'état parfait, se compose de trois parties principales : lit tête, le thorax et l'abdomen, portant, chacune, un certain nombre d'organes accessoires.

Lit surfatce entiere du corps est composcie d'un tégument corne continu, dont l'épaisseur rarie seulement en certains endroits et devient très mince dans les articulations, de façon à. ne plus y conserver qu'une consistance membraneuse. 
Ce sculuclelle, tout extérieur, peut présenter une différence trésgrande, suivant les espèces, dans sa dureté et sa solidité. Il porte intérieurement des saillies, ou des apophyses, auxquelles viennent se fixer les muscles de l'insecte. Enfin il présente plusieurs ouvertures nécessaires pour l'entrée et la sortie des alimenis, ainsi que pour laisser place aux organes de la respiration, de la vision et à ceux de la reproduction.

La surface extérieure de ce squelelte offre des modifications extrêmement nombreuses qui s'expriment par des termes différents, et rui se rapportent a!x sculptures dont elle est ornce, à son état glabre ou velu, lisse ou chagriné, etc. Toutes ces expressions devant trouver leur place et leur explication rigoureuse dans le glossaire qui va suivre cette introduction, ce serait faire double emploi que de les rapporter ici. Je me contenterai seulement d'insister surla nécessité absolue qu'il y a à s'accorder, d'une façon complète, sur la valeur de chacun de ces mots techniques et, aussi, sur leur équivalent dans les langues étrangéres les plùs usitées.

\section{TÊTE}

La tête (pl. I) placće, comme toujours, à la partie antérieure du corps, est distinctement sćparée du thorax qui la suit. Elle est portée sur une sorle de pidicule li menteux ou col plus ou moins court, quelquefois mème invisible, qui lui permet certains mouvements souvent trés-etendus, autour de son axe. Sa iorme varie dans d'assez grandes proportions; elle peut être arrondie, cubique, conique, aplatie, prolongée ou non en musealt, ełc. Par sa position relativement au thorax, elle est avancée, penchée, inclinée, infléchie, ete. Elle peut porter des appendices cornis, être lisse, ou plus ou moins ponctuce, striće, rhagrince, etc.

Eilic est fixce au thorax par l'intermédiaire de téguments et de muscies qui s'attachent à sa partie posterieure. Les organes intérieur', filets nervoux, œsophage, appareil circulatoire, cic. passent de l'un à l'autre au travers du col, et pénètrent dans la tête par une ouverture situćc à sa partie la plus postérieure, souvent au fond d'une concavité profonde, et qui porte le nom de trou occipital. La region avoisinant ce trou est l'Occiput (fig. 1, a). Au- 
dessus, et ì la partic la plus élevée do la tête so trouve le vertex (b) qui porte les ocelles (c) ou yeux lisses. En redescendant vers la bouche, nous trouvons, entre la partie supérieure des yeux $\langle i\rangle$, et au-dessous des ocelles, un espace non clélimité d'une façon nette et portant le nom de front $(d)$.

Au-dessous et précisément entre les yeux, la région qu'ils enferment est la face. Elle porte les antennes et est parfois garnie de lamelles, de carènes, de sillons, de cavités diverses. Le plus souvent, elle se confond plus ou moins avec le front.

La face est limitce en avant, d'une façon quelquefois indistincte, par la pièce recouvrant immédiatement la bouche et que l'on nomme l'épistome (n) ou le chaperon. Celui-ci peut-êtro entouré de sillons profonds, sur le milieu des bords latéraux desquels se voit souvent une fossette spéciale, cqui porte le nom de fossette clypéale. Rarement l'épistome porte des appendices cornés. Entre la face et lui, se voiț, dans quelques genres, une pièce distincte et limitée qui a reçu le nom de postépistome. Enfin le nom de joues est réservé à l'zspace situé derrière les yeux au-dessus des mandibules.

Quelles que soient sa forme et la nature de sa surface, la tête porte toujours des organes fort importants, qui se divisent en organes fixes, et en organes mobiles, savoir :

$1^{\circ}$ les yeux;

?० les ocelles,

pour les pièces fixes.

Et : $1^{\circ}$ les antennes;

$2^{\circ}$ les parties de la bouche, pour les pièces mobiles.

\section{PIÈCES FIXES DE LA TÉTE.}

Ces pièces ne comprennent que les organes de la vision, qui sont ordinairement très-perfectionnés ou plutôt très-complexes chez les hyménoptères. Ils se composent, d'abord, des yeux proproment dits, puis des ocelles appelés quelquefois stemmates. Je vais les examiner successivement, mais je dois dire, dès maintenant, que souvent les ocelles font défaut, ou au moins s'oblitèrent complètement, et que, dans quelques cas rares, les yeux 
eux-mémes manquent tout-à-fait, constituant ainsi des insectes aveugles. Ce phénomène, qui se retrouve dans d'autres ordres, surtout chez les coléoptères, a lieu, pour les hyménoptères, dans 'quelques espèces de fourmis, dites hypogées, c’est-à-dire vivant profondément enterrées sous des pierres, des pièces de bois, des piquets, etc.

1. - Yeux. - Les ycux (pl. I, fig. 1, i), souvent très-gros, relativement à la taille de l'insecte, sont toujours situés de chaque côté de la tête et à une place variable dans le sens longitudinal. Ils arrivent quelquefois jusqu'à l'angle d'insertion des mandibules, d'autres fois en restent très-éloignnés.

Ils sont enchâssés dans des ouvertures pratiquées dans les téğuments de la tête, et présentant généralement un rebord plus ou moins prononcé. C'est ce qu'on appelle l'orbite des ycux, souvent entouré de fossettes profondes.

Les yeux peuvent offrir des dispositions diverses qu'il faul noter. Ils sont rapprochés ou éloignés, leur circonférence peut-être arrondic, ovale, réniforme, etc.; enfin ils sont généralement convexes et saillants sur la surface de la têic. Leur couleur vario dans des limiles très-étendues, et nous y trouverions des caractères très-commodes, si elle ne changeait pas, la plupart du temps, après la mort.

Leur surface peut être velue ou glabre et celte circonstance est quelquefois invoquée avec avantage pour séparer certaines espèces.

Si nous venons à examiner leur structure intime, nous trouvons qu'ils ne constituent pas des organes simples, mais que, examinés à un faible grossissement, ils se laissent décomposer en une multitude d'yeux élémentaires juxtıposés et formant, par leur ensemble, un appareil complet et unique. Par suite de cette disposition, la surface des yeux présente une structure en facettes hexagonales plus ou moins nombreuses (depuis une seule, dans les espèces presque aveugles, jusqu'à plusieur's milliers), dont chacune est une cornée correspondant à un œil distinct. A chacun de ces yeux ćlémentailes, aboutit un filet nerveux qui transmet au gangrlion céphalique l'impression des objets extérieurs. Toutes ces impressions doivent sans aucun doule se confondre, 
de faşon à procurer à l'insecte une imagre unique, arec tous ses relicfs, de l'objet qu'il considère. Les facettes d'un même oil sont le plus souvent égales; il arrivo cependant quelquefois qu'elles. diminuent de grandeur sur certaines de ses parties.

Cetle structure spéciale a fait donner à ces organes le nom d'yeux composés ou réticulés.

Ces yeux sont immobiles, mais leur dimension et leur convexité leur permettent de voir, sans mourements, ce qui existe dans un rayon très-étendu autour de la têto de l'insecte.

La vision à distance ne peut qu'être fort utile à des êtres qu'un. vol rapide exposerait à des chocs dangereux, s'ils ne pouvaient se détourner à temps des obstacles. La vision très-rapprochéc lcur est aussi nécessaire pour qu'ils puissent se rendre compte des. objets sur lesquels ils se trouvent, des travaux qu'ils exćcutent, des entraves apportées à leur marche. Il est difficile de comprendre, arec les seules données de l'optique, la manière dont peuvent. se satisfaire, au moyen d'un même organe, des'besoins si distincts. Il faut admettre, ou que les facettes subissent quelques modifications. dans leur courbure quand cela est nécessaire, ou que, pour les. objels rapprochés, le toucher et l'odorat remplarent presquue. complètement la vision.

2. - Ocelles. - Les Ocelles (pl. I, fig. 1, c) sont placés au sommet de la tête, sur le vertex. Ce sont de véritables yeux, de dimension bien plus restreinte que les autres, mais jouissant des mèmes propriétés visuelles. Ils en diffèrent cependant, d'une faģon complète, en ce sens qu'ils sont simples, et non à facettes, comme les yeux proprement dits.

Ils sont presque toujours au nombre de trois, disposés soit en lignne droite, soit en triangle, soit en ligne plus ou moins courbée, le sommet du triangle ou de la eourbe se trouvant du cóté de la face. Rarement on n'en apergoit qu'un scul, plus souvent ils sont presque indistincts ou même manquent tout-i-fait, par suite de leur oblitération plus ou moins complète.

Les ocelles se présentent sous la forme de points arrondis, saillants, lisses et convexes. Leur coulcur est très-variće, ot ils forment quelquefois, au sommet de la tête de l'insecte, comme un diadème étincelant de diamants ou de rubis. 
Leur fonction spéciale pour la vision est peu connue, et je crois inutile de rappeler ici les hypothèses diverses émises sur leur compte, car elles ne sont rien moins que certaines.

\section{III. - PIÈCES MOBILES DE LA TÉTE.}

1. - Antennes. - Les antennes (pl. II) sont ces appendices mobiles, plus ou moins allongés, qui ornent la tête de tous nos insectes, et dont la forme est des plus variables.

Elles sont insérées soit près de l'épistome, soit au milieu ou au-dessus de la face. Cetle insertion a lieu, le plus souvent, dans une fossette creusée de chaque còté de la têle, et qui est tantôt courte, tantôt allongée pour recevoir, dans le repos, une partie des antennes. Elle porte le nom de fossette antennaire (pl. I, fig. 1, $k$ ).

L'espace situé sur la face, entre les deux insertions, est quelquefois large, el les antennes sont dites alors écartées, quelquefois, au contraire, très-étroit et les antennes sont, dans ce cas, rapprochées.

Sur la face ou au fond de la fossette antennaire, se trouve une proéminence fixe qui sert de point d'attache et d'articulation à cet organe, on l'appelle la radicule ou le torulus. (pl. I, fig. 1, l). Quelques auteurs l'ont considérée comme un premier article, mais bien à tort, puisqu'clle n'est pas articulće, et fait partie intégrante de la tête.

L'antenne se continue en une série de segments ou anneaux portant le nom spécial d'articles, dont les grandeurs relatives et la forme donnent des caractères précieux au classificateur.

Souvent le premier article, ou article basilaire, est beaucoup plus gros et plus allongé que les autres. Il porte alors le nom spécial de scape. Le reste de l'antenne, pour des familles entières, forme un angle avec ce scape, et l'on dit alors que l'antenne est coudée ou brisée (pl. I, fig. 1, m). La portion de l'antenne articulée avec lo scape prend la dénomination de funicule ou fouet de l'antenne. Quelquefois entre le scape et le funicule, ou entre le premier et le second article de celui-ci, se placent de petits articles de dimensions très-restrẹintes, nommés entr'articles, annelets ou articles supplémentaires. (PI. II, fig. 4, 5, 6).

Enfin les derniers articles peuvent se resserrer, se gonfler et 
former, à l'extrémité du funicule, une sorle de bouton plus ou moins conique, ou ovoide, parfois aplati et foliacé, qui est la massue. Celle-ci peut comprendre, dans son ensemble, plusieurs articles distincts : elle est alors articulée (fig. 12), ou bien on ne distingue, ì sa surface, aucune division, et elle est dite alors inarticulée. (fig. 27).

Rarement l'article terminal de l'antenne forme un véritable crochet. (fig. 26).

Le nombre des arlicles de l'antenne varie considérablement, suivant le genre de l'insecte, depuis 3 seulement jusqu'à plus de 60 .

Considérée dans sa forme générale, l'antenne peut être : droite, quand elle a la méme direction dans toute sa longueur. (Fig. 2, 18, 24, etc.)

coudée, quand le funicule forme un angle avec le scape, (Fig. 1, 3 à 12, 32, 33̀).

filiforme, quand son épaisseur est la même dans toute sa longueur, et qu'elle a l'apparence d'un fil. (Fig. 34).

sétiforme ou sétacée, quand elle "est rigide et que son diamètre diminue peu à peu de la base à l'extrémité, qui devient une pointe aigüe. (Fig. 25).

fusiforme, quand elle est plus grosse au milieu qu'aux deux e:strémilés. (Figg. 17).

moniliforme, quand ses articles sont arrondis, bien séparés et qu'ils rappellent un chapelet. (Fig. 3 et 6 ). claviforme, quand son exirémité se renfle en massue. (Fig. 12, 27 et 30 ).

cultriforme, quand, ètant renflée au milieu d'un seul cỏté, sa forme rappelle celle d'un couteau ou d'un sabre. (Fig. 31).

flabelléc ou flabelliforme, quand la plupart de ses articles donnent naissance à des appendices allongés et aplatis, rappelant les branches d'un éventail. (Fig. 29).

pectince, quand ses articles donnent naissance latéralement à des appendices, conservant leur écartement et leur direction, comme les dents d'un peigne. (Fig. 15, 16 et 19). 
dentée en scie, quand, par la forme des articles successifs, l'antenne présente, sur sa longueur, l'apparence d'une scie. (Fig. 14).

appenuiculée, quand quelques-uns de ses articles offrent des prolongements de formequelconque.

fourchue, quand un ou plusieurs articles se divisent en deux branches. (Fig. 28).

subulée, quand elle a la forme d'une alène, et que, après un renflement, l'extrémité pointue est allongée. (Fig. 35).

épaisse, si le diamètre est grand relativement à la longueur. (Fig. 13).

grêle,

atténuée, si le diamètre est petit relativement à la longueur. (Fig. 18). quand, épaisse jusque près de l'extrémité, celle-ci s'amincit subitement.

noueuse, quand quelques articles intermédiaires sont plus gros que les autres.

irrégulière, quand la structure de ses articles ne permet pas de la rattacher à une forme connue. (Fig. 22).

\section{Etc.}

Dans certains genres, les antennes d'un sexe sont toutes différentes de celles de l'autre sexe. Elles sont, très-souvent, plus longues chez le mâle, quoique la proportion contraire se présente aussi plus rarement. Les mâles les ont parfois plus longuement velues, munies d'appendices plus singuliers et plus visibles. La couleur enfin peut être différente en tout ou en partic. (Fig. 4 et $5,8$ et 9,14 et 15,16 et 17$)$.

Quant à la composition intime des antennes, il y a peu de choses à en dire, si ce n'est que leurs anneaux, successirement articulés les uns aux autres, ne sont que de véritables tubes creux, dont la surface, au moins à l'extrémité, est percée de pores plus ou moins nombreux. Ces tubes servent d'enveloppes et d'abri à des filets nerveux divers, qui donnent à ces organes leur sensibilité extrême et leur fournissent le moyen de remplir les fonctions dont ils sont chargés; ils contiennent en outre tous les muscles qui transmettent le mouvement aux diverses portions de l'antenne. 
Les filets nerveux antennaires prennent naissance sur le gainglion situé dans la tête ou ganglion cérébral. Dans les antennes à massue, celle-ci semble destince à favoriser la ramification de la substance nerreuse sur une plus grande surface; il paraît certain, d'ailleurs, que le sićge de la fonction dévolue à l'antenne se place plus particulièrement dans la massue ou dans les appen. dices foliacés ou autres, quand ils existent.

Cette fonction, olle-mème, a divisé de tous temps les expérimentateurs et on ne peut assurer encore (que l'opinion adoptée soit eractement vraie. Cependant des observations nombreuses qui ont ćté faites ì ce sujet, il résulte que l'antenne scrait le siège de l'odorat chez les hyménoptères et, en général, chez tous les insectes. Des preures multipliées indiquent que ce sens existe à un haut deré chez eux, et qu'il supplée à ce que d'autres peuvent avoir d'imparfait. C'est lui qui leur indique de loin la présence des lleurs qu'ils affectionnent, et qui, sans cela, resteraient bien souvent cachées it leurs yeux. C'est lui encore qui guide les mâles jus!fu'i leurs femelles, alors que celles-ci sont à peine sorties de leur eoque. L'odorat est donc un des sens les plus importants pour eux, et l'antenne qui en serait le siège, serait, par conséçuent, un organe essentiel à l'existence normale de nos insectes.

De plus, il est permis de supposer que les antennes possèdent aussi des propriélés tactiles bien développées, et le mourement continuel, que beaucoup d'espèces leur impriment dans la marche, peut leur servir, en même temps, pour leur indiquer les menus obstacles qui les gêneraient et pour leur permettre de saisir dans l'air, d'une façon plus certaine, les émanations où ils puisent la piste, soit des fleurs qui lcur fournissent le miel, soit des insectes qu'ils doirent donner comme aliments à leurs larves, soit des fomelles vers lesquelles le vœu de la nature les appelle.

2. - Parties de la bouche. - La bouche (pl. I) est, bien entendu, placcic it la partic anterieure de la tête. Les pièces qui lia composent, sont des plus importantes chez les insectes et surtout chez les, hyménoptires. Ce sont, en effet, non-sculement les instruments de la capture et de la déglutition des aliments, mais, cn outre, èlles renferment de véritables outils qui servent, aux femelles, à parfaire la construction de leur nid, à puiser le micl 
et les sucs destinés aux jeunes larves, aux mâles à atteindre les. femelles et à s'en emparer. Ces pièces sont assez compliquées, et leur forme ou leur importance respective varie avec les instincts divers assignés à chaque espèce, et aussi avec ses besoins.

D'une manière générale, la bouche d'un hyménoptère se compose, en dessus de l'ouverture buccale, où aboutit l'œesophage :

$1^{\circ} \mathrm{D}$ 'une pièce médiane, unique, cornée, appelée labre (fig. 6 et 8 ), fermant la partie supérieure de la bouche et jouant le rỏle de la lèvre des animaux vertébrés. Sa forme est très:variable et on ne peut, souvent, le distinguer de l'épistome. (fig. 1 et 15).

$2^{\circ}$ De deux pièces cornées, symétriques, simples ou plus ou moins dentées et irrégulières, aigües ou obtuses, souvent en partie recouvertes par le labre, se mouvant horizontalement autour de leur base, comme autour de deux charnières. Ce sont les mandibules (fig. 1, 3, 7, 9, 11, 14, 15, 24, 25, 26 et 28); elles représentent les parties les plus dures et les plus puissantes des pièces de la bouche, celles qui sont chargées des fonctions les plus difficiles. Ce sont les pinces qui saisissent les proies, qui creusent les terriers, qui soutiennent les fardeaux pendant la marche ou le vol. Presque toujours, elles sont trèsdures; les muscles qui les font agir sont vigoureux et d'autant plus fortement altachés à la boîte crînienne que l'insecte est destiné à s'attaquer à des substances plus résistantes. Leur forme varie beaucoup, comme je l'ai dit, et est toujours appropriće aux besoins que la nature a donnés à l'hyménoptère. Le plus ordinairement, elles sont à peu près triangulaires, avec un côté extérieur lisse, tandis que l'autre cóté, qui est la partic travaillante, est denté et présente des aspérités diverses et très-variables d'un genre à l'autre. Quelques auteurs ont cru pouvoir classer ces dentures, comme on l'a fait pour les animaux supérieurs, at y ont distingue des incisives, des canines, des molaires, etc. Je ne veux pas m'arrêter à ces divisions, qui ne peuvent nous être utiles en rien. Les formes en sont, en effet, si variables qu'il ne me semble pas possible de les désigner d'une façon nette et cxacte, et surtout de manière à ce qu'une mandibule étant donnée, on puisse, à coup sûr, la rapporter à une denture déterminée. Quand je devrai m'appuyer sur un caractère tiré de la forme des mandibules, je croirai plus pratique de l'indiquer en langage ordinaire 
d'une façon approchée, et de renvoyer, pour plus de précision, à la figure qui le représentera.

Souvent les mandibules sont glabres, souvent aussi elles sont pourvues de poils plus ou moins longs, formant quelquefois de véritables panaches. Leur couleur est encore assez caractéristique; elles peuvent être noires, brunes, jaunes, etc., en tout ou en partic. Elles sont profondément sillonnées ou présentent des pans coupés en divers sens. Dautre fois, ce sont de véritables scies, des ciseaux tranchants, des pelles à transporter le sable et à gâcher le mortier, etc. Il existe encore des formes quelque peu extroordinaires et anormales, surlout dans certains genres exotiques; leur dimension peut s'exagerer et atteindre des proportions réellement curieuses avec des dispositions plus ou moins contournées.

D'après leur forme et leur destination, elles se croisent comme les lames d'un ciseau où elles viennent seulement se juxtaposer. (fig. 14 et 15).

Elles varient enfin souvent aussi d'après le sexe, ce qui a bien sa raison d'être, puisque les femelles ont à remplir un róle beaucoup plus complexe que les mâles. Chez les fourmis où il y a, dans quel(ques cas, quatre sortes d'individus dont les rôles sont bien distincts, les mandibules d'une même espèce sont très-différentes, suivant qu'elles appartiennent, par exemple, aux ouvrières ou aux soldats.

Pour que le croisement des mandibules puisse s'opérer convenablement, il arrive souvent que les dentelures ou les sillons de l'une ne sont pas exactement reproduits dans l'autre, que si, par exemple, l'une des mandibules a deux dents, l'autre en a trois, etc.

Considérées dans leur structure intime, on peut constater qu'elles sont creuses ou plutòt remplies seulement de matières pulpeuses, de nerfs et de trachées. Les muscles qui les font mouvoir se fixent sur des portions cartilargineuses qui sont peut-être, d'après M. Mrarcel de Serres, une prolongation de la substance interne.

$3^{\circ}$ Sous les mandibules se trouve l'ouverture buccale ou pharynx, qui peut se fermer et s'ouvrir à volonté au moyen d'une valve, qui est l'épipharynx, de Savigny, l'épiglotte ou sous-labre, de Latreille. Cette pièce est insérée verticalement sur la voùte de 
la bouche, derrière l'origine du labre. Inféricurement, et opposée à l'épipharynx, est une seconde valve ou hypopharynx, insérée aussi verticalement au bord inférieur du pharynx. L'ensemble de ces deux valves forme comme deux lèvres qui ferment complètement le pharynx, à la volonté de l'insecte, et y retiennent les matières, toujours très-liquides, qu'il $y$ intróduit, et que ses autrés appareils buccaux, à peine modifiés de ceux des insectes seulement broyeurs, seraient inhabiles à contenir. Lies hyménoptères sont, à peu-près, les seuls à posséder ces appendices.

$4^{\circ}$ Sous le pharynx, ou plutót sur ses cólés inférieurs, prennent naissance deux pièces qui existent dans tous les autres ordres broyeurs, mais qui, ici, sont profondément modifices. Ce sont les mâchoires (fig, 2, 10, 13, 16, 20, 23, 27). Elles sont au nombre de deux, de consistance beaucoup moins dure que les mandibules, mais peuvent, au besoin, prendrecomme elles un mouvement horizontal.Comme chez tous les insectes, elles se composent, chacune, de deux parties principales : la tige (fig. 12, a) articulée à la tête, et le lobe $(f i g, 12, b)$ qui est fixé sur la lige. Celle-ci est toujours d'une nature plus ou moins cornce. Son articulation, les bords du pharynx, les valves qui ferment celui-ci, forment un ensemble de parties membraneuses très-flexibles, contractiles ou protractiles, en relation avec des muscles nombreux, et limités par de pelits fils capillaires plus durs, qui en forment les bords. La déglutition s'opère par les mouvements simultanés de tous ces organes élastiques, dès que les aliments liquides arrivent à l'eur portée. La seconde portion de la mâchoire, ou le lobe maxillaire, est chargée de les y amener, concurremment avec une dérnière pièce buccale, que nous étudierons ensuite sous le nom de languette (fig. 12, e).

Le lobe de chacune des mâchoires a moins de consistance que la tige; il reste plus membraneux et élastique. Sa forme varie dans des proportions considérables. Tantôt, et lorsque les insectes n'ont pas besoin de recueillir de miel pour leur postérité, mais seulement pour eux-mêmes, ce lobe a une forme plus ou moins irréguliérement arrondie et il est peu prolongé; tantòt, lorsque des provisions de miel doivent être faites pour les jeunes larves, il prend des dimensions exagérćes, s'allongeant en une forme lancéolée souvent très-aigüe, concave en dedans, et appelće, par la réunion des deux lobes et de la languette, à constituer une 
sorte de trompe ou de suçoir. Des poils et des cils plus ou moins raides concourent, par leur mourement vibratile, joint à l'élasticité des parties de celte trompe, it faire monter les liquides sucrés dans son intérieur, de façon à les amener au pharynx.

Vers la jonction des parties cornées et membraneuses de chaque mâchoire, se trouvent fixés extérieurement des appendices, uniques pour chacune d'elles, mobiles, arliculés, qui sont les palpes dits maxillaires (fig. 12 et 13, c). Ce sont de véritables petites antennes, qui autrefois ont même porté le nom d'antennules. Ils sont composés d'un nombre rariable d'articles, depuis un à six, suirant les genres. Quelquefois même, ils manquent complètement. Leur substance est assez solide; le dernier scul, doué aussi sourent de formes spéciales, présente une consistance plus molle, une surface papilleuse, qui est évidemment le lieu de terminaison de filets nerveux, chargés de leur donner des aptitudes, sur lesquelles il n'est guère possible aujourd'hui que de faire des hypothèses.

Le róle des palpes ést en effet assez obscur, et a donné licu à bien des interprétations; on peut cependant supposer qu'ils sont destinés, d'abord, à remplacer les antennes pour les objets trèsrapprochés, et particulièrement ceux destinés ì la nourriture ou à la confection des nids. On ne peut évidemment leur refuser des propriétés tactiles très-développées, et ils doivent servir de mains pour manier; concurremment arec les mandibules, les matières si diverses mises en ouvre par nos hyménopteres. L'odorat ou le gout doivent bien aussi rentrer dans leurs fonctions. Il j a ia ce sujet des expériences extrêmoment délicates à tenter.

Enfin, je dois ajouler que les palpes sont; il est vrai, de trèspetits organes, mais comme ils sont faciles à sćparer et à étudier, on peut en tirer de bons caractères, quand on n'en a pas rencon"trẻ d'autres plus aisés à vérifier.

$5^{n}$ Enfin, et pour terminer l'étude de la structure de la bouche, nous trourons, piacée entre les deux michoires et insérée it lit partie inférieure du pharynx, une piéce intermediaire unique, qui est la lère inférieure (fig. 5, 17, 22, 27). Elle se compose, comme les mâchoires, d'une base plus cornece, ei d'une poriion, courte le plus souvent, quelquefois au contratre trés-allongée, membraneuse et tris-flexible. Lat premiere a été nommce, par Latreille, le menton (fig. 5, al), et la seconde est la lannjuelle ou ligula (fig. 5, 6 . 
Le menton est une petite pièce, ordinairement rectangulaire, qui ne sert que de support i l'autre partie, concourant cepenclant à fermer la partie inférieure de la bouche, entre les michoires, avec lesquelles elle se trouve relice, puisque, quand celles-ci s'ouvrent, la lèvre s'avance en même temps.

La languette est une lame membraneuse ou cartilagineuse très-flexible, dont l'extrémité peut être bifide ou trifide, et est ordinairement garnie de poils plus ou moins soyeux, en forme de brosse. Sa longueur est en raison des besoins de l'insecte, et mesurée à peu près sur celle des lobes maxillaires, qu'ell: dipasse cependant le plus souvent un peu. Appliquée contre ces lobes, auxquels elle peut s'unir très-exactement, elle forme avec ceux-ci une sorte de tube à trois parois, où les liquides nourriciers s'introduisent et sont poussés vers le pharynx par les contractions simultanées de la languette et des lobes, et par les mouvements vibratiles des cils, comme je l'ai dit. Mais la languetle a encore un autre rôle qui lui est spécial, et que son extrémité très-flexible et très-délicate, le plus souvent aussi très-velue, est chargée d'accomplir : c'est de puiser directement les sucs mielleux des fleurs pour les amener à l'orifice du tube.

Ce qui contribue encore à faire varier la longueur de la languette et des lobes maxillaires, est l'obligation où se trouvent les insectes, par suite de leurs différents besoins et de leur instinct particulier, de chercher le miel dans des fleurs à corolle plane ou tubuleuse, et le rapport harmonique qui existe sous ce point de vue, comme sous bien d'autres encore, entre l'entomologie et la botanique n'est pas ce qu'il y a de moins admirable et de moins attachant dans l'étude que nous entreprenons.

A la base de la languette se placent symétriquement, et plus ou moins près les unes des autres, quatre pièces, savoir :

D'abord deux palpes, dits labiaux, (fig. 5, c, 12 f, 18), composés, comme les maxillaires, d'un nombre variable d'arlicles et servant vraisemblablement aux mêmes usages; la forme et le nombre de leurs articles peuvent aussi fournir, dans quelques cas difficiles, des caractères très-précieux.

Ensuite, et au-dessous de ces deux palpes, deux appendices, soit lancéolés, soit allongés comme de véritables fils, généralement velus, de consistance molle ou membraneuse, et qui portent 
le nom de paraglosses. Leurs fonctions ne sont pa:s connucs, au moins avec certitude, et leur étude demande des observations nouvelles, dont la difficulté ne peut qu'être très-gुrande.

Ces pièces (lobes maxillaires, languette, etc.) très-longues et très-visibles, dans cerlaines espèces, lorsqu'elles sont en action, deviennent, au contraire, difficiles à apercevoir au repos; car elles se replient sur elles-mêmes, de façon à se loger et à se cacher complètement dans une cavité pratiquée inférieurement dans la tête, entre le pharynx et le trou occipital. La partie cornée des machoires leur scrt alors d'ćtui. Illiger a donné le nom de promuscis au prolongement formé par la trompe des hyménoptères, quand ce prolongement est isensible et en forme de museau

\section{IV. - THORAX}

La partio intermédiaire du corps des insectes porte le nom général de thorax. Il comprend un cerlain nombre de divisions que nous définirons tout-à-l'heure, et sert de support aux appareils de la locomotion, les pattes et les ailes.

Le thorax, (pl. III), pris dans son ensemble, forme une masse très-irréguliẹre, allongée ou ovoïde, quelquefois gilobulcuse.

On peut déjà le diviser en cleux parties, sclon que l'on considère le dessus ou lo dessous. La partie supćricure, ou dorsale, porte le nom collectif de notum ou tergum, la partie inférieure, celui de stemaum.

Si on l'examine, au contraire, en partant de la tête pour aller vers l'abdomen, on lo trouve composé de trois parties ou $\mathrm{seg}$. ments principaux, qui sont en commençant vers la tête:

$1^{\circ}$ Le Prolhorax, comprenant en dessus le pronotum, en dessous le prosternum, ce dernier ne portant que les pattes antéricures.

20 Le Mésothorax, formé par le mesonotum auquel sont fixćes les ailes antérieures ou supérieures et le mesosternum, qui est le point d'attache des pattes inlermédiaires.

$3^{\circ}$ Le Métathorax, composé du metanotum, qui porte les ailes postérieures ou infírieures, ct du melasternum, qui soutient les pattes postérieures.

Chacune de ces truis parties se sublivise, en outre, en un cerTOME I 
tain nombre de régions séparées plus ou moins distinctement par des sillons, et qu'il nous reste à examiner.

Je ne m'arrêterai, d'ailleurs, qu'aux pièces visibles sans entrer dans le détail de celles qui en sont seulement des prolongements internes.

1. - Prothorax. - Le prothorax, nommé aussi collier, s'unit directement avec la tête, comme nous l'avons vu, par l'intermédiaire d'tune sorte de mince pédicule ou col. Les téguments qui forment le col, passent au travers d'une ouverture arrondic du prothorax, et se fixent sur ses bords. Cette ouverture est formce. partie par l'extrémité antéricure du pronotum, partie par celle du prosternum.

Le pronotum est souvent peu visible, enfoncé sous l'occiput et n'apparaît parfois que sous la forme d'un mince ruban bordant en avant le thorax. D'autres fois, il prend beaucoup plus d'importance, etsa forme ést alors très-variable. Il pcut être très-étroit en son milieu et large sur ses bords, ou sa forme générale peut paraître, vue en dessus, triangulaire, quadrangulaire, trapézoidale ou en croissant. Les parlies latérales antéricures du pronotum, souvent plus développées ou autrement colorées que le reste, sont les épaules. Sur la ligne médiane se voit fréquemmentun sillon plus ou moins profond ou simplement une ligne plus lisse Sa surface peut acquérir les mèmes variations de poli ou de ponctuation, de pubescence ou de nudité que la tête ou les autres parties du thorax; ces variations sont indiquées par une sćrie d'expressions que j'inscrirai plus tard. Enfin cette surface même s'appelle le disque du pronotum.

On admet généralement que les trois segments du thorax sont composés des mêmes parties et en même nombre; les unes s'oblitérant quelquefois en même temps que d'autres prennent un accroissement proportionnel. Dans cetle hypothèse, le disque du pronotum en serait le scutellum. En avant, et réduites à l'état membraneux, ou oblitérées, en tous cas invisibles, seraient deux pièces, le præscutum et le scutum du prothorax, tandis qu'en arrière, une autre pièce, le postscutellum serait devenue interne. Dans tous les cas, nous n'avons à tenir compte ici que de celle qui est visible que nous nommerons simplement le pronotum.

Dans le même ordre d'idées, le prosternum devrait présenter 
beaucoup plus de pièces qu'il n'est possible d'en apercevoir à l'extéricur. Au centre et sur lit parie médiane serait le mredisternum, toujours risible, en arant duyuel se placerait une partie interne, l'entothoriax. Sur les cótés, nous trouvons deux pièces latéales antérieures, nommćes les episternum, récluites souvent a un filet très-rèle, disparaissant mème quelquefois, tandis que, dans d'autres circonstances, clles prendraicnt, au contraire, assez d'accroissement pour, en se rejoignant en dessus, former une sorte de deuxième pronotum, qui a jeté dans l'erreur quelques naturalistes.

Derrière les episternurn, se trouvent encore deux pièces-latérales, les épimères, qui, avec le medisternum, forment deux ouvertures où pisssent les articulations des hanches. Ces épimères ne peuvent se détruire, puisqu'elles servent de support direct aux hanches qui existent toujours.

Enfin une pièce spéciale que présentent presque constamment le second segment thoracique, le paraptere, manque dans le prosternum parce qu'elle est lice intimement a l'existence des ailes.

L'avantage de celte hypothèse d'un même plan pour l'arrangece. ment et le nombre des parties du thorax, se saisira facilement. Elle permet, en effet, de reconnaîle par l'analozie, le but et la nature des pièces existantes, celles qui manquent ayant pu s'oblitirer, les autres prenant un accroissement proportionnel, tandis que jamais ne peut s'en intercaler une nouvelle.

On a signalé l'existence de stigrmates prothoraci(pues entre les pro-et-mésothorax, au-dessus des ailes antéricures, mais ils sont à peu près invisibles.

On voit donc que le prothorax a une structure très-simple, la plupart des pieces qui existent dans les autres segments ayant disparu. Ise prosternum est d'ailleurs toujours plus important que le pronotum, ce qui s'explique par le grand nombre de muscles qui doirent s'y insérer pour les articulations des paltes et de la tête.

2. - Mésothoraz. - Le mé:othorax présente une complication plus grande que le prothorax en raison des insertions des ailes antérieures qui s'y trouvent placées.

Le mesonotum offe, immódiatoment derrière le pronolum 
une surface étendue placée au milieu du dos, qui est lo scutum du mésothorax; il est quelquefois partagé en deux parlies par un sillon mćdian, ou en trois par deux sillons latéraux, mais ce ne sont que des divisions superficielles. En arrière, et aussi sur le milicu du dos, se voit encore une large pièce, souvent plus grande que le sculum, qui est le scutellum du mésothorax, divisé aussi souvent par des sillons plus ou moins apparents. Les prescutum etpostscutellum restent internes, comme dans le prothorax.

C'est dans le scutum que s'ouvre le passage de l'articulation des ailes antéricures. On voit à cet endroit deux petites pièces, que l'on a nommées les parapsides, et qui'ne seraient, d'après M. Lilcordaire, que de simples divisions du scutum.

Vers l'angle formé latéralement par le scutum et le scutellum, et au-dessous de l'ouverture d'insertion des ailes, se trouve une pièce ronde ou en triangle plus ou moins irrégulier, non soudée, mais seulement articulée avec les parties voisines, de façon à supporter quelques mouvements peu élendus. Cette pièce, qui sert à protéger l'articulation des ailes antérieures, a reçu beaucoup de noms différents, selon les auteurs. C'est l'écaillette, l'écaille, la pterygode, le point calleux ou squamula. C'est enfin le paraptère des autres ordres d'insectes. Yous adopterons la première de ces expressions, l'écáillette, en raison de la forme de cette partie, qui rappelle la coquille d'un mollusque bivalve.

Le mesosternum contient, ou peut contenir, les différentes pièces que j'ai signalćes à propos du prosternum, savoir : le medisternum, les deux episternum et les deux épimères. Souvent le mesosternum se prolonge très-loin sous le métathorax, ce qui reporte en arière les pattes intermédiaires. Il peut même présenter une foule de dispositions particulières, des échancrures, des prolongements de nature diverse, qui forment de bons caractères spécifiques.

Disons enfin, en terminant, que le mésothorax semble porter, dans son articulation avec le métathorax, une paire d'orifices stigmaliques généralement tout-à-fait invisibles, comme ceux du prothorax.

3. - Métathoraz. - Le métathorax présente en-dessus une surface mćdiane, qui est le scutum clu métathorax, immédiate- 
ment suivie par une autre, qui est le scutellum du métathorax.

Ces deux pièces, ou l'une d'elles, sont quelquefois peu visibles et peu distincles; la dernière manque même souvent. D'autres fois, elles montrent des sillons superficiels qui les partagent $\mathrm{en}$ diverses régions. Presque contigüie au mésotharax, se voit pratiqué dans le scutum métathoracique, l'ouverture d'insertion des ailes postérieures. Celle-ci n'ost pas couverte d'une ćcaille, comme dans les ailes antérieures, et c'est tout au plus si l'articulation est sarantic par un repli du scutum du métathorax, presque recouvert par les cótés du scutellum mésothoracique, quand il existe. Le prascutum et le postscutellum sont encore ici invisibles à l'extéricur, sauf, en ce qui regarde le dernier, dans une famille à abdomen sessile, les Tenthrédines.

Sur le scutum se laisse apercevoir, dans quelques cas, une sorte de cicatrice simulant une ouverture de stigmate, mais ce n'en est que l'apparence, le métathorax ne portant jamais ces organes.

Dans beaucoup de cas, ces divisions du métathorax se confondent et s'encherêtrent les unes dans les autres, de fitçon à rendre leur identification fort difficile, et ce n'est alors qu'au prix de dissections extrêmement minutieuses qu'on arrive ì l'établir. Quoi qu'il en soit, il n'y a jamais que les parties que j'ai énumérées, plus ou moins petites ou étendues, plus ou moins divisées par des sillons.

A la face inférieure, le metasternum présente, sans plus de complication, les parties que j'ai indiquées pour les autres sệments, medisternum, épimères et episternums.

Ces pièces inféricures sont refoulées souvent presque en entier sous l'abdomen, et les hanches postérieures sont alors situées très en arrière.

T'elle est, dans ses formes les plus générales, l'économic du thorax des hyménoptères. Si l'on suit attentivement, sur nature, sur un frelon, par exemple, la succession des parties qui le composent, on arrivera toujours à trouver, dans la masse thoracique, une division ou un segment de plus que ceux que j'ai indiqués. En effel, ì la suite du métathorax, se trouve, intimement soudce avec lui, une pièce souvent très-grande, à la(quelle s'atlache l'ab)domen proprement dit. Cette pièce a été remardée comme une division du thorax, et on y trouvait l'analogue du posiscutellum 
des autres segments. Latreille, d'abord, puis Audouin, ont démontré, d'une façon irréfulable, que celte partic extrême constituait le premier segment abdominal, tandis que le pédicule, dans le frelon, par cxemple, n'en était que le second. Je ne veux rappeler ici qu'une des preuves qui démontrent la vérité de celle assertion; elle consiste dans la présence d'une paire de stiggmates. I co métathorax en est constamment dépourvu, tandis que les segments. abdominaux en portent presque tous. Latreille a assigné à cette partie spéciale le nom de segment médiaire. Il a, en général, une forme demi-circulaire, ouverte à la face postérieure en fer à cheval, pour laisser place à l'insertion de l'abdomen.

Celle-ci se fait souvent par la simple continuation des téguments du segment médiaire au segment abdominal suivant. Chez quelques familles, où l'abdomen est trís-mobile, on trouve, en outre, une disposition particulière pour assurcr cette mobilite. A la partie supérieure de l'ouverture du segment médiaire se fixe. une sorte de ligament filiforme tendineux, contractile, dont l'autre extrémité va s'attacher au pédicule de l'abdomen. Ce ligament, en se contractant, agit comme un levier pour fairc tourner l'abdomen autour de l'extrémité de son pédicule, et, par conséquent, pour le relever. Quand ce ligament se détend, l'abdomen retombe. On lui a donné le nom de funiculus.

Je viens de montrer que le premier segment abdominal apparent n'est, en réalité, que le second. Cependant, pour éviter toute confusion, et pour faire concorder mes explications avec les formes qui frapperont les yeux, je dois prévenir que je donnerai toujours, dans les descriptions, au pédicule, le nom de premier segment abdominal, et au segment médiaire celui d'extrémité du mélathorax. L'erreur éviclente que je commettrai ne pourra avoir de conséquences fâcheuses après Jes explications auxquelles je viens de me livrer, et le lecteur y trouvera l'avantagge d'une détermination plus simple et plus facile.

Le thorax étant ainsi décrit dans ses formes les plus complexes, il reste i indiquer les modifications et les simplifications qui s'y présentent.

La premiere qui saute aux yeux, consiste dans l'absence des ailes, et par conséquent de l'ouverture d'insertion, et des paraptères. Ce fait se produit dans diverses familles, les Ichneumo- 
nides, les Braconides, les Chalcidites, les Cynipides, les Proctotrupiens, les Mutilles, les Formicides, les Scoliens. Mais, mèmo parmi ces insectes aptères, le thorax subit de nombreuses modifications, depuis les Mutilles où l'on n'aperçoit presque aucune division jusqu'aux fourmis où un grand nombre des régions indiquées existent.

De plus, sinon dans leur nombre, au moins dans leur forme, les pièces thoraciques nous montrent des variations très-grandes. Elles sont souvent complètement irrégulières, ou démesurément allongées, (fig. 12) elles portent des épines ou des dents caractéristiques, des fossettes régulièrement disposćes, des stries les partageant en aires, constantes dans un même genre, et dont on s'est servi efficacement pour la classification, comme dans le métathorax des Ichneumons. On y remarque aussi quelquefois des dépressions ou des sillons très-prononcés, des séries de points élevés etc., toutes modifications que nous aurons occasion de signaler chaque fois qu'elles se présenteront.

\section{V. - APPENDICES DU THORAX}

Il me reste à étudier maintenant les différents organes qui prennent leur point d'attache sur le thorax. Ce sont les appareils de locomotion, comprenant :

$1^{\circ}$ les pattes,

$2^{\circ}$ les ailes.

1. - Pattes. - Les pattes (pl. III) des hyménoptères à l'état parfait, comme celles de tous les insectes proprement dits, sont au nombre de six, savoir: deux pattes antérieures, articulées au prosternum, deux paltes intermédiaires, articulées au mesosternum, deux pattes postérieures, articulées au metasternum.

Les pattes sont, on le sait, les organes spéciaux de la locomotion terrestre. Aucun hyménoptère, it l'élal parfait, n'en est privé, et, dans toutes les familles, elles sont composées de mêmes parties, qui existent toujours, et qui ne se modifient que sous le rapport de la forme.

Qu'elle appartienne ì une paire ou ì une autre, charque palte se compose de :

$1^{\circ}$ La hanche, articulée directement arec les bords de l'ouver. 
ture coxale formée par l'épimère et l'episternum. Audouin a signalé entre le thorax et la base des hanches une petite pièce servant à faciliter l'articulation et le mouvement de la patte. Il l'a nomme le trochantin. Je n'ai pu la découvrir chez les hyménoptéres, et il est à supposer que, si elle existe, elle est cachée dans l'intérieur des téguments.

Les hanches sont ordinairement courtes, épaisses, plus ou moins triangulaires, quelquefois dentées on épineuses. Leur face intérieure présente des portions plates ou courbées, se croisant ì angle saillant, qui se logent dans des parties creuses correspondanles du thorax et s'y appliquent parfailement. L'extrémité qui s'articule au thorax est la plus large, c'est la base des hanches. La partie opposée ya en se rétrécissant jusqu'à l'extrémilé ou partie apicale. Les hanches sont le plus souvent velues, au moins à la face externe.

$2^{\circ} \mathrm{A}$ la suite des hanches, apparaissent, soit une, soit deux petites masses cornćcs assez irrégulières, articulées entre elles, ot ayant pour but de donner une grande ćtendue aux mouvements du reste do la patte, tout en les limitant à la façon d'une rotule; on les nomme les trochanters.

$3^{0}$ Les trochanters s'articulent directement avec les cuisses. Celles-ci sont ordinairement la partio la plus considćrable de la patte, Elles prennent des formes très-variées, mais, en tous cas, lours deux extrémités se réduisent à deux articulations fort étroites. Le plus souvent la cuisse est linéaire, conique ou pyramidale, cylindrique ou fusiforme; tantôt elle présente des lignes saillantes, dentées ou non en scie, armées d'épines; elle est glabre ou garnie de poils plus ou moins longss; tantôt elleprend des climensions exagérées, relativement à la grosseur de l'insecte, présentant alors une forme lenticulaire ou tout-à-fait aplatic, parfois concave en dedans. Ces formes diverses varient aussi avec le sexe, et fournissent des caractères bons à employer pour les. distinguer.

$4^{0}$ Les tibias viennent ensuite et offrent, eux aussi, des formes très-diverses, mais moins variées cependant que lẹs cuisses. Le plus ordinairement, ils sont cylindriques ou coniques, allongés, avec des arêtes saillantes, des dents, des épines ou des éperons en nombre variable. Leur longueur peut devenir très-grande, et ils sont alors très déliés. 
Les éperons qu'ils portent trìs-souvent sont plus ou moins mobiles et affectent des formes; très-direrses. Chez quelques espèces, il leur est adjoint de petites pelotes membrimeuses, appelées patella.

$5^{\circ}$ Les tarses, enfin, terminent la patte. Ils sont composés d'une séric de petites pièces ou arlicles, mobiles les uns sur les autres, ct en nombre variable. Le premier article est souvent plus gros et plus long que les autres. Dans quelques familles, il a reçu lo nom particulier de métatarse. Il prend alors une importance spéciale, en ce sens qu'il sert aux abeilles, par exemple, au transport du pollen récolté sur les fleurs; il devient alors aplati, rectangulaire. Ordinairement tous les articles du tarse sont cylindriques ou coniques, quelquefois cordiformes avec une échancrure inféricure qui les rend bilobés. A la base de l'articulation de charjue article, on aperçoit parfois des pelotes ou vésicules membraneuses (patellæ) où bien le dessous des tarses est couvert d'une couche de poils courts, soyeux et serrés, ayant l'apparence du velours. On a donné à cette disposition le nom de brosse. Enfin on peut signaler encore, dans quelques tarses, de véritables appareils pneumatiques, portant le nom de ventouses. Ce sont des petites cupules dans l'intérieur desquelles, par un mouvement musculaire, l'insecte peut faire complètement le vide.

Tous ces appendices divers servent à la marche des hyménoptères, et c'est avec leur aide (qu'on peut les voir avancer sur les surfaces les plus lisses et s'y maintenir fácilement, même qquand ces surfaces sont verticales ou renversées et que rien alors ne les soutient.

Chaque article des tarses est muni, en outre, dans quelques cas, de poils ou de cils plus ou moins raides. Le dernier porte toujours deux appendices spéciaux, cornés, qui sont les ongles. Ils ont la la forme de véritables griffes, sont simples ou bifides, armés ou non de petites dents très-fines, et sont accompagnés d'uno petite pelote membraneuse. Ces ongles leur servent aussi it assurer la marche et à assujettir des proies difficiles ì transporter.

Les pattes peuvent être glabres ou courtement velues. Elles présentent encore, en quelques circonstances, sur les cuisses, des touffes allongées et épaisses de poils soyeux. Elles font alors partie de l'appareil pollinigère, et Klug leur a donné le nom de 
floccus. La même disposition se retrouve, mais infiniment plus rarement, aux tibias.

2. - Ailes. - Les ailes (pl. IV) sont, comme je l'ai dit, les organes spéciaux du vol, et leur importance ne laisse aucun doute, puisqu'un insecte, qui, devant en avoir, vient à en être privé accidentellement, ne peutplus pourvoir à tous les besoins qui le sollicitent. Les Hyménoptères ont généralement quatre ailes, savoir : deux ailes antérieures ou supérieures, plus grandes et plus forles que les autres, liées au mesonotum, et deux ailes inférieures ou postérieures, liées au metanotum.

Chez un certain nombre d'espèces, les ailes manquent totalement, au moins dans l'un des sexes, et constituent ainsi des individus aptères. Ce sont ordinairement les femelles qui sont privées de cet organe. Il existe aussi cependant des mâles aptères, quoiqu'en bien petit nombre. Chez les fourmis, la femelle vierge est ailée, mais ses ailes tombent ou sont arrachées, dès qu'elle est fécondée. Les femelles stériles, que nous connaissons sous le nom d'ouvrières ou de soldats n'ont jamais d'ailes chez les Formicides.

Enfin il en existe dont les ailes sont bien déreloppées, mais restent toujours à l'état rudimentaire, où n'alteignent qu'une partie de la longueur qui serait normale pour la taille de l'insecte. Elles sont alors à peu près inutiles au vol.

Les ailes sont attachées au thorax par l'intermédiaire d'articulations assez compliquées, et elles sont mues par des muscles trìs-puissants. Si l'on réfléchit, en effet, combien grand doit être l'effort nécessité par l'aclion du vol, non seulement parce que l'aile n'a qu'une surface fort limitée par rapport au poids du corps, mais aussi parce que l'insecto est obligé souvent, à un moment donné, de transporter des fardeaux réellement énormes pour sa taille, on reste étonné de voir que cet effort est transmis par une surface aussi petite que l'est l'articulation de l'aile.

Ceite articulatlon se fait au moyen d'une série de petits corps de substance cornée, s'enchevêtrant les uns dans les autres, et noyés dans une partie membraneuse. Ces petits corps, nommés osselets ou épidèmes diarticulation, sont combinés de telle sorte (qu'on roulant les uns sur les autres, ils forcent 
l'aile à prendre, quand elle est mise en jeu par les muscles cqui lui sont spéciaux, toute la série des mouvements successifśs qui sont nécessaires pour donner lieu au vol. Il ne faut pas seulement un mouvement rectiligne d'ascension ou de descente, mais il faut cque la surface alaire prenne des inflexions particulieres, des inclinaisons calculées, pour que l'air oppose le plus de résistance que possible pendant la descente de l'aile, et qu'au contraire, il s'échappe avec la plus grrande facilité pendant sa montéc. Cotte étude intéressante du vol des insectes, comme de celui des oiseaux, a tenté l'esprit observateur de plus d'un savant distingué, et nous possédons, it cet égard, des travaux extrêmement sćrieux qu'il ne n'est mème pas permis d'effleurer ici, malgré lo grand intérêi qui s'y raltache, mais dont on trourera l'indication dans le relevé bibliographique placé plus loin.

Jurine qui, le premier, a éludié, d'une façon complète, la structure de l'aile, a distingué les épidèmes d'articulation par différents noms, qui sont, pour l'aile supérieure:

le grand radial;

le petit radial;

le grand cubital;

le petit cubital ;

le grand huméral;

le pelit huméral;

le naviculaire.

Le cuilleron, ou épaulette, ce que j'ai appelé écaillette, est plutôt, à mon sens, une pièce appartenant au thorax qu'ì l'articulation de l'aile, puisque, dans les autres ordres, elle devient fixe, de mobile (qu'elle est chez les hyménopteres, et prend place parmi les divisions du mésothorax.

L'aile inférieure nous offre des épidèmes nommés :

l'échancré;

le scutellaire;

le diadémal;

le fourchu;

la massue.

Sur ces épidimes viennent s'articuler, par de solides ligaments, deux ou trois apophyses cornćes qui forment la base réclle de l'aile. 
Si nous passons à la structure même de celles-ci, nous la voyons formée par une membrane mince, parcheminée, brillante, le plus souvent transparente, quelquefois, au contraire, diversement colorée. C'est la membrane de l'aile. Elle est composée par la réunion intime de deux feuillets très-minces superposés. Pour lui donner de la rigidité, et la rendre propre à la fonction qu'elle a à remplir, cette membrane est soutenue, sur toute sa surface, par des tiges saillantes, cornées, prenant naissance dans les apophyses de la base de l'aile dont elles ne sont qu'un prolongement et un développement. On leur a donné le nom de nervures. Elles sont placées entre les deux feuillets membraneux dont je viens de parler, qui les recouvrent exactement; de plus elles se divisent et se subdivisent en ramifications qui forment un réseau plus ou moins compliqué. Ces nervures sont creuses et forment de véritables tubes plano-convexes dont la partie supérieure surtout est saillante sur l'aile, et diminuant graduellement de diamètre jusqu'à lcur extrémité. A l'intérieur, ces nervures conticnnent une trachée, ou tube respiratoire roulé en spirale. Ces trachées amènent l'air dans les ailes, ct celui-ci, tout en leur donnant de la légèreté, contribue, parait-il, aussi, à les distendre lors de l'éclosion de l'insecte. Les nervures sont le plus souvent colorées d'une façon assez obscure, et, en tous cas, ont une teinte plus foncée ou au moins aussi foncće que celle de la membrane.

* Les tubes qui constituent les nervures sont toujours continus, " excepté chez quelques hyménoptères à abdomen pétiolé, où * l'on observe, principalement aux points où ils s'anastomosent " entre eux, des espèces de petites taches arrondies, transpa* rentes, ct auxquelles leur ressemblance avec des bulles d'air a "fait donner ce nom. Elles sont produites par l'interruption * subite des nervures qui, en arrivant aux points où ces taches " sont situées, perdent leur forme tubulaire et s'éparpillent en a petits filets imperceptibles, lesquels, en se réunissant plus * loin, reprennent leur figure première. Leur couleur répandue " sur une plus grande surface, perd nécessairement de l'intensié a de sa nuance et produit cette transparence dont nous avons " parlć. Les trachées contenues dans l'intérieur des nervures ne

" sont jamais interrompues. En examinant ces bulles d'air au " microscope, on s'aperçoit qu'elles sont toujours accompagnées 
* d'un léger pli de la membrane qui coupe la nervure exictement « au point où clles existent, et si ce pli change de direction, elles * en changent avec lui. On peut en conclure qu'elles ont pour " but de diminuer l'épaisseur de l'aile, afin cul'elle puisse se. " distendre un peu, lorsque cela est nécessaire, et qu'elles " jouent ainsi le róle de véritables articulations. »

(Lacordaire, Introduclion à l'Entomologie).

Vue sous un cerlain jour, la membrane des ailes est très-fréquemment irisće, d'autres fois elle présente les colorations les. plus diverses, jusqu'it devenir presque noire el opaque avec des. reflets d'or ou d'azur les plus riches. Ordinairement clle est: transparente, et dite hyaline. Si elle a une partic plus ou moins assombrie, elle est nuageuse ou enfumée.

L'aile inférieure offre, ì peu près, la même structure que l'aile supérieure. Elle possède cependant en plus, à son bord supérieur, unesérie de petits cils très-raides formant de véritables épines. dont l'extrémité est recourbce à angle aigu de façon à constituer de petits crochets, presque microscopiques. Leur but est de relier l'une à l'autre les deux ailes pendant le rol, et d'en empêcher la séparation. Ils sont on nombre très-variable. J'en ai trouvé quelquefois seulement trois, d'autres fois plus de ringt, selon les espèces considérées. On pourrait même peul-ĉtre en tirer un caractère spécifique, si l'on n'était exposé i des crreurs fréquentes par suite de la chute aceidentelle de quelques-uns de ces crochets. La membrane alaire peut être glabre; le plus souvent elle est velue et les poils excessivement ténus qui la couvrent, forment parfois des lignes continues donuant lieu ì de véritables dessins. Il y a des espèces où un espace délimité est glabre, le reste étant velu. Enfin les bords des ailes sont souvent garnis de longs cils parallèles qui en prolongent la surface, el donnent une élasticité complète à ces bords sous la pression de l'air.

Beaucoup d'hyménoptères présentent, à un certain point du bord supérieur de leurs grandes ailes, un renflement de la nervure, souvent asse\% considérable, faisant peut-être l'office d'un contrepoids. On le nomme le carpe ou stigma.

Ajoutons enfin que, che\% un certain nombre de nos insectes, les ailes, au lieu de rester étendues dans le repos, comme cela se produit le plus habituellement, se plissent longitudinalementet se 
replient de façon à ramence la partic inférieure sous la partie supérieure. On dit alors que les ailes sont pliées.

Considérées sous le rapport de leur position générale, les ailes des hyménoptères sont croisces sur le dos, de façon à voiler l'abdomen. Leur longueur varie considérablement relativement à celle du corps. Tantòt elles dépassent de beaucoup l'abdomen; elles sont alors dites : longues; tantòt elles sont bien plus courtes que lui et en atteignent seulement la moitié ou le tiers; elles sont alors courtes. Toutes les dimensions relatives intermédiaires se rencontrent aussi.

Je ne puis étendre davantage ces renseignements généraux; les expressions spéciales à chaque forme, à chaque parlie, ou à chaque manière d'être, trouveront leur explication suffisante dans le glossaire.

J'ai dit que les nervures, en se croisant et en s'anastomosant, formaient un véritable réscau. C'est ce réseau qu'il me reste à examiner avec détail, son ćtude étant des plus importantes pour la connaissance des hyménoptères.

Les portions membraneuses ainsi comprises entre plusieurs nervures qui se croisent sont ce qu'on appelle des cellules.

Les cellules présentent, dans leur dispositions générales, des analogies constantes qui ont permis de les classer et de leur donner des noms spéciaux, ainsi qu'aux nervures.

Le nombre des nervures et des cellules est très-variable; il faut d'abord considérer l'aile dans sa forme la plus compliquée et arriver ensuite, par élimination, à la connaissance de celles qui sont plus simples. (1)

La nervure qui suit le bord supérieur de l'aile antéricure et traverse le carpe, prend le nom de nervure costale ou marginale. Elle est souvent double enfermant alors une cellule nommée cellule brachiale, sa nervure inférieure etant dite sous costale. Son ćpaisseur dépasse celle de toutes les autres dans la plupart des espèces.

(1) Le lecteur devra, pour l'intelligence facile du texte, suivre sur la planche IV, les descriptions que je vais donner des différentes parties de l'aile, cette planche représentant une aile idéale et montrant toutes les nervures et cellules indiquées. 
En dessous et partant aussi de l'articulation, se trouvent successivement la nervure médiane et la nervure anale.

Entre les nerrures sous-costale et médiane, est enfermée la cellule costale dont le troisième côté est formé par la nervure margino-discoïdale.

Entre les nervures módiane et anale est la cellule médiane, terminée par la nervurr médio-discoídale. Au-dessous de la nervure anale est la cellule anale limitée par le bord inférieur de l'aile.

Ces quatre cellules, brachiale, costale, médiane et anale, constituent la partie basilaire de l'aile, ou partie brachiale.

Si nous continuons cet examen en nous dirigeant vers le centre de l'aile, nous rencontrerons d'abord trois autres cellules qui seront:

La première diecoïdale, limitée par la nervure margino-discoïlale, la nervure discoïdale, la première nervure récurrente et la nervure cubitale.

La deuxième discoïdale, limitée par les première et deuxième nertures récurrentes, par la nervure transverso-discoïdale, la nervure postéricure et la nervure cubitale.

Et la troisième discoïdale limitee par la nervure anale, la nervure médio-discoïdale, la nervure transverso-discoïdale, et la nervure discoïdale.

L'ensemble des trois cellules discoidales constitue le disque de l'aile.

Entre le disque et la nervure costale, nous trouvons, d'abord, une série de une à quatre cellules, qui sont les cellules cubitales, distinguées entre elles par les dénominations de première, seconde, etc., la promière ćtant celle qui confine à la nervure costale. La dernière est le plus souvent incomplète et seulement amorcée. Elles sont séparées des discoidales par la nervure cubitale; de la cellule supérioure, qui est la cellule radiale, par la nervure radiale, et entre elles par les première, deuxième, etc., nervures transverso-cubitales.

La cellule radiale, dont je viens de parler, est quelquefois double ou triple, ce qui donne la première, la deuxième et la troisieme radiales. Elles sont comprises entre la nervure costale et la nervure radiale. Quelquefois la première cubitale est coupée 
en partie par une très-faible nervure allant dans son milieu de thas en haut, ou plus souvent de haut en bas. La première, la deuxième et la troisième cubitales peuvent être pétiolées, c'est-àdire que les deux nervures transverso-cubitales qui les enferment se réunissent avant d'alteindre la nervure radiale. La forme et les grandeurs relatires, ainsi (que lo 'nombre des collules cubitales, sont des caractères très-frécquemment employés dans les classifications, et il importe de se rendre parfaitement compte de la position de ces cellules et de toutes les autres, pour savoir les distinguer au premier coup d'oeil. Dans toute une grande famille (Ichneumonides), la deuxième cubitale plus petite, mais de forme régulière et le plus souvent constante pour chaque genré, a reçu un nom particulier en raison de sa grande importance. On l'appelle l'aréole.

La cellule radiale peut aroir son extrémité pointue sur la nervure costale même, ou en dehors de cette nervure. Dans ce cas, il arrive souvent qu'elle se prolonge par un fragment de nervure plus ou moins long, parallèle ou non au bord de l'aile. On dit alors que la radiale est appendicée ou appendiculée. Si cet appendice alteint la côte de l'aile, il forme une petite cellule supplémentaire, appelée cellule appendicée.

La réunion des cellules radiales et cubitales forme la partie cubito-radiale de l'aile, plus connue sous le nom de région carac. téristique, en raison des caractères très-nombreux qu'y trouvent les entomologistes pour classer les hyménoptères.

Enfin l'extrémité inférieure de l'aile ne contient gुénéralement pas de cellule fermec, mais seulement des amorees de nervures donnant lieu à des divisions incomplètes que l'on a cependant distinguées sous les noms de première et deuvième cellules postérieures, sćparées entre elles par la nervure postérieure, des discoïdales par la deuxième récurrente et la nervure postéricure, et enfin tes cubitales par la nervure cubitale qui, souvent, n'existe plus à cet endroit, ce qui confond toutes ces parties en. semble.

Cette région mal dessinéc, formant l'extrémité de l'aile porte le nom de limbe proprement dit. Signalons encore au bord inféricur de l'aile une nervure qui n'occupe qu'une partie de sa longueur et va souvent rejoindre la nervure anale pour se souder 
ou s'articuler avec elle. Je l'appellerai nerrure inférieure. Son but est évidemment de servir de point d'attache aux crochets qui garnissent le bord supérieur de l'aile inférieure.

Dans un certain nomble d'insectes (Tenthrédines), il existe encore, en dessous de la nervure anale, une cellule allongée, étroite, (fu'il est très nécessaire de connaître parfaitement parce (qu'elle est d'un usage constant pour séparer certains grenres entre eux. On lui a donné le nom de cellule ou aréole lancéolée. Elle est limitce inférieurement par une nervure spéciale dite: accessoire. Elle peut offrir diverses modifications que l'on distingue ainsi :

On dit qu'elle est contractée, quand la nervure accessoire vient se joindre à la nervure anale et elle est longuement ou courtement contractée, suivant que les deux nervures se réunissent sur une portion plus ou moins grande de leur longucur, ou ne font que se toucher.

On dit qu'elle est pétiolée, quand les deux nervures se confondent en une scule vers le milieu de la cellule et ne se séparent plus, de façon à former à celle-ci comme une tigre ou un pédicule.

On dit qu'elle est traversée par une nervure droite, quand une pelite branche, perpendiculaite en même temps aux deux nervures, vient la diviser en deux cellules.

On dit, enfin, qu'elle est traversée par une norvure oblique, rfurud cette br:anche n'est pas perpendiculaire aux deux nervures constituant l'arćole lancéolée.

Elle est ouverle, quand aucun de ces cas ne se présente.

Chez les mêmes insectes. la cellule brachiale peut rarement chre trarerséc longitudinalement par une nelvure supplémentaire fourchue, dite nerture intercalaire, qui la divise en trois parties, ou transversalement par un court rameau vertical qui la partage en deux portions.

On y rencontre aussi quelifuefois, en dessous de la nervureacessoire, un frament de nervure que Thomson appelle nervers axillaris, nervure axillaire.

Il faut encore expliquer (que je donne le nom de nervure inters. liliale ì toute nervure qui semble fitire le prolongement d'une autre nervure, par exemple quand une nervure récurrente est immérliatement au-dessous d'une nerrure transverso-cubitale. 
Il n'existe pas d'aile présentant toutes les nervures ou cellules, offrant aussi toutes les dispositions dont je viens de parler. Un grand nombre de ces divisions manque souvent et certaines espèces n'offrent même aucune nervure visible ou n'en montrent qu'une ou deux. Il y a de grandes simplifications, mais quelles que soient les nervures ou les cellules qui subsistent, on peut toujours les ramener au type que nous venons d'étudier.

Les petits hyménoptères parasites (Chalcidites, etc.), sont ceux où l'aile a le moins de complication. Il peut même ne s'y trouver aucune nervure visible. Le plus souvent il y en a une seule qui est la nervure sous-costale.

Chez quelques uns cependant de ces mêmes parasites, qui forment passage avec les groupes a ailes moins simples et moins nues, on rencontre, outre la nervure sous-costale, d'autres nervures très-peu distinctes qui ne sont peut-être que des plissements de la membrane; on les a réunies sous le nom collectif de veñe spurix. Quelques auteurs leur ont cependant donné des noms particulicrs, ainsi qu'aux cellules qu'elles enferment, cubitus, cellula basalis, etc., mais nous entrerons dans ces détails iorsque nous viendrons à étudier ces petites familles.

Très-souvent la nervure unique dont j'ai parlè donne naissance, chez ces insectes, à une branche terminée ou non par un bouton en massue de forme variée. On lui a imposé le nom de rameau stigmatical et les diverses portions de la nervure ont reçu des dénominations distincles, savoir :

$1^{\text {e }}$ Rameau huméral, pour la partie qui va de la base de l'aile au point où elle rejoint le bord supérieur. Cette portion a même été par M. Thomson subdiviée en postcosta et præstigma.

$2^{\circ}$ Rameau marginal pour celle qui suit le bord de l'aile jusqu'au rameau stigmatical.

$3^{\circ}$ Rameau postmarginal, pour celle qui part de ce même point pour suivre plus ou moins loin le bord de l'aile.

On a distingué, enfin, dans la massue du rameau stigmatical sous le nom de uncus, l'appendice pointu qu'elle présente quelquefois.

Il n'y a en général pas lieu, dans ces ailes si simples, de s'occuper des cellules, puisqu'en réalité il n'en existe point.

Un petit nombre d'espèces (mymar) présentent enfin des ailes 
. où la nervure sous-costale subsiste scule et sans membrane sur une partie de la longueur de l'aile. La membrane forme alors à l'extrémité de cette tige comme une palette longuement ciliće.

L'aile inféricure ou postérieure des hyménoptères n'a, au point de vue de l'étude, qn'une importance bien moindre. Il faut cepen. dint savoir (fuclles sont les parties qui la composent, pour ne pas être arrêté par les cas assez rares où il est nécessaire d'en faire usage.

File offe aussi une nervure costale et une sous-costale, enfermant entre elles la cellule brachiale. Nous trouvons encore audessous les nervures, médiane et anale.

Entre les nervures sous-costale et médiane, se place la cellule costale, limitée d'autre partpar une nereure margino-discoïdale.

Entre les nervures, médiane et anale, est aussi la cellule médiane, limitée, au troisième cóté, par la nervure médio-discoüdale.

Ce nom de cellule médiane a été appliqué à tort par beaucoup d'auteurs, à toute cellule fermée situéc dans le champ de l'aile inférieure, et ils ont entendu parler de ce que nous allons apprendre à connaître sous le nom de cellule discoïdale.

Entre la nervure anale et le bord inférieur, est la cellule anale.

Au centre de l'aile, nous trouvons deux ou trois cellules le plus souvent non fermées ou n'en présentant qu'une seule qui soit complète. Ce sont les cellules discoïdales, séparées entre elles par la ou les nervures transierso-discoïdales.

Lit se bornent les divisions de l'aile inférieure. Il y a bien en. core une amorce de cellule radiale, mais pas de cubitale, à moins que l'on ne considère comme telle, avec quelques auteurs, la ou les cellules discoïdales contigües à la radiale.

Enfin, dans un grand nombre de petites espèces, cette aile est nue ou presque nue. Peut-être même se réduit-elle quelquefois à ún fil.

Si nous revenons i l'aile antérieure, nous pourrons constater que toutes les cellules indiquées, ou une partie d'entre elles, se rencontrent le plus souvent les mêmes dans tous les individus d'un mème genre. On y a done trouré, comme je l'ai déjì dit, des caraciòres trís-faciles à saisil. Aussi tous les auteurs, depuis que Jurine a initie les savants à celte composition de l'aile, s'en sontils emparcis et les ont-ils employés dans leurs ouvrages. Il en est 
résulté malheureusement uné certaine confusion, renant de ce que chaque auteur a cru pouvoir adopter, pour la désignation des nervures et des cellules, des expressions spécialement choisies par lui. De là ressort aujourd'hui la nécessité d'établir, pour tous ces noms différents, se rapportant aux mêmes objets, une table de concordance. C'est celle que je place ici et où j'ai réuni les termes adoptés par les principaux autcurs, ajoulant qu'il serait désirable que de nouvelles dénominations ne vinssent plus s'y ajouter à l'avenir.

\section{TABLEAU SYNONYMIQUE}

DES DIFFÉRENTES PARTIES DE L'AILE ANTÉRIEURE DES HYMÉNOPTÈRES

\section{I. - Bords de l'Aile. - Margines}

1. Bord antérieur. - Margo anterior.

Syn. - Le bord externe, Jurine. - Le bord costal, de RomandCosta, Latreille. - Bord extérieur, Lepelletier (1825). - Nervure costale, Lacordaire. - Nervus costalis, Fallen, Dahlbom. Margo anticus, Gravenhorst. - Première Nervure humérale, Vesmaël. - Radius supérieur, Lepelletier (1836). - Radius. Hartig. - Costal Nervure, Kirby, Shuckard.

2. Bord postÉrieur. - Margo posterior.

Syx. - Le bord interne, Jurine. - Bord posterieur, de Romand. - Bord intérieur, Lepelletior (1825). - Nervure anale, Lacordaire. - Margo internus, Gravenhorst. - Côté intérieur, Wesmaël. - Bord inférieur, Lepelletier (1836). - Posterior Margin, Shuckard.

3. Bond apical. - Margo apicalis.

SYn.-Le bord postérieur, Jurine et Lepelleticr.-Le bord apical, de Romand.-Margo posticus, Gravenhorst. - Côté postérieur, Wesmaël: - The apical Margin, Shuckard.

II. - Nervures. - Venæ ou Nervi.

\section{A. - NERVURES LONGITUDINALES}

1. Nervune costale. - Nervus costalis.

Syn.-Radius, Jurine, IIartig.-Cosla, Latreille.-Nervure costale, 
Lacordaire. - Première Nervure humérale, Wesmaël.-Radius supérieur, Lepelloticr. - Nervus coslalis, Fallen, Iuliday, Dahlbom, Schenck. - Costa, Thomson. - Vena marginalis, Focster. - Costal Nervure, Kirby, Shuckard. - Randrippe, Costa marginalis, Mayr. - Randader, Randnerv, Zaddach.

\section{Nervure sous-costale. - Nervus subcostalis.}

Syn. - Cubitus, Jurine, Hartig. - Post costa, Latreille. - Nervure sous-costale, Lacordairc. - Première Nervure humérale, Wesmaël. - Cubitus supérieur, Lepelleticr. - Nervure post costale, de Romand. - Nervus auxiliaris, Fallen, Dahlbom, Schenck. - Post costal Nervure, Kïby, Shuckard. - Nervus subcostalis, Nees ab Escnbeck, Ialiday. - Vena submarginalis, Foerster. - Schulterrippe, Costa Scapularis, Mayr. - Unterrandnerv, Zaddach. - Nervus postcostalis, ou Postcosta, Thomson.

\section{Nervure médiane. - Nervus medius.}

Srs. - Nervure brachiale, Jurine. - Nervus internus, Latrelle. - Nervure médiane, Lacordaire. - Deuxième Nervure humérale, Wesmaël. - Première Nervure intermédiaire, Lepelletier. - Nervure externo-médiane, de Romand. Externo-mediane Nervure, Kirby, Shuckard. - Nervus radians. Dahlbom. - Vena media, Hartig, Foerster. - Nervus anterior, ou prebrachialis, Haliday. - Mittelrippe, Costa media, Mayr. - Nervus cubitalis, ou Cubitus, Thomson. Nervus submedialis, Schenck.

\section{Nervure ANale. - Nervus analis.}

Sys. - Nervure sous-médiane, Lacordaire. - Troisieme Nervure humérale, Wesmä̈. - Seconde Nervure intermédiaire, I.epelletier. - Nervure anale, de Romand. - Anal Nervure, Kirby, Shuckard. - Vena postica, IIartig. - Nervus posterior ou probrachialis, Ialiday. -Vena postica, II interader, Foerster. - Innenrippe, Costa Internomedia, Mayr. - Nervus bram chialis, ou Brachium, Thomson. - Nervus analis, Dahlbom, Schenck.

\section{Nervere radiale. - Nervus radialis.}

SYx. - Radius, Lepelletier (1825), IVesmaël, Dahlbom, IIaliday, Schenck. - Radius inférieur, Lepelletier (1836). - Nervure radiale, Lacordaire, de Romand, Sichel. - Vena radiatis, Hartig, 
Focrster. - Radial Nervure, Slsuckard. - Subradialader, Zaddach: - Nervus marginalis, Thomson.

6. Nervune cubitale. - Nervus cubitalis.

Syn. - Cubitus, Lepelletier (1825), Wesmaël, Dahlbom, Haliday.

- Nervure cubitale, Lacordaire, de Romand, Sichel. - Cubitus inférieur, Lepelletier (1836). - The Cubital Nervure, Schuckard: - Vena cubitalis, Hartig, Foerstor. - Cubitalrippe, Mayr. Innere et aussere Ast der Cubitalrippe, Mayr. - Cubitus, Zaddach. - Nervus submarginalis, Thomson.

7. Nervure discoidale. - Nervus discoïdalis.

Srv. - Nervure discoïdale, de Romand. - Vena media, Foerster. Nervure parallèle, Wesmaël. - Nervus analis, Haliday. Discoïdalnerv, Zaddach. - Subdiscoïdal Nervure, Shuckard.

8. Nervure postériedne. - Nervus posterior.

Syn. - Nervure parallèle, Wesmaël. - Vena media, Foerster. Subdiscoïdal Nervure, Shuckard. - Nervus analis, Haliday.

9. Nervure intercalaire: - Nervus intercalaris.

Syn. - Vena intercalaris, Foerster. - Nervus mediastinus, Thomson.

10. Nervure accessoire. - Nervus accessorius.

Syn. - Begleitader, Vena accessoria, Forster - Nervus humeralis, ou Humerus, Thomson.

11. Nervure inférleure. - Nervus inferior.

12. Nervure axildatre. - Nervus axillaris.

\section{B. - NERVURES TRANSVERSALES}

13. Nervure margino-discordale.- Nervus margino-discoidalis.

Srn. - Vena basalis, Foerster, Hartig. - Nervus ou Vena basalis, Thomson. - Nervus brachialis, Haliday. - The externo medial Nervurc, Shuckard. - Grundrippe, Costa basalis, aussere Ast der Mittelrippe, Mayr: 
14. Nenyures traxsverso-Radiates - Nervi transverso-radiales.

Sys. - Nervures récurrentes radiales, de Romand. - Radialscheidnerv, Zaddach.

15. Nervures transvenso-cubitales. - Nervi transverso-cubitales.

Sys. - Nervures récurrentes cubitales, de Romand. - Nervus connectens, Dahlbom. - Nervi transversi, Fallen. - Querrippe, Mayr. - The transverso-cubilal Nervure, Shuckard.Venula transverso-cubitalis, Costa. - Cubitalscheidnerv, Zaddach.

16. Nenvure transvenso-discoidale. - Neruus transverso-discoïdalis.

Syx. - Vena media, Foerster.

17. NenvURES RËCURRENTES. - Nervi recurrentes.

Syn. - Nervures récurrentes, Jurine, Wesmaël, Lepelletier. Nervi recurrentes, Dahlbom, Schenck, Hartig, Thomson, IIaliday, Nees ab Esenbeck. - Nervures rẻcurrentes discoïdales, de Romand. - Anastomoses medii alx, Latreille. - Venæ transverso-discoüdales, Foerster. - Venule transverso-discoïdales, Costa. - Ruchlaufendadern, Hartig.

18. Nerture medo-discoidale. - Neveus medio-discoïdalis.

Sys. - Nervus connectens, Dahlbom. - Nervus brachialis, IIaliday. - The transverso-medial Nervure, Shuckard. - Vena transverso-humeralis, Foerster. - Innere Ast der Mittelrippe, Mayr. - Nervus transversus ordinarius, Thomson.

19. Nervune transverso-Brachiale. - Nervus transcerso-briachialis.

SYs. - Vena transuerso-submarginalis, Foerster.

$$
\text { III. - Cellules. - Areole }
$$

\section{Cellule brachiale. - Areola brachialis.}

Syn. - Cellule brachiale, Lepelleticr (1825). - Première Cellule brachiale, Lepelleticr (1836). - Cellule costale, Lacordaire, de Romand. - The Costal Area, Kirby.-The costal Cell, Shuckard. 
- Cellula intercubilalis, Dahlbom. - Areola subradialis; Hartig. - Areola costalis, Haliday. - Areola mediastina, Nees ab Esenbeck. - Cellula costalis, Thomson. - Area submarginalis, Foerster. - Schulterzelle, Mayr.

2. Cellule costale. - Areola costalis.

SYN. - Cellule sous-costale, Lacordaire. - Première cellule humérale, Wesmaël. - Deuxième cellule brachiale, Lepelletier.Cellule médiane, de Romand.- The intermediate Area, Kirby. - The externo medial Cell, Shuckard. - Cellula humeralis externa, Gravenhorst. - Areola brachialis anterior, Nees ab Esenbeck. - Areola præbrachialis, Haliday. - Area humeralis antica, Foerster. - Aussere Mittelzelle, Mayr. - Area costalis, Fallen, Dahlbom.

3. Cellule médiane. - Areola media.

Syn. - Cellule médiane, Lacordaire. -Deuxième Cellule humérale, Wesmaël. - Troisième cellule brachiale, Lepelletier. Cellule sous-médiane, de Romand. - Cellula humeralis intermedia, Gravenhorst. - The interno-medial Cell, Shuckard. Areola humeralis media, IIartig. - Area humeralis media interna, Foerster. - Innere Mittelzelle, Mayr.

4. Cellule anale. - Areola analis.

Syn.-Cellule anale, Lacordaire, de Romand.- Troisième Cellule humérale, Wesmaël. - Quatrième Cellule brachiale, Lepelletier.-Anal. Area, Kirby. - The anal Cell, Shuckard.-Cellula humeralis interna, Gravenhorst. - Cellula postica, Dahlbom.Areola humeralis postica, Iartig. - Area humeralis postica, Foerster.

5. Phemière cellule postérieune. - Areola posterior prima.

Sxn. - Première Cellule du limbe, Lepelletier. - Quatrième Cellule discoïdale, de Romand.- Troisième Cellule discoüdale, Dahlbom, Sichel. - Cellula postica externa, Gravenhorst. 2. Apical Cell, Shuckard. - Areola externa media, Haliday. Areola discoïdalis tertia, Foerster. - Erste Hinterzelle, Zaddach.

6. Deuxième cellule postérieure.-Areola posterior secunda.

Syn. - Cellule anale, Wesmaël, Haliday. - Deuxième Cellule du limbe, Lepelletier. - Cellule apicale, de Romand. - 1 apical 
Cell, Shuckard. - Apical Areole, Kïby. - Cellula discoüdalis externa, Gravenhorst. - Areaspecularis, Necs ab Esenbeck. Area terminalis, Dahlbom. - Aussere II interzelle. Zaddach.

\section{Cellule lanciéolée. - Areola lanceolata.}

Srx. - Areola lanceolata, IIarlig. - Area humeralis lanceolata, Focrster. - Cellula lanceolata, Thomson. - Lanzeltformige Zelle, Zaddach. - Cellula analis, Costa.

Peutse diviser en deux autres qui forment la premiére (vers l'articulation), et la seconde aréoles de la cellule lancéolée. - Ia petite nervure divisante, droste ou oblique, est appelée par Thomson. Nerus transterso-huneralis.

8. Premiere gellule discoidale. - Aruola discoïdalis prima.

Syn. - Première cellule discoürlale. Lepelletier. - Cellule discoïdale supérieure externe, Wesmaëı. - Deuxième cellule discoüdale, de Romand. - Areola costalis, Fallen. - Cellula discoüdalis interior, Gravenhorst. - The 1 discoïdal, Shuckard. - Areola exterior ou prediscoüdalis, IIaliday. Areoladiscoïdalis prima, Foerster. - Discoïdal Cell, Smith. Discoüdalzelle, Mayr. - Cellula discoüdalis prima, Costa. Erste Discoïdalzelle, Zaddach. - Cellula furcata, Thomson.

9. Deuxidine celdule discoidate. - Areola discoüdalis secunda.

Syx. - Cellule discoüdale inférieure, Lepelletier (IS25). - Troisieme cellule discoïdale, Lcpelletier (1836), de Romand. Cellulediscoüdale inférieure, IVesmaël. - Areola specularis, Vallen, Dahlbon.-Cellula discoüdalis intermedia, Gravenhorst. - 3 Discoüdal Cell, Shuckard. - Areola exterior, IIaliday. Areola intermedia, Grarenhorst. - Areola discoïdalis secunda. Foerster. - Cellula discoüdalis secunda, Costa. - Zweile Discoüdalzelle, Zaddach. - Cellula discoüdalis; Thomson.

10. Thorsikie gellule discoidale. - Areola discoïdalis tertia.

Syx. - Deuxième cellule discoüdale supérieure, Lepellelier (1825). - Deuxieme cellule discoülale, Lepellelier (1836).-Cellule discoïdale interne, Wesmaë̀. - Cellule sous-discoüdale, do Romand. - Area costalis, Fallen, Dahlbom. - Middle Areole, Kirby. - Cellula postica interna, Grarenhorst. - Areola posterior ou podiscoïcalis, Haliday. - Areola humeralis media externa, Foerster, - Cellula discoïlalis tertia, Costa.-Cellula secunda brachialis, Thomson.-Drille Discoïdalzelle, Zaddach. TOME I 


\section{Première cellule cubitale. - Areola cubitalis prima.}

Syn. - Première cellule cubitale, Lepelletier, de Romand, Jurine, Sichel. - Areola submarginalis, Latreille.-A reola intermedia, Fallen. - Middle Areole, Kirby. - Cellula cubilalis interna, Gravenhorst. - Areola costalis, Dahlbom. - The 1 Cubital Cell, Shuckard. - Areola cubitalis prima, Foerster.-Submarginal Cell, Smith. - Erste Cubitalzelle, Mayr, IIartig, Zaddach, Cellulacubitalis prima, Costa. - Cellula prima submarginalis, Thomson.

12. Deuximine cellule cubitale. - Areola cubitalis secunda.

Syn. - Deuxième cellule cubitale, Lepelletier, Lacordaire, Wesmaël, de Romand, Sichel, Jurine. - Cellula intermedia (areola) Gravenhorst. - Areola intermedia, Dahlbom. - Areola cubitalis secunda, Foerster. - The 2 Cubital Cell, Shuckard. Zweite Cubitalzelle, IIarlig, Zaddach. - Cellula cubitalis secunda, Costa. - Cellula secunda submarginalis, Thomson.

13. Troisik̀me cellule cubitale. - Areola cubitalis tertia.

SyN. - Troisieme cellule cubitale, Lepelletier, Lacordaire, Wesmaël, de Romand, Sichel, Jurine.-Cellula externa, Gravenhorst. - Areola terminalis, Dahlbom. - Areola cubitalis tertia, Foerster. - Dritte Cubitalzelle, Hartig, Zaddach. - Cellula cubitalis tertia, Costa. - Cellula tertia submarginalis, Thomson.

14. Quatriène cellule cubitale. - Areola cubitalis quarta.

Syn. - Quatrième cellule cubitale, Lepelletier, Lacordaire, Sichel, Jurine. - Areola cubitalis quarta. Foerster.-Cellula cubitalis quirta, Costa.-Vierte Cubitalzelle, Iartig, Zaddach.-Cellula quarta submarginalis, Thomson. - Apical Areole, Kirby.

15. Première cellule radiale. - Areola radialis prima.

Syn. - Première cellule radiale, Lepelleticr, Lacordaire, de Ro. mand, Jurine, Sichel. - Areola marginalis prima, Latreille. Area costalis prima, Fallen.-Areola radialis prima, Foerster, IIaliday. - Erste Radialzelle, Iartig, Zaddach. - The 1 Costal Area, Kirby. - Prima cellula radialis, Gravenhorst, Costa. The 1 Radial ou Margin Cell, Shuckard. - Marginal Cell, Smith. - Cellula prima marginalis, Thomson. 
16. Deuxieme gellule radiale. - Areola radialis secunda.

Sxs. - Seconde cellule radiale, Lepelletier, Lacordaire, de Romand, Jurine, Sichel. - Areola marginalis secunda, Latreille. - Area costalis secunda, Fallen. - Areola radialis secunda, Focrsler, Ifaliday. - Zweite Radialzelle, Hartig, Zaddach. - 2 Costal Area, Kirby. - "Secunda cellula radialis, Gravenhorst. - Cellula secunda marginalis, Thomson.

17. Trioisibiag cellule Radiale. - Areola radialis tertia.

Syn. - Troisieme cellule radiale, Lepelletier, Lacordaire, de Romand, Jurine, Sichel. - Areola marginalis tertia, Latreille. Area costalis tertia, Fallen. - Areola radialis tertia, Foerster, IIaliday. - Dritte Radialzelle, IIartig, Zaddach. - 3 Costal Area, Kirby. - Cellula tertia marginalis, Thomson.

18. Cellule appendicée. - Areola appendicea.

Syn. - Areola appendicea, Foerster, IIartig. - Cellula appendicea, Costa.

\section{TABLEAU SPÉCIAL}

DE LA SYNONYMIE DES DIFFÉRENTES PARTIES DE L'AILE DES CHALGIDITES

Nervure sous-costale. - Unterrandader.

(Voir plus haut sa synonymie).

Elle se divise en :

1. Rameau huméral, - Schulterast. - Schulterstuck.

Syn. - Ramus humeralis, Foerster (1856). - Abscissa humeralis, Focrster (1877). - Humerus, IIaliday.

2. Rameau marginal. - Randast.

Syv. - Ramus marginalis, Focrster (1856). - Abscissa marginalis, Foerster (1877). - Ulna, Ialiday. 
3. Rameau stighatical. - Zweig.

Syn. - Ramus stigmaticus, Focrster (1856). - Abscissa radialis, Forster (1877). - Ramulus stigmaticus, Nees ab Esenbeck. Cubitus, Ialiday.

4. Ramiau post-iranginal. - Hinterrandast.

Svv. - Ramus post mainginalis, Foorster (1856). - Abscissa post marjinalis, Foerster (1S77) - Radius, IIaliday.

SYNONYME DU CARPE OU STIGMA

Carpe, Lacordaire-_Randmal,Harlig.-Stigma, Nees ab Esenbeck, Gravenhorst, Shuckard, Wesmaël, Dahlbom. de Romand, Thomson. - Le Point, Jurine. - Le Point épais, Lepelletier. Punctum costale, Fallen. - Carpus, Zaddach.

\section{VI. - ABDOMEN}

A la suite du thorax vient se placer le troisième segment de l'insecte ou segment abdominal.

L'abdomen est lié au thorax par des téguments qui, tantôt embrassent une grande partie de son diamètre, tantôt, au contraire, sont resserrés et réunis on un pédicule plus ou moins mince et allongé; d'où les dénominations d'ab tomen sessile pour le premier cas, d'abdomen pédiculé ou pétiolé pour le second.

A propos du thorax, j'ai signalé le cordon tendineux ou funiculus qui soutient l'abdomen dans certaines espèces, ainsi que le segment médiaire, ou premier anneau de l'abdomen soudé au thorax; je n'y reviendrai donc pas.

L'abdomen, pris dans son ensemble, présente des formes trèsvarićes. Le plus ordinairement, il est ovalaire et allongé; d'autres fois, au contraire, il est presque globuleux, ou conique, comprimé latéralement jusqu'à devenir foliacé, ou bien déprimé par-dessus. Les femelles l'ont ordinairement plus allongé et plus pointu que les mâles. La face inférieure, en général convexe, peut devenir plane et môme foriement concave. Les anneaux suecessifs 
présentent quelquefois des étranglements ou leur ensemble est complètement cylindrique. Dans d'aulres cas, l'abdomen devient à peu près filiforme. Il peut enfin être glabre ou velu, lisse ou ponctué, etc., et presenter toutes les conditions supcrficielles que nous ont montrées les autres parties du corps.

La portion soudce au thorax est la base de l'abdomen, lia partic opposce en est la région apicale ou anale. Le dessus est le dos ou tergum, le dessous est le ventre.

Il ne porte point d'appendices comme le thorax, mais son extrémité renferme les organes très-importants de la reproduction, auxquels nous aurons it nous arrêter longuement tout-it-l'heure.

La jonction de l'abdomen avec le thorax se fail, le plus habio tuellement tout-ì-fait à l'extrémité postérieure de celui-ci, et il en est le prolongement naturel. Dans des cas assez rares, cette insertion a lieu à la partie supéricure du métathorax, ou, plus rarement encore, en-dessous de celui-ci, qui avance ainsi un peu sur le pédicule abdominal.

Si nous jetons maintenant les ycux sur chacun des anneaux dont l'ensemble constitue l'abdomen, nous remarquerons d'abord qu'ils présentent deux portions complètement distinctes, l'une supérieure, qui est le demi arceau dorsial, l'autre inférieure qui est le demi arceau ventral. Ces arceaux ne sont pas simplement soudés l'un à l'autre par leur bord, mais les dorsaux recouvrent un peu les arceaux du ventre qui leur correspondent, do façon que la membrane qui les unit est replice en dessous. Celte disposition, peu visible dans beaucoup d'espèces, le devient bien davantage dans quelques autres, où le bord de l'arceau dorsal peut même former une ligne tranchante.

Les segments successifs s'emboitent aussi l'un dans l'autre de la méme manière, et les portions qui sont recouvertes perdent de plus en plus leur consistance cornée, de façon à devenir complètement membraneuses a leur jonction avec le segment supéricur.

La ligne de séparation des arceaux dorsaux et ventraux est souvent placće sur les cótés, de telle sorte que ces arceaux sont à peu près égaux; d'autres fois la partie ventrale est bien plus étroite que la portion dorsale du même segment.

Les segments successifs sont loin d'avoir la mème forme, dans beaucoup de cas, ni même souvent des formes analogues. Dans 
un certain nombre d'abdomens pédiculés, le pédicule donne un segment filiforme, linéaire, dont l'arceau ventral est presque impossible à constater. Ce pédicule peut devenir conique ou pyriforme, noueux ou aplati, enfin diversement sculpté par des stries ou des sillons. Une modification très-curieuse se présente encore chez les fourmis, où le pédiculo prend le nom spécial de pétiole. On voit, en effet, celui-ci surmonté d'une lame aplatie ou écaille, de forme très-diverse suivant les espèces, tantòt simple, tantôt munie d'épines ou d'appendices. Chez les Myrmicides, ce pétiole, au lieu d'être formé par un segment abdominal unique, en comprend deux, unis entre cux par une véritable articulation plus ou moins noduleuse.

Souvent le segrment pédiculaire se dilate de façon à reprendre les dimensions normales de la base de l'abdomen; d'autres fois, il reste en enticr linéaire, et le second segment seul présente le diamètre de l'ensemble de l'abdomen; enfin il y a des cas où ce pédicule étant en forme de poire ou d'entonnoir, l'abdomen offre une contraction très-visible ì l'insertion du segment suivant. Il ne serait pas possible de détailler toutes les formes diverses qui peuvent se rencontrer, sous ce rapport, chez les hyménoptères. Les autres segments, tout en offrant encore bien des variations, ont cependant entre eux une plus grande similitude.

Avant d'aller plus loin, je dois encore signalersur les arceaux supérieurs, la présence ì chacun de leurs angles antérieurs et près de leur jonction avec l'arceau inférieur correspondant, d'ouvertures rondes ou elliptiques, qui sont les orifices par lesquels l'air extérieur pénètre dans les organes respiratoires de l'insecte. On leur a donné le nom de stigmates, et le re. bord corné qui les entoure a reçu la dénomination de péritrème. Leur couleur est parfois un peu différente de celle de l'ábdomen, et leur nombre est légèrement variable suivant les espèces, les derniers segments abdominaux pouvant ou non en présenter.

Le nombre réel des segments de l'abdomen, chez les hyménoptères, est de huit, dont trois sont spécialement affectés à contenir les organes de la génération. Mais si l'on considère les segments apparents, on arrive ì des chiffres tout autres, et souvent différents d'un sexe à l'au tre, ce qui lient à ce que les derniersarceaux se recouvrent ou deviennent rudimentaires. Ainsi certains 
lyyménoplères semblent n'aroir qu'un scul serrment abdominal, c'est-ì-dire un abdomen d'une seule pièce, tandis que d'atutres présentent trois, quatre, cinq ou six segments.

Il est essentiel aussi de tenir compte que, dins ce nombre de huit segments, je ne fais pas rentrer le serment médiatie de Latreille soudé au thorax, et que je considère l'abdomen tel cu'il se présente à la vue.

Le sixième segment, quand on l'aperçoil, offre souvent, entre ses arceaux dorsaux et ventraux, une fente transversale, qui termine l'abdomen, et est destince à laisser passer les cxeréments et les organes reproducteurs. C'est le segment apical ou anal; ce nom s'adapte aussi aux segments précédents quand les derniers ne sont pas visibles.

Le septième est souvent incomplet et ne présente alors qu'un arceau dorsal, ou plutòt l'arceau ventral s'est transformé en une pièce annexe des organes reproducteurs. Il est ordinairement invisible, et caché dans l'intérieur du précédent. Il renferme l'orifice du rectum.

Enfin le huitième, habituellement encore plus incomplet ou plus transformé, enveloppe directement les organes générateurs. Sa moitié dorsale a reçu, quand elle est visible et qu'elle a conservé l'apparence d'un arceau, le nom d'épipygium, et la moitié ventrale, dans le mème cas, celui d'hypopygium. L'épipygium, dans un petit nombre d'espèces, présente aussi deux stigmales (Ibalia, Phasganophora, Leucospis). Il protège la poche à venin lors(qu'elle existe, l'oviducte ou canal excréteur des oufs, chez les femelles, et il soutient la base des pièces intéricures de l'aiguillon, ou de la tarière, comme nous le verrons. L'hypopygium est le plus souvent divisé lui-même en deux pièces ayant la forme d'écailles. Quelquefois il laisse voir seulement à sa partie inférieure, une fente plus ou moins large où passe chez les femelles les pièces de la tariere ou de l'aiguillon. Enfin, dans le même sexe, chacune de ses écailles se prolonge en arrière en une sorte d'appendice demicylindrique, quelquefois à peine visible à la loupe, d'autres fois extraordinairement allongé en dehors du corps. Ces appendices sont, soit soudés, soit articulés avec l'hypopygium, selon. qu'ils doivent rester fixes, ou subir des mouvements plus ou moins étentlus. La réunion des deux appendices forme un fourreau cylindrique qui contient et protège la tarière ou l'aiguillon. 
Chez les insectes mâles, on trouve les mêmes segments abdominaux, mais il est tout aussi difficile de les suivre dans leur transformation. Les organes reproducteurs offrent des appendices qui ne sont que ces segments modifiés. Il arrive cependant très-souvent que ce sexe présente un segment abdominal apparent de plus que la femelle de la même espèce. Ce fait trouve son explication dans la simplification des organes reproducteurs. Les segments apicaux présentent aussi chez les mâles, plus rarement chez les femelles, des sculptures particulières, des épines, des dents plus ou moins aigües ou nombreuses, des fossettes ou des appendices quelconques.

Chez les femelles de certains genres, la partie ventrale est couverte d'une couche de poils fins formant une brosse, qui sert à recueillir le pollen des fleurs. On nomme cette brosse la palette ventrale.

Nolons enfin que le bord des segments est souvent garni de cils plus ou moins allongès et que, dans quelques cas, l'abdomen, pouvant se recourber sous le sternum, en même temps que la tête se penche aussi en dessous, l'insecte ne semble plus former qu'une boule, et y trouve un moyen particulier de défense, puisqu'il ne présente plus ainsi aux atlaques de ses ennemis qu'une cuirasse polie et impénétrable.

\section{VII. - APPENDICES DE L'ABDOMEN.}

\section{Organes de reproduction ou de défense.}

Ces organes, intimement liés à l'abdomen, doivent s'étudier en môme temps. Ils présentent, chez tous les hyménoptères, la même série de pièces, mais celles-ci subissent des modifications excessivement profondes dans leur forme et même dans leur destination, au moins en ce qui regarde les organes femelles:

1. - Organes femelles. - Les organes reproducteurs des hyménoptères femellesse composent: $1^{\circ}$ d'une partio intérieure, ou ovaire, donnant naissance aux oufs et les contenant jusqu'au mo- 
ment de leur expulsion; il se prolonge en un conduit excréteur membraneux, qui se nomme l'oviducte.

$2^{\circ}$ D'une partie extérieure comprenant une série de pièces diverses qui concourent it la ponte des oufs sur les objels ou insectes destinés à les recevoir, et servent, dans d'autres cas, à obtenir la paralýsie de ces insectes mêmes, ou à coopérer à la défense de l'hyménoptère.

Je ne veur pas insister sur les organes intérieurs dont nous n'aurons jamais it faire usage et qui sortent du cadre de celte introduction, mais je dois, au contraire, donner sur les organes exlé-

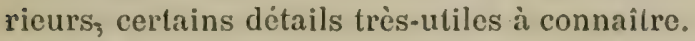

Quel que soit l'hyménoptère femelle considéré, les organes en question sont composés de pièces en nombre égal et de même nom, bien que leur forme puisse varier considérablement.

Chez la plus grande partie des hyménoptères, ces organes extéricurs ont pour but de déposer les œufs dans l'intéricur des plantes, ou sur les insectes destinés ì servir de patture aux jeunes larres qui en écloront. Dans ce cas, cet appareil porte le nom collectif de tarière ou oviscapte, et l'insecte qui en est pourvu, eșt un insecte térébrant.

Chez les autres, au contraire, les mêmes organes avec des pièces à peu près identiques, ont pour mission, soit de porter dans l'intérieur des insectes que la mère destine comme victimes à sa progéniture, un poison (jui les rend inertes sans les tuer, soit de leur servir d'arme défensive, quand un ennemi vient les inquiéter. Ils portent alor's le nom d'aiguillon, et les insectes sont dits: porte-aiguillons.

Tarière ou aiguillon, les pièces qui les constituent sont renfermées entièrement, comme je l'ai dit, dans les trois derniers serments abdominaux. Il faut seulement observer que, dans des cas très-nombreux, le dernier arceau ventral, ou hypopygium, est prolongó au loin, en dehors du corps, souvent d'une façon démesurée, tandis que d'autres fois, on ne voil absolument rien à l'extéricur, quand ces organes sont au repos. Dans le premier cas, la tarière est dite saillante, dans le second elle est pachée. L'aiguillon n'est jamais saillant dlans le repos. Dans quelques cas très-rares la tarière est recourbée sur lo dos.

Ce prolongement soudé ou articulé de l'hypopygium, qui 
enferme toutes les autres pièces, se compose ainsi que je l'ai déjà dit, de deux valves sćparées, domi cylindriques, plus ou moins velues, diversement colorées, quelquefois beaucoup plus longues que le corps entier, d'autres fois entièrement couvertes par les précédents segments de l'abdomen. Ces deux valves, par leur réunion, forment un cylindre complet, que l'on nomme le fourreau. Son but est de proléger les autres organes. souvent trés-délicats; quand ceux-ci doivent entrer en action, les valves s'écartent, et les pièces intérieures, poussées par des muscles spéciaux, saillissent en dehors, et prennent différents mouvements, suivant l'opération qu'elles doivent accomplir, comme nous le verrons plus loin.

Si l'on entr'ouvre ces valves, on en voit sortir une sorte de tube allongé, aigu, portant en dessous une fente longitudinale, qui le parcourt d'un bout à l'autre, et qui lui donne l'aspect d'un canal à ouverture très-étroite. Ce tube, qui s'évase à sa base en forme d'entonnoir, porte le nom de gaîne ou de gorgeret. Ce n'est encore qu'une enveloppe, mais elle a aussi un rôle spécial, qui consiste à pratiquer, dans les plantes ou les animaux, l'ébauche des trous par lesquels doivent penétrer les instruments plụs délicats contenus dans l'intérieur. Cetle gaine est reliée, à sa partie la plus interne, avec la base de l'hypopygium, au moyen d'arcs cornés, sortes d'apophyses qui en sont les supports, et par l'intermédiaire desquelles, sous l'impulsion de certains muscles, elle peut saillir en dehors du fourreau pour remplir son office.

Dans l'intérieur de ce tube incomplet, se meuvent deux pièces très-déliées, en forme de pique ou de sabre, trés-souvent dentées à leur extrémité sur le bord inférieur, tandis qu'elles sont tranchanteș au bord supérieur. Ce sont les stylets. Leur base se prolonge aussi en forme d'ares, qui sont les supports des stylets, et leur donnent, à la volonté de l'insecte, des mouvements de va-etvient qui peuvent être très-rapides. Ces supports sont reliés avec la base de l'épipygium.

L'extrémité de celui-ci forme aussi deux sortes de valves plus ou moins nettement caractérisées qui enferment l'extrémité du rectum, tandis que l'ouverture de l'oviducte aboutit vers la base de la gaine.

A l'élat de repos, l'extrémité de l'aiguillon se trouve relevée 
près de l'anus, tandis que, dans les tarières, surtout celles qui sont saillantes, leur extrémité est souvent bien loin en dehors du corps.

L'ensemble de ces organes comprend done cinq pièces : deux valves de fourreau, une gaine et deux stylets, et elles se relrourent chez tous les hyménoptères femelles. Mais les modifications de ces partiessont si variceesetsi profondes, qu'il faut à l'obsorvateur li plus grande habileté de dissection pour pouvoir les distinguer dans beaucoup de cas. Je n'appellerai ici l'altention que sui' quelques formes principales.

Dins toute une famille ì larves phytophages, celle des Tenthrédines ou mouches à scie, la femelle pond souvent ses œufs, comme nous le verrons, sous l'écorce des rameaux tendres de diverses plantes et, pour chaque ouf, elle est obligée de faire une petite incision longitudinale dans cette écorce. Elle y arrive par le mouvement alternatif et rapide qu'elle donne à ses stylets. Ceux-ci, pour cet usagge spécial, ont une forme aplatie, plus ou moins courbée, ct le bord inférieur présente une véritable denture de scie, tandis que les cótés offrent des saillies successives qui lui donnent l'apparence et lui font remplir l'office d'une lime.

Chez les pupivores, immense aggglomération d'insectes, dont les larves vivent en parasites dans le corps d'autres larves, le stylet n'agit plus par son cólé ou sa tranche, mais par sa pointe. Il pratique une blessure que le tranchant de son arme élarorit en se retirant, et où pénètre l'œuf.

Chez les guépes, les abeilles et les autres porte-aiguillon, celuici est finement dentelé ì son extrémité. Il a seulement pour but de porter dans une plaie une liqueur acide, qui agit comme un venin et produit une tuméfaction souvent élendue chez l'homme, la paralysie ou la mort chez les petits animaux et les insectes. Ce venin est secrété par des landes spéciales et il s'emmatasine dans une poche membrancuse situce dans les dernier's segments abdominaux. Un vaisseau délié, part de cette poche el ra conduire le venin à l'origine de la gaine. Il s'écoule le long du canal de celle-ci jusque dans la blessure. Très-souvent, dans la précipitation qu'il met à les retirer après aroir piqué, lorsqu'il est ì son tour menacé, l'insecte abandonne ses stylets dans lia plaie, et c'est pour lui une grosse lésion qui entruine toujours sa mort. 
Une scule tribu, chez les hyménoptères, scmble privée de ces organes, tarière ou aiguillon, c'est celle des Formicides; mais par une dissection minutieuse, on arrive cependant à retrouver intérieurement des petiles pièces très-rudimentaires, mais qui n'en sont pas moins les analogues de celles que nous venons d'étudier. Elles n'ont plus aucune fonction, et représentent seulement un organe tout-à-fait atrophié. Chez ces mêmes insectes, on ne retrouve même plus le nombre connu des segments abdominaux. Il y a lieu de croire cependant que celte disparition d'un segment n'est qu'apparente et que des recherches approfondies amèneront la découverte de quelque vestige, qui permettra de faire rentrerrette exception dans la règle.

Chez les térébrants, les arceaux dorsaux de l'abdomen sont leplus souvent plus prolongés en arrière, de façon que la base de la tarière semble sortir du corps avant son extrémité. Plus rarement, elle prend naissance tout-ì-fait à la pointe de l'abdomen.

2.- Organes mâles.-Chezles mâles nous trouvons aussi des organes intérieurs et des organes extérieurs; les premiers sont des tubes en forme de fils dẻliès, chargés de secréler le liquide. fécondant, qui va se réunir dans un canal collecteur, ou canal déférent, aboulissant au pénis.

Les organes extérieurs comprennent différentes pièces ayant seulement pour but de maintenir la jonction des sexes pendant l'accouplement, et d'autres servant à l'accomplissement de cet acte même. Cette dernière fonction.est remplie par le pénis seul, renfermé et protégé par une enveloppe cornée. Les parties servant à relier les deux sexes se composent de pinces de formes très-diverses, variant même d'une espèce à l'autre dans un même genre. Chez le plus grand nombre, nous trouvons extérieurement deux grosses pièces recourbées en dedans, souvent velues au moins à l'extrémité, curieusement contournées et dentées d'une façon quelquefois singulière. Elles saisissent la femelle par les derniers segments abdominaux, et les sculptures particulières dont je viens de parler ont pour but, soil en s'encastrant dans d'autres anfractuosités qui garnissent ces segments, soit en les embrassant seulement d'une façon étroite, de les assujettir solidement. Entre ces pinces, s'en trouvent deux autres plus minces et plus déliées 
ayant vraisemblablement pour objet de pénétrer dans l'intéricur de l'extrémité de l'abdomen de la femelle et de le maxintenir ouvert afin d'y faciliter l'introduction du pénis. Pendant l'accouple. ment, celui-ci qui est membraneux sort de son enveloppe cornce, devient fortement saillant et va pénétrer jusque dans l'orifice de l'oviducte, où il dépose la liqueur qui doit féconder les oufs ì lcur passage. Nous appellerons les premières grosses pièces, pinces extéricures, les secondes pinces intérieures, sans entrer d'avantage dans le détail de ces organes qui varient, bien entendu, d'une manière considerable suivant la famille que l'on examinc. Leur étude approfondic, est, d'ailleurs, encore à faire, et les observations devront nécessairement se porter de plus en plus de ce cólé, car il est présumable que l'on y trouvera des caractères trés-sérieux pour distinguer les espèces des simples variétés.

Dans un grrand nombre de genres, ces organes mâles sont fixés d'une manière si intime a la femelle pendant l'accouplement, que, lorsque celui-ci est termine, les deux sexes ne peuvent plus se séparer. Ce n'est qu'au prix d'efforts réitérés, où leurs pattes poslérieures jouent un grand rôle, que les femelles parrienment, dans ce cas, à se débarrasser du mâle. Aussi les organes générateur's de celui-ci sont-ils souvent, par suite de ces efforts, violemment arrachés de son corps, et restent-ils fixés pendant un certain temps à l'abdomen de la fomelle. Cetle mulilation amène nécessairement la mort de ce mâle.

\section{VIII. - NEUTRES.}

Je dois dire maintenant quelques mots d'ure modification cxtrêmement curicuse de certaines femclles, celles des abcilles, des gुuêpes, des bourdons, des fourmis. Sous l'influence d'une nourriture, spéciale, le plus grand.mombre n'acquier' point la faculté de procréer lcur espèce. Elles restent des êtres incomplets sous ce rapport, mais chez lesquels des qualités d'autre nature viennent remplacer ce qui leur manque ainsi. Ce sont des travailleurs infatinables, pour lestuels l'instinct parait souvent s'applocher de bien près de l'intellience. I.es oreanes purprement dits de la génération s'atrophient chez olles ì peu pures 
complètement, et leur róle change en entier par ce seul fait. Aussi leur a-t-on donné le nom d'ouvrières.

Chez les fourmis, ces mêmes femelles peuvent encore, dans quelques espèces, acquérir des facultés particulières, différentes de celles altribuées aux ouvrières proprement dites. Leur office est de protéger le nid, et de pourvoir aussi, dans certains cas, à l'acquisition de véritables esclaves. On les a nommées à bien juste titre, les soldats, leur fonction étant, en effet, exclusivement celle de nos armées

Les ouvrières, de même que les soldats, diffèrent souvent beaucoup des femelles fécondes et des mâles de la même espèce. La taille diminue, quelquefois les ailes disparaissent, la forme elle-même change ainsi que la couleur, et il est essentiel de trouver dans un même nid tous ces individus différents pour pouvoir, d'une façon certaine, les rapporter à une seule et même espèce. Ces modifications si profondes sous l'influence seule d'un changement dans la nourriture de la larve, modifications qui rendent les neutres si parfaitement appropriés à l'accomplissement des devoirs qu'ils ont à remplir, ne sont pas une des moindres merveilles de l'étude que nous entreprenons. Nous traiterons d'ailleurs tout au long ces questions, lorsqu'il y aura lieu.

\section{§3.- FONCTIONS DE REPRODUCTION.}

1. - Accouplement. - Chez les IIyménoplères, comme chez la plupart des insectes, la jonction des deux sexes est le plus souvent nécessaire pour assurer la fécondation des oufs qui seront pondus par la femelle. Cet acle si important a toujours été très-difficile à observer, car, la plupart du temps, c'est au sein des airs, à une grande hauteur qu'il se produit. Dans certaines espèces, il ne peut même s'effectuer que pendant le rol, et l'on a observé que des reines d'abeilles enfermées dans une ruche restaient toujours vierges, malgré le grand nombre de mikles qui les entouraient. Comme chez la plupart des ètres animés, le mâle est plus ardent que l'autre sexe et bien que, dans 
-des cas nombreux, cet acte doit lui coúter la vie, il met la plus grande activité ì poursuivre les femelles, auxquelles il dome parfois ì peine le temps de sortir de leur coque.

Quelques observateurs ont été assez heureux pour voir s'accomplir l'accouplement, et je ne puis mieux faire que de rapporter ici les remarques qu"ils nous ont laisscees à ce sujet.

Réaumur, qu'il faut toujours citer quand on arrive à ces observations si délicates, décrit l'accouplement des Torymus, très-potites espèces d'hymènoptères aux brillantes couleurs, parasites des larves d'autres insectes. On peut résumer ainsi son observation :

Le mâle se place d'abord sur le milieu du corps de la femelle, de manière que les deux têtes sont tournées du même cóté; mais il y a èncore loin de celle du mâle à celle de la femelle, parce que celle-ci surpasse beaucoup l'autre en grandeur. Dès que le mâle s'est posé, il marche en avant, jusqu'it ce que sa tête excède un peu celle de sa compagne. Alors il incline tellement sa tête du côté de la sienne qu'il semble lui donner un baiser. Cette caresse, qui ne dure cqu'un instant, une fois faite, il va promptement à reculons jusqu'ì ce que son derrière se trouve par delà celui de la femelle. Il le recourbe et le fait passer sous l'extrémilé du ventre de celle-ci; lit il le tient fixé un moment, puis il commence son manène. Réaumur l'a vu renouvelerpar le meme juspu'it vingt fois; le mâle ne s'est retiré que pour céder forcément la place à un individu du mème sexe plus frais.

Lepelletier de St-Fargeau décril ainsi l'accouplement des Anthophora et des Xylocopa, hyménoptères mellifères :

"Dans le vol, les parties qui accompagnent celles qui caracté" risent le sexe et qui servent à saisir les parties de la femelle, " sont sorties du corps el très-visibles. Ainsi j'ai souvent vu, dans " la plus grande chaleur d'un beau jour, plusieurs mâles de di"verses especes d'Anthophora, parcourir plusicur's fois de suite " une ligne horizontale de plus d'une trentaine de pas en face * d'une muraille ou tertre de sable, où existaient un grand " nombre de nids de leur espece et oit de jeunes femclles sortatent " incessamment de ces nidls. Lorscque l'une de celles-ci ressent le a désir des approches du mâle, elle se pose sur ces endroits, "l'anus entrouvert et les ailes médiocrement écartécs. Alors te 
" mâle se précipite sur elle et la saisit. Le mâle et la femelle" réunis s'envolent ensemble et l'observaleur les perd souvent de " vue.

"Cependant la Xylocopa perce-bois, nous a laissé voir une" partie de ce qui se passe ensuite ...... J'ai vu plusieurs fois

" des couples de cette espèce posés sur le bord d'un toit ou sur "l'extrémité d'une gouttière, le mâle placé sur le dos de la "femelle, les deux anus étroitement unis, les pattes du mâle " serrant étroitement le corps de la femelle, les antérieures entre "les promière el seconde paires de celle-ci, les intermédiaires du " mâle entre la seconde et la troisième paires de la femelle; " et les postérieures du mâle étreignant, au-delà des posté"rieures de la femelle, l'articulation de l'abdomen au cor" selet. Dans cette position, les ailes de la femelle étaient dans " le repos, libres et un peu écartées: Elles entraient souvent, en " même temps que celles du mâle, dans un violent trémousse" ment, tandis que les deux corps restaient dans une immobilité absolue. Chaque trémoussement m'a toujours paru composé de " trois battements. L'accouplement, du moins après que le couple est posé, dure ordinairement un demi-quart d'heure au plus, et " je n'ai pas jugé nécessaire de compler le nombre des trémousse" ments d'ailes qui sont fréquents et très-nombreux. Vers la fin, le mâle paraît cesser d'étreindre sa femelle, ses trémoussements d'ailes s'affaiblissent visiblement, puis il se laisse aller tout-i"fait, et pend, renversé à l'anus de la femelle, qui seule agite " encore ses ailes. Bientôt elle le rejette violemment avec ses pattes de derrière. J'ai vu aussi ce dernier fait pour un mâle d'Anthophora pilipède dont la femelle s'élait rapprochée cle terre "après son accouplement. Les mâles, ainsi détachés de leurs "femelles, ne peuvent plus ni marcher ni se renvoler, ils se "roulent par un mouvement des ailes quelque temps sur la terre et périssent bientôt. En pressant leur abdomen, je me suis sou"vent assuré qu'ils avaient perdu entièrement leurs parties "génitales et celles qui leur servent à assujettir l'anus de la "femelle."

(II istorre naturelle des Hyménoptères, tome IJ, p. 19). 
Le même auteur raconte ainsi ce qu'il a pu observer pour: l'accouplement des Bembex, hyménoptères fouisseurs.

"...... Voit-il sortir la femelle de son trou, le mâle se

" précipite sur elle et fait ce qu'il peut pour la saisir dans ses

" embrassements. Heareux s'il y parvient, et si un ou plusicurs

"autres mîles, l'ayant aperçe en même temps, ne troublent

" pas ses brusques caresses. En effet, ces mîles sont tellement

" ardents que trois ou quatre se jeltent quelquefois en même

" temps sur la méme femelle et se roulent avec elle gir le sable.

"Alors il arrive quel(quefois qu'aucun d'ẹx ne parvient ì saisir

" la femelle, qui s'éloigne momentanémont. Si le mâle s'est fixé

*. sur la femelle (je n'ai pu en saisir les circonstances et n'ai vu

" que le fail), le couple s'envole hors de la portée des yeux etle

" reste de l'accouplement ainsi que ses suiles pour le mâle, restent

" nécessairement ignores. La lemelle, aubout d'un quart d'heure

* à peu près, ainsi que j’ai pu l'évaluer, revient à son trou et

" continue il le creuser. *

(II istoire naturelle des II!̣ménoptères, tome II, p. 531).

2. - Parthénogenèse. - J'ai dit, en parlant de l'accouplement, que la jonction des sexes est le plus souvent nécessaire pour la lécondation des weufs. En effet, cette condition que, justu'à ces derniers temps, on juereait indispensable, souffre des exceplions qui ont été révélées d'abord en Allemagne par le dlocteur Adler, puis expérimentées et rerifiés ensuito par divers entomologistes. Ce fait si curieux se produit parmi des hyménoptères. gallicoles el peul se résumer ainsi. Une femelle, fécondée par un mâle, pond des oufs et donne en même temps naissance à une galle, d'ou, apres le temps voulu, éclot un insecte tout différent desirmère, et rapporté jusque là, non-seulement ì une espèce, mais mêmo ì un genre distinct. Cet insecte ne présente absolument que des individus du sexe féminin, et il n'en existe réllement pas de mâles. Aussi pond-il à son tour, sans nouvelle fécontation, des oufs, yui se trourent bientit enfermes dans une nouvelle galle différente de la première. Il en sort plus lard un hymenoptere semblat)le a la première femelle considérée, et par conséquent d'aspect tout autre que celui de sa véritable mère. Cette rénération présente les deux sexes qui s'accou- 
plent, et la môme séric de faits se reproduit. C'est donc, pour ces insectes bisexućs, une apparition périodique de deux en deux générations, donnant, comme individus interméctiaires, des êtres constamment du sexe femelle et ne nécessitant pas le concours d'un mâle pour la fécondation de leurs produits.

D'autres ordres d'insectes, des hémiptères homoptères, quelques diplères, avaient déjà donné lieu à de semblables observations. Mais on no les avait pas encore failes pour les hymonop. tères, el elles viennent bouleverser de fond en comble la classification adoptée jusqu'ici pour beaucoup d'espèces.

On a même signalé aussi un fait semblable dans d'autres familles d'hyménoptères (Odynerus, Tenthrédines), mais c'est moins bien prouvé.

Rien n'est plus curieux que ce phénomène, dont la raison d'être nous échappe encore. Il vient ajouter une merveille et un problème de plus dans l'ćlude déja si complexe ct si intéressante de nos hyménoptères.

3. - Ponte. - Ce n'est que sur d'assez rares documents que nous pouvons étudier les circonstances diverses de la ponte, cet acte final des appareils générateurs.

Le nombre des œuls que pondent les femelles d'hyménoptères est nćccssairement très-variable, puisque, dans certains cas, comme pour les abeilles, une seule femelle est chargée du soin de peuple: une ruche et même d'y apporter un excédant de population constituant les essaims, tandis que d'autres fois, (Cerceriș), la femelle est obligée, pour chaque ouf qu'elle pond, de creuser, à grand travail, un nid en terre. Ce nombre varie depuis 5 à 6 jusqu'i plusieurs milliers.

Voici quelques observations d'auteurs illustres qui vont nous montrer les diverses manœuvres des femelles.

- J'ai eu, dit Degeer (mem. insect., tome II, p. 879), occaşion a de voir un Ichneumon doré à longue tarière (Degeer appelle * ainsi un petit parasite de la famille des Chalcidites) dans * l'action d'introduire cette tarière dans une galle de chêne. "L'Ichneumon commençait d'abord ì baisser la véritable tarière " et à la faire sortir d'entre les deux demi-fourreaux. Il la plaçait " ensuite dans une siluation perpendiculaire au corps et a la s'rr- 
" face de la galle, de sorle (qu'elle touchail avec sa pointe à cette " surface. Pour pouvoir se mettre dans une telle position, il fut * obligré de se hausser sur ses palles le plus qu'il citail possible. "Après cela, je vis que la tarière s'enfonçait peu à peu clans la " galle, et qu'i la fin, elle s'y trouvait introduite dans toute sa " longueur, de sorte que le ventre de l'ichneumon venait à tou" cher la surface de la galle. Alors l'insecte fit dlu mouvement " avec sa tarière de haut en bas; il la retirail un peu et d'abord “ après il l'enfonçail de nouveau : c'était comme s'il voulait litter " quelque chose dans l'intérieur de la galle, avec la pointe de sa " tarière. Sans doute qu'il y cherchait la loge du ver, ou bien le " ver même, pour y pondre ses oeufs auprès de lui; ensuite il re" tira sa tarière hors dela galle, en se haussant considérablement " sur ses deux pieds. Un moment après, il la pique de nouveau * dans un autre endroit de la galle, ct après l'avoir retirée encore, * il l'enfonce dans la galle pour la troisième fois, toujours de la * même manière. Après celle dernière opération, il s'envola. - Pendant l'action même, il n'élait point du tout farouche; il pa« raissait fort altaché à sa besogne et se laissait approcher avec "une loupe. "

Réaumur nous fait connaitre encore les circonstances de la ponte d'un autre hyménoptère dont la larve vit des feuilles du rosier. La mère, munie d'une larière en forme de scie, dont j'ai parlé plus haut, se place sur la partic la plus mince d'un rameau d'églantier, plante l'extrémité de sa tarière dans l'écorce, puis fait jouer les deux stylets qui forment scie, jnsqu'a ce qu'une courte entaille ail élé fitite dans l'écorce. Elle y dépose alor's un oeuf (fu'elle arrose avec une liqueur mousseuse, puis recommence à côté. Elle en place ainsi 5 à 6 à la suile l'un de l'autre. Ce (fu'il y a de très-curieux, c'est que le lendemain de cette opération la partic de la branche qui contient les oufs est derenue noire, et que, chaque ouf ayant acquis un volume bien plus gros que celui qu'il avait au moment de la ponte, l'écorce se trouve soulevée a la place de chacun d'eux et présente ainsi une série de petites convexités avec une fente sur l'un des cótés, laissant apercevoir l'ouf qui y est contenu.

IIuber, enfin, rapporte l'expérience suirante it propos d'une abeille : 
a..... Cette mère, presséc de pondre, ne put retenir ses " oufs plus longtemps; nous lui vîmes faire un dernier effort et * allonger son abdomen. La partie inférieure de l'anus s'écartait " assez de la supérieure pour laisser une ouverture qui mit à " découvert une partie de la capacité interne du ventre. Nous "vîmes l'aiguillon dans son étui dans la partie supérieure de " cette cavitć. La mère fit alors de nouveaux efforts, et nous " vîmes un œuf sortir du bout du canal de l'ovaire, et s'élancer " dans la cavité dont nous avons parlé; puis les lèvres se refer" mèrent, et ce ne fut qu'après quelques instants qu'elles se " rouvrirent bien moins que la première fois, et suffisamment " pour laisser sortir l'œuf que nous avions vu tomber dans cette * cavité. \#

\section{§IV. - MÉTAMORPHOSES}

La période pendant laquelle les hyménoptères sont aptes à la reproduction est la plus courte pour eux, et depuis longtemps déjà ils sont nés quand ils peuvent enfin s'élancer dans les airs.

Nous avons vu la femelle, recherchće par les mâles de son espèce, s'uccoupler, puis pondre des œufs que son admirable instinct lui apprend à placer dans les conditions les plus favorables. Ces oufs vont donner naissance à des larves, qui se transformeront plus tard en nymphes, et celles-ci produiront enfin, par une dernière métamorphose, l'insecte parfait; qui à son tour, mettra au jour une nouvelle génération.

Nos insectes passent done par quatre états différents: œuf, larve, nymphe el état parfait. Quelques entomologistes admettent une cinquième phase, se plaçant entre la larve et la nymphe, et lui donnent le nom de seconde larve ou larve contractée. Celle: ci ne diffère le plus souvent de la larve proprement dite que par son état de repos et sa privation complète de nourriture. Dans quelques cas assez rares, sa forme diffëre plus notablement de celle de la larve. Je ne m'en occuperai d'ailleurs pas davantage, me proposant seulement de signaler ce que celte forme transitoire présentera d'intéressant, lorsqu'il y aura lieu. 
1. - Eufs. - Les oufs des hyménoptères sont bien peu connus et ce que l'on sait d'eux, n'offre (qu'un médiocre intérêt. Pour la plupart, ils sont blancs, ovoïdes, plus ou moins allongés ou courbés; d'autres fois, ils présentent, au contraire, des colorations diverses, jaune, verte, etc. On en a signalé qui se trouvaient munis d'une sorte de pédicule serrant it les fixer sur le corps des chenilles destinées à servir de pâture aux jeunes larves qui vont ćclore. L'apparition des larves a lieu, presque toujours, très-peu de temps après la ponte des ocifs. Il est présumable que la température a une certaine influence sur la précocité ou le retard des éclosions. Les larves phytophages resteraient cependant en général un peu plus longtemps dans l'œuґ que les larves carnassières ou mellivores, sans que ce délai dépassât toutelois quinze à vingt jours. Ce n'est qu'arec le plus grand doute que quelques auteurs parlent d'œufs qui passeraient l'hiver.

La structure intime des œufs est, ì peu près, toujours la même, au moins pour ceux qui ont pu être observés. C'est une cnveloppe plus ou moins parcheminée et résistanle, enfermant un liquide où l'embryon acquier un déreloppement très-rapide. Plus la nourriture destinćc à la larve est exposće ì se détériorer rapidement, comme les chenilles anesthésiées par lo venin de la mère, ou les provisions miclleuses accumulées par celle-ci, plus la pelite lurve arrive à sortir vite de son enveloppe. Les œufs sont généralement enduits, en passant dans l'oviducte de la mère, d'une substance visqueuse et agglutinante, qui sert a coller l'ouf et à le maintenir à l'endroit courenable pour que la jeune larve trouve, dès en naissant, à portée de ses mandibules, une nourriture appropriée.

Disons enfin que quelques aufs i'Tenthrédines, Cynipides, Formicides', ont la singuliere propricie d'augmenter sensiblement de rolume apuess lat ponte. Ce phénoméne manupe encore d'exptication suffisante.

3. - Larves. - Les larves dies liymenoptires presentent des formes assez variées et, bien qu'on n'en ail encore qu'une connaissance tress-incomplete, il est cependant dejat possible d'en donner une description générale suflisante.

On peut d'albord les partager en deux grandes classes présenTоме s 
tant un aspect tout-i-fait distinct. Dans la première se rangent les larves de toute une grande famillequi, pourvues de patles cornées el membraneuses comme les chenilles des lépidoptères, ornées aussi de couleurs varićes, ont arce elles des ressemblances cxtérieures frappantes. Aussi les a-t-on désignées sous le nom de fausses chenilles. Elles sont herbivores ou phytophages, et, vivant souvent par troupes nombreuses, elles causent a nos plantations des dommages sérieux. Il est toujours facile de les distinguer des vraies chenilles ou larves de papilions, parce que celles-ci n'ont jamais moins de huit pattes, ni plus de seize, y compris les écailleuses, tandis que les fausses chenilles ont toujours, soit moins de huit, soit plus de seize pattes.

Les six pattes antérieures fixées de part et d'autre de chaque côté des trois premiers anneaux qui suivent la tête, sont articulées, de consistance cornce et pourvues de crochcts. Elles représentent les pattes que conservera l'insecte à l'ćtat parfait. On leur a donné le nom de pattes écailleuses.

Toutes les autres, dites pattes membraneuses, ne sont que des sortes de mamelons charnus, coniques, dépourvus de crochets, et qui n'ont vraisemblablement d'autre fonction que celle de soulenir la larve, sans aroir une action bien directe sur la progression. Ces appendices sont fixćs inférieurement de chaque côté des segments abdominaux, qui peuvent en être to sus munis, sauf le premier. Celles qui sont situćes sur le dernier on tordinairement une conformation et une direction différentes des autres; on leur a donné le nom spécial de pattes anales. Certaines espèces ne présentent absolument que les six pattes écailleuses.

La scconde classe, que l'on peut distinguer parmi les larves des hyménoplères, comprend toutes celles qui n'ont pas de vraies pattes, et qui sont dans l'impossibilité de pourvoir elles-mêmes à leur nourriture et cle se transporter d'un lieu à un autre. La mère les place à l'endroit même où elles trouveront, le plus souvent en même temps, un abri et une provision suffisanto pour leur alimentation. Cos larves, qui forment la très-grande majorité de celles des insectes que nous ćtudions, sont presque incrles et, comme elles ne sont jamais exposécs it subir les intempériestel'air ou le contact des objets extericurs, Icur ćpilerme semble bien plus délicat (que celui des fausses chenilles. Leur couleur est presque toujours 
blanche, cependant on roit aussi de fréquents exemples oì elle est jaune, rouge, eic. Tandis que les fausses chenilles sont toujousmuniesdemandibulesiris-visibles etrelativement puissantes, celles-ci n'en présen lent do semblables que dans quolques familles, les autres offrant des appareils buccaux on général difficiles it apercevoir et it clisséquer. Les larves de la première elasse ont aussi des yeux assez gros et simples placés sur les cólés de la téte, celles de la seconde elasse, au contraire, paraissent en ôtre privées complètement.

T'outes doivent posséder des antennes plus ou moins rudimentaires, en tous cas, plus oit moins membrancuses. Il fiut avouer cependant que, dans des cas nombreux, on n'en roit aucune trace, soil (qu'elles soient rétractiles et susceptibles de se cacher dans l'intérieur de la tète, soit que réellement elles n'existent pas.

Un très-grand nombre de larves ont les téguments de la tête durs et cornés, autrement colorés que le reste du corps. Souvent aussi ces parties plus solides ne se trouvent quesur quelques portions de la tête et du premier segment qui la suit, formant ainsi de bons caractères pour les distinguer les unes des autres. Cetle dernière disposition nese voit, d'ailleurs, que chez les larves apodes, les autres ressemblant tout-it-fatit, sous ce rapport, at de véritables cheniltes. Quelquefois les mandibules scules sont dures et colorées, et forment ainsi doux taches souvont imperceptibles au devant de la tête. Ajoutons enfin. qu'un grand nombre de larves portent-à la lère, siluće comme chez les insectes parfaits, mais fort difficile à distinguer, un appareil spécial (pui se présente sous forme d'un tube contractile percé ì son extrémité d'une ouverture en bee de flute il lacquelle vient aboutir le canal déférent d'une glande qui estlaglande séricifique. Cel organe est la filiere au moyen de laquelle ces larves construisent leurs copues ou tapissent de soie l'intérieur de leur logement.

Parmi les larves apodes enfin, un certain nombre offre it l'obscrvateur une série de mamelons, quelquefois ombiliqués, situés généralement sur la portion dorsale du corps. Ces mamelons complètement charnus servent à faciliter les mouvements très-restreints qu'ont à exceuler ces larves, soil dans les cellules qu'elles occupent dans les galles, soit dans les interstices divers qu'elles habitent. On leur a domé le nom spécial de preudoprodes. 
Le nombre des segments composant le corps des larves d'hyménoptères semble être uniformément de douze, non compris la têle. Ces segments sont très-souvent presque impossibles à distinguer à cause des plis et des rides sans nombre qui les garnissent. D'autres fois, ils sont bien visibles, un étranglement très-sensible venant les séparer les uns des autres. Ce nombre de segments correspond ì celui que nous avons trouvé dans les insectes parfaits (trois pour le thorax et neuf pour l'abdomen y compris le segment médiairc).

Les larves sont pourvues de stigmates, comme les insectes parfaits. Ces ouvertures sont souvent fort-difficiles à apercevoir. Toules les fois que j'ai pu les constater, je les ai trouvés au nombre de huit paires placées sur les cótés des segments. Ce sont toujours les mêmes anneaux qui me les ont offerts, savoir le second (sans parler de la tête), ou segment mésothoracique, le cinquième, ou deuxième seğment abdominal et lous les suivants, sauf les deux derniers. Ces ouvertures stigmatiques se présentent, le plus souvent, avec une forme arrondie assez régulière, excepté celle du segment mésolhoracique qui, dins quelques cas assez rares, m'a semblé présenter une grandeur plus considérable et une forme plus allongéc. Chez les fausses chenilles fortement colorées, les stigmates forment souvent des taches rondes ou oblongues de couleur fort différente, ce qui les rend très-visibles.

Un certain nombre de larves apodes pourvues ou non de mamelons dorsaux, que j'ai appelé pseudopodes, possèdent, en outre, de chaque côté des segments abdominaux et alt-dessous des stigmates, une ligne saillante formant un bourrelet membraneux qui s'étend jusqu'à l'extrémité du corps. Ce doit être encore un appareil spécial pour un déplacement très-limité.

Les segments thoraci(ques, c'est-à-dire les trois premiers qui suivent la tête, sont en général plus gros et plus renflés que les suivants; dans quelques espèces, le premier de ces segments présente latéralement une tache ordinairement rouge, forméc de petits points colorés très-nombreux et très-rapprochés. Le dernier segment, ou sezment anal, a sourent une forme spéciale. Dans les fausses chenilles, il porte généralement deux fausses pattes membraneuses. Dans les larves apodes, il devient quelquefois arrondi en forme de calotte aree des sillons irradiés aboutissant tous à 
un point central qui est l'anus; d'autres fois, il est tout-i-fait cylindrique, strićet ombiliqué a son extrémité postérieure qui est aplatie; souvent, enfin, il est simplement conicque et continue la forme de l'abdomen. Enfin, certaines latres paraissent mancuer complètement d'orifice anal, ce qui revient à dire qu'elles assimilent la totalité de leurs aliments.

Fos larves sont quelquefois mblabes et tris-luisantes, d'autres fois plus ternes ou garnies de poils plus ou moins longs et diversement colorés, même chez quelques larves apodes et blanches. D'autres (parmi les fausses chenilles) ont ì la surface du corps de véritables épines soit simples, soit bifides ou même trifides.

Je laisse de côté les détails relatifs aux parties intimes de la bouche, machoires, livres, palpes, détails qui nous entrainelaient trop loin et que je pourrai aborder plus tard pour quelques espèces, s'il y a licu. Je ne parlerai pas davantage des organes intéricurs, qui ne peuvent nous intéresser, me contentant seulcment d'indiquer qu'ils sont en général différents de ceux des insectes parfaits qui derront en ćclore. Par exemple, les vaisseaux biliaires sont, presque toujours, bien moins nombreux dans la larve que dans l'insecte parfait.

A peine sortic de l'oeuf, la larve se met à dévorer la pâture mise i sa portée par la mère, et rapidement sa taille augmente, ses formes se dessinent, ses couleurs s'accusent, et changont même assez souvent, à mesure qu'elle avance en âge. Comme loutes les larves, colles des hyménoptères sont sujettes aux mues, c'est-idire quielles se dépouillent ì diverses reprises de leur peau, devenue un vêtement trop étroit et incommode. Ces mues, au nombre de trois ou quatre, sonttoujours un moment critique au(quel elles se préparent par l'abstinence, se réservant d'ailleurs de redoubler de roracité Iorsufuc cet événement important pour elles est terminé. Cependant, il y a, paraîl-il, des exceptions, en ce sens que plusiculs larves d'hyménopteres ne subissent aucune mue. On a simnalé celles des abeilles, des menes, des fourmis, etr.

Souvent des ouls pondus ì l'automne donnent immédiatement de tris-jemes fausses-ehenilles que vient surpendre l'hirer. Nlor's elles se cachent, et trouvert partout des abris contre les intempéries. Revienne le printemps, et les rayons vivifiants du soleil leur rendent toute leur activité. On les voit alors monter. à l'assaut de nos arbustes et dévorer les bourgeons. 
Les larves, enfermées dès leur naissance avec leur pâture, ont bien vite fait de la consommer et d'atteindre leur taille définitive. Elles restent alors ensuite de longs mois sans mouvements et sans nourriture, pour ne se transformer en nymphes que lorsque l'heure fixce a sonné pour elles. D'autres, au contraire, comme celles des abeilles, voient se succéder très-rapidement toules leurs métamorphoses, et trois semaines suffisent pour obtenir d'un œuf un insecte parfait.

Il y a des espèces qui ont seulement une double génération chaque année. L'une d'elles, qui a lieu pendant le printemps et l'été, passe très-vite par' ses diverses phases, tandis que l'autre, qui a à traverser l'hiver, nécessite des délais beaucoup plus prolongés.

Quand la larve est arrivée à son entière croissance el que le moment de la transformation approche, elle songe, dans beaucoup de cas, à se construire un abri ou une coque, ce qui d'ailleurs est loin d'être général. Les unes entrent en terre, d'autres sortent du corps de leurs victimes, la plupart restent dans la loge préparée par la mère et où elles ont vécu.

Ces coques sont de nature, de forme et de couleur extrêmement variées, et il ne me serait pas possible d'indiquer même sommairerement toutes les modifications que l'on peut y constater.

Quelques unes sont doubles el composćes extérieurement d'un réseau à larges mailles, résistant, élastique, enfermant et protégeant une autre enveloppe appliquée plus exaclement sur la nymphe, et qui est faite d'une pellicule mince et flexible.

D'autres ont une apparence parcheminée, colorées diversement en jaune ou en brun, ou simplement incolores et transparentes. Elles sont rondes ou ont des côtés anguleux, les extrémités sont aussi arrondies ou bien l'une d'elles estaplatie et forme comme un couvercle; d'autres fois cetle face aplatio porte en son centre une pointe relevée ef tortillce. Dans d'autres cas, une extrémité est ronde et l'autra plus ou moins pointue.

Quelques coques ont, au contraire, une apparence cotonneuse ; elles sont alors génćralement blanches bien que d'autres couleurs se rencontrent aussi.

Un grand nombre sont lisses et glabres; d'autres, au contraire, sont garnies de poils raides. 
Quant la larve ćlablit sa corfue, elle emploie, Jien entendiu, ses filières; mais il en est quelques-unes qui, pour donner de la so. lidité à leur petite construction, y incrustent divers fragments, comme, par exemple, les débris cornés des insectes dont elles ont vécu.

La larve reste quelquefois un long espace de temps dans sa coque, sans subir de métamorphose. Elle prend une apparence plus incrte, sa taille se raccourcit et se gonfle en même temps, et clle passe ainsi souvent bien longtemps dans l'immobilité. C'est cel élat que l'on a désigué sous le nom spécial de larve conIractée.

Beaucoup d'autres ne se construisent pas de coque et se mélamorphosent à nu. Mais elles sont alor's renfermées dans un nid de terre, dans une galerie profonde, ou dans l'intérieur d'une galle ou du corps d'une viclime, de sorte (qu'elles se trouvent touti-fait à l'abri des intempéries et des accidents. Quelques-unes ont seulement la précaution de grarnir auparavant leur réduit d'une mince couche de soie qui doit leur fournir un coucher plus moelleux.

Quelle que soit l'industrie d'une larve sous ce rapport, dès qu'elle est installéc dans son réduit, il se fait en elle un travail intéricur dont les anatomistes n'ont encore suivi les périodes que bien incomplètement. Non-seulement l'aspect extérieur va se modificr, mais les or rines internes eux-memes subissent de profonds changements. La peau de la larve se fend et, repoussće peu à peu par des mourements imperceptibles, elle va se pelotonner au fond de la coque ou de la loge, en compagnie d'exeréments dont un certain nombre de larves se dobarrassent avant de subir colle crise importante.

La nymphe apparail alors avec toutes les apparences extérieures de l'insecte parfait.

3.- Nymphes. - Ia nymphe pri-enie, en elfu!, soiten enticr, soit ì l'état rudimentaire, tous les organes dóvolus i l'insecte parfait. Les antenmes et les pattes sont entièrement développées et collées le long du corps. Les yeux, les ocelles, Ies pièces de la bouche sont apparentes ainsi que les organes externes de la génération. Parmi ceux-ci, les tarières allongées sont surtout visibles, 
et elles sont toujours couchées sur le dos de l'abdomen, alteignant celui du thorax, le derrière de la tête, et se poursuivant même plus loin suivant leur dimension relative. Les ailes sont à l'ćtat rudimentaire ou plus exactement on n'en aperçoit qu'une sorte de court fourreau dans l'intérieur duquel elles sont pliées et. chiffonnées. Ces fourreaux sont placés de chaque côté du thorax et couvrent plutôt sa partie inférieure que le dos. Tous ces organes ne sont pas libres et semblent soudés au corps. Il n'en est rien cependant, et si on soumet la nymphe à.un examen plus minutieux, on s'aperçoit bien vite que tous ces appendices, ainsi que le corps entier, sont couverts par une membrane continue qui en épouse à peu près toutes les formes et toutes les saillies, en les rendant cependant plus obluseś. Cette membranemaintiont en place des organes encore trop débiles, en même temps qu'elle les protège. Elle est toujours très-mince et transparente, nos nymphes ne se montrant jamais à l'extérieur, et l'on n'en voit pas qui soient pourvues d'une carapace dure et cornce comme les chrysalides de papillons.

C'est sous l'abri de cette enveloppe que mûrissent, pour ainsi dire, les différentes parties de l'insecte. Si l'on examine une nymphe quelconque peu après sa transformation, on lui voit une coloration uniformément blanche ou jaunâtre qu'elle conserve quelques jours; les yeux seuls ont une teinte beaucoup plus foncée. Si on continue à l'observer avec assiduité, on voit les yeux devenir plus sombres, en mème temps que la tôte et le thorax se colorent peu à peu des nuances qu'ils doivent avoir définitive. ment. Cette couleur apparaît d'abord avec le plus d'intensité sur les parties du thorax qui seront saillantes, comme si les portions enfoncées se trouvaient voilées par l'épaisseur des membranes interposées. Ces taches foncćes, d'abord séparées, se réunissent peu à peu et la nymphe présente bientôt la coloration même qui est propre à l'insecte parfait. L'abdomen se colore le dernier, ainsi que la poitrine, les pattes et les antennes. Les ailes, toujours enfermées flans leur fourreau, forment, quand la nymphe a acquis toute sa couleur, comme deux taches allongées translucides.

Lorsqu'elle est arrivée à cet état de perfection, la nymphe est bien près de rejeter ses langes, et, en effet, on voit bientôt une fente se produire à la partic supéricure du thorax dans la mem- 
brane protectrice. Le thorax, puis la tête se dógagent; les antennes sortent de leur fourreau avec les pattes antéricures; suivent les deux autres paires de pattes et enfin l'abdomen.

L'insecte est né, mais il est encore bien faible et il reste quelques houres, parfois plusieurs jours dans sa prison, pour permeltre it ses membres de s'affermir, à ses articulations d'apperendre à jouer convenablement. Les ailes sont ce qu'il y a de plus imparfait, on en aperçoit it peine des traces; elles sont chiffonnées et semblent mancuer de fermeté. P'eu à peu, cependant, sous l'influence (suivant quel(ques anatomistes) de l'air qui s'engate dans les nervures, el qui est doué d'une certaine pression par suite des contractions thoraciques de l'insecte, l'aile se dciploie, ses cellules se dessinent, elle se sèche, prend de la consistance el de la raideur.

A ce moment le nouveau né est prêt à prendre son essor. Mais il est enfermé et il lui faut encore tout un travail pour paraitre à l'air libre. Ici les procédés varient encore beaucoup suivant les espices. P'armi celles qui sont encloses dans une coque, les unes déchirent simplement et sans aucuns soins une des extrémités de celle-ci; les autres, au contraire, découpent avec leurs mandibules une calotte parfaitement régulière, qu'elles rejeltent de côté, et (yui tourne, comme autour d'une charnière, sur' une petite portion non entamce de son contour.

Si la coque était souterraine, placće dans un nid, une coquille, un frarment de bois sec, l'insecte sait se diriger immédiatement et par le chemin le plus court vers la liberté, en se creusant une route avec ses mandibules. Ainsi agissent ceux qui ont récu sans coque, dans les galles, les tipes sèches, etc. De petits trous ronds indiquent l'orifice de sorlie de la bestiole; et si nous couvrons nos flacons d'éducation avec un papier trop faible, nous nous apercevrons bien souvent d'une évasion, it la vue de ces petites ouvertures.

Va maintenant, frèle insecte, élance-toi dans les airs et viens, par les merveilles de ton admirable instinct, par les couleurs brillantes dont tu es paré, par tes formes si gracieuses el si cilancées, par l'étomnante perfection du dernier de tes or zanes, viens exalter les loutunges de ton Créateur. T'u es la preuve vivante de sa toute-puissance el c'est se rapprocher de lui que de l'admirel en apprenant à te connaître. 


\section{§. - PIIYSIOLOGIE ET BIOLOGIE GÉNÉRALES}

1. - Nourriture. - Si nous considérons les hyménoptères à l'état parfait, la question de leur nourriture est, la plupart du temps, peu importante; beaucoup d'entre eux, en effet, éclosent et meurent sans en prendre. Leur rôle principal repose dans la reproduction de l'espèce, et, ce résultat étant alteint, lcur conservation personnelle est entrée pour bien peu de chose dans le plan de la nature. Nous avons vu que beaucoup de mâles mouraient immédiatement après l'accouplement; les femelles, ayant en outre à s'occuper postérieurement de travaux plus ou moins compliqués et pénibles, une nourritnre un peu abondante leur est plus nécessaire.

La durée de lëur vie, à l'état de liberté, est très-variable et s'appuie surtout sur l'importance de ce qu'elles ont à accomplir arant de disparaitre. Les femelles qui n'ont pas besoin de se livrer à des constructions difficiles pour y abriter leur progéniture, celles qui vivent en parasites, etc., ont bientót fait de remplir le vou de la nature, et par suite leur existence est beaucoup flus limitée. Celles qui doivent creuser la terre ou le bois, gâcher le mortier ou se livrer, enfin, à des occupations assez compliquées, voient leurs jours se prolonger suffisamment pour que tout cela ait le temps de s'accomplir sans cependant que leur Axistence aille plus loin que le commencement de l'hiver venant succéder à l'été qui les a vu naitre. L'espèce, dans ces deux cas, n'existe pendant la mauvaise saison ' [u'ii l'état de larve, et si, par un hiver exceptionnellement doux, on peut rencontrer quelques individus plus ou moins engourdis, cachés sous divers abris, on ne doit les considérer que comme des exceptions. Il est cependant des cas assez rares, où, pour certaines espèces, celte exception devient la règle. On peut, en effet, les trouver à l'état parfait en plein hiver, soit sous les mousses épaisses ou les écorces, soit au fond des tubes creusés dans la moelle des tiges sèches.

D'autres, au contraire, dont les conditions de vie sont différentes, prarticulièrement les espices sociales, voient se perpétuer l'existence de leurs femelles en toute saison. L'hiver les engourdit, 
mais elles conservent cependant le germe fécondaleur (fu'ulles ont reçu d'un mâle à l'automne, et au printemps, leur ponte et leurs travaux commencent. ("est le cas des gucpes, des bourdons, etc. Dans les sociétés plus periecionnées, abeilles, fommis, le mêne engourdissement a lieu, à moins que l'hiver ne soit trèsclément, mais il se produit en même temps pour les femelles fécondes et pour les ouvrières. Dans ces deux dernier's cas, la durée de la vie de ces insectes est bien plus prolongée et peut s'évaluer d'un an et demi à deux ans.

Pendant ees périodes courles ou longues, il est indispensable (que ces mires si affairées prennent (quelyue nourriture. ()n peut dire que toutes se nourrissent des liqueurs sucrées qu'clles happent avec leur languetle dans le fond de la corolle des fleurs. Il en est cependant qui s'attaquent en outre aux matières animales; l'on connaîl, en effet, les déprédations que les guêpes font souvent dans les riandes frâthes lássées à leur disposition, surlout celles qui peuvent leur fournir quelques particules sucrées, comme le foie par exemple; personne n'irnore aussi les combats qu'elles livrent à nos mouches domestiques pour les mettre à mort. Ce n'est lit certainement (qu'une nourriture loute exeeptionnelle, ou plutôt même il ne faut généralement y voir que des provisions destinces aux jeunes larves. Qui ne sait aussi arec quelle habileté et quelle rapidité les fourmis dissèquent les petits animatux et en font des squelettes aussi bien préparés yüils pouratent l'ste par la main d'un habile anatomiste? Cesinsectes sont peut-être les seuls qüi soient à peu près omnivores, et il faut toujours considérer le suc des fleurs, des fruits, le miel ou le sucre comme la base de la nourriture de la genciralite des hymenopteres. Si l'on en voit en errand nombre qui s'attayuent i divers insectes, les transportent dius leur nid, ou pongent les fenilles de diverses plantes, recueillent le pollen des fleurs ou détachent les fibres iles bois morts, il ne faut pas considcrer tout celat comme des faits se raltachant à l'alimentation de l'insecte lui-même, mais y reconnatre seulement la récolte des matliriatux nécessatires soit à la nourriture des larves qui vont ćclore, soit à la construction des nirls (fue la nature lui a enseigne a donner pour abri a si progéniture.

A l'élat de la larve, au contraire, les hyménoptères ont uno 
nourriture beaucoup plus variće. Un certain nombre est franchement herbivore et dépouille de leurs feuilles nos arbres ou nos plantes utiles, nous causant ainsi des dommages souvent trèsgraves. La plupart vit de proie vivante, active ou paralyssée, soit à l'intérieur du corps même de ses victimes, soit à l'extćrieur; ce qui n'est pas là le moins curieux, c'est que ces larves carnassières, qui ont ì s'attaquer a des êtres infiniment plus grands et plus forts qu'elles, sont les plus inertes, et les moins capables, non-seulement de trouver seules leur nourriture, mais même de se défendre un seul instant en cas de résistance de leurs victimes. C'est à l'industrie de la mère ru'est dévolue la charge de pourvoir les petites larves, et cela de façon que celles-ci, nonseulement ne courent aucun risque, mais n'aient même pas à craindre en aucun cas l'évasion de leur proie, qu'il leur serait impossible de poursuivre.

Enfin, d'autres larves vivent exclusivement du miel qui a été préparé et rassemblé par la mère, et que celle-ci a mis à leur portée en quantité suffisante. Ces larves seraient, sans cela, aussi incapables que les précédentes de pourvoir à leur alimentation, et là encore, la mère a dû être dotée par la nature d'un instinct admirable qui lui apprend $\dot{a}$ construire et a approvisionner son nid.

2. - Station-Progression. - Les Hyménoptères èlant, pour la plupart, ailés, jouissent de l'admirable faculté du vol, tandis que leurs trois paires de paltes leur permettent une progression moins rapide lorsqu'elle est nécessaire. Leurs mouvements sont en général très-vifs, et il est bien souvent difficile de les atteindre, même avec nos instruments spéciaux de chasse. Certaines espèces s'ćlancent arec tant de précipitation, qu'au moindre mouvement de l'observateur', elles sont déja loin sans que celuici puisse même quelquiefois apprécier la direction prise.

Beaucoup de petites espèces ont un vol court et saccadé, ressemblant ì un véritable saut. Pendant le vol, le corps est ì peu près horizontal, les pattes postérieures sont longuement ćtendues en arrière pour maintenir un équilibre qui tend toujours à ètre rompu par le mouvementdes ailes. Dans le cas particulier où les miles poursuivent leurs femelles, la position du corps pendant le vol est anormale; il prend une direction presque verticale. 
Le vol peut être très-prolongé et les abeilles, on le sait, s'éloignent souvent it de grandes distances de leur ruche.

C'est pendant le vol et atu haut des airs qu'a lieu, la plupant du temps, l'accouplement. C'est en volant, enfin, que les espèces fouisseuses rapportent it leurs nids des proies d'un poids énorme relativement it leur errosseur; on en déduit de quelle force considérable doivent être pourrus les muscles qui font mouvoir les ailes. La chalcur influo beaucoup sur la rapillité et lia puissance du vol : le matin, quand le soleil levant ne darde encore que des rayons tris-obliques, nos insectes restent paresseux el leurs mouvements sont mous et lents; mais quand le soleil, au contraire, est au \%énith, l'œil ne peut plus les suivre dans leurs évolutions.

Ln cerlain nombre d'hyménoptères produisent, en volant, un son plus ou moins éleré' qui a reçu le nom de bourdonnement. Ce phénomène, connu de tout le monde, et qui doit son nom à ce (que les bourdons le produisent it un haut degré, a motivé, à bien des reprises, les recherches des savants, sans que, jusqu'ici, on ait encore réussi i en trouver une explication complètement satislitisante. Landois, qui a admis que le bourdonnement est causé par le passage rapide de l'air entre les valvules qui ferment plus ou moins les stigmates, ne doit pas être dans le vrai, car l'inșecte ne peut expulser l'air arec pression. T'out récemment un sarant professeur, M. I'ere\%, l'a attribué aux baltements répétés du moignon alaire contre les parties solides qui l'environnent. Mais celte hypothèse est combattue avec énergie par M. le docteur Jousset de IBellesme. Celui-ci admel deux sortes de bourdonnements : celui produisant un son grave, pendant le vol, et celui qui donne un son aigu, quand l'insecte est tenu entre les doigts ou gêné dans son mouvement. Co dernier est toujours à l'octave aigüe du son grave. Il se produit même quand les moignons alaires sont enlevés, ce qui infirmerait la théorie de M. Perez. - M. Jousset de Bellesme attribue le bourdonnement au battement rapide des ailes (112 viblations doubles par seconde dans le bourdon des mousses) combinéavec les vibrations thoraciques dont je vatis parler. Le son aiọu serait, i son tour, produit par les mouvements très-rapides de délormation que subit l'enveloppedu thorax. La coupe verticale de celui-ci, qui est ovale, rerrait en effel successivement son wrand axe devenir horizontal, puis vertical. Ces vibrations thoraciques, 
au nombre de 224 par seconde pendant le son aigu, produiraient donc ce son indépendamment des ailes, et celles-ci, par le frémissement très-rapide qu'elles subissent, quand on tient un bourdon prisonnier, viendraient seulement le renforcer. Il est certain que l'on ne sera absolument surr d'être dans le vrai, que quand les articulations des ailes et les muscles thoraciques seront assez connus, pour que l'on puisse, de leur structure, tirer l'explication du vol silencieux de beaucoup d'hyménoptères, du vol bruyant de certains autres.

3. - Produits de séerétion. - Les hyménoptères peuvent donner naissance à un grand nombre de produits et de sécrétions différentes utiles ì leurs travaux. Nous avons déjà parlé du miel recucilli par les mellifères sur les fleurs, avalé. puis dégorgé par eux. La cire sécrétée par les abeilles se fait jour chez elles à l'articulation de quelques uns des segrments abdominaux et est produite par l'élaboration que subissent dans leur corps les maticres recueillies sur les fleurs. Les mêmes insectes récoltent encore le propolis, sorte de gomme résineuse qu'ils trouvent sur les peupliers ou les bouleaux; et à laquelle ils font subir préalablement une véritable préparation. Nous avons vu que les femelles ont, en beaucoup de cas, à leur disposition une liqueur'spéciale, destinée à leur défense, qui est le venin, et a pour réservoir une glande particulière, ou glande à venin. Près de lai bouche, on trouve encore d'autres organes chargés de préparer un nouveau liçuide, qui a reçu le nom de salive, et qui sert, à beaucoup d'espèces, à ramollir et à détremper certaines matières dont, sans cela, la texture trop solide résisterait à leurs efforts. D'autres espèces, après avoir fait une plaie dans un rameau ou la féuille d'une plante, y laissent écouler un autre produit, qui possède la proprićté, soit d'empêcher la fermeture de cette plaie, soit, au contraire, de provoquer un afflux de sève donnant ensuite naissance à une galle ou exeroiśsance charnue ou ligneuse.

Les larves ont, dans un grand nombre de cas, la faculté de sécréler, au moyen de glandes, dites séricifiques, une sorte de soie, qui sert soit ì former une coque de toutes picces, soit à tapisser seulement l'intéricur de celle que la mère leur a construite.

Le groupe important des fourmis produit l'acide formiquequi 
leur donne leur odeur caractéristique et leur sert de moyen de défense.

Les eruêpes, meltant en usa les matériaux qu'elles trourent à leur portece, et les triturant avec (quelque produit spécial de sécrétion, en composent un véritable piapier ou carton qui constitue la charpente de leur nid.

Des larves enfin pouvent se recouvrir entierement d'un produit de sécrétion qui les dissimule tout-ì-fait aux yeux de leurs ennemis ou, au moins, leur lonne un aspect repoussant pour eux. D'autres peuvent, quand on les inquiète, lancer de chacun de leurs segments comme un jet d'une liqueur destinéc it les protéger. Chez quelques-unes, celle liqueur défensive sort par la bouche.

\section{4. - Moyens de défense - Parasitisme. - Chaque} espèce a son ennemi, et mûme souvent de nombreux ennemis, contre lesquels elle a à subir, durant tout le cours de son existence, des luttes acharnces. Sins parler des oiseaux insectivores, des petits animaux avides de larves, des intempéries même qui leur sont souvent fatales, bien d'autres adversaires, parmi les insectes seuls, sont it redouter pour nos lryménoptères, surtout pendint leur's premier's étals. Tantut ce sont des parasites cui, renant envahir le nid construit ì grands efforts et y déposer un ouf, produiront une larve destinée i consommer les provisions de son hòte; tantôt ce sont des carnassiers atlendant furtivement leur proie au coin de quelque branclic, ou venant au vol la saisir juscue sur les fleurs.

La nature qui, dans son harmonie, a voulu ces luttes, y a apporté, en même temps, un tempérament dans les moyens de défense (fu'clle a assignés i chacun. La rapidité du vol favorisant la fuite, l'aiıuillon empoisonne, sont dejicteux moyens que nous connatissons. Yousavons vu d'aulres insectes posséder la faculté de se rouler en boule, de façon à ne plus présenter qu'une cuirasse impénétrable. Nous renons de parler tout à i'heure de ces sécrétions diverses, destinées à cacher les larres ou à en faire un objet d'horreur.

Un crrand nombre, destiné ì la piraterie, a besoin de se soustraire it la vigilance de ses victimes, et aussi à leurs représailles; 
les uns savent se cacher à propos, s'élancer au bon moment, tandis que d'autres empruntent la livrée de leurs antagonistes, dont même un examenattentif permet à peine de les distinguer; ils se mêlent ìlcurs ébats, et en profitent pour aller porter un germe de mort dans les berceaux qui viennent d'être construils.

Mais tous ces moyens, et ceux que j'omets, sont bien souvent impuissants, surtout contre le parasitisme. La femelle a beau cacher son nid au fond de quelque crevasse, le fermer hermétiquement avec un mortier solide, l'ichneumon ou le chalcidite y ont déjà pénétré, et la pauvre mère enferme en mème temps, arec son œuf, un autre œuf qui détruira ses espérances.

Le parasitisme est le résultat d'une loi absolue de la nature qui défend à tout être créé de dominer soit par le nombre, soit par la force. Qu'une espèce, mise au sein de conditions favorables, se multiplie outre mesure, l'espèce parasite, qui lui est opposce, va se développer dans la mème proportion et rétablir l'équilibre, un instant interrompu. Puis, leur rôle terminé, les parasites euxmêmes sont condamnés à diminuer de nombre et à disparaître presque complètement, faute de nourriture. De lì ces apparitions immenses et subites de larves ou de chenilles, dont, l'annce suivante, on ne trouvo plus que quelques représentants.

A notre point de vue étroit, nous appelons du nom d'insectes utiles ces parasiles qui coopèrent à la destruction des ravageurs de nos plantations, et à ceux-ci nous appliquons l'épithète de nuisibles. Mais, dans l'ordre infini qui règne dans la nature, tout est utile, et si nous entrons directement en lutte avec elle, en protégeant une espèce végétale, par cxemple, aux dépens d'une autre, si nous voulons, dans notre égoisme, bouleverser ce qu'elle a établi, elle amène, pour combattre nos efforts, toute une légion d'insectes herbivores. Si reux-ci mènent la besogne trop rapidement et font courir a la plante le risque de disparaître, les parasites apparaissent en nombre et nous viennent en aide, pour les mèmes fluctuations se reproduire encore. Ce n'est qu'au prix de travaux incessants que nous arrivons a maintenir notre empire et à conserver ce que nous avons acquis.

Nous n'avons pas d'ennemis plus terribles quecertains insectes, nous n'avons pas d'amis plus dévoués que certains autres. N'est-ce pas là encore une raison qui doit nous porter vers celte ćtude de 
l'entomologie, (ue nous commaissions déja si awriable el si féconde en merveilles, et que nous trouvons maintenant si utile, même si indispensable.

5. - Instinct. - S'il est une occasion ou l'on doive admirer l'instinct des insectes, e'est bien lorsqu'on est amenó ì étudier l'ordre des Hyménoptères. C'est chez eux, en effet, que nous rencontrons les manifestations les plus étonnantes de cet instinct, et dans toutle cours de nos recherehes, nous aurons à le constater à chaque pas.

L'instinct, qui est l'éducation primordiale donnée par la nature à des ètres dont les besoins seraient, sans lui, loin d'étre en laipport avec leurs facultés, l'instinct est inné chez les animaux, et l'on peut dire que plus l'on descend bas dains l'echelle des êtres, plus ceux-ci sont éloignés du contact de notre intelligence, plus il a besoin d'être développé. L'homme a son instinct aussi, mais la raison et l'intelligence viennent, à chaque instant, rejeler dans l'ombre ses impulsions. Chez les mammifères, l'instinct est plus prononcé, mais il se combine avec certaines facultés, comme la mémoire, qui rendent moins uniformes les décisions qu'il suggrère. Chez les poissons ou les reptiles, son importance s'atcroil encore de tout ce (qu'ils perdent sous d'autres lapports. Chez les insectes enfin, il règne en mâtre, et aucune de leurs actions ne peut ètre reglce par autre chose que par celte science inconsciente qui les pousse, malgré eux, à remplir le rôle qui leur est assignné. Aussi pour chacun d'eux, l'étude des moeur's est-olle simple el ne comprencl-elle qu'une succession de faits qui, pour chaque individu, se renourellent toujour's les mèmes. si, parfois, che\% les especess soriales, surtout, on constate des actions qui doivent nécessiter un raisonnement ou une combinaison d'idées, il faut se garder de mettre en jeu, pour les expliguer, ce que nous appelons intelligence. L'instinct seul, yu'il soit guidé par lir nécessité de la conscrvation de l'espèce, de l'individu ou de la société, est capable d'amener des elfets qui nous surprennent, que nous ne pourons meme pas toujours explicuner, mais yui sont simples en eux-memes et qui peurent rentrer, par conséfuent, dlans les manifestations instinctives. Seulement, il faut avouer que certains insectes ne metlent pas habituellement en jeu tout ce que l'instinct leur per- 
met d'imarginer et de connaître, et que certaines portions du savoir inné que la nature leur a départi ne se produit au jour que dans des circonstances spéciales. Ainsi, par exemple, un hyménoptère ravisseur a à faire pénétrer dans son trou des victimes, pour les donner en pâture à ses larves futures; si l'une de ces victimes se trouve être, par hasard, plus grosse que les autres, ct ne peut entrer dans l'ouverture qui lui est préparée, l'insecte sait qu'il faut lui enlever les pattes, puis les ailes, pour faciliter son introduction. Ce cas se présentera fortuitement, et un hyménoptére donné n'aura peut-être jamais à y pourvoir dans tout le cours de son existence. Mais, de ce que ce besoin d'amoindrir le volume d'une proie ne peut se présenter que par hasard, il n'en est pas moins vrai que la nature a pu juger utile, pour ne pas entraver les travaux commencés, de doter l'opérateur du moyen de se tirer de cette difficulté en faisant seulement appel à son instinct, quilte à ne pas user de ce moyen, à ne pas se servir de la totalité de cet instinct, si les circonstances ne le rendent pas nécessaire. L'instinct, en un mot, pout être défini : la somme de connaissances diverses attribuées à chaque animal pour pourvoir à la conservation de l'espèce d'abord, de l'individu ensuite, connaissances qui naissent avce lui, qu'il possècle dès le premier jour aussi grandes qu'à la fin de sa vie, qui ne peuvent se perfectionner ni se dénaturer, et qui sont toujours les mêmes pour une même espèce, mais diffèrent essentiellement, s'il le faut, d'une espèce à l'autre.

Il est évident maintenant que cette somme de connaissances peut être restreinte ou étendue d'une façon plus ou moins considérable, sans que, pour cela, les conditions inscrites plus haut étant toujours remplies, clles cessent de ressortir de l'instinct. Il n'est pas non plus nécessaire, d'après cela, que la manifestation de toutes ces connaissances se produise toujour's, et on peut parfaitement admettre qu'un cas exceptionnel étant donné, une ressource aussi exceptionnelle de l'instinct se manifeste alors, s'il le faut, pour ne mettre en péril ni l'individu ni surtout l'espèce.

Pour tout cela, nous ne sommes que des spectateurs appelés à juger, ou mieux à admirer ce qui se produit sous nos yeux, mais qui ne sont initiés ni aux moyens employés, ni aux ressources mises en ouvre, visibles ou cachées. Si nous déchirons, de lomps en temps, un coin du voile qui couvre les mystères de la création, 
il n'en est pas moins vrai qu'il est des questions que nous ne pouvons aborder (qu'arec l'hypothèse, et celle de l'instinct est "du nombre. Il semble plus rationnel de n'admettre ni paisonnement ni intelligence chez los insectes, quelque haut placés qu'ils se trourent dans l'échelle animale, et e'est pouryuoi je crois pouvoir avancer que l'instinct seul, un instinct étroit et parfaitement limité, règle toutes leurs actions.

6. - Industrie - Mceurs. - Si nous passons une revue rapide des mours des grandes séries hyménoptéroloziques, nous trouverons des faits si intéressants, que nous regretterons qu'il ne soit pas possible de les inscrire ici tout au long. Mais je ne négligeriti atucune occasion de les indiquer avec detaillors de la descriplion de chacun des genres où cela sera utile.

J'ai dil (qu'une partic des hyménoptères était herbivore ou phytophage, à l'ćlat de larve. Celles-ci, ćclosant sur les branches mêmes (qui doivent leur foumir la nourriture, ont bientòt fait de ronger et de dévaster un arbuste. Nos jardiniers savent quels dégâts leur causent l'Hylotome ou l'Athalie; le chêne, le pin et pres(que tous les arbres en nourrissent quelques espèces. Arrivées au terme de leur croissance, en aout ou septembre, elles se laissent tomber sur la terre humide, s'y enfoncent et s'y construisent une double co(pue oì elles s'enferment, l'extérieure semblable ì un rros filet a mailles solides, l'intérieure étant seulement une fine tunique de soic destince à former une enveloppe plus herméliquuc. Là, apres un laps de temps plus ou moins long, arrive lit transformattion en nymphe, puis en insecte parfait, qui va pondre en incisant les branches, comme je l'ai dit. Cet insecte parfait, n'ayant aucunement à pourvoir à l'avenir de sa progéniture qui se tire fort bien seule d'affaire, n'a d'autre inclustrie que de placer ses œuts en lieu sur et sur un arbuste dont les fenilles pour'ont citre dévorées par les larves futures. Ces larves sont les seules qui soient munies de pattes et qui soient actives.

Un autre groupe pond ses ouís aussi sur les plantes, mais le résultat en est, le plus souvent, la production l'une alle de forme tress-varice, abritant el en même temps fournissant la nourriture à toute une famille de larves, qui y subissent leurs métamorphoses. Lii encore la mère n'a pas besoin d'une industrie spéciale ni bien compliquée. 
Si nous avançons d'un degré, nous arrivons à une suite d'inombrables parasites, s'attaquant à tous les ordres d'insectes, se dévorant même quelquefois entre eux, ce qui constitue alors des parasites de parasites ou des parasites au second degré. II n'est peut-être pas d'espèce d'insecte qui ne soit sujette à payer, pendant ses premiers étals, son tribut à cet multitude carnassière, qui renferme les hyménoptères les plus petits et peut-être les plus beaux. Les femelles sont souvent pourvues de longues tarières, qui leur servent à insérer leurs oeufs jusque dans les prolondeurs des galles, des calices des fleurs, des fruits, des nids divers, portout enfin où une mère prévoyante a cru pouvoir mettre ses œufs en sûreté. Mais il n'est guère de barrière qui puissent les sauvegarder, et si les murs en mortier solidement gâchés par l'Osmie ou l'Anthophore semblent devoir les préserver des Ichneumons ou des Chalcidites parasites, ceux-ci ont la précaution de prendre les devants et de pénétrer dans le nid, pour y déposer leurs propres œuls, avant sa fermeture. Les chenilles leur semblent un délicieux régal, car le lépidoptériste sait combien de déconvenues lui ont procuré ces parasites; la chenille, qui contient dans son sein une quantité souvent considérable de petits vers (qui vivent de sa substance, ne meure pas pour cela; car les maticires graisseuses de son corps sont d'abord altaquées à l'exclusion des organes essentiels à la vie. Il fallait, en effet, que des larves obligées de serepaître de proie vivante ne se trouvassent pas prises au dépourvu par la mort prématurée de leurs victimes. Celles-ci arrivent même souvent à se transformer en chrysalides, mais elles ne peuvent aller plus loin. Les petites larves parvenues au terme de leur croissance, se dirigent vers la peau de la chenille ou de la larve qu'elles habitent, la percent avec leurs mandibules, et en sortent, soit pour s'enfoncer en terre et y subir leurs métamorphoses, soit pour se construire de petits cocons feutrés sur le corps même du patient qui ne tarde pas à expirer, criblé cu'il est de plaies béantes. D'autres, au contraire, subissent toutes leurs transformations dans l'intéricur du corps qui les a nourries et en sortent seulement pour s'élancer dans les airs.

D'autre fois ces destructeurs s'attaquent aux œufs, et l'on voit souvent sortir, des paquets d'œufs de papillons, d'hémiptères ou d'orthopticres, loute une nichée de bestioles de la taille la plus exigüe et aux formes les plus délicates. 
Les pucerons nourrissent aussi des parasites spéciaux en grand nombre et j'aurai souvent l'occasion de les citer.

Bien des questions élonnanies suryissent déjai it propos de ces insectes, et on ne peut encore comprendre comment, au trivers de l'épaisseur d'une galle, d'un calice, etc., la mère peut, avec sa longue tarière, atteindre précisément le point où se tient la larre phỹlophagge. Si son ouf n'est pas déposé exactementsur cette larve, ('est un ocuf perdu, el il faut que la pondeuse ait comme un sens particulier qui la guide à défaut de ses yeux.

I côté de ces léwions innombrables viennent se placer d'autres espices vivant aussi de proie, mais de forme et d'habitudes différentes. Les Chrysides aux couleurs éclatantes ont encore une tarière, les. Mutilles dont les femelles sont aptères et munies d'un aiguillon redoutable, les Scolies dont la taille est généralement bien plus grande, et qui possèdent aussi un dard enrenimé, pénètrent i l'envi dans les nids des fouisseurs et des mellifères, ou bien s'attaquent aux grosses larves de Coléoptères.

Toutes autres sont les mœurs des fouisseurs dont les larves cependant doivent se nourrir aussi de proie virante. lei la mère n'a plus sculement le souci de déposer un œuf là où la larve qui en éclora, devra trouver sa pâture. Ses procédés sont déja bien plus perfectionnés. Elle est obligée de construire un véritable nid qu'elle creuse en terre ou dans le bois, ou qu'elle fasonne de toules pièces arec du mortier guiché. Puis ce travail fait, elle part en chasse et revient bientôt chargée d'une proie quu'elle a dû torrasser, vatincre el enfin paralyser par uno piquure de son aig̣uillon dans les centres nerveux. Cette victime, saisie entre ses pattes, est transportéc au vol ì l'orifice du nid préparé; lì, au prix d'elforts souvent considcrables, elle est emportée au fond de ce trou et arrange de façon it n'y pas causer d'encombrement. Puis une deuxième, une troisième proie, et sourent davantage, viennent la rejoindre de la mème façon. Quand la mère juge la provision suffisante pour (que lit petite larre, (qu'elle va mettre au jour, en ait assez pour arriver it toute sa taille, sams que cependant celte provision soit jamais plus grande qu'il ne faut, car l'excédant se corromprait et nuirait à l'existence ultérieure de celte larre, alors un ouf est pondu sur une des vietimes anesthésiées, précisément it l'endroit où l'aighuillon l'a rendue le plus insensible. 
Puis, soit (qu'elle y ait placé un seul œuf, soit qu'elle en ait enfermé plusieurs dans la même galerie, la pondeuse referme le trou qu'elle avait creusé, égalise la surface du terrain de façon à rendre l'orifice méconnaissable et va plus loin piatiquer la même série d'opérations pour d'autres œuls, heureuse si, pendant ces allées et venues, un forban ichneumonien ou chryside n'est pas venu cacher son propre ouf au milieu des victimes empilées, et apporter ainsi, dans ce nid si bien approvisionné, un germe qui va y faire entrer, en même temps, la mort et la disette.

Mais c'est assez nous arrêter sur ces batailleurs ne vivant tous que de rapine. Nous arrivons enfin à des tribus à mœurs plus douces, queseulle suc des fleurs vient tenter, et qui, tout en faisant preuve d'une industrie encore plus grande que les précédents pour la construction de leurs nids, n'y apportent que du miel et ne viennent pas ternir l'admiration que l'on a pour leurs travaux par l'horreur qu'inspireraient leurs habitudes. Les mellifères construisent des nids où un art véritable vient présider. T'antôt ce sont de simples trous, soit nus, soit garnis de tentures et de courtines d'émeraudes el de pourpre, empruntées aux feuilles du rosier ou aux pétales éclatants du pavot, tantôt ce sont de véritables communautés, où chacun apporte le concours de son savoir et de son travail, et dont les abeilles domestiques et les fourmis présentent les types le plus perfectionnés.

Pourquoi faut-il qu'au milieu de ces travailleurs paisibles viennent se glisser encore des fourbes qui, sous̃ une livrée à peu près semblable, arec des besoins identiques, préfèrent profiter du travail d'autrui plutôt que d'y coopérer eux-mêmes. Il est, en effet, des mellifères, dont les larves vivent exclusivement de miel, mais qui ne savent ni se construire des nids, ni récolter leur approvisionnement. Ils sont à l'affùt des travaux de leurs compagnons, et quand ceux-ci, ayant préparé avec soin le berceau auquel ils vont confier un si précieux dépôt, s'occupent à butiner sur les fleurs du voisinage, le voleur aux aguets, pénètre dans ce nid momentanément abandonné, y dépose un œuf, qui, éclos, donnera une larve destinée au meurtre dès sa naissance, au vol ensuite juscu'à son éclosion. La vraic propriótaire revenant chargée de pollen, ne peut s'apercevoir de rien, termine sa tâche, pond, referme le trou et se retire, ignorant qu'elle a emprisonné elle-même avec son œuf un ennemi mortel. 
La républirgue des fourmis vient enfin terminerect exposć riljuide et nous montrer, en même temps, la plus haute expression de ce à quoi peut arriver un frêle insecle, aidé par l'association et pall un admirable instinct. Iei tout est régle, chacun a sa besonne, et la vigilance, la préroyance, le dévouement se remarpuent souvent. Nous y voyons employés même, sans que ce soit à leur louanere, des procédés (pue l'homme seul s'était appropries; nous y royons de réritables sultans servis par de véritables esclaves, des troupeaux parqués et entrenus avec soin, des armées permanentes uniyuement occupées de la défense de la cité ou de la conquête de ces mêmes esclaves. Nille délails sembleraient impossibles ou cxagurés, s'ils n'avaient élé observés arec soin par d'éminents savants. Nous y reviendrons longuement lorsqu'il en sera temps.

\section{§ VI. - DISTRIBUTION GÉOGRAPHIQUE.}

Les limites d'une faune hyménoptérologique sont assez 'difficiles à définir, la facilité du vol de la plupart d'entre eux défiant des obstacles ([ui, pour d'autres insectes, sembleraicnt plus séricux. Les fleures ne peurent étre pris en aucune considération, les montagnes couronnées de neiges perpétuelles ofriraient plus de garanties sous ce rapport, s'il n'existait ni gorges ni défilés pouvant donner passage à nos insectes. Seuls les déserts paraissent deroir être un obstacle infranchissable, s'ils sont assez étendus. Aussi est-il peu rationnel de chercher à délimiter une faune restreinte, comme la faune frangaise, allemande ou italienne. J'our trourer des bornes réelles en dehor's desquelles les espices changent visiblement d'aspeet et de nature, il dovient nécessaire de pousser à l'est jusque par dela les monts Ourals aux déserts de l'Obi, puis à ceux de la T'artarie, de les poursuivre, à travers la l'er'se el lat P'alestine, jusqu'it ceux de la Syric ef de l'Arabie l'étrée, de continuer par les déserts de la IIaule-Eupte pour alleindre enfin le Sahara. On enforme ainsi dans la même faume toutes les rives de la Méditerranéc, ce qui lui a fait donner le nom de faune curopéo-méditerranéenne. On a lésigné aussi ruscelui de faune circa-méditerancenne l'ensemble des richenes natmelles rencontrées sur les rives de cette mer, d'un cóte just fu aux hatules 
montagnes qui s'étendent de la mer Noire aux Pyrénées, en passant par les Ballians, les $\Lambda$ pennins, les Alpes et les Cérennes, de l'autre jusqu'aux déserts asiatiques et africains. Celte faune plus restreinte ne peut se séparer d'une façon complèle de la fáune européenne bien qu'elle présente quelques allures spéciales.

La faune europén-méditerranéenne est donc vraiment délimitée, et il est possible d'examiner et d'ćtudier'ses productions naturelles sans trop craindre de voir les faunes voisines venir's'y mélanger en forte proportion.

Mais tous les hyménoptères sont loin d'habiter en méme temps toute cette large surface et il convient de la diviser en parties ou régions constituant des sous-faunes très-incomplètement bornćes, mais possédant cependant quelques caractères particuliers. Ici nous trouverons de très-grandes difficultés pour indiquer les frontières de ces sous-faunes, car bien des circonstances diverses peuvent influer sur la répartition de ces insectes, et ce n'est que par la réunion d'un très-grand nombre d'observations qu'on pourra, par la suite, arriver à les partager en séries suivant leur habitat. Il faut dire aussi que tandis que certaines espèces n'occupent qu'un espace de pays assez restreint, d'autres, au contraire, se rencontrent dans loute l'Europe et quelques unes même sont cosmopolites et se retrouvent aussi bien en Océanie ou en Amérique que chez nous.

Les conditions qui peuvent influer sur la dispersion d'une espèce d'hyménoptère sont: le climat, l'altitude, la nature du sol et par suite des plantes qu'il nourrit, enfin la répartition des autres insectes eux-mêmes, en ce qui regarde les parasites.

Le climat a surtout une grande influence et les espèces méridionales ne se rencontrent qu'exceptionnellement dans le nord. Mais il ne faudrait pas arguer de ce qu'un pays présente en été un soleil brûlant, pour conclure à la présence possible d'insectes méridionaux. La condition la plus essentielle ne réside pas seulement dans l'ardeur du soleil, mais surtout dans la prolongation des temps chauds. Plus l'hiver en moyenne finit vite, plus l'été est précoce, plus aussi les insecles méridionaux ont des conditions favorables à leur développement. C'est done la température moyenne d'une contrée qu'il faut considérer sous ce rapport plutót que les maxima el les minima. De temps en temps on si- 
gुnale, ça el là, la capture d'espèces réputées juscue lia benucoup plus méridionales, et ces trouvailles se maltiplient souvent it un point tel qu'on en vient ì croire au réchaufiement de ce pays. C'est ce qui arrive pour la Breląrne. Souvent aussi une vallée, convenablement situce a l'abri des vents froids ou dans des conditions particulierement favorables pour conserver la chaleur des rayons solaires, donne des espèces qui ne se retrouvent plus it quelques kilomètres. Je l'ai bien constaté en Bourgogne.

L'altitude a donné licu ì des observations fort remarquables. Beancoup d'espéces rencontrées dans les Alpes, par exemple, it des hauteurs plus ou moins grandes, se retrouvent dans les Pyrénées il des niveaux correspondants, sans se laisser voir aucunement dans les plaines ou les pay's intermédiaires.

La nature du sol a aussi une influence manifeste, et je me suis bien aperȩu, d'accord en cela aree de savants entomologistes, que le terrain de la formation jurassique, par exemple, était beaucoup moins riche en espices que d'autres couches crologiques. Il est très-probable (que les insectes ne font que suirre, diuns leur répartition, les plantes fui servent, soit i leur propre nourriture, soit it celle des victimes qu'ils ont it sacrifier. Il faut tenir compte aussi de l'aridité ou de l'humidité du sol, de son exposition, de sa nature même, sablonneuse, argileuse ou granitique. Les espries fouisscuses ont, en effet, sous ce rapport, des préférences bien marqueces.

Toutes les espéces parasiles stivent naturellement la répartition de celles auxquelles elles doivent s'atlaquer. Par exemple, le parasite spécial de la Mante religieuse se tronvera partont où sera cette Mante et seulement là.

En résumé, il n'est pas possible, au moirs dans l'état actuel de nos comnaissances, de classer chaque pays dans une region entomologrique particuliere, et pour l'indication de l'habitat d'une espice, il faut, en attendant mieux, indiguer seulement les points principaux ou elle a été rencontrée, ce qui permettra de lia placer approximativement dans une faune méridionale ou septentrignale, alpine ou maritime, occidentale ou orientale.

Ajoutons enfin, que la faune des iles est très-souvent caractérisce d'une fargon particulière pourru qu'elles soient suffisamment éloignées des continents et qu'elles n'y aient été réunies it 
aucune époque. Cette observation n'est donc pas applicalble à la faune européenne où toules les îles sont trop voisines de la terreferme pour que des espèces aient pu y rester spéciales.

\section{\$VII. - DIVISION DES IYYMÉNOPTÉRES EN FAMLLES}

\section{NATURELLES}

Si l'on veut bien se reporter à ce que j'ai dit plus haut ì propos des classifications, on y verra que celle, qui veut s'approcher le plus près de la vérité, doit s'appuyer non sur un certain nombre de caractères extérieurs, mais surr l'ensemble des faits capables d'influer sur l'organisation de l'insecte. J'ai dit aussi qu'il ćlait trop. tot pour songer à établir actuellement une semblable classification, car nous ignorons encore trop de faits essentiels à connaître.

Qu'il me soit cependant permis d'esquisser ici, à grands traits, un essai d'une méthode indiquant, bien imparfaitement et surtout bien incomplètement encore, la suite philosophique que doit garder le placement successif des familles ; je m'appuierai, pour y arriver, sur. la complication de plus en plus grande de leurs aptitudes instinctives, révélées par la série aussi de plus en plus longue des moyens successivement mis en jeu par nos insectes pour aboutir à l'accomplissement d'une même opération, qui a toujours pour but final la conservation de l'espèce.

Mais il ne serait pas possible, en quelques phrases, d'arriver ì comparer l'instinct et les mours quelquefois si compliquées de nos hyménoptères, et pour parvenir à faire un travail utile et dont l'ensemble puisse être facilement saisi d'un coup d'œil,; jo suis forcé de prendre un délour qui nous amènera au même but el aura même encore l'avantage de faire entrer dans notre examen les premiers états de l'insecte; ce point est cerlainement fort important, bien que l'ćtat parfait doive incontestablement être considéré comme représentant les articulés dans la plénitude de leur's moyens.

Il est facile de remarquer, en effet, que les hyménoptères les plus avancés dans la série, les plus perfectionnés sous le rapport 
de l'instinct et des outils (qu'ils doivent mettre en neurre, correspondent précisément aux larves les plus faibles, les plus inerles, les moins capables de pourroil elles-même à leur conservation et à leur nutrition.

Je puis done parfaitement, renversant le problème, imaginer une classification où les ètres larviformes les plus dégradés corres. pondraient aux types les plus élevés dans l'ordre naturel, et, co faisant, j'arriverai d'une façon très-correcte d'abord, beaucoup plur facilement ensuite, au but que je poursuis. Je ne veux pas engager le lecteur dans toutes les discussions philosophiques que peut soulerer la comparaison des organes entre eux, afin de voir lequel a une importance prédominante, quel autre, au contraire, se trouve être d'un intérêt moins scricux. Je ne puis que donner ici le résultat d'étuiles prolonges, et le tableau suirant le montrera, je l'espère, aussi simplement que possible :

I. - Larres munies de pattes proprement diles, capables de passer facilement d'un lieu à un autre, de chercher leur nourriture, possédant des moyens propres de défense, et un épiderme assez résistant pour les empêcher de soulírir du contact immédiat des objets extérieurs.

\section{PREMIERE DIVISION.}

II. - Larves non munies de pattes vraies, ne pourant se livrer qu’à des mouvements de translation très-limités ou nuls; incapables de pourvoir clles-mêmes à leur alimentation et de se défendre eontre lennemi le plus faible; n’ayant qu'un épiderme très-mince et très-délicat.

\section{DEUXIEME DIVISION.}

\section{PREMIILRE DIVISION}

Elle ne comprend qu'un seul groupe, celui de :

\section{I. - Les Mouches à scie ou Tenthrédines.}

\section{DEUXILME DIVISION}

A - La larve est placćc par la mère au milieu dun amas de nourriture, que celle-ci rencontre toule préparée et qui n'a ì subir aucune manipulation de sa part.

a - La larve se contente d'une nourriture uniquement végëlale. Elle est ordinairement enfermée dans une galle herbacćc ou ligneuse, dans l'intérieur de laquelle elle peut souvent se mouvoir au mogen de pseudopodes.

II. - Les Cynipides (ex parte). 
a' - La larve a besoin d'une nourriture animale. Elle vit soit dans le curps même d'une victime, soit à sa surface, mais toujours de sa substance même, et particulièrement des parties graisseuses.

$b$ - La mère pond ses œuĺs au moyen d'une tarière et est dépourvue d’aiguillon à venin. Les victimes ne sont done jamais paralysées et continuent à poursuivre leur existence habituelle, arrivent mème parfois à se transformer en nymphes ou en chrysalides ; d'autres fois elles sont attaquées à l'état d'ouf.

\section{III. - Les Parasites térébrants}

(comprenant les insectes que nous désignons sous les noms génćraux de : Cynipides (ex parte), Evanides, Ichneumonides, Chalcidites (1). Proctotrupides, Chrysides).

$b^{\prime}$ - La mère n'a point de tarière pour la ponte, mais possède un aiguillon à venin. Les victimes sont done probablement paralysces avant d'être livrées aux jeunes larves.

\section{IV. - Les Parasites aiguillonnés}

(comprenant les Scoliens, les Mutillaires, les Sapygiens).

$A^{\prime}$ - La larve est approvisionnée de nourriture par la mère, soit que celle-ci l'ail amassée d'avance, soit qu'elle l'apporte à la larve au fur et à mesure de ses besoins. Mais cetle nourriture doit d'être chcrchée et transportée en lieux convenables par la mère, qui en outre lui fait subir soit une paralysic, soit même une trituration qui la dénature plus ou moins.

a - La larve exige une nourriture animale paralysće. La mère est munie d'un aiguillon à venin, qui lui sert à prodaire ectte paralysie et à supprimer tout mouvement chez les victimes puissantes qui elle fournit a ses larves, et qui, sous les attaques de celles-ci, feraient, sans cela, des soubresauts dangereux pour elles. La mère creuse des cavités soit dars le bois, soit dans la terre, ou bien elle construit, de toutes piéces,

(1) On pourrait citer, comme objection, les observations de MM. Giraud et Perris. sur les Isosoma et les Megastigmus. Ces savants n'ont pu trouver trace de victime dévorée par les larves de ces insectes, dont cependant tous les congénères sont des parasites térébrants évidents. Ils ont donc été amenés à admettre, avec le plus grand doute, il est vrai, une nourriturc végétale pour ces insectes, au moins à la fin de leur existence larvaire. Mais on ne peut se laisser arrêter par des observations ainsí isolées et non probantes, et l'analogie la plus grande donnant la même manière de vivre à tous ces insectes, on doit, jus'qu'à plus ample informé, les faire rentrer dans le cadre que je trace, a la division III. 
des coques terreuses pour $y$ enfermer sa progéniture et les provisions animales quiclle apporte de loin.

\section{V. - Les Fouisseurs. (1)}

(comprenant les Pompiles, les Sphegiens, les Guépes solitaires.)

$a^{\prime}$ - La larve exige une nourriture ordinairement mielleuse, en tous cas parfaitement trituréc. La mère est mumic d'un aiguillon qui ne sert généralement qu’à sa défense; clle creuse des nids comme les fouisseurs, ou bien elle les construit de toutes pièces, on encore elle s'empare de ccux élablis par d'autres insectes.

$b$ - La larve, placée par la mère au milieu d'une provision mielleuse, se suftit ensuite à elle-même.

$c$ - La mère creuse, construit ou approprie elle-même son nid ou l'abri quelle a choisi; elle l'approvisionne elle-même de micl.

\section{VI. - Les Mellifères solitaires nidifiants.}

$c^{*}$ - La mère est incapable de récoller le miel et est obligée de s'emparer des travaux effeclućs ou des provisions réunies par les précédents, faisant ainsi acte de parasitisme indirect, puisque ses propres larves ne vivent pas de la substance de celle du nidiliant, mais siattaquent seulement is ses provisions et, par lỉ, la voucnt à la mort dès sa naissance.

\section{VII. - Les IYIellifères solitaires parasites.}

$b^{\prime}$ - La larve, placée ou non par la mère au milieu d'une provision mielleuse, ne se suftit plus à elle-même et a besoin, jusqu' î sa lransformation, des soins des individus parfaits de son espèce. De lì pour ceux-ci un sureroit considérable de travail, et la nécessité pour la mère de trouver une aide à côté d'elle. Pour cela, elle vit en société avec d'autres femelles de son espèce, qui concourent toutes à l'approvisionnement d'un seul nid plus ou moins compliqué, mais qui sont infécondes, et par conséquent ne font qu'apporter un secours eflicace, sans amener en même temps une cause supplémentaire de travail.

$c$ - Les socictés se dissolvent chaque amnéc à l'entréc de l'hiver, el il ne subsiste que quelques femelles fécondées qui s'engrourdissent.

(1) Ce nom de Fouisseurs n'est pas exact pour quelques-uns d'entre cux. Un grand nombre de guêpes solitaires se construisent, en ellet, des nirls de toutes pièces avec de la terre gâchée. Tous les nutres creusent le leur dans la terre, le sable, le vieux bois, les tiges sèches, etc. 
d-La nourriture destinéc aux larves est extraile des fleurs, des fruits, des matières animales, partout enfin où pouvent exister des particules sucrées. Ce n'est pas, à proprement parler, du miel, mais une matière analogue au miel et n'en différant que parce qu'au lieu d'avoir subi une préparation spéciale dans l'estomac des femelles infécondes, elle n'en ạ éprouvé aucune, si ce n'est une trituration.

VIII. - Les Guêpes ou Vespides sociales.

$d$ ' - La nourriture destinćc aux larves est un véritable miel dégorgé par les femelles stériles, et extrait. uniquement des fleurs.

IX. - Les Bourdons ou Bombides.

$c^{\prime}$ - Les sociétés sont permanentes et se renouvellent perpétuellement.

d-La nourriture est exclusivement mielleuse. Les femelles fécondes sont toujours uniques dans chaque nid. Elles pondent et placent elles-mêmes leurs œufs dans les loges préparées pour les recevoir et d'où le nouvel insecte ne sortira qu'à l'état parfait. Les femelles stériles ou ouvrières, sont toujours ailées; elles se bornent, pour tous soins, à fournir aux larves la nourriture nécessaire et à les enfermer complètement lors de la transformation en nymphe. La femelle féconde ost l'âme de la socićté et les ouvrières la suivent en partic, quand, dans des circonstances spéciales, clle quitte le nid commun.

\section{X. - Les Abeilles ou Apides sociales.}

d' - La nourriture est très-variée, en même temps animale et végétale. Le miel destiné aux larves provient de ces sources diverses. Les femelles fécondes ne sont pas uniques dans chaque nid. Leur importance morale est beaucoup moindre que chez les Abeilles, et les ouvrières, au contraire, qui sont toujours aptères, voient s'accroitre les ressources de leur instinct. Les femelles ne placent pas clles-mêmes les œufs oủ ils doivent éclore. Les larves et les nymphes ne sont plus enfermées dans des loges, et les ouvrières peuvent les transporter d'un endroit à un autre du nid suivant les circonstances almosphériques. La supériorité de leur instinet sur celui des $\Lambda$ pides sociales se révèle encore, chez un certain nombre d'espèces, par la possession de véritables troupeaux chargés de fournir une liqueur sucrée d'esclaves conquis par la force, d'individus 
spécialement destinćs ì combattre, soit pour défendre la colonic, soit pour lui procurer ses esclaves, formant ainsi uno réelle arméc permanente.

\section{XI. - Les Fourmis ou Formicides.}

Je viens de définir ainsi onze groupes principaux d'hyménoptères différent essentiellement entre eux par les conditions mèmes de leur existence. Beaucoup de ces groupes devraient encore se subdiviser en plusieurs autres, et on y arrivera, certainement, quand nous en saurons davantage sur les mœurs de ces insectes.

Mais, pour le but pralique que je me suis proposé, il est évident que le tableau ci-dessus ne peut être d'aucune utilite et c'est pourquoi je le fais suivre, dès maintenant, d'une division artificielle de toutes les familles, permettant d'arriver facilement et rapidement ì constater celle dans laquelle rentre un hyménoptère donnć. (1)

\section{§ VIII}

\section{TABLEAU ANALYTIQUE DES FAMILLES}

SÉPARÉES D'APRES LEURS CARACTK̇RES IXTÉRIEURS

I. - Abdomen sessile, soudé au thorax par le diamètre enticr de sa partic basilaire, non muni a'une articulation mobile. - Trochanters bi-articuless. Ailes antẻricures pourvues d'une cellule lancéoléc.

a - Tibias antérieurs avec deux éperons.

\section{I. - Tenthredinidæ.}

$a^{\prime}$ - 'Tibias antéricurs avec un seul éperon.

$b$ - Abdomen presrfue toujours plus ou moins comprimé. Ailes antéricures arec deux cellules radiales et quatre cellules cubitales, dont la première est plus grande que la deuxième.

II. - Cephidæ.

(1) Ce talylcau n'est que provisoire ct je donnerai is la fin de l'ouvrage un nouveau tableau définitif plus complet et plus exact, qui sera le résultat des études successìves que j'aurai faites de chaque famille et rui résumera l'état de la science à l'êpo. que oùil paraitra. 
$b^{\prime}$ - Abdomen cylindrique ou déprimé. Ailes antérieures avec une ou deux cellules radiales, et deux, trois ou quatre collules cubitales, dont la première est plus petite que la deuxième.

III. - Siricidæ.

II. - Abdomen non soudé au thorax par le diamètre entier de sa partie basilaire, mais muni d'une articulation mobile. Ailes antéricures sans cellulc lanećolée.

A - Trochanters bi-articulés.

a-Des ailes.

$b$ - Ailes présentant toujours plusicurs cellules fermées, ou, au moins, une cellule cubitale. Antennes non coudées.

$c$ - Ailes antérieures sans stigma.

IV. - Cynipidæ.

$c^{\prime}$ - Ailes antérieures avec un stigma.

$d-$ Abdomen fixć sur le dos du métathorax.

v. - Evaniadæ.

$d$ - Abdomen fixé à l'extrémité du métathorax.

$c$ - Prothorax réuni à la tête par un cou bien prononcé.

VI. - Stephanidæ.

$e^{\varphi}$ - Prothorax non rẻuni à la tête par un cou distinct, mais seulement par un mince pédicule.

$f$ - Ailes antérieures munies de deux nervureś récurrentes.

$g$ - Ailes antérieures avec quatre cellules cubilales. Métathorax terminé par un rebord enclavant une partie nembraneuse.

VII. - Trigonalydæ.

$g^{9}-$ Ailes antéricures avec trois cellules cubitales au plus. Métathorax sans partic membrancuse.

VIII. - Ichneumonidæ.

f" - Ailes antérieures munies d'une seule nervure récurrente.

IX. - Braconidæ.

b' - Ailes sans cellule fermée et sans cubitale.

$c$ - Pronotum n'alteignant pas l'insertion des ailes par son bord posterieur. Antennes portant de un it trois annelels. 'Tariere 
des femelles ayant son origine sous le ventre. Antennes toujours coudées.

X. Chalcididø.

$c^{\prime}$ - Pronotum atteignant l'insertion des ailes par son bord postéricur. Tarière des femelles sortant de la pointe méme de l'abdomen. Antennes coudées ou non coudées.

\section{XI. - Proctotrupidæe.}

$a^{\prime}$ - Pas d'ailes.

$b$ - Antennes non coudées.

c-Antennes de seize articles au plus. Abdomen plus ou moins comprimé.

$$
\text { IV bis. - Cynipidæ. }
$$

$c^{\prime}$ - Antennes de plus de seize articles. Alodomen non comprimé. $d$ - Antennes pourvuos d'un annelet après le deuxiême article.

VIII bis. - Ichneumonidæ.

d' - Antennes non pourvues d'un annelet après le deuxième article. Segments abdominaux deux et trois soudés, séparés seulement par une fausse articulation.

IX bis. - Braconidre.

$b$ - Antennes coudées.

$c-$ Vertex pourvu d'ocelles assez visibles. T'arière des $q$ naissant sous le ventre.

\section{$\mathbf{X}$ bis. - Chalcididæ.}

c' - Vertex dépourvu d'ocelles, ou ceux-ci à peu près invisibles. Tarière des. $q$ naissant at la pointe mème de l'abdomen.

XI bis. - Proctotrupidæ.

$A^{\prime}-$ 'Trochanters uni-arliculés.

a - Des ailes.

$b$ - P’as de cellule cubitale complètement fermée.

$c$ - Abdomen de plus de quatre segments apparents. Pas de coureur métallique. Quelquefois des cellules cubitales incomplètes. Métanotum arrondi en arrière. Les femelles ont parfois les pattes antérieures de forme ravisseuse.

\section{XII. - Cenopteridæ.}

$c^{\prime}$ - Andomen de trois ou quatre semments seulenent, trèsrarement avee un cinguieme tres-petit chez les o. Corps toujours pare de couleurs métatlinges en totalite on en partie. 
Métanotum présentant des angles ou des dents sur les còtés postérieurs.

\section{XIII. - Chrysididæ.}

$b^{\prime}-A u$ moins unc cellule cubitale ferméc.

$c$ - Base des ailes protégće par une écaillette.

$d$ - Premier article des tarses postéricurs cylindriques, peu ou pas velu au còté interne.

$e$ - Première cellule discoïdale pas particulièrement allongée, plus petite que la cellule médiane.

$f$ - Le bord postérieur du pronotum atteint la base des ailes.

$g$ - Premier segment abdominal visiblement séparé des autres par une contraction de l'articulation, les autres s'emboitant régulièrement. Pattes courtes.

$h$ - Hanches intermédiaires très-éloignées l'une de l'autre. Abdomen allongé, ovale. Chez le mâle, l'anus est souvent terminé par trois épines aiguies; antennes $\sigma$ longues, droites, épaissies graduellement jusque vers l'extrémité. Chez la laisse voir un aiguillon unique; antennes $q$ courtes, un peu noduleuses, contournées en corne de bélier.

XIV. - Scoliadæ

h'- Hanches intermédiaires peu distantes. Abdomen conique. Anus ne laissant voir que deux dents très-courtes ou aucunc. Antennes droites, allongées, filiformes.

XV. - Mutillidæ $\sigma$.

$g^{\prime}$ - Premier segment abdominal non séparé des autres par une contraction de l'articulation.

$h$ - Liextrémité des tibias postérieurs n'atteint pas la pointe de l'abdomen.

XVI. - Sapygidæ.

$h^{\prime}$ - L'extrémilé des tibias postérieurs dé- 
passe la pointe de l'abdomen. Pattes dentées, éperonnẹes, velues ou épincuses.

\section{XVII. - Pompilidæ.}

$\Gamma$ - Le bord postéricur du pronotum n'atteint pas la base des ailes.

\section{XVIII. - Sphegidæ.}

e' - Première cellule discoidale dẻnresurẻment allongée, plus grando que la cellule médiane. Ailes le plus gẻnéralement pliées pendant le repos.

$f$ - Ailes antérieures avec trois cellules cubitales fermées.

$y$ - Ongles dentés en dessous.

\section{XIX. - Eumenidæ.}

g' - Ongles simples.

XX. - Vespidæ.

$f$ - Ailes antéricures avec deux cellules cubitales fermées.

\section{XXI. - Masaridæe.}

$d$ - Premier article des tarses postéricurs plus ou moins aplati et élargi, velu au côté interne.

$e$ - Nervure radiale non parallèle ì la nervure costale. Deux ou trois cellules cubitales égales ou inćgales entre elles. Dans le cas de trois cellules cubitales igales, la troisième est aussi large sur la nervure radiale que sur la nervure cubitale. Femelles sans oreillelte à l'angle externe du premier article des tarses postérieurs. Pas de femelles stériles. Vic solitaire.

\section{XXII. - Mellfferidæ.}

$e^{\prime}$ - Nervure radiale parallèle à la nervure costale et tilbias sans épines - ou bien nervure radiale non parallele at la nervure costale ef tibias épinoux, mais alors il y a trois cellules cubilales égales, dont la Iroisième est plus ètroite sur la nervure radiale que sur la nervire cubitale. Femelles avec une oreillette pointue ou mutique a langle externe du premicr ar- 
ticle des tarses postéricurs. Des femelles stériles. Vie sociale.

\section{XXIII. - Apiaridæ.}

$c^{\prime}$ - Base des ailes dépourvue d'écaillette.

XXIV. - Formicidæ ơ?.

$a^{\prime}$ - Pas d'ailes.

$b$ - Abdomen non pétiolé. Thorax peu ou pas divisé.

$c$ - Tarses antéricurs armés de deux grands crochets et repliés en forme de pattes ravisseuses. Pas d'aiguillon.

XII bis. - Cenopteridæ.

$c^{\prime}$ - Tarses antérieurs ordinaires. Un aiguillon très-actif.

\section{XV bis. - Mutillidæ $q$.}

b' - Abdomen pétiolé, le pétiole composé d'un seul article surmonté d'uné écaille aplatie, quelquefois sans écaille ou nodiforme, ou formé de deux articles noueux. Thorax offrant souvent de nombreuses divisions. Pas d'aiguillon ou un aiguillon assez peu sensible.

XXIV bis. - Formicidæ

Les $q$ de cette famille paraissent souvent prirées d'ailes; mais elles on ont toujours eu au début de leur existence à l'état parfait et elles se les arrachent aprés la fécondation ; il est cependant toujours facile de reconnaitre cette mutilation, ce qui les fait rentrer parmi les Hymėnoptères ailés). 


\section{III}

\section{BIBLIOGRAPHIE}

DES PRINCIPAUX OUTRAGES SE RAPPORTAN'T', D'UNE MANIİRE GÉNÉRALE, A L'ENTOMOLOGIE, a L'ANATOMIE DES INSECTES, ET PARTICULILREMENT AUX HMENOPTERES EROPELNS.

1. Agassiz. 1919 Mémoirc sur les frachées des insectes. (Proceding) american Association for the Alvanc. of Sciences., p. 140. - Traduction franc : Ammales des Se. natur., $3 \circ$ sirie, xr, p. 358).

2. Agricola. 1519 De animalibus subterrancis. - Bâle.

3. Aischinger. 1870 Beitrag $\%$ lienntn der IIym. Fauna 'Tyrols (Ztschr. des Ferdinandeum zu Innisbrïch).

4. Albin Elz. 1720 A natural IIistory of englisch Insects illustr. witl 100 copper Plat $\%$, etc. - London, in-4 ${ }^{\circ}$,

5. Aldrovande. 160? De animalibus inscelis. - In-folio, Bononir.

6. Antelme A. 18\%? Iisı, nat. des Insectes et des Mollusques. - Paris, in-12, $16 \mathrm{pl}$.

7. Audouin. 18:4 Recherehes anatomiques str to thorax des animaux articulés. - Ann. des Sc.nat. t. I, p. 97.

8. Barthélemy 1859 litudes et Considérations génćrales sur la Parthenogenésic. - Ann. des Sc. nat. p. 30-.

9. Bassi. 18.31 Rapport relatif au passage des substances introduites dans te système trachècen des insectes. $-A m$. des Sc. nat.p. 362 . 
10. Bauer.

1810 Versuch cines Unterrichts für den Fortsmann zur Verhütung der Waldverheerungen durch Insecten. Erlangx.

11. Bauhin J. 1598 Historia novi et admirabilis fontis balneique in ducatu Wittembergii, etc. - Montisbeligardi.

12. Bechstein et 1804 Vollstandige naturgeschichte der Schadlichen ForsScharfenberg. 1805 tinsekten. - Leipzig.

13. Berkenhut. 1789 Synopsis of the natural History of great Britain and Ireland. - London.

14Blainville(de) 1823 Principes d'anatomic comparéc. - In-80, Paris.

15. Blanchard. 181; Hist. natur. des Insectes, etc. -2 vol. in- $8^{\circ}, 20 \mathrm{pl}$. gr. Paris.

16. - $\quad 18.51$ De la circulation chez les insectes. - Ann. des Sc. nat. p. 359 et 371 .

17. - $189 ;$ Métamorphoses, mocurs et instinct des insectes. Gr. in-8', $40 \mathrm{pl}$. Paris.

18. Bock. 178.5 Versuch einer wirthschaftlichen Naturgeschichte von dem Konigr, ost-und Westpreussen.-Dessau.

19. Boitard. 1813 Entomologic. - Encycl. Roret.

20. Bolivar. 1876 Apuntes acerea de la caza y conservacion de los Insectos. - In-8 , Madrid.

21. Bonnsdorf.

De fabrica et usu palporum in insectis.

22. Borowski. 1787 Gemeinnützige Naturgesch. der Thierreichs, fortgesetz von J. Fr. W. Herbst. - Berlin.

23. Bouché.

1833 Naturgeschichte der Schadlichen und nützlichen garten Insecten. - In- $\mathbf{8}^{\circ}$, Berlin.

2. -

1831 Naturg. der Ins. Ihre ersten Zustande als Larven und Puppen. - In-8, $10 \mathrm{pl}$. gr. Berlin.

25. Brandt Ed. 1870 Recherches anatomiques et morphologiques sur le système norveux des hymén. - Ctes-rendus de l'Acad. des Sc. t. 83, no 12.

26. Bremi.

1819 Beschreibung einiger Hymenopteren - Stett. Ent. Zeit.

27. Brullé. 1832 Expédition scientifique de Morée- Paris.

$28 . \quad-$

$181 i$ Recherches sur la transformation des appendices dans les articulés. - Ann. des Sc. nat. p. 271.

29. Brunich. 176$\}$ Entomologia sistens insectorum tabulas systematicas cum introductione et iconibus. - In- $\AA^{\circ}$, Hafnix.

30.Buchwald(de) 1760 Specics inscetologix Danix. In-80, Hafnix. 
31. Burmeister 183? Handbuch der Entomologic. - In-80, $18 \mathrm{pl}$. in-1 ${ }^{\circ}$, 185.5 Berlin.

32. - 1836 Manual of Entomology, transl, by Shuchard. In-8', $32 \mathrm{pl}$. part. col. Londres.

33. Carpenter. 1859) Animal P'hysiology. - Londres.

31. Carus et 1863 Handbuch der Zoologic. - In-8n, Leipzig.

35. Carus C. G. 1829 Analekten zur Naturwissenschaft und Steilkunde.In-8;, Dresden, $p l$.

36. Carus V. 18 í Bibliotheca Zoologica. - T. II, Insecta, in-s", 1860 Leipzig.

3\%. Cederhjelm 1793 Fauna Ingrica, scu descript. method. Insectorum agri Petropolensis. - In- $8^{\circ}, 3 \mathrm{pl}$. col. Leipzig.

38. Christius

1791 Naturgeschichte, Rilassification und Nomenclatur der Insekten, vom Bienen; Wespen und Ameisongeschlechte. - In-1' $60 \mathrm{pl}$. col. Francforl-s.Mein.

39. Clairville. $\quad{ }_{1806}^{1793}$ Entomologie helvétique. - Zurich.

40. Claparéde. 1857 Sur la morphologic des yeux chez les arthropodes. - Ann.des Sc. nat. p. 381 .

41. Coquebert. 179) Illustratio iconographica Insectorum qua in Musœis parisiensis observavit et in lucem edidit J. C. Fabricius, etc. -3 parties, an vu, Parisiis.

42. Costa A. 1861 Faiuna di regno del Napoli. - In- $4^{\circ}$, Naples.

43.

186 fi $^{\circ}$ Annuario del Mfuseo zool. della R. universita di Napoli.

í. - 1866 Annuario del Museo zool. della R. universita di. Napoli.

45. - 186 I'rospetto sistem. degli imenotteri italiani con. 1871 illustr. di specie nuove. $-I n-4^{\circ}$, Naples.

4fi. - 1869 Annuario del Ifuseo zool. della R. universita di Napoli.

17. - 1871 Annuario del Museo zool. della R. universita di Napoli.

48. Curtis J. 182' British Entomology. - Londres.

49. Cuvier. 1836 Le règne animal distribué d'après son organisation, 1816 ete, -20 vol. gr. in- $8^{\circ}, 993 \mathrm{pl}$.col. Paris.

50. - $\quad 1798$ Traité élémentaire de l'histoiro naturelle des animaux. - In- $8^{\circ}$.

51. Cyrillo. 1787 Entomologix Neapolitanx Specimen primum. In-fol. Napoli. 
52. Dahlbom. 1831. Exercitationes lyymenopt. ad illustr. faunam Sueci1833 cam. - Londres.

53. Dætzel. 1802 Lehrbuch der praktischen Forstwissenschaft. 1804 Munich.

Degéer.

Voir : Geer (de).

54. Derham. 1720 Physico-Theology or a Demonstration of the Being and Attributes of God, etc. - In- $8_{0}$, Londres.

55. Déterville. 1816 Dictionnaire d'histoire naturelle. - 36 vol. Paris.

1819 (Entomologie par Latreille, Olivier, etc).

56. Dietrich. 1863 Beitracge zur Kennitniss dẹ im Kanton Zürich einheimischen Insekten. - Mitth. der Schw. ent. Ges.

57. Donovan. 1792 The natural IIistory of British Insects. - 16 fasc. 1816 in-8o. Londres.

58. Dours. 186 ' Catalogue raisonné des IIym. du département de la Somme. - Amiens.

5.) - -

$187^{\prime}$ Catalogue synonymique des Hym. de France. Mém. de la Société Linnéenne du Nord de la France.

69. Dufour et Perris.

61. - -

6?. -

63. - -

6't. -

65. -

63. -

67.Duftschmidt

63. Dujardin.

6). -

70

1867 Mémoires sur les yeux simples ou stemmates des animaux articulés. - Ann. des Sc. nat. p. 104. 
71. Duméril. 1799 Plan d'une méthode naturelle pour l'étude et la classification des insectes. - Bulletin de la Soc. philomatique, p. 153.

i̊. - 1833 Considérations générales sur les insectes. - In-8。, $60 \mathrm{pl}$. Paris.

73. - $\quad$ Lis Lapport sur un mémoire de Ch. Lespès relatif à l'appareil auditif des insectes. - Ann. des Sc. nat. p. 230 .

ii. - 1869 Entomologie analytique. - 2 vol. in-1。, $500 \mathrm{fig}$. Paris.

75. Dutrochet. 1810 Recherches sur la chaleur propre des êtres vivant à basse température. - Ann. des Sc. nat. p. 5.

76. -

7i. Eiselt.

78. Erichson.

79. Eversmann

S0. Fabre.

81. Fabricius. 1\%.) Systema entomologie, sistens ingectorum classes, etc. - In-So, Lipsix.

$\begin{array}{ll}\text { 8.. } & - \\ \text { ⒊ } & - \\ \text { si. } & - \\ 85 . & - \\ \text { si. } & - \\ 8 \% . & - \\ 88 . & - \\ 89 . & -\end{array}$

90. Fallèn.

91.

1818 Sur la métamorphose du canal intestinal des insectes. - Journal de Physique, tome Lxxxvr.

Iijic Geschichte, Sistematik und Litteratur der Inscktenkunde. - In-8 ${ }^{\circ}$ Leipzig.

1 S'i $^{\prime}$ De fabrica et usu Antennarum in inscctis. - In-1 $1^{\circ}$, pl.Berlin.

18.:- Fauna lyymenopterologica Volgo-Uralensis, etc. Bull. de la Soc. imp. des Nalural. de Moscou.

185. Etudes sur le rỏle du tissı adipeux dans les sécrétions urinaires che\% les insectes. - I mn. des Sc. nat. p. 351 .

1iTs Genera Insectorum. - In-S , Kiel.

Iтis Philosophia entomologica. - In- $\delta^{\circ}$, IIamburgi.

1irg Reise nach Norvegien. - Ilamburg.

Iisl Species Insectorum, etc- - 2 vol. in-se, IIamburgi.

IRT Mantissa Insectorum, sistens species nuper detectas. -2 vol. in-80, IIafnix.

1792 Entomologia systematica, emendata et aucta. it vol. Hapinix.

1798 Supplementum Entomologie systematice. - In.-8, IIafrix.

IS04 Systema piezatorum. - Brunswigx.

180? Obscrvationes entomologicic, -2 part. in-10, Lund.

1807 Specimen novam hymenoptera disponendi methodum exhibens. - Lund. 
92. Forster J. $1 \pi i 1$ Nove specicsinsectorum, centuriaprima.-Londres.

93. Foerșter A. 1877 Uber die systematischen Werth der Flügelgeader bei der inseckten, etc. - In-10, Aix-la-Chapelle.

94. Fourcroy. 1785 Entomologia parisiensis. -2 vol. in-12, Paris. 95. Frauenfeld 1861 Beitrag zur Fauna Dalmatiens. - Vienne.
(von).

96. Frisch. $\quad 1721$ Beschreibung von allerlei Insekten in Deutschland. $173 \times 13$ part. $38 \mathrm{pl}$. Berlin.

97. Fritsch. 1978 Die Hemtflügler, - Vienne, in-40, $70 \mathrm{p} .6 \mathrm{pl}$.

98. Fuesslin. 17\%5 Verzeichniss der ihm bekannten Schweizerischen Insecten. $-I n-4^{\circ}, p l$. Zurich.

99. - $\quad 179$ Archiv der Inseclen Geschichte. - In-10, $50 \mathrm{pl}$. col. Wintherthur.

100. Gauin M. 1869 Uber der Embryonalhülle der IIymenopt. und Lepidopt. Embryonen. - St-Petersbourg, gr. in-1 $\mathbf{4}^{\circ}$.

101. Geer (de) 1752 Mémoires pour servir à l'histoire des insectes. 1774 In-40, Stockholm.

102. Geoffroy. 176't Histoire des insectes des environs de Paris. 2 vol. in $-4^{\circ}, 22 \mathrm{pl}$. col. Paris.

103. Geoffroy 1823 Sur le système intravertébral des insectes. - Bull. St-Hilaire. de la Soc. philom. p. 40.

101. Gerstaecker. 1863 Handbuch der Zoologie. - Leipzig.

105. Ghiliani. 1810 Catalogo degl'Imenotteri raccolti in Sicilia nel 1839. - Atli dellAcademia gionia di Catania, vol. XIX.

106. Girard, M. 1869 Recherches sur la chaleur animale des invertébrés. et spécialement des insectes. $-2 \mathrm{pl}$. Paris.

107. - $\quad 18 \pi$ Les métamorphoses des insectes. - Paris.

108. - $\quad{ }_{1879}^{1876}$ Traité élémentaire d'entomologie. - Paris.

109. Giraud. 1863 Mlém. sur les ins. qui vivent sur le roseau commun. Verhandl.d. z. b. Gesells. Vienne.

110. - 1863 Hyménoptères recueillis aux environs de Suze. Verhandl. d. z. b. Gesells. Vienne.

111. - $\quad 1866$ Mém. sur les insectes qui nichent dans les tiges de ronce. - Ann. Soc. entom. franç. Paris.

112. Gleditsch. $17 \%$ systematische Einleitung in die neuere Forstwissenschaft. - Berlin.

113. Gliemann 1821 Geographische Beschreibung von Island.-Altona.

114. Gmelin. $178 \times$ Caroli a Linné systema naturx. Editio xırı, aucta, reformata. - Lipsix. 
115. Goedart J. 166? Metamorphosis et historia naturalis insectorum. In-12, 62 pl. Medioburgi.

116. Goeze. 1780 Editio germanica operis Geeriani.

117. Goureau. 1א6' Les insectes utiles et les insectes nuisibles. Auxerre.

118. Gravenhorst $1 \mathrm{~s} 01$ Dissertatio sistens conspectum historix entomologix imprimis systematum ontomologicorum. - In-f́s, IIelmstadt.

119. Griffith. 1832 The animal Kingdom arranged in Conformity with its Organization by the Baron Cuvier.-Londres.

120. Guérin- 1829 Iconographic du règne animal. -3 vol.gr. in-\{́, Méneville. 181't Paris.

121. -1835

Genera des insectes. - In $-80,60 \mathrm{pl}$, col. Paris.

122. Hæfnagel. 1630 Diversæ insectorum volatilium icones ad vivum depictac. - Francof.ad MI.

123. Hagen. $1 \& 63$ Bibliotheca entomologica, etc. - 2 vol. in-8o, Leipzig.

124. HarrisMoses.

1782 Exposition of english Insects. - London.

125. Haussmann.

126 Heer.

1803 De animalium cxsanguinum respiratione. - In-4, Hanovre.

1868 Uber fossile-Ilymenopt. aus CEningen und Radobodj. - In-1o, 3 pl. Zurich.

137. Hennert. 1798 Uber Raupenfrass und Windbruch in den Proussischen Forsten. - Leipzig.

128. Hentsch. 180 ' Epitome Entomologice systomaticæ sec. Fâbricium, continens genera et species Insectorum Eropæorum. - Lipsiie.

129. Hérold. 1835 Disquisitiones de Animalium vertebris carentium in oro generatione. - Francfort-s.-M., in-fol.

1:0. - -

131. Hooke. 1665 Micrographia, or some physiological Descriptions

1824 Physiologische Untersuchungen uber das Ruckengefass der Insecten. - Marburg. of minute Bodies made by magnifying Glasses.In-fol. Londres.

132. Illiger. 1795 Edition de la Fauna Etrusea, de Rossi,- 2 vol. in $-\mathrm{S}_{0}$, $11 \mathrm{pl}$. col. Helmstadt.

13:3. - -

1898 Entomologie helvétique. - 2 vol. in-80, Zurich.

131. - 1802 Magazin für Inscktenkunde. -6 vol. in-80, Braus1807 weig. 
CXL

135. Jacob 1'Admiral.

136. Jacquelin du Val.

137. Jaennicke

138. Joly .

139. Jonston.

140. Jurine.

111.

112. Kaltenbach (von)

143. Karsten.

144. Kawall.

\section{Kirby et} Spence.

146.

147. Kirschner

148. Künckel.

119. LacazeDuthiers.

150. Lacordaire

151. Laicharting.

152. Lamark(de) 1812 Sur les animaux sans vertèbres.-in-8, 127 p. Paris. 153. 1801 Système des animaux sans vertèbres. - in-8, Paris

151. Latreille. 1796 Précis les caractères génériques des insectes, disposés dans un ordre naturel. $-\Lambda n \mathrm{~V}$, Brives.
1740 Observations curieuses sur les métamorphoses de beaucoup d'insectes (en hollandais). - In-folio, $25 \mathrm{pl}$. Amsterdam.

18.ji Genera des Coléoptères d'Europe. - Introduction.

$186 \pi$ Zur IIymenopteren Fauna der Umgegend von Frankfurt-a-M. - Berliner entom. Zeitsch.

1819 Mémoire sur l'existence supposée d'une circulation péri-trachéenne chez les insectes. - Ann. des Sc. nat.

$16.33 \mathrm{~J}$. Jonstoni historix naturalis de Insectis. - Amslelodami.

181\% Nouvelle méthode de classer les liyménoplères et les diptères. - Genève, in-4ㅇ, $14 \mathrm{pl}$. col.

1818 Observations sur les ailes des hyménoptères. In-to, $6 \mathrm{pl}$. Paris,

1862 Die Pflanzenfeinde aus der Filasse der Insekten. Stullyard.

1789 Musoum Leskeanum.-Regnumanimale-Insectacura J.J.Z. Schachii.

1804 Beitraege zur Kenntniss der IIymenopteren-Fauna Russlands. - Bull. Soc. imp. d. Nat. de Moscou, p. 293.

1818 Introduction to Entomologry - $1^{\text {re }}$ édilion, $2 \mathrm{rol}$. in-so, $5 \mathrm{pl}$. col. Loudres.

185. Introduction to Entomology. - $7^{\mathrm{e}}$ édition, $1 \mathrm{vol}$. in-So, Londres.

1867 Catalogus Ifymenopterorum Europe. - In-\&o, Vindebone.

1868 Nole sur l'existence des vaisseaux capillaires artèricls chez les insectes.-Amn. des Sc. nat. p. 87.

1819 Mémoire sur lappareil génital femelle des hyménopt. Ann. des Sc. nat.

1837 Introduction à I'élude de l'Entomologic-2 vol. in-8o, pl. Paris.

1781 Verzeichniss und Beschreibung der Tyroler-Insckten. 178' -2 vol. int-8Zürich. 
155. Latreille. 18.2 Histuire naturelle des crustacés et des insectes. isit 1 1 rol., $113 \mathrm{pl}$. Paris.

15i. - 1806 Genern cruslaccorum el insectorum. - 1 vol. $16 \mathrm{pl}$. 1809 Paris.

15. - $\quad 1810$ Considerations grenirales sur l'ordre naturel des animaux composant la classe des crustacis, des arachnides et des insectes. - In-S $S_{0}, P_{i} r i s$.

15s. - 1816 Articles entomologiques dans le Nouveau Dict. 1819 Cllist. nat. appliquée aux arts, etc., par une réunion de naturalistes et d'auriculteurs, dit: Dictionnaire le Délerville.

15:. - 182? De la formation des ailes chez les insectes. - In- $\Theta^{\circ}$, Paris.

160. - $\quad$ 16:5 Famil'es naturelles du règne animal. - In-80.

161. - $183:$ Cours dientomologic. - In-S०, allas.

162. Leach. Tixlit The zoological Miscellany, being Descriptions of 1817 new or interesting Anima!s. - 3 vol. in-8。, 120 pl. col. Londres.

163. - 1st; Tabular View of the external Characters of Insects ne distribut of the Genera. - In-1n, Londres.

16\%. Lefebvre. 1838 Sur l'odorat des insectes. - Ann. Soc. ent. fr., p. 395.

165. Lehmann. 179) De sensibus externis animalium exsanguium.

166. - $\quad 180$ ) De antennis insectorum. Dissertatio prior et dissert. posterior. - Hamburgi et Londini.

16\%. Lepelletier 18:5 Encyclopédic méthodique (articles divers).

168. -elServille 1\$:3 Faune française. - Paris.

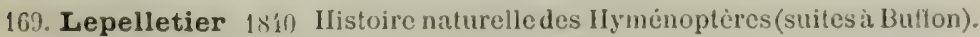
-In-so, 4 vol. Paris.

170. Lereboullet 185\% Coup d'œil sur l'organisation des insectes. - In-8०, Strasbourg.

171. Lespès. $\quad 1 \times 6.3$ Mémoire sur l'appareil auditif des insectes. $-A n n$. des Sc. nat., p. 2.25.

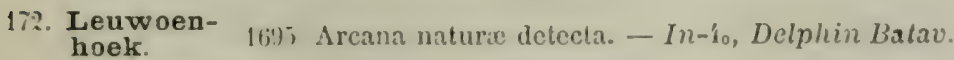

173.Lindemann 1 sil Das Skelet der IIymenopteren, - Bull. de la Soc. des Nat. de Moscou, p. 306.

17i. Linné. 17:2) Fauna Succica. 
175. Linné.

170. -

17\%. -

178.

179.

180.

181.

$18 \%$ - $\quad 1753$

$183 . \quad-\quad 17.55$

$184 . \quad-\quad 1759$

$185 . \quad-\quad 176 ?$

186. - 1766

187. - 1788

1788
1793

188. - -

189. -

190. Lister.

191. Lucas.

19?. Mac-Lexy

$193 . \quad-$

194. Marcel de Serres.

195.

740

1735 Caroli Linnxi Systema naturx, sive regna tria naturæ systematice proposita per classes, ordines, genera et species. - Lugd. Batav., gr. in-folio, $14 \mathrm{pl}$.

740 Systemanaturx.-2e édilion revue par Linné.

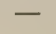

$3^{2}$ édition, réimpression de la $1^{\text {rs. }}$.

'́e édition, réimpression de la 2:.

5e édition, réimpression de la 22. Gédilion, revue par Linné.

édition, réimpression de la $6^{\mathrm{e}}$. $8^{\mathrm{e}}$ édition, réimpression de la $6 \mathrm{e}$. $9^{\circ}$ idition, réimpression de la $6^{\mathrm{e}}$. $10^{e}$ édition, revue par Linné.

- $\quad$ Lédition, réimpression de li L".

- $\quad 12 e$ édition, revue par Linné.

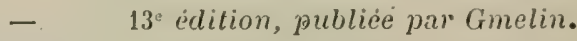

1761 Fauna suecica. - 2e éd., Stockholm.

1789 Entomologia faune Suecia descript. aucta; curis C. de Villers.-4 vol. in-S', $12 \mathrm{pl} . \mathrm{gr}$. Lugdunis.

1710 Ilistoria insectorum cui subjungitur appendix de scarabxis britannicis. - In-ta, Londres.

1845 Histoire naturelle des animaux articulés de l'Algérie (tiré de l'Exploration de l:Algérie). -3 vol. gr. in-1 $1^{\circ}, 122 \mathrm{pl}$. col. Paris.

1819 Hor entomologicx, or Essay on the amnulose Ani$18 ? 1$ mals. - 2 vol. in- ${ }^{\circ}$, Lonelon.

(13) Explanation of the comparative Anatomy of the Thorax in wingeds Insects, etc.-Zool--Journal, t. v, p. 45, et Ann. des Sc. nat., p. 95 .

1813 Mémoire sur les yeux lisses et les yeux composćs des insectes. - In- $\delta_{0}$, Montpellier.

1810 De l'odorat et des organes qui paraissent en être le siége chez les insectes. - Ann. du Museum, $t$. xvir. 

196. Marcel de 1813 Olservations sur les usages des diverses parties du
Serres. tube intestinal des insectes. - Ann. du Museum. t. $x x$

197. Marey. 1869 Némoire sur le vol des insectes et des oiscaux. In-8, fig- Paris.

198. Marquet. 1875 Apergu des insectes hyménoptères qui habitent une partie du I.anguedoc. - In- $\delta^{\circ}$, Toulouse.

199. Mayr.

1853 Beitrag zur Kenntniss der Insecterfauna Siebenbürgens.

90.) Merian. 1730 De Europische Insecten met beschrij. van d. planten. - Gr. in-folio, ĩ pl., Amsterdam.

2)1. Meyer-Dur 1si? Weilere Beilraege zur Schweizerischen Iymen.Kunde. - Mitth. ،. Schweiz. Gesull.seh., p. 37.

20?. Mink. 1sio springende Ilymenopteren Puppen. - Tijdschrifl von Entomologie, p. 28.j.

903. Mocsary. 18i i Zur IIymonopteren-Fauna Siebenbürgens, - IIermannstadt.

201. Molden-

hauer.

1812 Beitrage zur Anatomie der Pflanzen,-Kiel, in-1?

20). Moore J. 1831 liemarks on the Study of Entomology, and an IIymenopterous Insect. - Manchester.

206. Mouffiet. 153 Insectorum sive minimorum animalium theatrum, etc. - In-fol., Londres.

20\%. Muhr J. 1878 I) Mundheile der Insekten. - In-fol. Prague.

215. Miuller J. 1816 Dissertatio de vase dorsali insectorum.-1 vol. in-'tn. Berlin.

219) - - 1826 Zur vergleichende Physiologie der Gesichtsimnes.In-8 ${ }^{\circ}$, Leipzig. - Supplément dans les archives für die Entomologic, de Merkel. - Traduit et inséré par extrait dans les Ann. des Sc. nat., t. xitl et xim.

210. Muller A. 1 wit On the Dispersal of non-Migratory Insect hy atmospheric Agencies. - In-1, Bale (ex Trans. Ent. Soc. Lond. 187I).

211. Newport. 1אi:- Observations sur le développement des corpuscules sanguins che\% les insectes et autres invertébrés.Ann des Sic. nat., p. 391 .

21:. Oken. 18:1 Naturgeschichte für Schulen. - In- $8_{0}$, Leipzig.

213. Olivier. 1is, Entomologie.

211.

1\%у0 Encyclopédie méthodique. 
215. Orbigny(d' 1619 Dictionnaire universel d'listoire naturelle.

216. Owen. 1818 Lectures on the comparative Anatomy and Physiology of the Invertebrate Animals. - London.

217. Pallas. $\quad 1781$ Icones insectorum, prasertim Rossix Sibirixque 1782 peculiarum. - In-1", Erlangen.

218. Panzer. 1793 Faune insectorum Germanise initia.-Deutschlands 181't Insecten.-Continué par Germar, puis H. Scheffer. - In-12 obl., $45 \% 2 \mathrm{pl}$. gr. et col.

219. - $\quad 1803$ Kiritische Revision der Insckten Fauna Deutschlands, nach dem System bearbeitet.

220. Peinture d'histoire naturelle (manuel de). - Encyclopédie Roret.

221. Pelletan. 1876 Le microscope et ses applications. - 1 vol. in- $8^{\circ}$,

2:2. Percheron 1837 Bibliographic entomologique. -2 vol. in $-3_{0}$.

223. Perris. 18.50 Recherches sur lodorat chez les articulés. - Ann. des Sc. nat.

221. Perty.

22.). Petagna.

226. Petiver.

227. Picret.

228. Plateau.

229. Poda.

230. Posselt.

231. Preyssler

232. Ramdhor

233. - -

234. - -
Delectus animalium articulatorum.

1787 Specimen insectorum ulterioris Calabrix. - In-1 ${ }^{0}$, 1 vol. $1 \mathrm{pl}$. Napoli.

1702 Gazophylacium nature et arlis. - In-fol. Londres. 181 ' Sur lodorat des insectes. - Ann. Soc. ent. fr.

1871 Quest-ce que laile d'un insecte? - Stelt. Ent. Zeit. p. 33.

176! Insecta musæi grrecensis, gute in ordines, genera et species juxta Systema natura Caroli Linnæi digessit. - In- s. $^{\circ}$.

189't Beilraege zur Anatomic der Insekten. - Iit-ín, Tubingen.

1779 Verzeichniss Buemischer Insckten.-In-8', Prague.

1879 Abbildungen zur Anatomic der Insekten. - In- $\mathbf{l}^{\circ}$, IIalle.

1805 Beitraege zur Entomologie und IIelminthologic. In- $\mathbf{t}^{\circ}$, IIalle.

1 s11 Abbilungen ïber die Verdauns-werkzeuge der Insekten. In-4', Halle. 
235. Ray.

:3fi. Réaumur (de)

237. Redi.

233. Rengger. 1817 Physiologische Unfersuchungen über die thicrische Inushaltung der Insecten. - Tubingen.

23!). Retzius. 1783 Car. Tilsr. Bar. de Geer genera et species insectorum. clc. -In-\$", Lipsix.

2il. Robineau. 1818 Recherches sur l'organisation vertébrale des crustacés, des arachnides el des insectes.-In-80, Paris.

?'1. Roebuck 18 ii Yorkshire Iymenoptera, ctc. - e transact. of the. Yorkshire Naturalist's Union.

21:. Roemer. 17\$9 Genera Insectorum Lin. et Fabr., iconibus illustra1a. - Viloduri.

243. Roesel. 17 íl Monatliche Insecten belustigungen.-In-10. Nümberg. 43 pl. col.

2í. Roget. $\quad 1 \times 3 i$ Animal and vegetalule Physiology. - 2 vol. in-8o. Londres.

2ii. Romand (de)

1839 T'albleau de l'aile sup. des hyménoptères. - Gr. in4. pl. Paris.

2ili. Rondani. 18\%2 I)egli Inselti nocioi et de loro parassits. - Bull.

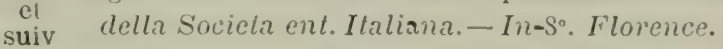

2ií. Rossi.

1790 Fauna etrusea syst. insecta in Provinciis F'lorentini et Pisanà collecta. - ? vol. in-10. $10 \mathrm{pl}$. col. Li_ bourne.

2K. - 179? Mantissa Insectorum, exhibens species nuper in Etru17'y't ria collec'as. - ? vol, in-4․ Pisis.

:i!). Rymes. 1:5i Gencral Outline of the Organisation of the animal lingdom. - Londres.

-2.). Samonelle 1sig) The entomologist useful Compendium. - London.

2.). Savigny.

1816 Memoire sur les animaux sans vertèlıres. - In-80. Paris.

2:2. Schæeffer 176' Ablandlungen ron Insckiten. - 3 vol. in-10. Regens17i!) burg. 
253. Schæffer 1769 Icones insectoram circa Ratisbonam indigenorum J.-C. - in-i ${ }^{\circ} .150 \mathrm{pl}$. col. 3 vol. Regemberg.

254. Scheffer J. 1851 Verzeichniss der Hymenopteren d. Viener gegend In-So. Vienne.

25.. Schelver. 179k Versuch ciner Naturgeschichte der Sinneswerkzcuge bei den Insekten. - in-So. Gottingue.

256. Schluga. $\quad 176 \pi$ Primelinex cognitionis insectorum. $-I n-80$, Vienne:

25\%. Schranck 1781 Enumeratio insectorum Austria indigenorum. - In(von Paula). $\quad 80,4 \mathrm{pl}$. Auguste Vindelicorum.

258. $\quad-\quad 1776$ Beitracge zur Naturgeschichte. - Leipzig.

259. - 1798 Fauna Boïca oder Beschreibung der in Baiern cinheimische Thiere. - Nïremberg.

260. Scopoli. 1763 Entomologia Carniolica, exhibens insecta Carnolice indigena. - in- $\delta^{\circ}$. Vindobonix.

261. - $\quad 1786$ Delicia florx ct faunx Insubrica.

262. Seba. 1734 Locupletissimi rerum naturalium thesauri accurata 1765 descriptio et iconibus artiliciosissimis expressis.

263. Sepp. $\quad 1760$ Merveilles de Dieu exposćes dans les insectes de la 18:9) IIollande. (en Hollandais). -5 vol. in-10.

264. Shuckard. 1836 A Description of the superior Wing of the IIymenoptera etc. - Entom Sociely of London.

265. Siebold (von).

266. Sirodot.

26\%. Sorg.

268. Spinola.

269. Spix.

2311. Sprengel. 1815 Commentarius do quibus insecta spiritus ducunt. -

2\%1. Staveley.

184:3 Uber das Receptaculum Seminis der Hymenopteren Weilssehen.-Germar's Zeitschrift vol. IV.

1858 Recherches sur les sécrétions chez les insectes. Ann. des Sc. natur. p. 1'11 et 251 .

180.5 Disquisitiones physiologica cirea respirationem insectorum et vermium. $-I n-8^{\circ}$. Rudolstalt.

1806 Insectorum Ligurix (imp. hymenop.) species nove 1808 aut rariores. - 2 vol. $i n-1^{\circ}{ }^{\circ}, 7 \mathrm{pl}$. Gênes.

1811 Geschichte und Beurtheilung aller System in der Zoologie, etc. - In- $\delta^{\circ}$, Nïremberg.

$$
\text { Gr. in-10, Leipzig. }
$$

1862 Observations of the Neuration of the Hind Wings of IIymenopterous Insects, etc. - Trans. lin. Sc. of London. 
272. Stephens. 1828 Illustrations of british Entomology, or a Synopsis of 18.46 british Insects. - $12 \mathrm{vol}$. in-So. $100 \mathrm{pl}$. Londres.

273. Strauss. 1828 Considerations générales sur l'anatomic comparée des animaux articulès. $-G r$. in-1̂. Paris.

274. Strœm H. 1762 Physik og acconomisk Beskriwelse over Snndmer

iri. - -

2ii. Sülzer. $\quad 1 \% 64$ heunzeichen der Insekten. - Zürieh.

$2 \pi$

17\%6 Al)gekürste Geschichte der Insckten. - In-1́. 3? pl. Vintherthur

2is Stwammer- 1669 Biblia nature, sive historia insectorum in classns redam. dacta, cun prefatione II. Boerhaave. - in- $\mathfrak{i}^{\circ}$, Leyde.

279. - $\quad 1682$ Traluction Crangaise de l'ouvrage précédent.

280. Taschen- $1866^{\circ}$ Dic Hymenopteren Deutschlands. -1 vol. in- $8^{\circ}$, berg. Leipzig.

281. - 18\% Praktische Inscktenkunde. - In- $\AA^{\circ}$.

282. Thomson. 1 \$ั1 Irmenoptera Seandinavia. - In- $S_{0}$

283. Thünberg. ${ }_{179 .}^{178.1}$ Dissertatio sistens insecta Succica. - In- $1^{\circ}$. Upsal

284. - 178: Muscum animalium academice Upsalensis.

285. Turton W. 1806 A general System of Nature, ete, transladed from Gmelin's last Edition of Systema Nature. Londres.

286. Udmann. 17.M Toveinsectorum species - Norimberge-20 edition revue par Panzer. La $1^{\text {re }}$ est de 1753 .

28\%. Vallisneri. 171:3 Nuove esperienze et osservatione intorno all' origine sui lappi e costumi di vari Insetti. - Paclua.

288. Verloren. 1814 Phénomènes de la circulation chez les insectes. In $10,96 \mathrm{p}$.

289. Villers (de) 1783 C. I.innei entomoloxia faunx Suecix descriptionibus aucta. - In 8o. Lugel.

?.ติ) -

17(M) P'rospectus dune histoire geinérale des insectes do lirance. - Lyon.

291. - -

$1 \% 90$ Nomenclator iconum entomologric Linneane. - Infol, $12 \mathrm{p}, 12 \mathrm{pl}$. 
292. Vogt C. 1839 Bcitraege zur Nerrologie der Insekten.-in-10 $\mathbf{t}^{\circ} \mathrm{pl}$. Neuchatel.

293. Walke- 1812 Faune parisicnne- - Insectes. -2 vol. in-8॰, $7 \mathrm{pl}$. naer C. Paris.

294. Weiss- $1 \$ 6: 3$ Uber dic Entstchung des vollendaten Insects in Larmann. ve und Puppe. - Frankf. a. $\boldsymbol{M}$.

295. Westwood. 1810 An Introduclion to the modern Classification of Insecten. - 2 vol. in-8․ Londres.

296. Wolff. $18 \%$ Das Riechorgan der Hymenopt. d. Wiener gegend. - In-So. Vienne.

29\%. Wood. 1※:1 Illustrations of the Linnean Genera of Inselits. Londres.

298. Wotton. 15: De differentiis animalium. - Lutetze.

299. Zetterstedt 1א2s Fauna insectorum Iapponica. - Pars. 1.

300. - - 1 into Insecta lapponica. - In-10, Lipsix.

301. Zinke. 1;9r Naturgeschichte der schædlichen Nadelholz. Insekten. - Weimar. 


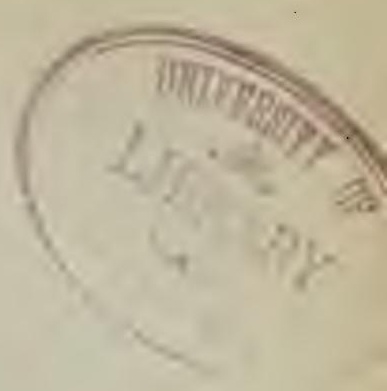

IV

\section{GLOSSAIRE}

Dans toute science, les manières d'être particulières des objets étudiés, ainsi que les diverses parties de ces mêmes objets, ont besoin de pouvoir être exprimées d'une manière claire el précise, de façon que le lecteur: comprenne parfaitement ce dont veut parler l'auteur dont il parcourt l'ouvrage. De là la nécessité de compléter la lanque vulgaire qui néglige les détails, el d'adopter, pour ceux-ci, des expressions spéciales et connues de lous les savants et de tous les travailleurs. C'est un bagage littéraire dont atucune science ne saurait se passer, et dont l'entomologie a besoin comme toutes les autres branches des investigations humaines. Ces termes techniques sont représentés, soit par des mots anciens et vulgaires dont l'acception est restreinte à un objet spécial, soit par des mots entièrement nouveaux.

Comme il est de toute nécessité que cette langue scientifique soit parfaitement connue de chacun, et surtout qu'elle soit trèsprécisée, j'ai pensé ne pouroir me dispenser d'insérer ici un vocabulaire, dont l'importance me semble capitale.

Chaque idiome a ainsi ses expressions spéciales, el, comme un grand nombre d'ouvrages entomologinues sont écrits dans les différentes lanırues usilées en Europe, j’ai eru bon d'étendre ce travail aux deux principales, savoir: l'Allgmand ei l'Anglais. Je

TOME I. 
sais trop quelles dillicultés j'ai dú surmonter pour arriver à m'approprice cette terminologie, pour n'avoir pas jugé utile de faciliter les recherches ultéricures des savants par-la publication de ces glossaires.

Jaurais même virement désiré joindre ici, de la même manière; les vocabulaires Suédois, IIollandais, Espagnols et Italiens; mais j'ai craint que cette longue énumération, tout utile qu'elle pût. ctre, ne fatiguât la bienveillance de mes lecteurs.

La langue latine, comme chacun sait, est l'idiome spécial des naturalistes; c'est elle qui supprime entre eux les frontières terrestres pour n'en faire qu'une seule nation, disons mieux, qu'une seule famille. C'est elle qui présente aussi le plus.de clarté dans la différentiation des expressions roisines. Aussi veux-je m'appuyer ici complètement sur elle, et la prendre pour base en y ramenant les autres langues (1).

J'ajoutcrai enfin deux obscrvations pour l'intelligence des [ables qui suivent. D'abord, certains mots étant employés dans toutes les langues arec leur forme latine, je les placerai seulement dans la liste des mots latins.

Ensuite, pour ce qui regarde spécialement les couleurs, je les ai toutes réunies à la suite du mot color'; mon but, ce faisant, a été de faire mieux ressortir, en les groupant l'une près de l'autre, les différences exprimées par les divers termes, différences sauvent trop peu prises en considération par les auteurs.

J'ajouterai enfin que je n'ai pas inscrit les diminutifs terminés ordinairement par ulus ou ellus. Leur sens exact se déduira facilement de celui du mot simple.

(1) Le glossaire latin donne l'explication de près de 700 mots, qui sont représentés dansles-autres listes par environ 510 mots franeais, 700 mots allemands et 560 mots anglais. 


\section{GLOSSAIRE EXPLICATIF}

\section{LATIN-EITANGAIS}

Abbresiatus, mosourci. - Se dit idune partive pliks courte qu'elle -inest d'ordiraire.

Abdomen, abdomen. - Troisiome ,partie du corps des insectes contenant les organos de la reproduction. (Int. p. IxIXx) (1).

Aciculatus, acionté. - Se dit des antennes ur des palpes, fuand un article très-enurt, aigu. les termine.

Aculeus, aigueillon.- Organe situé arl'extremitéde l'abdomen, dependant de ceux de la reproduction, et sclestiné à former une plaie et à $y$ yerser un venin. ( $\operatorname{Ia} t, p$. Ixxxy).

A whinatus, acumine. - Se dit d'une parlic derminée en pointe. ruand elle est fine, atigile et un peu railic.

Acuprinctatus, acuponclué-Qui eslinement et densément ponctuc.

Acutug, aigu. lmanchnint. - Terminéren pointe line. Se dit aussi du bord saillant ot tranehant d'un organe.

Adhreners, adhérest. - Qui ne peut se.dćlacher facilement.

Affinis, affine. - Se dit diune espece qui, sans etresemblable à une autre, sen rapproche beaucoup.

Alø, ailes. - Organes du vol. (Int. p. L, $\$ 11)$.

Altus, haut. - Indicfuc une partic plus élevérque d"ordinaire.

Ambulatorif pedes, palles ambilatoires. - Ee dit des patles deslinces spécialement à la marche.

Anales pedes, pattes anales. l'attes situées silr le dernier segmont abdominal.

Analis, anal. - Se dit soil des parties quí appartiennent à l'anus, soit de celles qui bont situces du eoté de l'anus.

Angulosus, anguleux. - Qui présente des angles plus ou moins saillants.
Angulus, anule. - Intersection to deux lignes ou de deux surfices.

Angustatus, rélrici. - Qui devient plus étroit.

Angustus, élroit. - Qui est long rolativement ì la largeur.

Annellus, anmelet.- Petils articles places dans les antennes entre 10 serpe et le funicule, ou cutre les premicr et deuxicme arlicles du funienle.

Annuliformis, annuliform:Ln forme d"anneal.

Annulus, anneau. - I.es diverses parties qui composent le thorax et l'aluomen; s'applirfue surtout aux laries.

Ante. - Prélixe indiquant une situation en avant.

Antenna, antemes. - Organes situés au devant de la tête, et composés dune sirie de pic̀ces articulces les mes aveo les autres. (Int.p. XIIV).

Antepectus. - On a appele ainsi lensemble des partics inférieures et latérales du prothorax.

Anterior anterienu. - Placé du coté ou en devant de la tète.

Anus. - Ouverture pratiquée à l'extrémité de l'abdomen pour la sorlie des aliments. - Extrémité méme de labiomen.

Apex, extrimile. - Partic terminale d'un organe.

Apicalis, apical. - Qui lient à lextrémité d'un organe ou d'une purtic du corps.

Apodemata, apodèmes.-Prolongrements intéricurs des parties externes soludées entre elles.

Apodus, apode. - Dépourvu de paties.

Appendiceus, appendice.- Se dit diue collule alairo qui présente a sia suile un fragment de nervure.

(1) Je renvoic ainsi à la page de l'introduction, oir l'on trouvera des détails plus circonstanciés sur le mot. 
Appendiculatus, appendiculé.Aliui d'appendices.

Appendix, appendice. - Toute piece accessoire qui est placée sur une autre.

Approximatus, rapproché. - Sc dit des antennes, des yeux, des himches, etc, quand l'espace qui les scipare est étroit.

Apterus, aptere. - Dépourvu d'ailes.

Arcuatus, arqué. - Fn forme diarc.

Area, champ, surface. - Espacc linnité de lorme quelconque.

Areola, aréole. - Petile cellule.

Areolatus, aréolé. - Qui porte des arèoles.

Armillatus. - Garni dune bande colorée comme un bracelet.

Articulatio, articulation. - Porlions contigües de deux organespar lesquelles ils sont articulés l"un avec l'autre.

Articulatus, articulé - Composé d'articles. - Se dit d'une partio crui peut se mouvoir sur une autre partie, tout en y étant fixée.

Articulus, article. - Pièces' qui sont liées ensemble, tout en conservant leur mobilité, et qui, par leur réunion, forment un corps ou un organe.

Asper, chagriné. - Parsemé de petils lubercules très rapprochés, comme la peau de chagrin.

Attenuatus, atténué.-Qui diminue subitement de largeur ou d'épaisseur.

Auriculatus, auriculé. - Se dit d'u ıe partic dilatée la téralement de part et d'autre en forme d'oreille.

Axillaris, axillaire. - Qui se rapporient it l'aisselle ou à l'épaule.

Baculiformis, baculiforme. - En forme de bàton; de bagnetle.

Barbatus, barbu. - Qui a des poils réunis en petits bouguets plus longs que ceux des parties voisines.

Basalis, basal. - Qui tient à la base.

Basilaris, basilaire, - Qui se rapporte it la base.

Basis, base. - C'est la portion de tout organe qui est la plus rapprochéc du milieu du thorax.

$\mathbf{B i},-$ Prélixe indiquant qu'une chose est double.

Bifidus, bifide.-Se dit d'une partic quelconque diviscee à son extrémité en deux branches.

Bombinatio, bombus, bourdonnemerit. - Bruit que font certains insectes en volant. (Int. p. CIX)

Brachialis, brachial. - Se dit quelquefoisd'une nervurealaire. - Nom de la cellule la plus supérieure des ailes à leur base.

Brevis, court. - Toute partie d une espece est dite courte quand clle reste au dessous des proportions ordinaires dans les espèces de la mênefamille. D une manière générale, lantenne est courte si elle égale seulement la longueur de la tête; les ailes sont courtes si elles n’atteignent pas l'extrémité de l'abdomen; les pattes sont courtes, quand les postérieures n'atteignent pas, dansleur plus grande extension, l'extrémité de l'abdomen, ou quand les antérieures ne dépassent pas le devant de la tète, etc.

Cælatus, ciselé. - Surface présentant des portions planes de forme varice, plus élevées que le reste.

Galcar, éperon. - Petits appendices pointus ou de forme diverse qui se trouvent aux extrémilés des tibias de beaucoup d'espèces, et sont souvent mobiles.

Galcaratus, éperonné. - Pourvu d'eperons.

Callosus, calleux.-Paraissant formé d'une substance sèche, épaisse. rugreuse et différente du reste de la surlace.

Gallum, callus,callositè.-Endroit calleux.

Galvus, chauve. - Se dit d'une portion dépourvue de poils dans une surface qui en est couverte.

Canaliculatus, canaliculé.-Présentant un canal longitudinal.

Capillaceus, capillace. - en forme de chevelt.

Caput, tête. - Partie antéricure du corps portant les yeux, les antennes et les pieces de la bouche (Int. p. xu).

Carina, carène. - Ligne élevée et tranchante.

Carinatus, carèné. - P'ortant une ligne longitudinale élevée et trancliante. - Se dit aussi d'une surface dont les bords se relèvent de facon ì former une gouttière au milieu.

Carpus, carpe ou stigma. - Portion épaissic de la nervure costale 
de l'aile antérieure choz beaucoup dhrménoptères. (Int. p. LXV. et Laxix).

Catenatus, catenulatus, enchaini. - Se dil d'une surface portant des seulptures dont l'ensemble simule une chaine.

Cauda, queve. - Derniers anneaux del iublomen, quand, dans quelques esprees, ils se prolongent d'une facen anormale

Caulis, tige. - Partie basılaire des machures plus ou moins cornèe. - In a aussi donné ce nom au funicule de lantenne, en dehors di: lit massue.

Gavatus, creusé. - Qui porte une cavilé.

Cavitas, cavité. - Partie enfoncés prolimdement.

Cellula, cellule. - Portion de la nembranc de l'aile enfermée entre plusieurs nervures.

Cenchri, grains. - Petites parties calleuses el souvent dérudées qui se llouvent, chez beatico:sp d'hymónoptères, a la base du métathorilx

Cerci, valoules hypopygiales.V. hypopygium.

Cernuus, incliné. - Se dit de la tète, inisfu'elle forme un angle droit avec le thorax.

Character, caractire. - Ce qui, dius lit structure diun insecte, le fail distinguer llun autre.

Cibaria instrumenta. - Ensembie des organes buccaux.

Cicatricosus, cicatrise. - Portant des parties saillantes avec des ligues légèrement enfoncées dans lesin! crvalles, imitant les cicatrices

Ciliatus, cilie. - Garni de cils.

Cilium, cil. - Petils poils courts et riaides placés parallèlement sur une ligne, ou sur le bord de quelrue orgathe.

Cinctus, cingulatus, ceint.-Qui purte une bande autrement colorée a la base ou au milieu de l'abdonien.

Gla thratus, barré. - Se dit diune surface dont les seulptures simulent des barreaux.

Clava, massue. - Rentlement de l'extrémité de l'antenne.

Clavatus, claviformis, claviforme. - Lin forme de massue.

Clypeatus, clypiace ou clypeiforme. - In forme de bouclier.
Glypeus, épistome. - Pièce située il la partic la plus antérieure de la tète.

Coarctatus, resserré. - Dont la largeur diminue.

Cochleariformis, en forme de cuiller. - Cavité allongée et trèsévasće

Collare, collier. - V. pronotum.

Collum, col.- Pédicule qui joint la tête au thorax.

Color, couleur. -

\section{DENOMINATION DES DIVERSES COULEURS}

COUleur NOIRE

Ater. - Noir pur mat.

Niger. - Noir pur brillant.

Carbonarius, anthracinus. - Noir de charbon.

Ebeninus, - Noir d'übène.

Atrovelutinus. - Noir velonté.

Piceus, picinus. - Noil de poix, un peu gris verdâtre

Fiuliginosus. - Noir de suie.

Fuseus, fusceseens. - Noil brun.

Atrocasinuleus. - Noir blenatre clair.

Atrocyaneus. - Noir bleuâtre soir bre.

Fumatus, fumosus. - Noir transparent enfumé.

Nebulosus. - Gris nuageux.

Nubeculosus. - Légèrement enfumé.

Plumbeus, - Gris jlombeux.

Cinereus, einerescens, leueophous, giltus. - Cris cendré

Griseus. - Gris.

Grisescens. - Grisûtre.

Livilus. - Pâle, plombé, légèrement noiratre.

Chalybeatus. - Gris d'acier, bleuâtre.

\section{covleur bleue}

Indigoteus. - Bleu indigro sombre.

Coruleus, corrulescens. - Bleu de mer loncé.

Cyaneus, cyaneseens. - Bleu azurí foncé.

Acureus, - Bleu d'azur clair.

Jenthinus. - BIeu violet un peu pourpré.

Hyacinthinus, amethystinus. - Azuré violet clair.

COULEUR VEITE

Oliorceus. - Vert olive.

Glanens, - Vert we mer.

Smarrydenus. - Vert émeraude

Prosinus. - Vert blenatre (couleur de Jusireitai)

Viridis. - Vert un peu jaundre

Virescens. - Jaune verciatre.

Eneus, cenescens. - Vert bronzé.

GOULEUR J.IUNE

Chalceus. - Jaune bronzé.

Fulves, - Jaune roux veriâtre.

Suecineus, - Jaune d'ambre, un peu verilitre. 
Citrinus. - Jaune citron clair.

Sulfureus. - Jaune soufre.

Flavescens, flavus, flavidus. - Jaune blond doré,

Aurichalceus. - Jaune d'or bronzé (laiton).

Chrysargyrus. - Vermeil.

Cruceus. - Jaune brillant de safran.

Aureus, auratus. - Jaune d'or métallique.

Stramineus. - Jaune paille.

l.uridus, - Jaunâtre pâle.

Ochraceus. - Jaune d'ucre.

Luteus, lutescens - Jaune un pcu rougeittre (jaune d'œuf).

Aur'cnticueus, - Jaune orangé.

T'estaceus. - Jaune rougre birique.

\section{COULEUR BRUNE}

Castaneus. - Marron.

Alutaceus. - Brun comme le cuir.

Spadiceus. - Kouge brun, bai.

Bacluss. - Rouge brun, bai

Cinnamomeus. - Brun cannelle.

Brtunneus. - Brun.

\section{COULEUR ROUGE}

Rubidus. - Rnuge brun.

Rubiginosus, ferrugineus, ceruginosus. - Rouge de rouille, ferrugineux.

$R$ ufus, riufescens. - Rouge roux.

Rutilus - Roux ardent.

Erythrocus. - Rouge.

Sanguineus, sanguinostes, sanguinolentus. - Rouge sang

Miniatus. - Rouge de miniun.

Ruber, rubescens, - Rouce vermillon.

Carminatus. - Rouge carmin.

Purpureus, Purpurascens. - Rouge pourpre.

Igneus, ignitus, ftammatus. - Rouge feu inétallique.

Cupreus. - Ruuge de cuivre.

Roseus. - Rose.

Violaceus, violaseens. - Roure bleuviolet.

\section{COLTELTR BLANCHE}

Pallidus. - Blanc jaunître.

Eburneus. - Blanc d'ivoire (ton jaunàtre).

Argenteus, argentatus. - Blanc d'argrent (ton bleuâtre).

Niveus. - Blanc de neige.

Albus, albiclus. - Blanc pur.

Albiechs, - Blancavec un ton gris.

Canus, incanus, canescens. - Blanc argentin (comme les cheveux).

Comatus, chevelu.-Portion limitéc diune surface, couverte de poils longs et tins, comme les cheveux.

Communis, commun. - Se ditdun insecte (fue l'on rencontre fréguemment et facilemenl. (te terme na rien d'absolu; il peul étre vrai, pour une espéce domnée, dans une localité et non dans une autre. Un insecte peut êfrotres-commun une année, el devenir rare l'année suivante. La comraissance de l'habitat d'un insecte suffil aussi pour le rendre commun, de rare quil était avant quion ne sut précisciment où le trouver

Complanatus. aplani. - Non rugueux.

Compositi oculi, yeux composes. - Yeux formés d'un grand'nombre de petits yeux élémentaires simples. (Int. p. XLII).

Compressus, comprime. - I'lus haul que large, ou aplati sur les còtés.

Goncolor. concolore. - Se dil rime partic, quand elle est en entier d'une seule couleur, ou cue sa couleur est la méme que celle dime autre partie à laquelle on la compare.

Conicus, conique - Dont le diametre diminue graduellement dine extrémité ì l'autre.

Gonnatus, conné. - Se dit des organes reunis a leur hase.

Constrictus, resserré. - Dont la largeur diminue.

Contiguus, contigu. - Se dit des antemnes, des yeux ou des hanches, quand ces olgancs se touc!ent presque à leur base.

Convexus, conveve. - Quand lo le centre est plus éleré que les bords.

Cordatus, cordiformis, cordiforme - En forme de coeur ou de triangle à angles émoussés.

Coriaceus, coriacé.-Quand la surface est incigale, raboteuse et rappelle cells du cuir brut.

Cornea, cornée.-Membrane extéricule de l'oeil.

Cornei pedes, pattes écailleuses. - Paltes situées, chez les larves, aux segments thoraciques.

Corneus, corné. - Qui a la consislance de la corne.

Corpus, corps. - Ensemble de lontes les parties d'un insecte, quelquelois plus spécialement lá l'éunion de la tête, du thorax et de l'ablomen.

Corrugatus, ridé.-Couvert de plis courts et irréguliers.

Costa, côte. - Bord extérieur de laile. - Ligne saillante élevéc et large sur une surface unic.

Costalis, costal.-Qui se rapporte à la cote (nervure, cellule, etc.).

Gostatus, à côtes. - Surface garnie de cotes. 
Coxa, hanche. - Partic les pattes directement articulec arec le thorax. (lut. p. Lis).

Crassus, ipais. - Quand le diametre est grand relatirement à la longtucur.

Creber, crebrè, serre. - Se dit des points ou des sculptures pressís les uns contre les autres.

Crenatus. erenele. - Se dit do loule parlic pourvac de petites dents obtuses et arrondies.

Cribratus, erible. - Se dit diune stulace qui a l'apparence diun tamis.

Crinitus, chevelu. - Conme comatus. (2ui a des poils longs et forts comme du crin.

Cristatus, is crite.-Qui porte une ligne élevée et franchante, et en nème temps crénelée.

Cubitalis, cubilal. - Se dit des nervures el cellules de l'aile. (Int. p. LAVII).

Cultriformis, cultriforme. - En forme de conleau.

Cuneatus, cuneiformis, cunéiforme - En forme de coin ou de cone.

Cursorii pedes, pattes conreuses. - Pattes, spécialement disposées pour la course rapide.

Cuspidatus, poinlu. - Qui est en forme de pointe.

Cylindricus, cylindrique. - D'un diametre cigal dans toute la lon(2)IIIII)

Deflexus, flichi, courbe, nenché. - Se dit d'un organe dirigé inférieurement.

Dens, dent. - 'Tout appendice dur corné. très-court et plus ou moins pointu ou triangulaire.

Densé, densus, densément, dense. - Se dit des poils, des points, ctc. très-serrés, pressés les uns contre les autres.

Dentatus, dente. - Muni de dents.

Denticulatus, denticule. - Iuni de petites dents.

Dentiformis, dentiforme. - Qui a la forme d'une dent.

Depressus, déprinee. - Se dil d'une partic dont la hauleur est plus courte que la largeur, ou aplatic dans le sens horizontal.

Digitatus, digile. - Se dit lorsque des divisions ou des dessins imitent, par leur disposition, les doigts d'une main.
Dilatatus, lilate. - Sc dit d'une partie qui subit un aceroissement anormal d'un cóté on de l'autre.

Dilutior, plus clair.-Se dit d'une partic dont la teinte est moins foncéc que le reste.

Discoidalis, discoïdal. - Nom d une nervure des ailes qui tient au disque. ( $V$. discus).

Discoïdeus, discoïle. - Qui ressemble à un disque ou it nu plateau.

Discus, disque. - Partic centrale de diverses portions du corps, ailes, thorax, etc.

Distantes, écartés. - Se dit des antemes, des yeux ou des hanches élorgues l'un de l'autro à leur base.

Distinctus, distinct, visible. Facile ì voir ou à constater.

Dorsum, clos. - Pillic supéricure du corps.

Durus, clur. - Difficile à entamer ou à pirfuer.

Echinatus, épineux. - garnì d'épines.

Elatus, íleve. - Qui est porté vers le haut.

Elongatulus, diminutif d'Elongatus

Elongatus, allongé. - Qui est long et un peu étroit.

Emarginatus, échancré. - Se dit quand un bord présente un angle ou une courbe rentrants.

Ensiformis, ensiforme. - Se dit de l'antenne rui est comprimce et à trois côlcis, dont l'un est plusetroit que les deux autres.

Entothorax, Partic thoracique toujours interne (lnt. P. LV).

Epicranium, épicrane. - On appelle ainsi toute la partic supérieure et latérale de la boite qui forme la têle.

Epidemata, épiclemes. - V. Ossicula.

Epiglottis, épiglotte. - V. Epipharynx.

Epimeri, épimères. - Pic̉ces thoraeiques inlerieures recevant les hinches. (Iut, p, LV).

Epipharynx, valie qui sert dopercille au pliaryux et qui est situéc verlicalement at bord superieur ie celui-ci. (lnt. p. xhax).

Epipygium. irecau dursal du derniel segment de lablomen. (Int. p. LxxxIII). 
Episternum, Pièce thoracique inférieure (Int. p. Lv).

Epistomus, épistome. - V. Glypeus.

Erectus, dressé. — Qui s'élève droit.

Excavatus, excavé. - Qui porte une cavité:

Exilis, grêle. - Qui est long et mince.

Exodermus, exoderme. - Se dit d'un parasite qui attaque extérieurement sa victime.

Expansio alarum, envergure. Distance d'une extrémité des ailes antérieures à l'autre, lorsqu'elles sont étendues.

Exsertus, exscrle. - Se dit d'un organe visible à l'extérieur, spécialement de la tarière, quand elle dépasso l'abdomen.

Externus, externe. - Ce qui est en dehors.

Facies, face. - V. Vultus.

Facies, physionomie, apparence particuliere d'une espèce.

Falcatus, falciforme. - Qui a la forme d'une faux.

Farinosus, farineux. - Convert d'une pulvérulence comme de la farine.

Fascia, fascie. - Bande colorée.

Fasciatus, fascié.-Qui porte des fascies.

Fasciculatus, fasciculé. - Se dit des poils ramassés en faisceaux, en huuppes.

Femina, femelle. - Individu du sexe feminin.

Femur. cuisse. - Partie de la patte articulée aux hanches par l'intermédiaire des trochanters et recevant, à son tour, le tibia à son autre extrémité. (int. p. LX).

Filiformis, filiforme. - Qui est linéaire ct allongé comme un fil.

Fimbriatus, frangé. - Garni de poils placés comme des cils, mais non parallèles.

Fissus, fendu. - Dont les divisions sont profondes.

Flabellatus, flabellé. - Se dit de l'antenne, quand la plupart de ses articles émettent des rameaux longs, flexibles, et aplatis. comme les branches d'un éventail.

Flagelliformis, flagelliforme.- En forme de fouct.

Flagellum, funicule. - Partic de l'antenne articuléc au scope. (Int. p. XLIS).

Floccus, poils frangés longs, fius et denses, un peu frisés, de la face inf rieure des cuisses, surtout des postérieures, chez quelques Mellifères.

Foliaceus, foliacé. - Aplati en forme de feuille.

Folliculus, coque. - Enveloppe soyeuse, fermee de toutes par's, où s'enferme un grand nombre de larves pour se translormer en nymphes.

Forcipes, pinces.-Parties externes de l'organe générateur mâle. (Int. p. LXxix).

Forcipiformis, en forme de pinces.

Fossorii pedes, pattes fouisseuses. - Pattes courtes, fortes, appropriées pour creuser la terre.

Fossula, fossette. - Enfoncement assez grand.

Fossulatus, fossulé. - Portant une ou plusieurs fossettes.

Foveatus, foveolatus, fovéolé. Garni d'impressions assez grandes arrondies.

Fractæ, brisées, coudées. - Se dit des antennes quand le funicule peut se replier sur le sçape.

Frons, front. - Partie antérieure de lit tête, située au-dessus des yeux et suus le vertex.

Fumatus, enfumé. - Se dit des ailes quand la membrane est lavee de noir ou de gris, sans perdre Sil ransparence.

Funiculus, funicule. - V. Flagellum. - C'est aussi le ligament qui soutient l'abdomen dans quel(jues cas,

Furcatus, fourchu. - qui présente deux branches.

Fusiformis, fusiforme. - Se dit des organes qui présentent des renllements entre deux paries plus minces.

Fusus, fitière. - Organe secréteur de la soie dont se servent les larves pour construire leur coque.

Geminatus, geminé. - Se dit de deix points très-rapprochés et isolés, ou de deux parties semblables el adhérentes par la base.

Genæ, joues. - Parties de la tête siluees derrière les yeux et audessus de la base des mandibules.

Geniculatus, coudé. - V. Fractæ. 
Genitalia, parlies sevuelles. Organes de la reproduction dans Jos deux sexes.

Genu, genou. - Arliculation de la cuisse el du libia. - On désigne très-souvent ainsi l'extrémité de la cuisse.

Genus, genre. - Rémion de plusiculs especes ayant un grand nombre de caracteres commens. (int, 19. vili).

Gibba, bosse. - Saillic eleréc sur une surlace plane ou aron!ic.

Gibbosus, gibbus, gibbeux: - renflé en forme de bosse.

Glaber, glabve. - bépourvu de poils.

Globosus, ylobuleux: - En forme de boule.

Gracilis, grele. - Qui est diun petil diametre relativement à la longueur.

Granulatus, granulosus, gramule. - Parscme de grains.

Granulus, grain. - Petit point éleve sur une surface unie, pareil it ceux d'une peau de chagrin.

Guttatus, tachete. - Marqué de points colorés ronds en forme de gouttes.

Habitat, Endroit spécial, plante particulière etc..- oik se trouve un insecte.

Hamuli, erochets. - Sortes de petites epines erochues situées sur la cole des ailes inféricures et selvant à les maintenir fixces aux ailes supéricures pendant le vol.

Hemipterus, himiptive. - Dont les ailessont tres-raceourcies.

Hemisphæricus, hémisphérique.En forme de demi-spisere.

Hexapodus, ltexapode. - Qui a six pattes.

Hirsutus, hirtus, hirisse.-Couvert de poils courts, raides et peu serres.

Hispidus, hispide. - Couvert de puils raides et courts comme de jelites épines.

Holosericeus, soyeux. - Qui a un uspicel satinc.

Humeralis, huméral. - Qui se rappurte à l'épaule.

Humerus, épaule. - Parties latérales. souvent ćlargies du prothoritx.

Hyalinus, hyalin. - Transparent.
Hybrida, h!/lride. - Individu né par la réunion des sexes de denx especes roisines.

Hymen, membrane. - Partic tlexible, transparente, mince comme une feuille.

Hypoglossis, h!npoglotte. - V.hypopharynx.

Hypopharynx, valve verticale situéc ch devant el au bolel inféricur du pliaryox, selvant a le fermer avec l'épipliarynx. (Int. p. L).

Hypopygium, Arecau ventral du dermer semment abdominal. (Int. p. เxхxi11).

Imago, insecte parfait. - Insecte qui a subi toutes ses metamorphoses, et est apte à la reproduclion.

Imbricatus, imbriqué. - P'osé l'm sur l'autre, cotmme les tuiles d'un toil

Immaculatus, immaculé. - Sans tilches.

Impressio, impression. - I'oinl vit matuc imprimee.

Impressus, imprimé. - Légècment enfonce dans la surface.

Inæqualis, inégal. - Se dit diune surface qui a des élévations et des entoncements irrégulicrs.

Incisus, coupe. échancre - Qui présente sur sou bord tune incision ou une échancrure.

Incompletus, incomplet. - Se dit d'une cellule qui reste ouverte.

Incrassatus, épaissi. - Qui devient plus épais.

Inermis, v. muticus.

Inferior, inférieur. - Se dit dune partic situéc en dessous d'une autre; du dessous du corps; des ailes postćricures. etc.

Inflatus, enfle. - Se dit de la mas: sue, ruand clle est d'urie grosseur disproportionnece avec le reste de liantenne.

Inflexus, infléchi. - S'applicuc à la tête quand clle forme un angle aigu avee Ic thorax. - Se dit aussi de toule partic courbée en dessous.

Infundibuliformis, infundibuliforme.-Qui a la forme d'um entonnoir.

Infuscatus, assombivi. - $\mathrm{Se}$ dit d'une couleur qui tourne au noir.

Inocularis, inoculaive. - Sc dit do 
l'insertion des antennes dans une échancrure des yeux.

Insertio, insertion. - Endroit où une partie est altachée à une autre

Insertus, inséré. - Placé, attaché.

Integer, entier. - Sans découpure ni division.

Inter. - Préfixe qui ajoute à un mot l'idée que les parties qu'il désigne sont situées entre deux autres ou en enserrent une autre.

Interior, interne. - S'applique it la portion des divers organes quî regarde le corps ou peut s'y appliquer.

Intermedius, intermédiaire. - Se dit de la deuxième paire de pattes fixées au mésothorax.

Interocularis, interoculaire.-placé entre les yeux. Se dit surtout de l'insertion des antennes.

Interruptus, interrompu. - Se dit de toute ligne ou fascie dont quelque portion manque.

Interstitium, intervallum, intervalle. - Surface comprise entre deux stries.

Intricatus, embrouillé. - Se dit d'une sculpture sans forme précise.

Intumescens, gonflé.-Qui se renfle en forme de bosse.

Iricolor, iridescens, irisé. - Qui a tes couleurs de l'arc-en-ciel.

Irregularis, irrégulier. - Se dit des antennes dont - Ia forme ne peut se rattachor à aucune autre connue ou au moins symétrique.

Jubatus, à crinière. - Portant des poils longs et pendants.

Labialis, labial. - Qui se rapporte à la lèvre ou qui y est fixé.

Labiatus, labié. - Qui est en forme de levre.

Labium, lèvre. - Partie inférieure des organes de la bouche comprenant le menton et la languette (Int. p. LI).

Labrum, labre. - Partie de la bouche située au-dessus des mandibules et contiguie à l'épistome. (Int. p. xLvIи).

Laciniatus, laciniẻ.-Qui présente des découpures irrégulières. mais à peu près égales.

Lævigatus, lævis, lisse. - Se dit d'une surface sans inégalités.

Lamella, lamina, lame. - Por- tion aplatie fixce à une partie quelconque du corps.

Laminatus, pourvu d'une lame élevée.

Lanatus, laineux. - Couvert de poils fins, serrés et longs, frisant un peu à l'extrémité, comme la laine.

Lanceolatus, lancéolé. - Allongé et aminci en devant comme un fer de lance.

Lanuginosus, lanugineux. - Couvert d'un duvet long et moëlleux.

Larva, larve. - Etat d'un insecte depuis sa sortie de l'ocuf jusqüà sa transformation en nymphe.

Latus, côté. - Toute partie lalérale du corps.

Latus, large. - Dont la dimension transversale est proportionnellement plus grande que la dimension longitudinale.

Latuscula, facettes. - Petites cornées des yeux composés.

Ligamentum, ligament. - Petits muscles ou tendons qui servent à relier différentes parties.

Ligula, languette. - Partie membrancuse de l'extrémité de la lèvre inférieure. (Int. p. LI).

Ligulatus, ligulé. - Portant un appendice en forme de languette,

Limbatus, bordé. - Dont le bord est coloré autrement que le reste de la surface.

Linea, ligne. - Narque linćaire ćtroite.- Mesure ćgale à $2^{m} 2$ environ.

Linearis, linéaire. - Allongé et à bords parallèles.

Lobatus, lobé. - Porlant des lobes. Lobus, lobe. - Appendice court, arrondi, latéral.

Longitudinalis, longitudinal. Se dit de tout caractère qui règne dans la direction de la longueur du corps.

Longitudo, longueur.- Dimension d'un insecte, du devant de la tête à l'extrémité de l'abdomen.

Longus, long. - L'antenne est longue quand elle égale ou dépasse le corps; les pattes sont longues si elles paraissent hors de proportion avec les dimensions du corps.

Lucidus, luisant. - Qui a un certain ćclat.

Lunatus, luné. - En forme de lune. 
Lunula, lunule. - 'Tache en forme de croissant.

Macula, tache, macule. - Portion limitée, irreguliére, relativement petite el d'une autre couleur que la partic sur laquelle elle se trouve.

Maculatus, taché. - Qui porte des taches.

Mandibulæ, mandibules. - Parties de la bouche placées sous le labre, au nombre de deux, sevant a broyer et à saisir la nourriture (Int. p. $\mathbf{x}_{4} \mathrm{VIII}$ ).

Marginalis, marginal. - Se dit des nervures ou cellules de la partie supérieure des ailes antérieures (Int. p. LXYi).

Marginatus, margine, reborde. Dont le bord est saillant ou d'autre coulcur.

Margo, bord. - Contour d'un organe.

Mas, mâle. - Individu du sexe masculin.

Maxilla, mâchoire. - Parties de la bouche, au nombre de deux, situées au-dessous des mandibules. (Int. p. L).

Maxillaris, maxillaire, - Se dit des palpes fixés aux màchoires.

Medipectus, On a donné ce nom aux parties inférieures et latérales du méso horax.

Medius, médian. - Nom d'une nervure et d'une cellule des ailes. (Int. p. LxviI).

Membranacei pedes, pattes membraneuses. - Pattes fixées, che\% les larves, aux scigments ventraux.

Membranaceus, membraneux. Qibi est de faible consistance, diapliane et minee.

Mentum, menton. - Partie basilaire de la lèvre, cornéc, fixée au bas du pharynx et fermant inféricurement la bouche. (Int. p. LII),

Mesonotum, Partic supéricure du mésothorax.

Mesopleuræ, mésopleures.-Côtés du mésothorax.

Mesosternum, Partic inférieuro du mésothorax.

Mesothorax, second segment thoracique.

Metallicus, métallique. - Qui a le brillant d'un métal poli.

Motamorphosis, métamorphose. Passago des insectes d'un état à un autre.
Metanotum, Parlic supérieure du métathorax.

Metapleuræ,métapleures. - Côtés du métathorax.

Metastornum, Partic "inférieure du métathorax.

Metatarsus, mélatarse. - Premier article des tarses postérieurs.

Metathorax, troisième segment thoracique.

Micans, V. nitens.

Moniliformis, moniliforme. - Se dir des antennes, lorsque leurs arlicles sont arrondis, bien séparés et semblables à des grains de chapelet.

Mucronatus, mucrone. - Terminé par une pointe courte et mousse.

Multi, prétixe joignant l'idèe de grand nombre atu mot qu'il précède, celui-ci étant d'origine latine.

Muricatus, muriqué. - Se: dit de la forme d'une surface, quand elie se lermine en pointe mousse et un peu allongéc.

Musculus, muscle. - Faisceau de fibres contractiles, donnant le mouvement aux organes qui en sont susceptibles.

Mutatio, mue. - Changement de peau que subissent les larves, at plusieurs reprises, avant leur métamorphose en nymphe.

Muticus, mutique. - Qui n'a point d'épine.

Natatorii pedes, pattes natatoires. - Pattes destinées spécialement, par leur forme, à la natation.

Nebulosus, nébuleux. - V. Fumatus.

Nervulatio, nervulation. - Ensemble des nervures.

Nervus, nervure. - Tubes fins parcourant toute la surface do laile et mervant à en soutenir la membrane ot à lui donner de la rigidité.

Nitens, nitidus, brillant. - Etat d'une surface qui presente un éclat particulier.

Nodosus, noueux. - Se dit des articles antennaires qui sont plus gros que les autres, tuberculeux, en forme de nouds.

Nodus, noud. - Partie épaissie du pétiole chez les Fourmis, et en géral tout épaississement arrondi ou tuberculeux.

Notatus; note. - Qui porto des taches rẻgulières et p̧etites. 
Nuditas, nudite. - Endroit nu de lablomen de cerlains hyménoptères.

Nudus, nu. - P'live de poils on d'écail!cs.

Nutans, penche. - Se dit de la têle rfuand clle forme un angle obtus avee le thorax.

Obliquus, oblique. - Qui riest ni triusversal, ni longitudinal.

Obliteratus, oblitéré. - Qui est en partic détruit et dont les fonctions ne peuvent plus s'exécuter.

Oblongus, oblong. - Arrondi aux deux bouts, tout en restant d'egral diametre dans sa longueur.

Obsoletus, obsolete. - P'eu apparent.

Obtusus, obtus.- 'T'erminé en pointe monsse large, non aigile.

Occiput, Partic postérieure de la tête,

Ocellus, ocelle: - Veux lisses et simples stu' le 'rel'tes.

Oculus, wil. - Organe de la vision

Gsophagus, osophage - Première partic du canal digestif s'ouvrant dans le pharynx.

Opacus, opaque, mat. - Non transparent ni translueide, employé aussi dans le sens de : mat, opposé à brillant.

Operaria, ouvrière. - Indivirlu sterile chez quelques groupes d"hyménoptères sociaux,

Orbicularis, orbiculaire. - Qui est d'une forme ronde.

Orbita, orbite. - Porlion de la têle oì est enchassó l'oejl.

Os, bouche. - Ensemble des organes bucenux inféricurs.

Ossicula, osselets. - Petites pièces cornćes servant à l'articulation des ailes avec le thorix.

Ovatus, ovale. - Arrondi ct d'égal diamètre aux deux bouts, mais de plus petit diamètre aux extrémités qu'au milieu.

Oviductus, oviducte. - Canal conduisant les oeuls des ovaires à l'extérieur.

Oviformis, oviforme, ovoide. Arrondi et d'inćgal diamètre aux deux bouts, et de plus pelit diamètre aux cxtrémilés qu’au milieu.

Oviscaptus, oviscapte. - Ippareil de la ponte des ocifs.

Orum, œuf. - Premicr ctat des in- sectes, celui sous lequel ils sont pondus par la mere, et rui donne naissance a la larve.

Palmatus, palme.-Se dil d'un orgranc divisé latéralement ou à lextrémitécn plusieur's pointes comme des doigts.

Palpi, palpes. - Organes arliculés fixis aux machoires et à la levre. (lint. p. LI)

Paraglossæ, paraglosses.- Appendices menilsancux de la languelte.

Parallelus, parallèle. - Pas plus ćcalté d'un cuté que de l'autre.

Parapsices, parapsides. - Division du mesonotum.

Patella, pelote. - Pclites pièces membrancuses ovales, placées cutre les ongles et quelquefois aux articulations des articles tarsaux.

Patria, patrie. - Localifé où se trouve un msecte.- Diffère de l'habitat en ce que ce dernier indique plus spcialement, non le pays, mais les conditions dans lesfuels se rencontre un insecte.

Pectinatus, pectine. - Se dit de l"antenne ruand ses articles portent des appendices latéraux allongés et parallèles, comme les dents d'un peigne.

Pectus, poitrine. - Parlic inféricure du thorax.

Pediolatus, pedunculatus, pidunculé. - P'ourvu d'un péduncule.

Pediolus, pedunculus, pédoncule, pédicule. - I'artie trés-rc' récie pai laquelle labdomen s insère. sur le lhorax - En général tout susport étroit et court.

Pellitus, fourré. - Se dit d'une surface couverte de poils longs et pendants, mais en dósordre.

Penicillatus, penicille. - Portant des houppes de poils, divergents à leur sommet comme un goupillon.

Penis. Organe copulateur mile.

Pennaceus, penracé. - Qui a l'apparence diune plume.

Pentamerus, pentamère. - Qui a cinf articles aux tarses.

Per, prélixecfui, joint à un mot, l'amplitic, le rend analogue au superlatif.

Perfoliatus, perfolie. - En forme de feuille.

Perlatus, perle. - Portant des points en relief et arrondis.

Pes, patte. - Organe de Ia locomotion terrestre. (Int. p. r.y.u). 
Potiolatus, pelioli. - Nui a un pitiole. - Se dit aussi d'une cellule da laile qui se lerme avant datteindre la ecllule roisine et ne s'y ratlache que par une nervore unicrue.

Petiolus, piliole. - Synonyme de pérlicule; employé spéciálement pour certains insectes, par exemple les fourmis.

Pharynx, ourerture Juceale recevanl les aliments du dehor's et les menant it l'o'soplage rfui le stit. (InL. P. XrरIHI).

Pilosus, poilu. - Couvert de poils longs, rares et sans raideur.

Pilus, poil. - Sens connu.

Planus, plan. - Sc dit d'une surface dont le disque et le bord sont de même niveau.

Pleuræ, plenres. - Cólés du thorat.

Plicatus, plip. - Se dit des ailes qui ne restent pas étendues dans lc repos, mais dont un bord rient se poser sur la parlic supéricure.

Pluri, préfixe gui ajoute i un mol d'origine latine l'idèc de pluralité.

Pluridentatus, pluridenlé. - Muni de plusieurs dents.

Pollinigera instrumenta, appareil pollinigere. - Ensomble des orranes destinés à la récolte du pollen.

Pollinosus, pollineux. - Garni d'unc poussiere ressemblant it du pollen.

Poly, préfixe qui ajoule à un mot d'origine greeque l'idée de pluralité.

Polyphagus, polyphage. - Qui se nourrit de plusieurs plantes indifféremment.

Porcatus, sillonne. - Portant des ligues larges et enfoncées.

Porosus, poreux. - Se dil diun tégument ou diune membrane perlorés de petits trous qui traversent leur substance.

Porrectus, avance. - Se dil de la tête cuarud elle ne forme pas d'angle avec le thorax et ruiclle est prolongece en avant.

Post, préfixe rfui donne au mot dans lequei il entre lidce d'une siluatinn en arriere.

Postepistomus, postépislome. Partic de la tête situćc derrière l'épistome.
Posterior, postivieur. _. stapplirruc it la portion de chargue partie du corps qui est la plus eloignée de la lite ou du devant dis la téte, spécialement ì la denxième paire d'ailes et a la troisieme paire de patles fixées au métalhorax.

Posticus, postérieur. - Silué en arrière.

Postscutellum, pic̀ce dı thorax. (Int. p. E[H]).

Præe, prélixe qui éveille l’idéc d'une situation en avant ou saillante.

Præocularis, pricoculaime. - Se dit de linsertion des antennes devant les yeux.

Præscutum, piece thoracique situéc cn avant du scutum.

Prismaticus, prismatique. - Formé de plans qui se coupent à angles saillants.

Pro, préfixe qui implique l'idée d'une position ou d'une direction en avant.

Proboscis, museau. - Configuration de la têle allongéc en avant.

Productus, prolongis. - Se dit d'un organc qui s'allonge d'une manicere queleonque.

Proeminens, proéminent. - Se dil de la tête quand elle est horizontale et ne forme pas d'angle avec le thorax; de toute partic saillante úleréc.

Prominens, saillant.-Qui sillonge en avant ou en dehors d'un autre organo.

Promascis, trompe formic pat l'ensemble des machoires et de la langucte. - Lussi comme proboscis

Pronotum, dessus du prolliorax.

Prosternum, dessous du prothorax.

Prothorax, premier segment du thorax.

Pruinosus, pruineux. - Couvert diunc poudre, rappelant du givre.

Pseudopodus, psoudopode. - Organe remplissant les fonctions d'une pafte sans en avoil la forme.

Pubescens, pubescent. - Couvert le poils tres fins coucheis, courts.

pulverulentus, pulvirulent. Couvertilune poussiere farineuse.

Punctatus, ponclue.-Parsomé de points enlonces moyens.

Punctiformis, punctiforme. - Qui a l'aspect d'un point. 
Punctulatus, pointillé. - Parsemé de très-petits points enfoncés.

Punctum, point. - Petit enfoncement arrondi sur une surface.

Pupa, nymphe. - Etat dans lequel se métamorphose la larve avant d'arriver à celui d'insecte parfait.

Purus, pur, net. - Se dit d'une couleur vive, franehe.

Pustulatus, pustulé. - Pourvu de petites gibbosités en forme d'ampoules.-Qui a des marques colorées en formo de bulles.

Pygidium, dernier anneau de l'abdomen portant et recouvrant l'anus.

Pyriformis, pyriforme.-En forme de poire.

Quadratus, carré. - Qui a ses angles droits.

Quiete (in), en repos. - Etat de l'insecte quand il est arrêté et qu'il contracte plus ou moins ses membres.

Radialis, radial. - Nom diune nervure et d'une cellule des ailes. (Int. p. LXvis!

Radicula, radicule.-Petite saillie le la tête où s'articule l'antenne.

Ramosus, rameux, ramifié. Portant des appendices ou branches irrégulières.

Raptorii pedes, paltes ravisseuses - Pattes spécialement conformées pour saisir et retenir une proie. Cette disposition ne s'applicue qu'aux pattes antérieures.

Rarus, rare.-Opposé de commun. V. communis.

Rectus, droit. - Se dit de l'antenne quand elle conserve sa direction de la base à l'extrémité.

Recurrens, récurrent (voir recurrentes).

Aecurrentes nervi, nervures récurrentes - Nom de nervures qui aboutissent dans les cellules cubitales. (Int. p. Lxvir).

Refloxus, rèfléchi. - Tourné en arrière ou en dessus.

Remotus, écarté. - V. distans.

Reniformis, réniforme. - Qui a la forme d'un rein.

Reticulatus, réticulé. - Nom donné quelquefois aux yeux composés. - Se dit aussi d'une surface qui offre des lignes entoncées peu marquées, se coupant en diverses directions pour former un réseau.

Retusus, rétus, émoussè ${ }^{\circ}$ - Dont l'cxtrémité est arrondic, n'est pas en pointe.

Rostrum, rostre, bec. - Ce nom s'applique parfois improprement à la trompe des liyménoptères.-On ne rencontre que dans d'autres ordres le rostre proprement dit.

Rotundatus, arrondi.-Deforme circulaire.

Rudis, rude.-Se dit d'une surface parsemée de points élevés, irréguliers, inégaux.

Rugatus, plissé.-Se dit d'unesurface ondulée dont les ondes sont serrées, petites et d'inégale hatteur.

Rugosus, rugueux.- Parsemé de lignes élevées, irrẻgulières, ou se dirigeant en tous sens.

Sagittatus, sagilté. - En forme de fer de llèche.

Saltatorii pedes, pattes sauteuses - Pattes spécialement disposées pour le saut.

Scaber, scabre. - Se dit diune surface à points saillants numbreux. invisibles, qui la rendent dure au toucher.

Scapu», Scape. - Premier article allongé et grossi de l'antenne.

Scariosus, scarieux. - Fait d'unc substance sèche, cartilagineuse.

Scopa, palette ventrale ou brosse. Partie du ventre ou des tarses couverte, chez quelques espèces, de poils fins et courts, faisant partie de l'appareil pollinigère. (Int. p. LXXXIv).

Scrobiculatus, scrobiculé.-Pourvu de serobes.

Scrobs, scrobe. - Fossette ou sillon où peuvent entrer les antennes dans le repos.

Scutellum, scutellum, écusson.Portion de chacun des segments thoraciques. (Int. p. LIV)

Scutum, Portion de chacun dessegments thoraciques. (Int. p. LIV).

Securiformis, sécuriforme. - En forme de hache, triangulaire, comprimé.

Segmentum, segment - Parties du corps constiluant des anneaux.

Segmentum medium, segment médiaire. - Premier segment abdominal fixé au thorax. (Int.p.Lviri)

Semi, - Préfixe donnant l'idée de moitić.

Semicircularis, semicirculaire. - En forme de demi-cercle. 
Semilunaris, en croissant. - En forme de demi-lune.

Sericans, sericous, soyeux. Couvert de poils doux, couchés et brillants.

Serra, scie. - Nom de la tarière des mouches ì scie.

Serratus, en scie. $-\Lambda$ dentelures très-fines et régulières.

Sessilis, sessile. - Se dit d'unc partie fixće sur une autre sans l'intermédiaire de tige ni de pédicule.

Seta, soie. - Poils fins et brillants comme de la soie.

Setaceus, sétacé. - Diminuant insensiblement d'épaisseur de la base à l'extrémité, comme une soie de porc.

Setiformis, sétiforme. - Se dit de l'antenne qui est sétacée et terminée en pointe allongée.

Setiger, setosus, sétigère. - hérissé de suies rigides.

Setula, soie. - V. seta.

Setulosus, situleux, Couvert de poils rigides, tronqués à leur extrémité.

Sexus, seve. - Etat masculin ou féminin.

Signatus, marqué de taches.Portant des taches de forme diverse.

Similis, semblable. - Se dit d'un organe d'une espèce, conforme de tout point à celui d'une autre.

Simplex, simple. - Se dit d'une partie qui n'a rien de spécial, ni dents, ni divisions, etc., ou qui est unicrue.

S inuatus, simué. - Qui a des sinuosités.

Sinus, sinuosité. - échancrure a angle très-arrondi et peu profonde

Solldus, marticulé. - Se dit de la massue quand elle n'est pas divisée.

Sordidus, sâle.-Se dit d'une couleur assombric, salie.

Sparsus, épars. - Se dit de poils ou de points qui sont clairsemés.

Spatulatus, spatule. - Elargi et arrondi à l'extrémité.

Species, espéce. - Réunion des individus qui se reproduisent entre cux. (Int. p. VIII).

Specularis, spéculaire. - Se dit d'une partio limitée Irès brillante au milieu diune autre qui l'est moins.
Sphæricus, sphérique. - Arrondi comme une boule.

Spiculiformis, spiculiforme-Qui a la forme d'un poignard.

Spiculum, stylet. - Partio activo de la tarière ou de l'aiguillon.

Spina, épine. - Appendice fin, pointu, immobile.

Spiniformis, spiniforme. - Qui ressemble à une épine

Spinosus, épineux. "- Pourvu d'épines.

Spiracula, stigmates. - Ouvertures extérieures des conduits aérifères et respiratoires.

Squama, écaille. - Petite pièce cornée et aplatie. - Pièce spécialo aux fourmis.

Squamosus, squameux. - Couvert de petites écailles.

Squamula, squamule. - Petite ecaille rui rend une partie squameuse - Aussi écaillette des ailes.

Stemmata, stemmates. - Synonyme d'ocelles.

Sternum, partie inférieure du thorax.

Stigma, v. carpus.

Stigmata, v. spiracula,

Strangulatio, étranglement. Diminution subite de diamètre.

Stria, strie. - Petites lignes enfoncées parallèles.

Striatus, strié.- Portant des stries. Striga, raie.- Bande étroite trans. verse colorée.

Strigatus, rayé. - Portant des raies.

Striolatus, striolé. - Portant des petites stries.

Sub, préfixe donnant l'idèc d'infériorité comme position, ou de diminution dans l'iutensito d'une qualité.

Sublabrum, sous-labre. - C'est l'épipliarynx pour Latreille.

Submarginalis, sous-marginal.-. Nom d'une nervuro des ailes.

Subocularis, suboculaire. - S'applique à l'insertion des antennes au dessous des yeux.

Subulatus, subulé. - Se dit d'un organe qui, après un renllement, a un amincissement poinfu et allongé comme une alc̀ne.

Sulcatus, sillonné. - Marqué do sillons. 
Sulcus, sillon. - Ligne large et enfoncée.

Superior, superieur. - Ce rui est en dessus du corps ou d'un organe.

Sutura, sulure. - Ligne de jonction de deux parties contigutes et fixées l'une à l'autre.

Troniatus, mbanne. - Qui porte des bandes colorées.

Tarsus, tarse.-- Partie extrême de de la patte composée de portions articulées les unes sur les autres.

Tectiformis, tectiforme. - Qui aflecte la formo d'un toit.

Tegulæ, écaillettes. - Petites pićces cornees, mobiles, situces î la base des ailes antérieures.

Tégumentum, tégument. - Partie cornée formant la surface ou la peau du corps des insectes. C'est leur siquelette, qui est extéricur.

Tempora, tempes. - On a donné ce nom à la partie supérieure des joues.

Terebra. lariere. - Appareil servant à certains hyménoptères à déposer leurs ouls, soit dans les plantes, soit dans le corps de larves ou de chenilles. (lnt. p. Lxxxy).

Teres, arrondi, mousse. - S'applique aux bords des organes ou des segments qui ne sont pas tranchants.

Tergum, clos. - Parlic supérieure du corps.

Tetra, - Préfixe indiruant qu'il y a quatre fois un objel.

Tetragonus, tetragone. - Qui a quatre cótés.

Tetramerus, tétramere. - Qui a quatre articles aux tarses.

Thorax. - Yartie intermédiaire du curps portantles ailes et les paltes. (Int. p. LIII).

Tibia. - Partie de la palte articulée a la cuisse et recevant le larse à sun extrémité.

Tomentosus, tomenteux. - Couverts de poils lins, courls, serrés, commie entrelacés oll feutrés. Syuonyine de cotonneux.

Torulus. - Partic do la tête qui sarticule aice l'antenne.

Trachia, trachee. - Vaisseau puisant i'air' par les stigmates et lo conduisant dans l intericur du corps pour l'y distribuer.

Translucidus, translucide, trans. parent. - Qui laisse apcreevoir les oljels inféricurs à travers sa substance. Cette qualité n'empêche pas souvent une certaine coloration.

Transversus, transversal. - Se dit d'une partic plus large que longue.

Trapeziformis, trapezoidalis , lrapezoidal. - En forme de trapèze.

Tri.- Préfixe indiquant qu'il y a trois fois un objet.

Triangularis, triangulaire. - En forme de triangle.

Trimerus, trimere. - Qui a trois articles aux tarses.

Triquetrus, triquétre.-Qui a trois côtés ou trois faces et trois angles.

Trochanter.- Pièces cornées simples ou doubles situées entre les hanches et les cuisses.

Truncatus, tronqué.-Coupé brusquement et carrément ì son extrémité.

Tuberculatus, tuberculé. - Qui p. rte des tubercules.

Tuberculum, tubercule - I'oint èlevé, assez gros, irrégulier, saillant sur une surlace.

Tunicatus, tuniqué. - So dit de la massue des antennes quand l'un des articles de sa base est creux. et recouvre plus ou moins les suivants.

Turbinatus, turbine. - Se ditdu dernier article des palpes, quand il est renflé à la base et terminé brusquiement en pointe.

Umbilicatus, ombiliqué. - Se dit d'une impression ou d'un tubercule qui a une dépression à son centre.

Undatus, ondé:- Se dit d'uno surface renflée et creusée alternativement:

Undulatus, ondulé.- Comme undatus.

Unguiculatus, unguiculé.-Pourvit d'ongles ou de crochets.

Unguiculus, petit ongle. - V.ungula.

Ungula, ongle ou crochet.-Petite piece crochue située à l'extrémité des larses.

Vagina, fourreau ou gaine.-Partie de la tarière. (Int. p. Lxxxyi).

Validus, robuste. - Qui 'est gros, qui a un aspect fort, solide.

Valvula, valve ou valvule - $\mathrm{Ce}$ 
sont les deux petiles lames cornés (fui enferment, à sa base, Je fourreau de l'aiguillon.

Variolosus, variole.- I’arsemé de points enfoncés, larges, incigaux, peu profonds, moins grands cfue ceux indiques par: foveolatus.

Velutinus, velouti. - I poils courts, perpendiculaires, ressentblant a ru velours.

Vena, Veine ou nereure. - V. nervus.

Venter, venlre.- I'arlic infericure de l'abdomen.

Ventosa, ventouse. - Cupule membraneuse siluée sur les tarses, stisceptible de dilatation el de contraction, all mogen de batuelic fuelques insectes, en y liusant lo vide, peuvent so tenir sur les corps polis et s'y allacher.

Vermiculatus, vermiculí.-I'risentant des excavations torlueuses rappelant les galcries des laries lignivores.

Verruca, verrue. - Ilivation crinde, cicatrisćc.

Verrucosus, verruqueux - Qui porte des verrues.
Versatilis, versatile. - Se dit de la téle, fuand elle peut finire un tour presfue entice sur elle-mime autour diu col.

Vertex. - Partie supéricure de la tète, entre le front et l'occiput, porlant les ocelles.

Verticalis, verlical.- Qui s'ilcre directement de bas en haul.

Vesicularis, vesiculaire. - bir forme de ressic.

Vibrantes, vibratiles(antenna). antemesvibrantes ou vilmatiles. - Celles que les insectes agitent continuellement et rapidement.

Villosus, villent.x - Couvert do poils longs, llexibles el serres.

Vitreus, villeux. - Qui est rinnsparent comme du verre.

Vitta, - Parlie coloréc en lorme de hande ou de ruban.

Vittalus, rubane. - Portant des bandes colorées.

Vulgaris, vulgaire-Se dit dune espece qui se trouve partoul tresfacilement et en grand nombre.

Vultus, face:- Parlic de la tele situce sous le tront entre les yeux. 


\section{V \\ TERIINOLOGIE FRANCSASE}

AVEC IA TRADUCTION IATINE RENVOYANT AU GLOSSAIRE EXPICATIF

Abdomen, abdomen.

Acicule, aciculatus.

Acuminé, acuminatus.

Acuponctué, acupunctatus.

Adhérent, adherens

Affine, affinis.

Aigu, aculus.

Aiguillon, aculeus.

Ailes, alx.

Aire, area.

Allongé, clongatus.

Ambré, succineus.

Ambulatoires (pattes), ambulalorii pedes.

Anal, analis.

Anales (pattes), anales pedes.

Angle, angulus.

Anguleux, angulosus.

Anneau, anmulus.

Annelet, annellus.

Annuliforme, annuliformis

Antennes, antennx.

Antérieur, antèrior.

Apical, apicalis.
Aplani, complanatus.

Aplati, depressus.

Apode, apodus.

Apodèmes, apodemata.

Appareils buccaux, cibaria instrumenta.

Appareils génitaux, genitalia.

Appendice, appendix.

Appendicé, appendiceus.

Appendiculé, appendiculatus.

Aptère, apterus.

Aréole, areola.

Aréolé, areolatus.

Argenté, argenteus. $-V$. color.

Arqué, arcuatus.

Arrondi, rotundatus.

Article, articulus.

Articulation, articulatio.

Articulé, articulatus.

Assombri, infuscatus.

Attenue, altemalus.

Auricule, auriculatus.

Avance, porrectus.

Axillaire, axillaris. 
Azuré, azureus. $-V$. color.

Baculiforme, baculiformis.

Barbu, barbatus.

Barré, clathratus.

Basal, basalis.

Base, basis.

Basilaire, basilaris.

Bec, rostrum.

Bifide, bifidus.

Blanc, albus, etc. $-V$. color.

Bleu, cyaneus, elc. $-V$. color.

Bord, margo.

Bordé, murginatus, limbatus.

Bosse, gibba.

Bouche, os.

Bourdonnement, bombus.

Brachial, brachialis.;

Brillant, nitens, nitidus.

Brisé, fractus.

Bronzé, rneus. $-V$. color.

Brosse, scopa.

Brun, brunneus.- $V$. color.

Buccaux, $V$.appareils.

Calcariforme, calcaratus.

Calleux, callosus.

Callosité, callum.

Canaliculé, canaliculatus.

Capillacé, capillaceus.

Caractère, character.

Carène, carina.

Carêné, carinalus.

Carmin, carminatus.- V. color.

Carpe, carpus.

Carré, quadralus.

Cavite, cavilas.

Ceint, cinctus.

Cellule, cellula.

Cendré, cinereus. $-V$. color.

Chagrine, asper.

Champ, area.

Chaperon, clypeus.

Chauve, calvus.

Chevelu, comatus, crinitus.

Cicatrisè, cicalricosus.

Cil, cilium.

Cilie, cilialus,

Ciselé, crlalus.

Citrin, citrinus. $-V$. color.

Clair, clamus.
Glaviforme, clavatus.

Clypéacé, clypeiforme, clypeatus.

Gol, collum.

Collier, collare.

Commun, communis.

Composés (yeux), oculi compositi.

Comprimé, compressus.

Concolore, concolor.

Conique, conicus.

Conné, comnatıs.

Contigu, contigurs.

Convexe, convexus.

Coque, folliculus.

Cordiforme, cordatus.

Coriacé, coriaceus.

Corné, corneus.

Gornée, cornea.

Corps, corpus.

Costal, costalis.

Cōte, costa.

Cotè. latus.

Côtes (à), costalus.

Goudè, geniculatus.

Gouleur, color.

Coupé, incisus.

Courbé, deflexus.

Coureuses, (pattes) cursoriipedes.

Court, brevis.

Crenelé, crenulalus.

Grête (à), jubatus.

Greusé, cavatus.

Criblé, cribratus.

Grochet, ungula, hamuli.

Groissant (en), semilumaris.

Cubital, cubilalis.

Cuiller (en formede), cochleariforinis.

Cuisse, femur.

Cultriforme, cullviformis.

Guneiforme, cuneiformis.

Cylindrique, cylindricus.

Dense, densus.

Densément, densè.

Dent, dens.

Denté, denlalus.

Denticulé, denticulatus.

Dentiforme, dentiformis.

Déprimé, depressus.

Dessous, m/erior pars.

Dessus, superior pars. 
Digité, digitalus.

Dilaté, clilatatus.

Discoïdal, discoidalis.

Discoïde, discoideus.

Disque, discus.

Distinct, distinctus.

Doré, auralus. - V. color.

Dos, dorsum, lergum.

Dressé, ereclits.

Droit, rectus.

Dur, duru:i.

Ecaille, squama.

Ecaillettes, legulie.

Ecailleuses(pattes), comei pedes.

Ecarté, distans. remotus.

Echancré, emarginatus.

Ecusson, scutellum.

Elargi, dilatalus.

Elevé, elatus.

Embrouillé, intricatus.

Emoussé, retusus.

Enchaîné, catenulatus.

Enfle, inflatus.

Enfumé, fumalus.

Ensiforme, ensiformis.

Entaillé, incisus.

Entier, integer.

Envergure, expansio.

Epais, crassus.

Epaissi, incrassatus.

Epars, sparsus.

Epaule, humérus.

Eperon, calcar.

Eperonné, calcaratus.

Epicrane, epicranium.

Epidémes, epidemata.

Epiglotte, epiglossis.

Epimères, epimeri.

Epine, spina.

Epineux, spinosus, cchinalus.

Epistome, epistomus, clypeus.

Espéce, species.

Etranglement, strangulatio.

Etroit, angustus.

Excavé, excavatus.

Exoderme, exodermus.

Exserte, exsertus.

Externe, externus.

Extrémité, apex.
Face, facies, vultus.

Facettes, latuscula.

Falciforme, falcatus.

Farineux, farinosus.

Fasciculé, fasciculatus.

Fascie, fascia.

Fascié, fasciatus.

Femelle, femina.

Fendu, fissus.

Filière, fusus.

Filiforme, filiformis.

Flabellé, flabellatus.

Flagelliforme, flagelliformis.

Flanc, latus,

Fléchi, inftexus.

Foliacé, foliaceus.

Fossette, fossula.

Fossulé, fossulatus.

Fouisseuses (pattes), fossorii pedes.

Fourchu, furcalus.

Fourreau, varina.

Fourré, pellitus.

Fovéolé, foveolatus.

Frangé, fimbriatus.

Front. frons.

Funicule, flagellum, funiculus.

Fusiforme, fusiformis.

Gaîne, vagina.

Geminè, geminatus.

Genitaux. $-V$. appareils:

Genou, genu.

Genre, genus.

Gibbeux, gibbosus, gibbus.

Glabre, glaber.

Globuleux, globosus.

Gonflè, intumescens.

Grain, cenchri, granulus.

Granulé, granulatus.

Grêle, gracilis, exilis.

Gris, griseus.-V. color.

Grossier, rudis.

Hanche, coxa.

Haut, altus.

Hẻmiptère, hemipterus.

Hemisphérique, hemispharicus.

Hérissé, hirtus.

Hexapode, hexapodus.

Hispide, hispidus. 
Huméral, humeralis.

Hyalin, hy/alinus.

Hybride, hybrida.

Hypoglotte, hypoglossis.

Imbriqué, imbricalus.

Immaculé, immaculatus.

Impression, impressio.

Imprime, intpressus.

Inarticule, inarliculalus.

Incline, cermuus.

Incomplet, incompletus.

Indigo (bleu), indigoteus. - I. color.

Inègal, inequalis.

Inférieur inferior.

Inflèchi, inflexus.

Infundibuliforme, infundibuliformis.

Inoculaire, inocularis.

Insecte parfait, imago.

Inséré, insertus.

Insertion, insertio.

Intermédiaire, intermedius.

Interne (coté), interior.

Interoculaire, interocularis.

Interrompu, intermutus.

Intervalle, intervallum.

Irisé, iricolor, iridescens.

Irrégulier, irregularis.

Jaune, luteus. $-V$. color.

Joues, genx.

Labial, labialis.

Labié, labialus.

Labre, labrum.

Lacinié, lacinialus.

Laineux, lanatus.

Lame, lamella.

Lancéolé, lanceolatus.

Languette, ligula.

Lanuginoux, lanuginosus.

Large, lalus.

Larve, larva.

Lévro, labium.

Ligament, ligamenlum.

Ligne, linea.

Ligulé, ligulalus.

Linéaire, linearis.

Lisse, lweis.
Lobe, lobus.

Lobé, lobatus.

Long, longus.

Longltudinal, longiludinalis.

Longueur, longitudo.

Luisant, lucidus.

Luné, lunalus.

Lunule, lumula.

Nâchoire, maxilla.

Macule, macula,

Mâle, mas.

Mandibules, mandibulix.

Marginal, marginalis.

Marginé, maryinatus.

Marron, castamens. - I. color.

Massue, clava.

Mat, opacus.

Maxillaire maxillaris.

Median, medius.

Mombrare, h!mmen.

Membraneux, membranacens:

Membraneuses (pattes), membranacei pedes.

Menton, mentum.

Mésopleures, mesopleurx.

Métallique, metallicus.

Métamorphose, metamorphosis.

Métapleures, melapleurx.

Métatarso. metatarsus.

Moniliforme, moniliformis.

Mousse, teres, obtusus.

Mucroné, mucronatus.

Mue, mutatio.

Muriqué, muricatus.

Muscle, musculus.

Museau, promuscis, proboscis.

Mutique, mulicus.

Natatoires (pattes), natatorii pedes.

Nébuleux. nebulosus.

Nervulation, nervulatio.

Nervure, n(s)vus, vena.

Net, purus.

Noud, noclus.

Noir, niger, ater, etc. $-V$. color.

Noté, nolalus.

Noueux, nodosus.

$\mathbf{N u}$, nuclus.

Nuditè, nuditas. 
Nymple, pupa.

Oblitéré. oblileratus.

Oblique, obliquus.

Oblong, oblongus.

Obsolète, obsoletus.

Obtus, oblusus.

Ocelles, ocelli.

OEil, oculus.

CEsophage, nesophagus.

GEuf, ovum.

Ombiliqué, umbilicatus.

Ondé, undalus.

Ondulé, unduluatus.

Ongle, ungula.

Onguiculé, unguiculatus.

opaque, opacus.

Orangé, ilurantiacus- $-V$. color.

Orbiculaire, orbicularis.

Orbite, orbila.

Osselets, ossicula, epirlemata.

Ouvrière, operaria.

Ovale, ovatus

Oviducte, oviductus.

Oviforme, oviformis.

Oviscapte, oviscaptus.

Ovoïde, oviformis.

Pâle, pallidus.-V. color.

Palette ventrale, scopa.

Palmé, palmatus.

Palpes, palpi.

Paraglosses, paraglossa.

Parallèle, parallelus.

Parapsides, parapsides.

Parfait (insecte), imago.

Patrie, patria.

Patte, pes.

Pattes ambulatoires, ambulatorii pedes.

Pattes anales, anales pedes.

Pattes coureuses, cursorii pedes.

Pattes écailleuses, comei pedes.

Pattes fausses, membranacei pedes.

Pattes fouisseuses, fossorii pedes.

Pattes membraneuses, memLranacei pecles.

Pattes natatoires, nalalorii pedes.

Pattes ravisseuses, raplorii pedes.
Pattes sauteuses, sallatorii pedes.

Pattes thoraciques, comei pedes.

Pattes ventrales, membranacei pecles.

Pectiné, pectinatus.

Pédicule, pédoncule, pediolus, pedunculus.

Pédonculé, pediolalus, pedunculatus.

Pelote, patella.

Penché, nutians.

Pénicillé, penicillatus.

Pennacé, pennaceus.

Pontamère, pentamerus.

Perfolie, perfoliatus.

Perlé, perlatus.

Pétiole, petiolus

Pétiolé, petiolatus.

Pinces, forcipes.

Plan, planius.

Pleures, pleurie.

Plié, plicatus.

Plissè, rutuatus.

Elombé, plumbeus.-V. color.

pluridenté, pluridentalus.

Poil, pilus.

Poilu, pilosus.

Point, punctum.

Point epais, carpus, stigma.

Point calleurs, callum.

Pointille, punctulatus.

Pointu, cuspidatus.

Poitrine, peclus.

Pollineux, pollinosus.

Pollinigère (appareil), pollinigera instrumenta.

Polyphage, polyphagus.

Ponctue, punclatus.

Ponctiforme, punctiformis.

Poreux, porosus.

Postépistome, poslepistomus.

Postericur, posterior.

Pourpre, purpuratus. - V. color.

Preoculaire, preocularis.

Prismatique, prismaticus.

Proéminent, proeminens.

Profond, pro/undus.

Prolongé, productus.

Pruineux, pruinosus. 
Pseudopodes, pseudopoda.

Pubescent, pubescens.

Pulvérulent, pulverulentus.

Pur, purus.

Pustule, pustulatus.

Pyriforme, pyriformis.

Queue, cauda.

Radial, radialis.

Radicule, radicula.

Raie, slriga.

Rameux, ramifie, ramosus.

Rapproché, approximatus.

Rare, ravus.

Ravisseuses (pattes), raplorii pedes.

Rayé, strigalus.

Reborde, marginalus.

Récurrentes (nervures), recurrenles: nervi.

Réflèchi, reflexus.

Réniforme, reniformis.

Repos (en), in quiete.

Resserré, constrictus, coarctatus.

Reticulé, reticulatus.

Rétréci, angustalus.

Rétus, retusus.

Ride, corrugatus.

Robuste, validus.

Rose, roseus. - V. color.

Rostre, rostrum.

Rouge, ruber. - Y, color.

Roux, rufus. $-V$. color.

Rubané, viltatus.

Rude, rudis.

Rugueux, rugosus.

Sagitté, sagiltatus.

Saillant, prominens.

Sale, sordidus.

Satiné, holosericeus.

Sauteuses (pattes), saltatorii pecles.

Scaure, scaber.

Scape, scapus.

Scarieux, scariosus.

Scie, serrar.

Scie (denté en), serralus.

Scrobe, scrobs.

Scrobicule, strobiculatus.

Scutiforme, clypealus.
Sécuriforme, securiformis.

Segment, seumentum.

Segment médiaire, medium sergmentum.

Semblable, similis.

Semicirculaire, semicincularis.

Serré, creber.

Sessile, sessilis.

Sétacé, sctaceus.

Setiforme, seliformis.

Setigère, setiger.

Setuleux, setulosus.

Sexe, sevus.

Sexuelles (parties), genitalia.

Sillon, sulcus.

Sillonné, sulcatus.

Simple, simplex.

Sinué, simualus.

Sinuosité, sinus.

Soie, seta, setula.

Sous-labre, sublabrum.

Sous-marginal, submarginalis.

Soyeux, sericeus.

Spatulé, spatulatus.

Spéculaire, specularis,

Sphérique, sphrricus.

Spiculiforme, spiculiformis.

Spiniforme, spiniformis.

Squameux, squamosus.

Squamule, squamula.

Stemmates, stemmata.

Stigmates, spiracula.

Strie, stria.

Strie, striatus.

Striole, slriolatus.

Stylet, spiculum.

Suboculaire, subocularis.

Subulé, subulatus.

Supérieur, superior.

Suture, sutura.

Tache, macula.

Tache, maculatus.

Tacheté, gutlatus.

Tarière, terebra.

Tarse, larsus.

Tectiforme, lecliformis.

Tégument, lemumentum.

Tempes, leinpora.

Tostace, lestaceus. $-V$. color.

Tète, caput. 
Tétragone, tetragonus.

Tétramère, tetramerus.

Tige, caulis.

Tomenteux, tomentosus.

Trachèe, trachia.

Tranchant, acutus.

Translucide, transparent, translucidus.

Transversal, transversalis.

Trapézoide, trapezoidalis.

Triangulaire, triangularis.

Trimere trimerus.

Triquêtre, triquetrus.

Trompe, promuscis.

Tronque, truncatus.

Tubercule, tuberculum.

Tuberculé, tuberculatus.

Tuniqué, tunicatus.

Turbiné, turbinatus.

Uni, levis.

Valve, valvule, valvula.
Valvules hypopygiales, cerci.

Variole, variolatus.

Veine, vena.

Velouté, velutinus.

Velu, villosus.

Ventouse, ventosa.

Ventre, venter.

Vermeil, chrysargirus. $-V$. color.

Vermiculé, vermiculatus.

Vermillon, ruber.-V. color.

Verrue, vermuca.

Verruqueux, verrucosus.

Versatile, versatilis.

Vert, viridis. $-V$. color.

Vertical, verticalis.

Vésiculaire, vesicularis.

Vibrantes (antennes), vibrantes antenne.

Vibratiles (antennes), vibratiles antennx.

Villeux, villosus.

Vitreux, vitreus.

Vulgaire, vulgaris. 


\section{VI}

\section{TERIINOLOGIE ALLEMANDE}

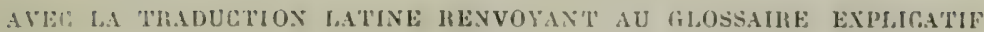

Abgeplattet, depressus.

Abgerundet, rolundalus.

Abgeschnitt, abgestützt, truncrlus.

Abstehend, ereclus.

Acisel, lumerus.

Achsel- (1), humeralis.

Ador, revolus.

After, anus.

After-, analis.

Afterdecke, pygidium.

Afterklappe, valurila analis.

Afterraupe, larva.

Aftersptitzchen, cerci.

Ahlförmig, subulatus.

Abnlich, affinis.

Allgomein, communis.

Amberfarbig, succineus.

Analring, segmentum anale.

Anhang, appenclix.

Anhangend, adherens.

Anhangzelle, appiendicea cellulia.

Anliegend, contignus.

Anliegend Haare, pubescentia.
Arbeiter, Arbiterin, operaria.

Arm-, brachialis.

Art, species.

Atlassartig, holosericeus.

Aufgejogen, elalus, reflexus.

Aufstchend, reflexus.

Auge, oculus.

Augenhöhle, orbilia.

Ausgebuchtet, le/levus, sinuatus.

Ausgehölt, cavalus.

Ausgerandet, emarginalus.

Ausgeschnitt, incisus.

Ausgezackt, lacinialus.

Äusser, externus.

Backen, gena.

Band, fascia.

Bärtig, barbatus.

Bauch, venter.

Bauchfusse, membranaceipedes.

Bauchringe, segmenta ventris.

Beborstet, hirsutus.

Bedornt, spinosus.

Behaart, comatus, hirsulus.

(1) Les muts suivis d'un - s'emploient en composition et modifient le sens du mot aupuel ils sont joints, en lui ajoutant feur prope signification. - Leur indieation me

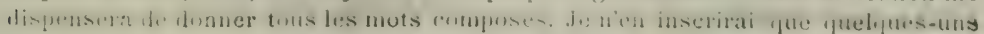
pour exemple, et surtout ceux qui seront les plus usités. 
Beilformig, securiformis.

Bein, pes.

Benarbt, cicalricosus.

Bernsteingelb, succineus.

Berührend, contiguus.

Bewimpert, cilialus.

Bewölkt, nebulosus.

Binde, fascia.

Birnenartig, birnformig, pyriforinis.

Bläschen, blasig, vesicularis.

Blass, pallidus.

Blattericht, pustulatus.

Blatternpunktirt, variolosus.

Blattformig, foliaceus.

Blau, cyaneus. $-V$. color.

Blauschwarz, correlens. $-V$. color

Bleifarbig, bleigrau, plumbeus.$V$, color.

Bloss, nudus.

Blösse, nuditas.

Blutroth, sanguineus. $-V$. color.

Bogig, arcualus.

Bohrer, terebra.

Borste, seta.

Borstenförmig, selaceus.

Borstig, hispidus, ietosus.

Braun, urumeus. $-V$. color.

Braunroth, rubidus. $-\mathrm{Y}$. color.

Braunschwarz, fuscus - V. color.

Breit, latus.

Brust, pectus.

Brustbein, sternum.

Brustbeine, brustfüsse, comei pecles.

Brustkasten, bruststuick, thorax.

Buckelig, gibbosus.

Bürste, scopa.

Buschelformig, fisciculatus.

Carmin-, carminatus, $-V$. color.

Chytin-Panzer, tegumentum.

Gitronengelb, cilrinus.-V. color.

Costal-, costalis.

Cubital-, cubitalis.

Dachförmig, tectijomis.

Decke, tegumentum.

Degenförmig, ensiformis.

Deutlich, distinctus.
Dicht, densus, denses.

Dick, crassus.

Discoidal, discoidalis.

Dolchförmig, spiculiformis.

Drehrund, rotunelalus.

Drei-, tri.

Dreieckig, triangularis.

Dreigliedertfüssig, trimerus.

Dreiseitig, triquetrus.

Dorn, spina.

Dornförmig, spiniformis.

Dornig, eqhinalus, spinosus.

Dunkel, obscurus.

Diinn, gracilis.

Durchblättert, perfolialus.

Durchscheinend, Iranslucidus.

Eben, lievis, planus.

Ebenholz (von), ebeninus.

Ecke, angulus.

Eckig, angulosus.

Ei, ovum

Eiförmig, ovalus.

Eigelb, luteus. $-V$. color.

Einbug, sinus.

Eindrück, impressio.

Einfach, simplex.

Einfarbig, concolor.

Einfügung, insertio.

Eingebogen, in/lexus.

Eingedrückt, impressus.

Eingefügt, insertus.

Eingeschnitt, incisus.

Eingeschnürt, constrictus.

Einschnürung, strangulatio.

Eiröhre, oviductus.

Eirund, oviformis.

Elfenbeinernfarbig, cburneus. $V$. color

End-, terminalis.

Ende, apex.

Endknöpfe, clava.

Entfernt, distans, reinotus.

Erhaben, exserius.

Erhöhung, gibba.

Erlängert, elongatus.

Erweitert, dilalalus.

Erzfarbig, metallicus.

Facherförmig, flavellatus. 
Fadenförmig, Fadig, filiformis.

Falschfuss, pseudopodus.

Faltig, rugatus.

Fangbeine, raptorii pedes.

Farbe, color.

Federförmig, pennaceus.

Feld, as'ea.

Fest, soliclus.

Feurig, ignilus.-V. color.

Filsig, tomentosus.

Fingerig, digitatus.

Flach,-planus.

Fläche, plana area.

Flachgedrückt, depressus.

Fleck, macula.

Flügel, alta.

Flügelmahl, carpus, stigma.

Flügelschuippe, tegula.

Flügelspannung, expansio alarum.

Fortsatz, appendix.

Franzig, fimbriatus.

Freswerkzeuge, cibaria instruineula.

Fühler, antennx.

Fühlereinleukung, insertio antennallin.

Fühlergrube, fossulaantennarum, scrols.

Fünf-, penta-.

Fünfgliederfüssig, pentamerus.

Furche, sulcus.

Fuss, larsus, pes.

Flussglieder, taisorum articuli.

Fusslos, apodus.

Gabelförmig, furcatus.

Ganzrandig, cum margine inte(j)o.

Gattung, genus.

Geàder, nervulatio.

Gebiegt, inflexus.

Gebogen, arcuatus.

Gebrochen, practus.

Gebuchtet, sinualus.

Gedehnt, dilatatus.

Gedrückt, compressus.

Gefaltet, plicatus.

Gefingert, digilatus.

Geflammt, ignitus. $-V$. color.

Gefleckt, maculatus.
Gefurcht, canaliculatus, sulcatus.

Gefuttert, pellilus.

Gegliedert, arliculatus.

Gehöckert, luberculalus.

Geissel, funiculus, flagellum.

Gekämmt, pectinatus.

Gekerbt, crenalus.

Gekielt, carinatus.

Gekniet, geniculatus.

Geknöpft, clavatus.

Gekrümmt, deftexus, curvatus.

Gelb, plavus.-V. color.

Gelbbraun, fulvus.-V. color.

Gelblich, luteus.-V. color.

Geleistet, marginalus.

Gelenk, articulatio.

Gemein, vulyaris.

Genähert, approximatus.

Geneigt, cernuus, nulans.

Gerade, reclus.

Gerandet, marginalus.

Gereifelt, striatus.

Geringelt, annulatus.

Gerunzelt, corrugatus.

Gesägt, scrratus.

Gesaumt, marginatus.

Geschalt, lunicatus.

Geschärft, aculus.

Geschlecht, sexus.

Geschlechttheile, -Organe, -Wer-

kzeuge, genitalia.

Geschnitzt, cxlatus.

Geschuppte, imbricatus.

Geschweift, emarginatus.

Geschwollen, inflatus.

Geschwungen, sinuatus.

Gesicht, facies, vultus.

Gespaltet, fissus.

Gespinnst, folliculus.

Gestielt, petiolatus.

Gestreift, striatus.

Gestriechen, strigatus.

Gestuitzt, truncatus.

Getrennt, remotus.

Getrübt, fumatus.

Gewimpert, cilialus.

Gewölbt, convexus.

Gezähnelt, denticulatus.

Gezähnt, dentalus.

Gezeichnet, notatus. 
Gezweit, geminalus.

Gitter, clathratus.

Glänzend, nilidus.

Glanzlos, obscurus.

Glashell, hyalinus.

Glatt, levigalus. levis.

Gleich, similis.

Glied, arliculus.

Gliederig, articulatus.

Goldgelb, auratus. $-T$. color.

Grabbeine, fussori pedes.

Granulirt, granulatus.

Grau, griscus.-V. color.

Graulichgelb, griseo-luteus. $-V$. color.

Grob, rudis.

Grube, fossula.

Grubenförmig, Grubig, fossulatus.

Grund, basis.

Grund-, basilaris.

Grundfarbe, principalis color.

Grundglied, hasilaris articulus.

Grün, viridis.-v . color.

Gürtel-, cinclus.

Haar, pilus.

Haarformig, capillaceus.

Haarig, pilosus, hirsitus.

Haarkleid, pili.

Häkchen, unguıla.

Halb-, semi-, hemi-.

Hafbflügelig, hemipterus.

Halbkr eisförmig, semicircularis.

Halbkugelíg, hemisphxricus.

Halbmondförmig, semilunaris.

Hals, collare, collum.

Halskragen, pronotnm.

Halsring, collare.

Halsschild, prothorax.

Haltzange, forcipes.

Handförmig, palmalus.

Hart, durus.

Haufig, communis.

Hauptfarbe, principalis color.

Haut, hymen.

Hautahnlich, Hautig, membranaceus.

Hell, nitens, purus.

Hellbraun, pallidè brunneus.- $V$. color.

Herabgebogen, deflexus.
Hevorragend, proeminens.

Hervorstehend, proeminens.

Herzförmig, cordatus.

Himmelblau, azureus. $-V$. color.

Hinter-, posterior.

Hinterbrust, metasternum.

Hinterfläche, paris inferior.

Hinterflügel, alx inferiores.

Hinterhaupt, Hinterkopf, occiput.

Hinterkopfschild, postepistomus.

Hinterleib, audomen.

Hinterrand, posterior, inferior margo.

Hinterrücken, melanotum.

Hinterschildchen, postscutellum.

Hoch, allus.

Höcker, tuberculum, gibba.

Höckerig, gibbosus.

Hohle, cavilas.

Holperig, scaber.

Hornartig, corneus.

Hornhaut, corriea.

Hornig, comeus.

Hüfte, coxa.

Inaugen, inocularis.

Indigblau, Indigo, indigoteus. $V$. color.

innenwinkel, angulus internus.

Innere, interior.

Kahl, calvus, glaber.

Kammformig, pectinatus.

Kammzähne, pectinata cluntes.

Kannelfarbig, cinnamomeus. $-V$. color.

Kantig, angulosus.

Kasianienbraun, castaneus. - V. color.

Kegelig, conicus.

Kehldecke, epiglottis.

IKehle, pharynux; os.

Keilformig, cuneiformis.

Kettenartig, catenulatus.

Keule, clava.

Keulenformig, Keulig, clavalus.

Kiefer, maxilla.

hiefertaster, maxillares palpi.

Kiel, carina.

Bielformig, carinatus.

Kinn, mentum. 
Kinnbacken, mandibulw.

Klappe, valvula.

Klar, pievus.

Klaue, ungula.

Klauig, unguiculatus.

Knie, genu.

Knöchlien, ossicula, epidemala.

Knoten, nodus.

Knotig, nodosus.

Köhle, clava.

Kohlschwarz, carbonarius, $-V$. color.

Kolbig, crassus.

Kopf, caput.

Kopfschild, clypeus, epistomus.

Korn, granulus.

Körnicht, Körnig, granulatus.

Kralle, ungula.

Hrallig, unguiculatus.

Kreiselartig, turbinatus.

Kreisförmig, orbicularis.

Krümme, sinus.

Kugelförmig, Kugelig, globosus, spharvicus.

Kupferfarbig, cupreus.- $V$. color.

Kurz, brevis.

Kurzhaarig, pubescens.

Lang, longus.

Länge, longitudo.

Längen-, longitudinalis.

Langhaarig, villosus.

Länglich, oblongus, elongatus.

Länglichrund, ovatus.

Lanzettförmig, lanceolatus.

Lappe, lobus.

Lappig, lobalus.

Larve, larva.

Laufbeine, cursorii pedes.

Lazurblau, Lazurfarbig, azureus. $V$. color.

Lederartig, coriaceus.

Legapparat, oviscaptus, genitalia femine.

Legbohrer, terebra.

Legeröhre, vagina.

Legescheide, oviduclus.

Legstachel, terebra.

Lehmgelb, luteus. $-V$. color.

Leib, corpus.

Leiste, lamella.

\section{Licht, clarus.}

Linie, linea.

Linienförmig, linearis.

Lippen-, labialis.

Lippenförmig, labiatus.

Lippentaster, labiales palpi.

Locker, porosus.

Löffelformig, cochleariformis.

Luftgefäss, trachia.

Luftlöcher, stigmata.

Mahnig, jubatus.

Mandibeln, mandibula.

Männchen, mas.

Matt, opacus.

Mause, mulatio.

Mehlartig, farinosus.

Mehlstaubig, pruinosus.

Mennigfarbig, miniatus, $-V$.color.

Merkmal, character.

Messerförmig, cullviformis.

Mittel-, intermedius.

Mittelbrust, medipectus, mesosternum.

Mittelbrustbein, Mittelbruststück, mesosternum.

Mittelleib, thorax.

Mittelrück, Mittelrückenstück, mesonotum.

Mondchen, lunula.

Mondförmig, lunatus.

Mondsichelförmig, semilunaris.

Mund, os.

Mundtheile, instrumenta cibaria.

Muskel, musculis.

Nabelförmig, umbilicatus.

Nacken, occiput.

Nadelförmig, aciculatus.

Nagelartig, unguicutatus.

Narbig, cicatricosus.

Nath, sutura.

Nebelig, nebulosus.

Nebenaugen, ocelli.

Nebenzungen, paraglossa.

Netzaugen, compositi oculi.

Netzen-, reticulatus.

Nierenformig, reniformis. 
Ober, superior.

Oberfläche, pars superior.

Oberflügel, alie superiores.

Oberkiefer, mandibulx.

Oberlippe, labrum.

Ochergelb, ochraceis. $-V$. color.

Ohrig, auriculatus.

Olivenfarben, Olivengrün, olivaceus. $-V$. color.

Orangengelb, aurantiacus. $-V$. color.

Parallel, parallelus.

Pechbraun, Pechschwarz, piceus, picinus. $-V$. color.

Peitschenförmig, flagelliformes.

Pergamentartig, membranaceus.

Perlartig, Perlenförmig, perlatus.

Perlschnurförmig, moniliformis.

Pfeilformig, sagittatus.

Pfriemartig, subulatus.

Pinzelförmig, penicillatus.

Platt, depressus.

Platte, lamina.

Prismatich, prismaticus.

Punkt, punctum.

Punktaugen, ocelli.

Punktförmig, puncliformis.

Punktirt, punclatus.

Puppe, pupa.

Purpurroth, purpureus. $-V$.color.

Quadrat, quadralus.

Quer, transversus.

Radial, radialis.

Rand, margo.

Rand-, marginalis.

Randmal, carpus, stigma.

Raubbeine, raptorii pedes.

Rauchbraun, Raucherig, fumatus.

Rauh, rudis.

Rauhkörnig, asper.

Raupe, larva.

Rauten, latuscula.

Regenbogenfarbig, iricolor, iridescens.

Rein, purus.

Ring, annulus.

Ringelchen, anniellus.
Ringförmig, annuliformis.

Rinne, stria.

Rippe, costa.

Rippig, costatus.

Rosenfarbig, Rosig, roseus. $-V$. color.

Rostroth, ferrugineus.-V. color.

Roth, rufus. $-V$. color.

Rothbraun, rubidus.- $V$. color.

Rothgelb, aurantiacus. $V$. color.

Rücken, dorsum.

Rückenkörnchen, cenchri.

Rücklaufendader, recurienles nervi.

Runzelig, corrugatus.

Rüssel, rostrum.

Ruszbraun, fuliginosus. $-\mathrm{I}$. color.

Ruthe, penis.

Säbelförmig, ensiformis.

Safrangelb, croceus.- $\mathrm{V}$. color.

Säge, scrra.

Sägezähne, serralx clenles.

Sammetartig, velutinus.

Sammetschwarz, alro-velulinus. $-V$. color.

Satinirt, holosericeus.

Saugnapfe, ventosa.

Schädelhaut, epicranium.

Schaft, scapus.

Schalenförmig, squamiformis.

Scharf, acuminatus.

Scharrbeine, fossorii pedes.

Scheibe, discus.

Scheide, vagina.

Scheitel, verlex.

Schenkel, femur.

Schenkelanhang, trochanter.

Schenkelkopf, coxa.

Schenkelring, trochanter.

Scherbengelb, testaceus. - V.color.

Schief, obliquus.

Schiene, tibia.

Schild, scutum, clypeus.

Schildchen, scutellum.

Schildförmig, clypeatus.

Schildwinkel, scutelli angulus.

Schimmernd, lucidus.

Schläfe, tempora. 
Schlank, gracilis. anguslus.

Schlund, pharynx.

Schmal, gracilis, angustus.

Schmutzig, sordidus.

Schnause, proboscis.

Schneeweis, niveus.- Y. color.

Scheidig, acutus.

Schrag, obliquus.

Schreitbeine, ambulalorii peles.

Schulter, humerus.

Schultereckel, Schulterwinkel, pronoti angulus.

Schüppchen, squamulit.

Schuppe, squama.

Schuppig, squamosıs.

Schwanz, cauda.

Schwarz, nigel.- $-V$. color.

Schwefelgelb, sulfureus. - $V$. color.

Schwiele, callum.

Schwielig, callosus.

Schwimbeine, nalalorii pel.s.

Schwingend, vibrans.

Sechsfüssig, hevapodus.

Seefarbig, glaucus. $-V$. color.

Seide, sela, selula.

Seidenartig, Seidenglänzend, sericeus.

Seite, lalus.

Selten, ramus.

Senkrecht, verlicalis.

Siebförmig, cribratus.

Silberfarbig, argenteus, - V. color.

Sitzend, sessilis.

Smaragdgrün, smaragdimus. $-V$. color.

Spatelförmig, Spatelig, spatulalus.

Speiseröhre, wsophagus.

Spiessformig, specularis.

Spindelformig, Spindelig, fusiforinis.s.

Spinloch, Spinnöffnung, Spinnwarze, fusus.

Spitz-, apicalis.

Spitze, apex.

Spitzenwinkel, apicalis angulus.

Sporn, calcar.

Spornartig, calcaralus.

Springbeine, saltatorii pedes
Stabförmig, baculiformis.

Stachel, aculeus spiculum.

Stahlblau, carruleus.-V. color.

Stamm, caulis.

Staubig, pulverulentus.

Stiel, Stielche, pelliolus.

Stirn, frons.

Strahlenrippen, radiales nervi.

Streif, Strich, striga.

Striechförmig, linearis.

Strohgelb, stramineus.

stumpf, obtusus.

Stumpfspitzig, mucronalus.

Summen, bombus.

Tarsen, larsi.

Taster, palpi.

Tegument, tegumentum.

Tibien, libia.

Tief, proiondus.

Trapezoid, trapezoidalis.

Trichterf"rmig, infundibuliformis.

Tuberkel, luberculum.

Uberragend, prominens.

Unbewehrt, mulicus.

Undeutlich, obsoletus.

Undurchsichtig, opacus.

Uneben, iniequalis.

Ungefleckt, immaculalus.

Ungeflügelt, apterus.

Ungegliedert, inarliculalus.

Ungleich, inxqualis.

Unregelmässig, irregularis.

Unter-, sub-.

Unteraugen, subocularis.

Unterbrochen, iuterruplus.

Unterflügel, ale inferiores.

Unterkiefer, muxilla.

Unterkopf, pars inferior capilis.

Unterlippe, labium.

Unteroberlippe, sublabrum.

Unterrand-, submaroinalis.

Unterseite, pars inferior.

Unterzungen, hypoglossis.

Unvollständig, incompletus.

Veilchenblau, violaceus. - V. color. 
Verbreitert, elatus.

Verdickt, incrassatus.

Verdunkelt, infuscatus.

Verdünnt, attenualus.

Verdüstert, Verfinstert, infuscatus.

Verlängert, productus.

Verschmälert, anguslatus.

Verwandlung, metamorphosis.

Verwischt, obliteratus.

Viel-, multi-, poly-.

Vielfrass, polyphagus.

Vier-, telra-.

Viereckig, quadrangulus, quadratus.

Viergliedertfüssig, tetramerus.

Vierseitig, tetragonus.

Violett, violaceus. $-V$. color.

Vollständig, integer.

Vor-, prex, ante.

- Voraugen, pricucularis.

Vorbrust, an lepectus.prosternum.

Vorder, pro- anterior.

Vorderbrust, prothorax, prosternum.

Vorderbrustbein, prosternum.

Vorderbrustücken, pronotum.

Verderflügel, ala anteriores.

Vorderrücken, pronotum.

Vorderschild, prescutum.

Vorgestreckt, porrectus.

Vorragend, Vorspringend, porrectus, exsertus.

Walzenförmig, Walzig, cylindrieus.

Warze, cerruca.

IVarzig, verrucosus.

Wasserhell, Wasserklar, hyalinus.

Weibchen, femina.

Weichhaarig, pubescens.

Veiss, albus, albidus.-V. color.
Weissgelb, albo-luteus, pallidus. - V. color.

Wellenförmig, undatus.

IVendend, versatilis.

Wespe, imago.

Vimper, cilium.

Winkel-, angulosus.

Vollicht, lanuginosus.

Wollig, lanalus.

Wurmlinig, vermiculalus.

Wurzel, basis.

IVürzel-, basilaris.

Würzelchen, radicula.

Würzelglied, basilaris arliculus.

Zahn, dens.

Zahnförmig, dentiformis.

Zange, forcipes.

Zangenartig, forcipiformis.

Zapfenförmig, conicus.

Zelle, areola, cellula.

Zerstreat, sparsus.

Ziegelroth, rubro-lestaceus. $-V$. color.

Zinnoberroth, ruber.- $V$. color

Zottig, fasciculalus.

Zugespitzt, acuminatus.

Zunge, ligula.

Zuruckgezogenen, Kopfe (bei), in quiete.

Zurucklaufend, recurrens.

Zusammen-, simul.

Zusammengedrückt, compressus.

Zusammengesetze (Auge), oculi compositi.

Züsammengewachsen, connalus.

Zwei-, bi-.

Zweizig, ramosus.

Zweispaltig, bifidus.

Zwischen-, inter-.

Zwischenglied, annellus.

Zwischenraum, intervallum.

Zwitter, h!ybrida. 


\section{VII}

\section{TERIINOLOGIE ANGLAISE}

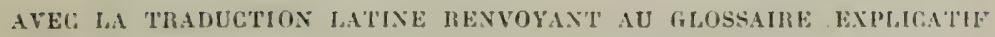

Abdomen, abdomen.

Aciculate, aciculatus.

Acuminate, acuminatus.

Adherent, adhrerens.

Aeneous, aeneus.-V. color.

Ambercoloured, succineus. - $V$. color.

Ambulatory Legs, ambulalorii pedes.

Anal, analis.

Angulated, Angulose, angulosus.

Annulet, annellus.

Antennx, antennx.

Anterior, anterior.

Anthrax black, anthracinus. $V$. color.

Anus, anus.

Apex, apex.

Apical, apicalis.

Apode apodus.

Apodema, apodemala.

Appendicial, appendiceus.

Appendicle, appendix.

Appendiculate, appendiculatus.
Approximate, appioximatus.

Apterous, apterus.

Arcuate, arcualus.

Areolet, areola.

Argenteous, argenteus. $-\boldsymbol{V}$. color.

Articulation, articulatio.

Ashgray, cinereus.- $Y$. color.

Atrous, ater, - $V$. color.

Attenuate, atlemuatus.

Aureous, aureus. $-V$. color.

Auriculate; auriculatus.

Axillary, axillaris.

Azured, azureus.-V. color.

Back, dorsum.

Bald, calvus.

Band, fascia.

Banded, fascialus.

Barbate, barbalus.

Basal, basalis.

Base, basis.

Basilar, basilaris.

Bare, nudus. 
Bared, clathratus.

Boarded, barbalus.

Bed of Antennæ, torulus.

Belly, venter.

Bifid, bifidus.

Body, corpus.

Borer, terebra.

Black, niger.-V. color.

Blue, cyaneus. $-V$. color.

Blunt, teres.

Brachial, brachialis.

Branched, ramosus.

Brassy, eneus. $V$, color.

Breast, pectus.

Broad, latus.

Broken, fractic.

Brown, brunneus. $-V$. color.

Brush, scopa.

Callosity, callum.

Callous, callosus.

Canaliculate, canaliculatus.

Gapillaceous, capillaceus.

Careen, carina.

Carinate, carinatus.

Carminate, carminatus.-V. color.

Carpus, carpus.

Caulis, caulis.

Cavity, cavilas.

Cell, Cellule, cellula.

Cenchri, cenchri.

Cerci, cerci.

Chain-, catenatus.

Chalceous, chalceus.

Chalybeate, chalybeatus.

Characteristic, character.

Cheek, genæ.

Chestnut, castaneus, spadiceus. $-V$. color.

Cicatricose, cicatricosus.

Giliate, ciliatus.

Ginnamonbrown, cinnamomeus. - V.color.

Gitrine, citrinus. $-V$. color.

Clavate, clavatus.

Glaw, unguta.

Clear, distinctus.

Cleft, fissus.

Glub. clava.

Glubshaped, clavatus.
Clypeate, clypeatus.

Clypeus, clypeus.

Coalblack, carbonarius. - V.color.

Gocoon, folliculus.

Collar, collare.

Colour, color.

Comate, comatus.

Common, communis.

Compound Eyes, oculi compositi.

Compressed, compressus.

Concolorate, concolor.

Conical, conicus.

Connate, connatus.

Contiguous, contiguus.

Contracted, angustatus.

Convex, convexus.

Cordate, cordatus.

Goriaceous, coriaceus.

Cornea, comea.

Corneous, corneus.

Costa, costa.

Costal, costalis.

Costate, costatus.

Country, patria.

Coxa, coxa.

Grenate, crenatus.

Grescentshaped, semilunaris.

Cribrate, cribratus.

Grinite, crinitus.

Cristate; cristatus.

Crocusyellon, croceus.

Gubital, cubitalis.

Gultriform, cultriformis.

Guneiform, cuneiformis.

Gupreous, cupreus.

Gylindrical, cylindricus.

Daggershaped, spiculiformis.

Dark, obscurus.

Darkblue, atroceruleus.

Deflexed, deflexus.

Dense, densus.

Dentate, dentatus.

Depressed, depressus.

Digger Legs, fossorii pedes.

Digitate, digitalus.

Dilatate, Dilated, dilatalus.

Disk, discus.

Distant, distans.

Distinct, distinclus. 
Dot, punctitm.

Down, pubescentia.

Draw-Thread, fusus.

Ebonyblack, ebeninus. - $V$. color.

Echinate, echinatus.

Egg, ovum.

Elongated, elongatus.

Emarginate, emarginatus.

Embossed, celatus.

Encircled, cinctus.

Enlarged, dilatatus.

Ensiform, ensiformis.

Epidema, epidemata.

Epiglottis, epiglollis.

Epimeri, epimeri.

Epistomus, epistomus.

Exodermous, exodermus.

Exserte, exsertus.

External, externus.

Eye, oculus.

Face, facies.

Facet, latuscula.

Farinaceous, farinosus.

Fascia, fascia.

Fasciate, fascialus.

Fasciculate, fasciculatus.

Feeler, antennx.

Female, femina.

Femur, femur.

Ferrugineous, ferrugineus.

Fiery, ignilus. $-V$. color.

Filiform, filiformis.

Fimbriate, fimbriatus.

Flabellate, flabellatus.

Flat, complanatus.

Flutings, strix.

Foliaceous, foliaceus.

Foot, pes, tarsus.

Footlees, apodus.

Fore, anterior.

Forebreast, antepectus.

Forked, furcatus.

Fossulate fossulalus.

Fossulet, fossula.

Foveolate, foveolatus.

Front, frons.

Fuliginous, fuliginosus.

Fulvous, fulvus $-V$. color.
Funiculus, funiculus.

Funnelshaped, infundibuliformis.

Furred, pellilus.

Fuscous, fuscus. $-V$. color.

Fusiform, fusiformis.

Geminate, geminatus.

Generative Organs, genitalia.

Geniculate, geniculalus.

Genus, genus.

Gibbous, gibbosus.

Glabrous, glaber.

Glassy, vitreus.

Glaucous, glaucus.-V. color.

Globose, globosus.

Granulate, gramulatus.

Granule, granulus.

Gray, griseus.- $V$. color.

Green, viridis. $-V$. color.

Guttate, guttatus.

Hair, pilus.

Hairy, hirtus.

Hard, curus.

Head, capul.

Hearshaped, cordatus.

Hemipter, hemipterus.

Hemispheric, hemisphericus.

Hexapode, hexapodus.

Hind, posterior.

Hip, coxa.

Hirsute, hirsutus.

Hispid, hispidus.

Holosericeous, holosericeus.

Humeral, humeralis.

Humerus, humerus.

Humming, bombus.

Hyaline, hyalinus.

Hybrid, hybrida.

Hypoglottis, hypoglollis.

Imago, imago.

Imbricate, imbricalus.

Immaculate, immaculatus.

Impressed, impressus.

Impression, impressio.

Incised, incisus.

Inclined, cernuus.

Incomplete, incompletus.

Incrassate, incrassalus.

Indigo coloured, indigoleus. $-V$. 
CLXXXIV

Inferior, inferior.

Inflated, inflatus.

Inflexed, inflexus.

Infuscate, infuscatus.

Inocular, inocularis.

Inserted, insertus.

Insertion, insertio.

Integer, integer.

Interior, interior.

Intermediate, intermedius.

Interocular, interocularis.

Interrupted, interruptus.

Interstice, interstitium.

Interval, intervallum.

Iridescent, iricolor, iridescens.

Irregular, irregularis.

IX̌orywhite, eburneus.

Join, articulus.

Jointed, articulatus.

Jubate, jubatus.

Jumper-Legs, sallatorii pedes.

Kidneyshaped, reniformis.

Knee, genu.

Labial, labialis.

Labiate, labiatus.

Labium, labium.

Labrum, labrum.

Laciniate, laciniatus.

Lacteous, lacteus.

Lævigate, lævigatus.

Lamellated, laminatus.

Lamina, lamella.

Lanate, lanatus.

Lanceolate, lanceolatus.

Lanuginose, lanuginosus.

Larva, larva.

Lash, citium.

Leadblack, plumbeus. $-V$. color.

Leathery, coriaceus.

Leg, pes.

Length, longitudo.

Ligament, ligamentum.

Light Yellow, luridus. $-V$. color.

Ligula, ligula.

Ligulate, ligulatus.

Like, affinis.

Line, linea.

Linear, linearis.
Livid, lividus. $-V$. color.

Lobate, lobatus.

Lobe, lobus.

Long, longus.

Longitudinal, longitudinalis.

Lunate, lunatus.

Male, mas.

Mandibles, mandibula.

Many-Thooted, pluridentalus.

Margin, mrrgo.

Marginal, marginalis.

Marginate, marginatus.

Marroon coloured, castaneus.

Maxilla, maxilla.

Maxillary, maxillaris.

Medial, medius.

Membranous, membranaceus.

Mentum, mentum.

Metallic, metallicus.

Metamorphosis, metamorphosis.

Metatarse, metatarsus.

Middle, intermedius.

Miniatous, miniatus.

Moniliform, moniliformis.

Moonshaped, lunatus.

Moulting, mutatio.

Mouth, os.

Mouth Organs, instrumenta cibaria.

Mucronate, mucronatus.

Muricate, muricatus.

Muscle, musculus.

Naked, nudus.

Narrow, angustus.

Natatcry Legs, natatorii pedes.

Nebulous, nebulosus.

Neck, collum.

Nerve, Nervure, nervus.

Nodose, nodosus.

Nudity, nuditas.

Nutant, nutans.

Oblique, obliquus.

Obliterate, obliteratus.

oblong, oblongus.

Obsolete, obsoletus.

Obtuse, obtusus.

Occiput, occiput.

Ocellus, ocellus. 
Ocreous, ochraceus. $-V$. color.

Esophagus, wisophagus.

Olive coloured, olivaceus.

Opaque, opacus.

Operative, operaria.

Orange coloured, aurantiacus:

Orbicular, orbicularis.

Orbit, orbita.

Osselet, ossicula.

Ovate, ovalus.

Oviduct, oviductus.

Oviform, oviformis.

Ovipositor, oviscaptus.

Pale, pallidus.

Palmate, palmalus.

Palpus, palpus.

Paraglossæ, paraglosse.

Parallel, parallelus.

Parapsides, parapsides.

Patella, patella.

Pectinate, pectinatus.

Pectoral Legs, cornei pedes.

Pediolate, pediolatus.

Pedunculate, pedunculalus.

Penicillate, penicillatus.

Penis, penis.

Pennated, pennaceus.

Pentameri, pentameri.

Perfoliated, perfolialus.

Perlate, perlatus.

Petiole, petiolus.

Piceous, piceus. $-Y$. color

Pilose, pilosus.

Pincers, forcipes.

Pitchy, piceus.-I color.

Plaited, mugatus.

Plane, planus.

Pleuræ, pleurx.

Plicate, plicatus.

Point, punctum.

Polyphagous, polyphagus.

Porose, porosus.

Porrect, porrectus.

Posterior, posterior.

Preocular, preocularis.

Prismatic, prismalicus.

Prominent, proeminens.

Promuscis, promuscis.

Protuberance, gibba.
Pseudopodous, pseudopodus

Pubescent, pubesicens.

Pulverulent, pulverulenlus.

Punctate, punclalus.

Punctulate, punchulatus.

Punctured, punclalus.

Pupa, pupa.

Pure, purus.

Purple, purpureus.

Pustulate, pustulatus.

Pyriform, pyriformis.

Quadrate, quadralus.

Quiet, in quiete.

Redial, radialis.

Radicle, radicula.

Ramose, ramosus.

Rare, ravus.

Recurrent, recurrentes.

Red, ruber.-I. color.

Redbrown, muidus. $-V$. color.

Reflexed, reflexus.

Region, area.

Reticulate, reliculatus.

Ring, ammulus.

Roofshaped, lectiformis.

Rose coloured, roseus.-V.color.

Rostrum, rostrum.

Rotundate, rotundalus.

Rude, rudis, asper.

Rufous, ru/us. $-V$. color.

Rugose, rugosus.

Runner Legs, cursorit pedes.

Rutilous, rutilus $-V$. color.

Saffronyellow, croceus.-V.color

Sagittate, sagillatus.

Sanguineous, sanguineus.

Saw, serra.

Scabrous, scaber.

Scale, squama.

Scape, scapus.

Scariose, scariosus.

Scutiform, clypealus.

Seagreen, glaucus.

Securiform, securiformis.

Segment, segmentum. 
Sericeous, sericeus.

Serrate, serratus.

Sessile, sessilis.

Setaceous, setaceus.

Setiform, seliformis.

Setigerous, setiger.

Setose, setosus.

Setulose, setulosis.

Sex, sexus.

Shank, tibia.

Shield, sculum.

Sheat, vagina.

Shining, nitidus.

Short, brevis, angustus.

Shoulder, humerus.

Side, lalus.

Silk, seta.

Similar, similis.

Simple, simplex.

sinuate, simuatus.

Sinus, Sinuosity, sinus.

Sky-blue, corruleus.

Slaty, coruleo-griseus.

Small, gracilis.

Smaragdine, smaragdinus.

Smooth, lavis.

Solid, solidus.

Spatulate, spatulatus.

Species, species.

Specular, specularis.

Sphærical, sphrricus.

Spina, spina.

Spineshaped, spiniformis.

Spinose, spinosus.

Spoonshaped, cochleariformis.

Spot, macula.

Spread of the Wings, expansio alarum.

Spur, calcar.

Spurred, calcaratus.

Squamose, squamosus.

Squamula, squamula.

Stalk, caulis.

Steel coloured, chalybeatus.

Stemmata, stemmata.

Stickshaped, baculiformis.

Stigma, sligma.

Stigmata, stigmata.

Sting, aculeus.

Sthraight, rectus.
Straitened, angustalus.

Straw coloured, straminens.

Striate, striatus.

Striga, striga.

Strigate, strigatus.

Stripe, fascia.

Stylet, spiculum.

Submarginal, submarginalis.

Subocular, subocularis.

Subulate, subulatus.

Sulca, sulcus.

Sulcate, sulcatus.

Sulfureyellow, sulfureus.

Superior, superior.

Suture, sutura.

Swoked, fumatus.

Tail. cauda.

Tarsus, tarsus.

Tawny, fulvus.

Tegulæ, tegulæ.

Tegument, tegumentum.

Temples, tempora.

Tergum, tergum.

Testaceous, testaceus.

Tetragon, tetragonus.

Tetrameri, tetrameri.

Thick, crassus.

Thigh, femur.

Thorax, thorax.

Tibia, tibia.

Tip, apex.

Tomentose, tomenlosus.

Tooth, dens.

Toothed, dentakis.

Toothshaped, dentiformis.

Trachea, trachia.

Translucid, translucidus.

Transverse, transversus.

Trapezoïdal, trapezoidalis.

Triangular, triangularis.

Trimeri, trimeri.

Trochanter, trochanter.

Truncate, truncalus.

Tubercle, tuberculum.

Tunicate, tunicatus.

Turbinate, turbinatus.

Umbilicate, umbilicatus.

Unarmed, mulicus. 
Undate, unclatus.

Undulate, undulatus.

Unequal, inrqualis.

Unguiculate, unguiculatus.

Valvule, valvula.

Variolosus, variolosus.

Vein, nervus, vena.

Velutinous, velutinus.

Velvetblack, atrovelutinus.

Venter, venter.

Ventose, ventosa.

Vermiculate, vemiculatus.

Verrucose, verrucosus.

Versatile, versatilis.

Vertex, vertex.

Vertical, vertical.
Vesicular, vesicularis.

Vibratile, vibratilis.

Villose, villosus.

Violet, violaceus.

Vitreous, vitreus.

Vulgar, vulgaris.

Vultus, vultus.

Wart, verruca.

IVhite, albus.

Whitish, albicans.

Widened, elatus.

Wingless, apterus.

Wings, alx.

Wrinkled, corrugatus, rugosus.

Yellow, flavus. 



\section{TABLE}

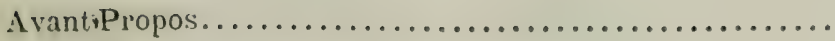

\section{De l'Entomologie en général.}

1. Les études entomologiques.............. I

2. La nomenclature entomologique......... vi

3. Aperçu historique sur la classification des insectes en général ............... x.tu

II. Etude particulière des Insectes hyménoptères.

?. I I $^{\text {er }}$ Formation des Collections.

1. Chasse aux hyménoptères............. xis

2. Préparation................................

3. Conservation des collections .......... xixiv

4. Rédaction du catalogue................ xxxvi

5. Détermination des insectes et usage des tables dichotominues................. xxxvis

8. II. Structure externe ...................

1. Tête..............................

2. Pièces fixes de la tête................ xu

1. Yeux...................... xun

2. Ocelles..................... xhir 
3. Pièces mobiles de la tête.

1. Antennes ..................... Xl.

2. Parties de la bouche............. xhvi

4. Thorax......................... LIII

1. Prothorax ................. LIV

2. Mésothorax................... LV

3. Métathorax .................. Lvı

5. Appendices du thorax.

1. Pattes....................... Lix

2. Ailes....................... L.xu

Tableau synonymique des diffẻrentes parties de l'aile antérieure des hy ménoptères,.................

1. Bords de l'aile...............

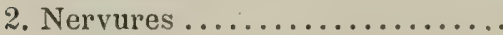

A. Nervures longitudinales ....

B. Nervures transversales ....

3. Cellules..................

Tableau spécial de la synonymie des diffẻrentes parties de l'aile des Chalcidites................. Lxxix

Synonymie du carpe ou stigma....

6. Abdomen

7. Appendices de l'abdomen.

1. Organes femelles

LXXXIV

2. Organes mâles.

Lxxxv111

8. Neutres.

LXXX1:

\section{₹्द III. Fonctions de Reproduction.}

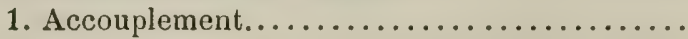

LXXX

I.XXX

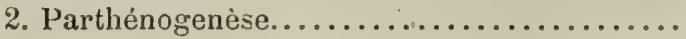

3. Ponte

$\mathrm{xc}$

xClII

$\mathrm{xClv}$

$\mathrm{xCV} 1$

xcvil

xcvil

3. Nymphes ....................... C11

\& V. Physiologie et biologie générales.

1. Nourriture ...................... CVI

2. Station-mprogression................ cvill

3. Produits de sécrétion................. $\mathrm{cx}$

4. Moyens de défense, parasitisme.......... cxı 
5. Instinct.......................... c.m

6. Industrie, mours ................ cxv

8 VI. Distribution gèographique ............ cxix

\& VII. Division des Hyménoptères en familles naturelles....................... Cxxin

\& VIII. Tableau analytique des familles ......... cxxvit

III. Mibliographie des ouvrages généraux..... cxixil

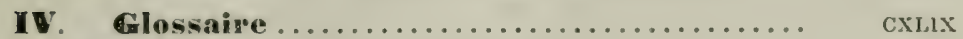

Glossaire latin-français........... CL1

v. Terminologie francaise.............. chxvi

VI. Terminologie alleanande ............ Chxxi

VI. Teminologie anglaise.............. chxxu 



\section{EXPLICATION}

\section{DES PLANCHES}

TUME 1. 


\section{PLANCHE I.}

\section{Tête et Pièces de la Bouche}

Fig. 1. Devant de la tête de Vespa Crabro.

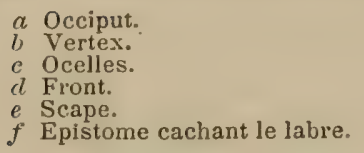

$g$ Mandibules.

$h$ Joues.

$i$ Yeux.

l. Fossettes antennaires.

$l$ Radicule ou Torulus.

$m$ Antennes.

Fig. 2. Mâchoire de Vespa Crabro.

a Tige.

c Palpe maxillaire.

Fig. 3. Mandibule de Blastophaga, pourvue d'un appendice (d'après Wes(wood).

Fig. 4. Mandibule de Blastophaga, vue latéralement (d'après Westwood).

Fig. 5. Lèvre de VespaCrabro.

$$
\text { a Menton. }
$$

$b$ Languette.

c Palpe labial.

Fig. 6. Labre de Vespa Crabro.

Fig. 7. Nandibule de Leucospis gigas (d'après Blanchard).

Fig. 8. Labre de Leucospis gigas

Fig. 9. Nandibule de Bethylus formicarius (d’après Audouin).

Fig. 10. Màchoire de Perilampus auratus (d'après Błanchard), mếmes lettres que figure ?.

Fig. 11. Mandibule d'A masis lieta.

Fig. 12. Bouche de Megachile centuncularis.
a Tige de la machoire
$b$ Lobe de la machoire
c Palpe maxillaire.
$e$ Languette.
$f$ Palpe labial.
y Place des paraglosses invisibles.
d Menton.

Fig. 13. Mâchoire de Bombus lapidarius.
a Tige.
$b$ Lobe
c Palpe maxillaire.
c Membrane du pharynx.

Fig. 14. Mandibules de Polyergus rufescens.

Fig. 15. Mandibules et devant de la tête de Formicide.

Fig. 16. Mâchoire de Leucospis gigas (đ'après Blanchard).

Fig. 17. Lèvre de Leucospls gigas

mêmes lettres que fig. 5.

Fig. 18. Palpe labial d'Astata boops

Fig. 19. - d'Evania appendigaster -

Fig. 20. Mâchoire de Lycophaga rrassipes (l'après Vestwood).

Fig. 21. — de Chalcis minuta (d'après Audouin).

Fig. 22. Lèvre de Lycophaga crassipes (d'après Westwood).

Fig. 23. Nâchoire de Blastophaga

Fig. 21. Mandibules d'Emphylus (d'après Hartig).

Fig. 25. - de Myrmica (d'après Lepelletier).

Fig. 26. - de Tenthredo (d'après IIartig).

Fig. 27. Pièces de la bouche de Cladius (d'après Hartig).
a Machoire.
$b$ Lèvre.

Fig. 28. Mandibule do Bombus lapidarius. 
Species des Hymén. Introduction.

P1. 1

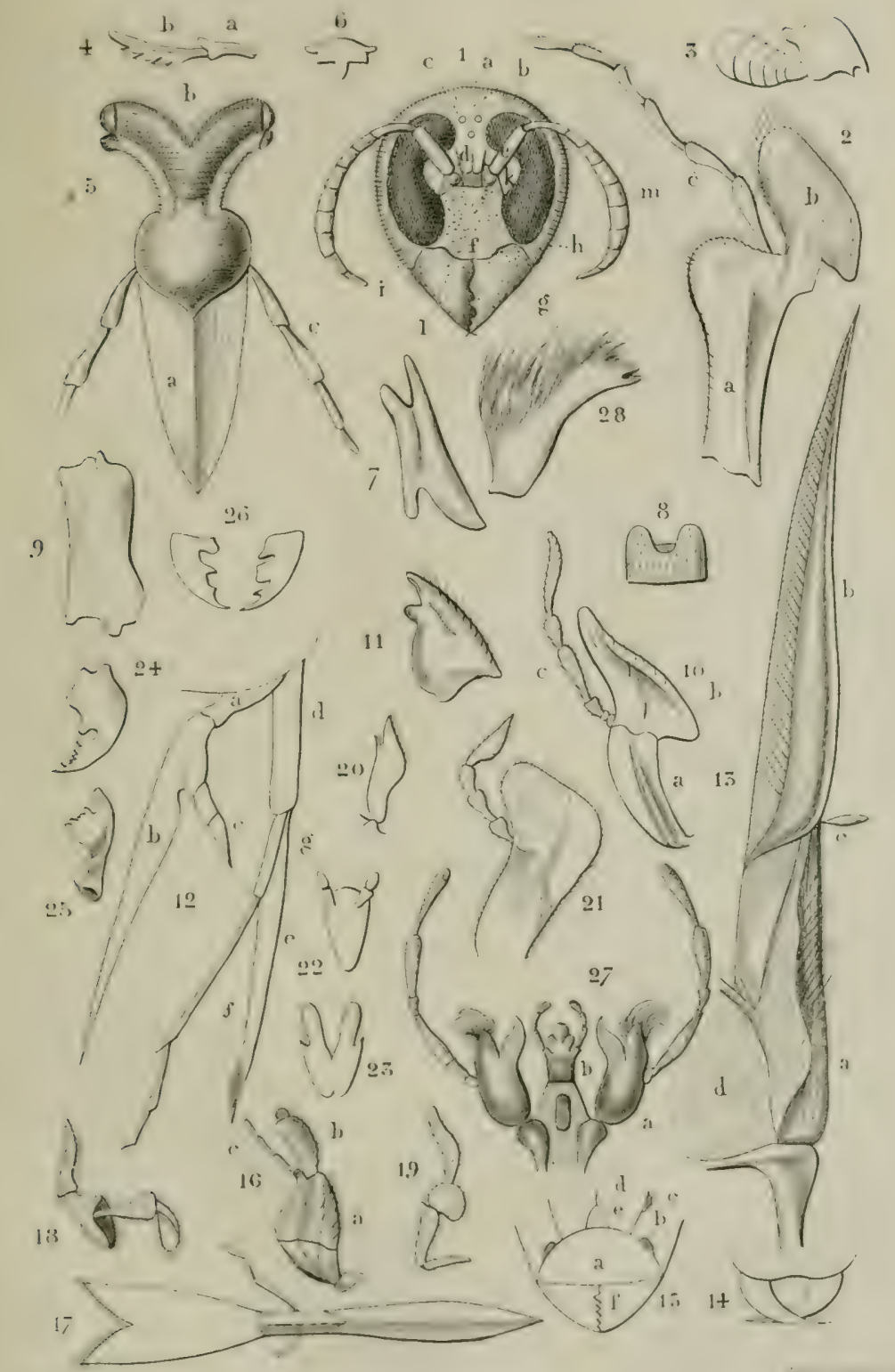

Ed.André, del.

Tête _ Pièces de la Bouche. 




\section{PLANCHE II.}

\section{Antennes}

Fig. 1. Antenne de Phasganophora 우 (coudée, filiforme).

Fig. ?. - d'Hylotoma rosarum.

Fig. 3. - d'Encyrtus (coudée, moniliforme, massue foliacée)

Fig. 4. - de Pteromalus of (filiforme).

Fig. 5. - - ot (moniliformes).

Fig. 6. - de Torymus bedequaris ơ (moniliforme coudée).

Fig. 7. - de Podagrion pachymerus (claviforme, coudée).

Fig. 8. Scape de Tetrastichus obscuratus 9

Fig. 9. Antenne de Misochoris oomysus (daprès Rondani).

Fig. 10. Antenne de Misochoris oomysus (d apress Rondani).

Fig. 12. - d'Abianitens (massue articulée).

Fig. 13. - de Chulcis minuta (épaisse).

Fig. 11. - de Lophyrus pini o (d'apres Hartig) (dentée en scie,

Fig. 15. - - - (pectinée pennacée)

Fig. 16. - de Chalcis pectinicornis o" (daprès L. Dulour) (fusiforme).

Fig. 17. -

Trio 18 - d'Ichneumonirle (sétacée)

Fig. 19. - de Cladius ơ (d'après IIartig) (pectinée).

Fig. 20. Scape d'Halticella denticornis.

Fig. 21. Antenne d'Omphale viticola (d'après Rondani)

Fir. 22. - de Blastophaga (d'après Westwood) (irrégulière).

Fig. 23. Base de l'Antenne d'un Thynnus of (cupuliforme).

Fig. 2'. Antenne de Cephus pygmixus (claviforme, non coudée).

Fig. 25. - de Lyda (sétiforme).

Fig. 26. - d'Arpactus (extrémité) (en crochet).

Fig. 27. - dA masis obscura (massue inartículée).

Fig. 28 - de Schizoccra furcata o" (fourchue).

Fiv. 29. - de Chirocerus (d'après Lepelletier) (flabellée)

Fig. 30. - de Celonites abbreviatus massue avec une apparence inarticulée).

Fig. 31 - do Philanthus triangulum (cultriforme).

Fig. 32. - de Elachistus phytomizx (d'après Rondani).

Firr. 33. - de Bombus terrestris (filiforme).

Fig. 34. - de Pompilus viaticus (filiforme).

Fig. 35. - de Joppa antennata (d'après Lepelleticr) (subulée). 
Species des Hymén. Introduction.

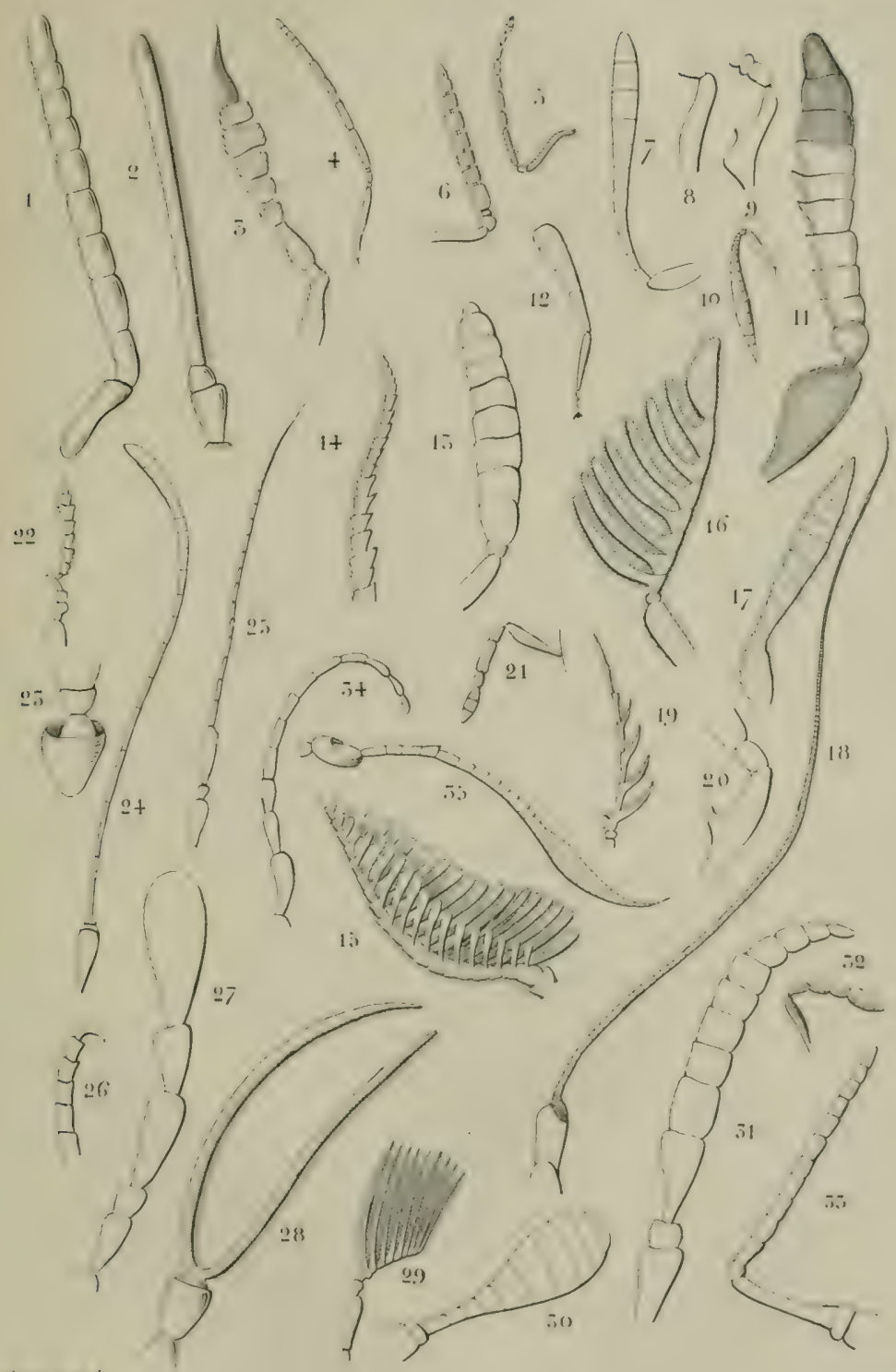






\section{PLANCHE III.}

Thorax. - Pattes.

Eig. 1. Thorax de Vespa crabro (vu de côté), mêmes lettres qu'à la ligg. 2. Fig. 2. - - (vu par dessus.)
a Pronotum.
$b$ Prosternum.
- Scutum du mésothorax.
¿l Scutellum du mésothorax.
$e$ Division du scutum formant parap- sides.
$f$ Ecaillette.
Gpisternum du mésothorax,
$h$ Epimeres
$i$ Articulation de l'aile antérieure.
j. Scutum du métathorax.

let Episternum du métathorax.

$l$
$m$ Articulation de l'aile postérieure.

$n$ Faux stigmate.

o Hanche antérieure.

p - intermédiaire.

$q$ - postérieure.

7. Segment médiaire ou premier sersment abdominal.

$s$ Funiculus.

$t$ Abdomen.

y Stigmates du segment médiaire.

Fig. 3. Thorax de Torymus (vu de côté), mêmes lettres qu'à la fig. ?.

Eig. 4. - de Formica pratensis $\not$.

Fig. 5. Ecaillette de Vespa crabro.

Fig. 6. Patte postérieure de Torymus.
a Hanche,
$b$ Trochanter bi-articulé.
e Cuisse.
e Eperon.
$f$ Tarse de 5 articles.
$g$ Ongles.

d Tibia.

Fig. 7. Patte postérieure de Podagrion pachymerus.

Fig. 8. - d'Abeille ouvrière.

Fig. 9. - de Smicra.

Fig. 10. Hanche (dentée) de Monodontomerus.

Eig. 11. Patte postérieure de Blastophaga (d'après WVestwood).

Fig. 12. Ongle bidenté.

Fig. 13. - unidenté. 


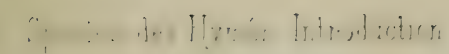

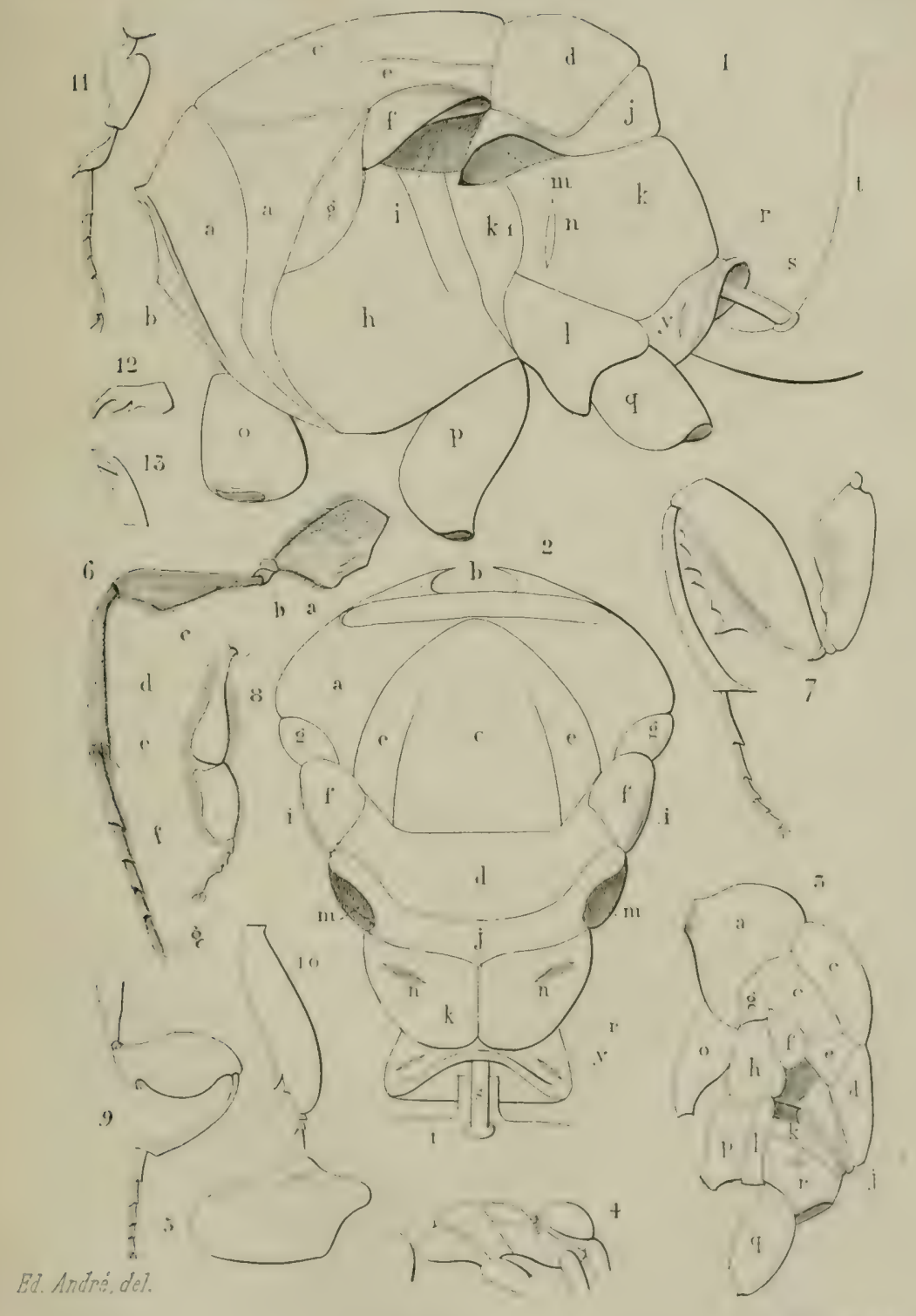

THORAX-PATTES. 




\section{PLANCHE IV.}

\section{Ailes.}

1. Ailc supéricure d'un hyménoptère contenant toules les cellules et toutes les nervures qui pouvent y exister (tigure theorique).
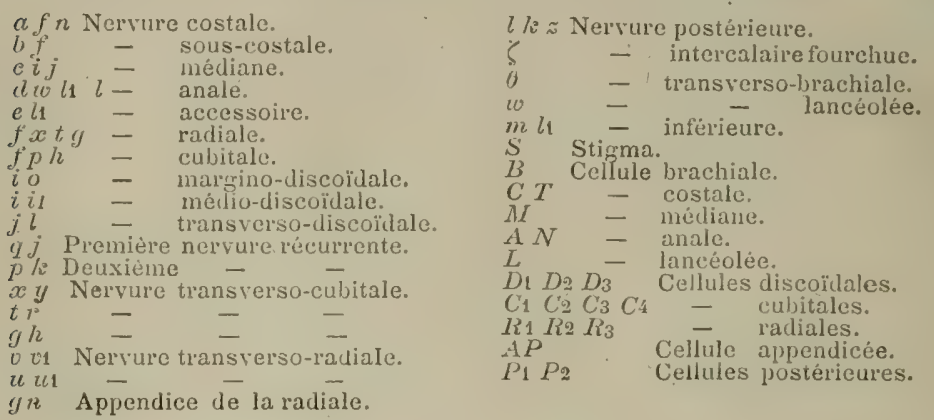

2. Aile inférieure d'un hyménoptère (ligurs théorique).

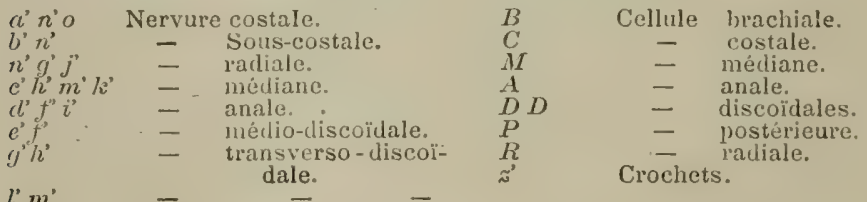

3. Aile supérieure de Chalcidite (figure théorique).
$x \beta \gamma \delta$ Nervure sous-costale.
* $\beta \quad$ Rameau huméral.
$\gamma \omega$
$\gamma \delta$
Rameau stigmatical.
ק. $\gamma$
- marginal.
- post-marginal.

\section{Aile supéricure théorique d'Ichneumonide.}

a Aréole.

5. Aile supérieure de Cynipide.

6. $\quad$ - de Proctotnupide (Platygns!cr).

7. - - - (Prosacantha).

8. - - - (Mymar pulchellus).

9. - de Chalcielite(Macrosticrma aphiclum) d'après Rondani.

10. - de Proctolmupide Flajorinus labarius

11. Cellule lancćolée pétiolće.

12. - ouverte.

13. - longuement contractéc.

1.4. - brievement contractéc.

15. - - divisćc par une nervure oblique.

16. - - droite.

17. Aile supérieure de Chalcidite (Torymus becleguaris, montrant la disposition des cils et des poils.

18. Aile inlérieure du mème. 
Species des Hymén. Introduction.

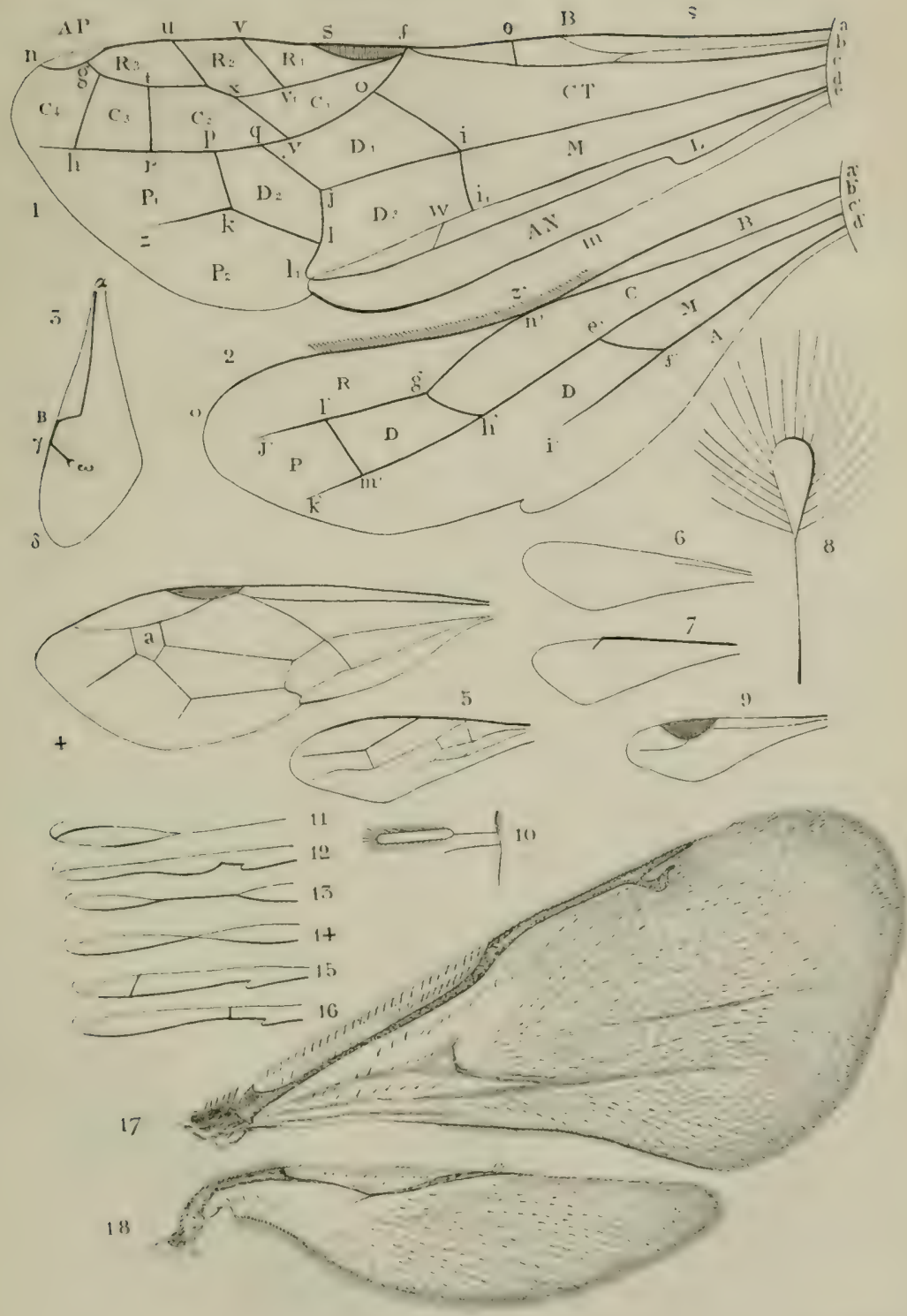

Ed. André, del.

A ILES 



\section{PLANCIIE V.}

\section{Abdomen.}

\section{Abdomen de Vespa Crabro ф}

\begin{tabular}{|c|c|c|c|}
\hline & $\begin{array}{l}\text { Segment médiaire arec ses } \\
\text { stigmates. }\end{array}$ & & $\begin{array}{l}\text { Arceaux ventraux de l'abdo- } \\
\text { men. }\end{array}$ \\
\hline $\begin{array}{l}b \\
c \\
r l 1 \text { \& } d_{b}\end{array}$ & $\begin{array}{l}\text { Funiculus. } \\
\text { Pédicule. } \\
\text { Arceaux dorsaux de l'abdo- } \\
\text { men. }\end{array}$ & $\begin{array}{l}s \\
1 / G \\
f^{\prime} \\
y\end{array}$ & $\begin{array}{l}\text { Stigmates. } \\
\text { Segment apical ou ana!. } \\
\text { Aiguillon. } \\
\text { Thorax. }\end{array}$ \\
\hline
\end{tabular}

?. Septième segment abdominal de Vespa Crabro entièrement caché dans l'intérieur du sixième segment.

d7 Arceau dorsal.

c7 Arceau ventral presque membraneux.

(Le huitième et dernier segment enveloppe directement les organes génitaux et se voit sur la planche VI).

3. Abdomen de C'ynipide (Rhodites rose).

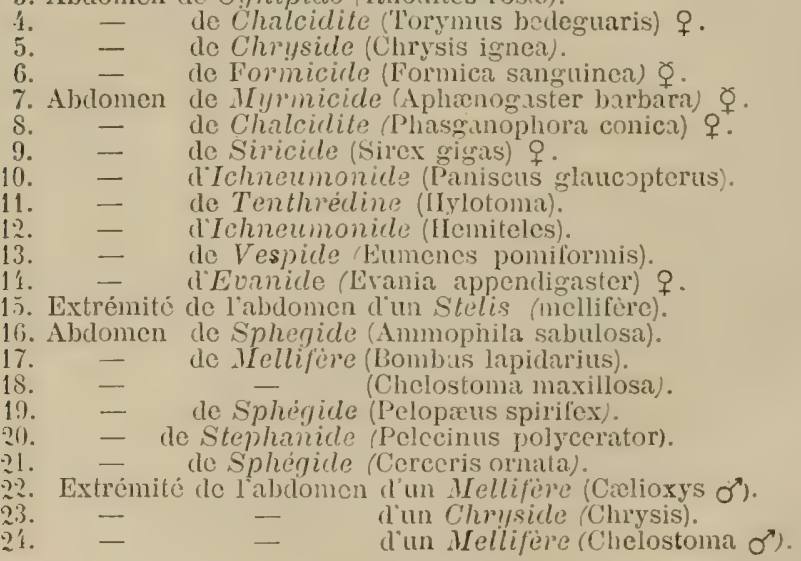


Species des Hymén. Introduction.

PI. V.
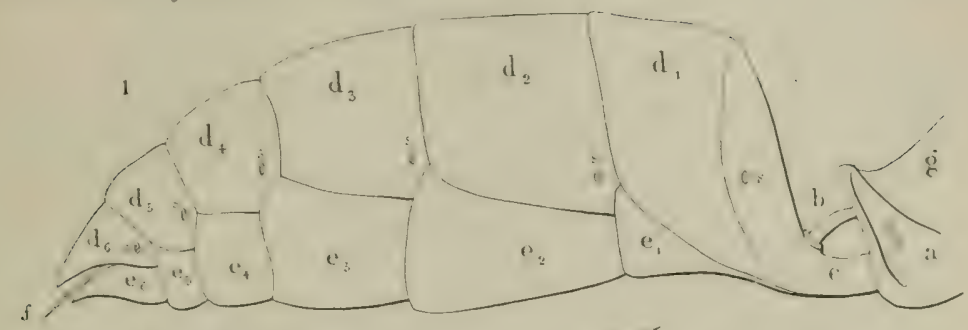

$$
\text { b) Ppi }
$$

j. $\left\{5^{\circ}\right.$
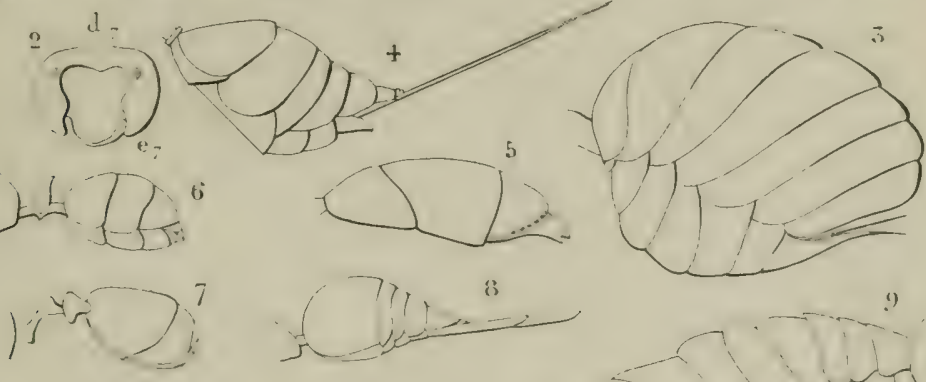

()

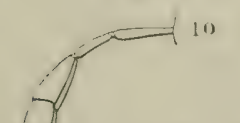

घ
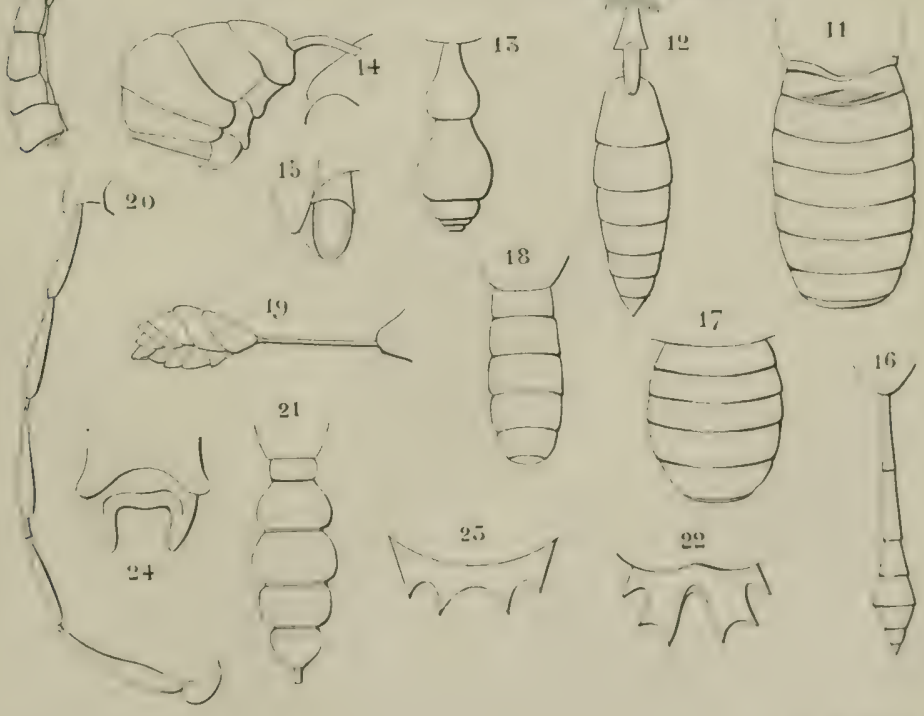

यूิ

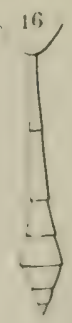






\section{PLANCIrE VI}

\section{Appareils de reproduction et de défense.}

1. Aiguillon de Vespa Crabro, et pièces annexes.

(L'aiguillon est ałaissé hors de sa position normale pour en montrer les diverses parties).

a Rectum

b) Oviducte

c. Gaine de l'aicruillon.

ds Epipyrium, ou huitieme arcenu (lorsal transformé en une (louible écaille.

es Hypoprgium ou huitieme arceau ventral transformé aussi en une clouble écaille.

$f$ Glande a venin.

g Canal déférent de la glande à venin

conduisant le venin dans la gaine.

h Support des stylets relié ¿̀ l'épipygium et,par un prolongement en arc, it l'hypopycium.

l. Support de la saine, relié à l'hypopygium.

m Fourreau, prolongement de l'hypopygium enserrant la gaine, quand elle est dans sa position ite repos.

․ Gaine vue de face (mêmes lettres que fig. 1).

3. Couje grossic de la gaine et des stylels, montrant l'emboitement de cenx-ci.

1. Extrénité de la guine et des stylels de Vespa Crabro.

5. - - llu stylet d'un Chalcidite (Torymus).

6. - Stephanido (Pelecinus).

7. Stylet ou scic de Cimbex (diapres Hartig).

s. Extrémité dia strlet d'un Ichneumonide (Ephialles).

!. - - Evanide (Erania).

11. - $\quad$ - C Chalcidite (Phasganophora).

11. Organes génératcurs cxternes o" dim Bourdon (Bombus terrestris).

1:. Gaine de la tariere d'un Cimbex (d'anpès IIartig).

1.i. Organes ginirateurs o" exteries de Loph?!rus pini (daprès Iartig).

1:. Extrénito do labdomen d'un Proctotrupirle (Blastophaga) arec la fariere naissant à la pointe de cet aludomen.

1.). Ajdomen din Ichnermonide, montrant la naissanec de la tarière sous le ventre.

16. Fragment ic l'extrémité de l'aladomen d'un Leucospis (Chalcidite), montrant la tarière recourbée sur le dos. 
Species des Hymén. Introduction.

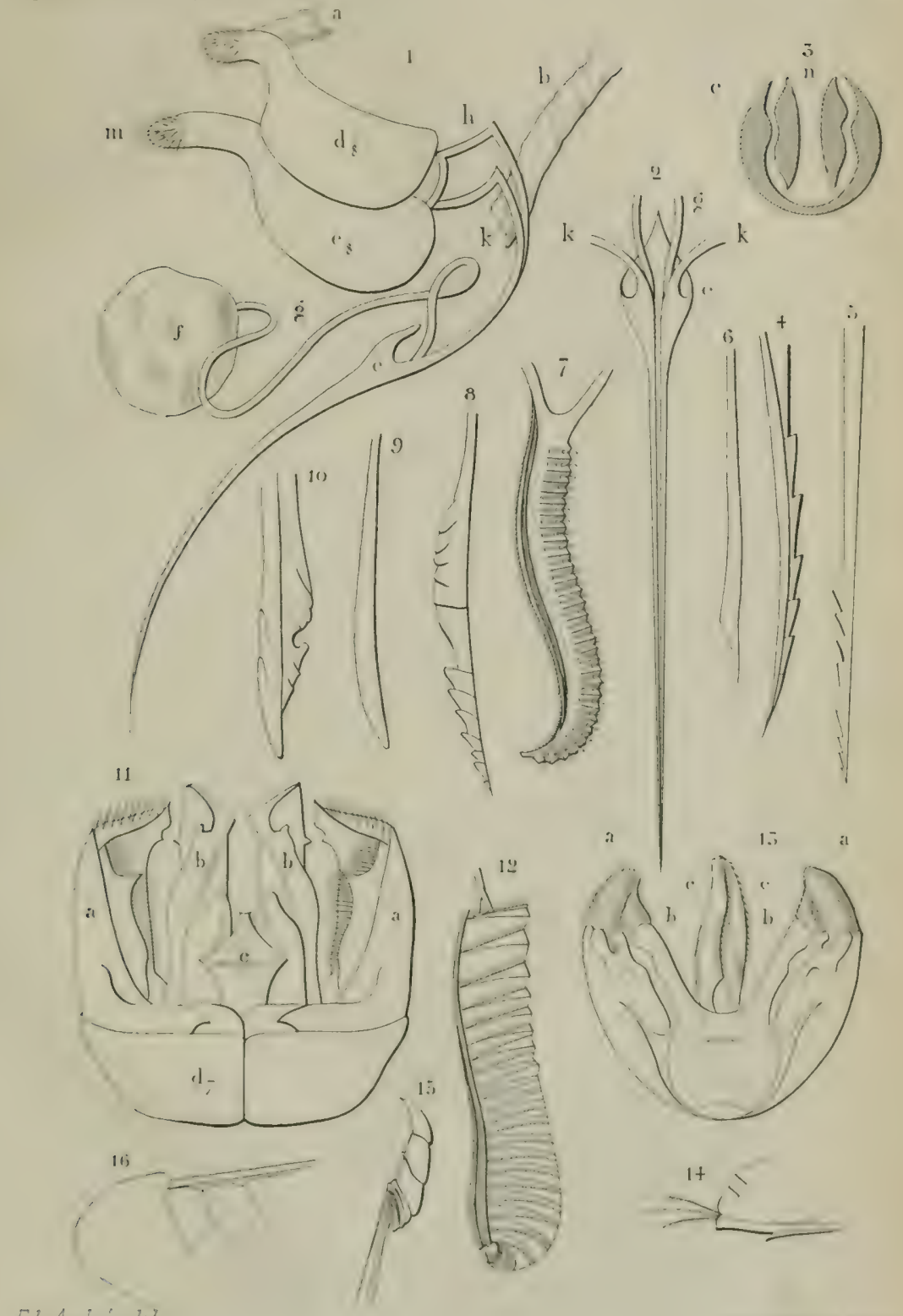

Fi. Andié, del.

Organes de la Reproduction. 




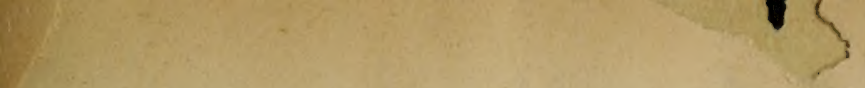




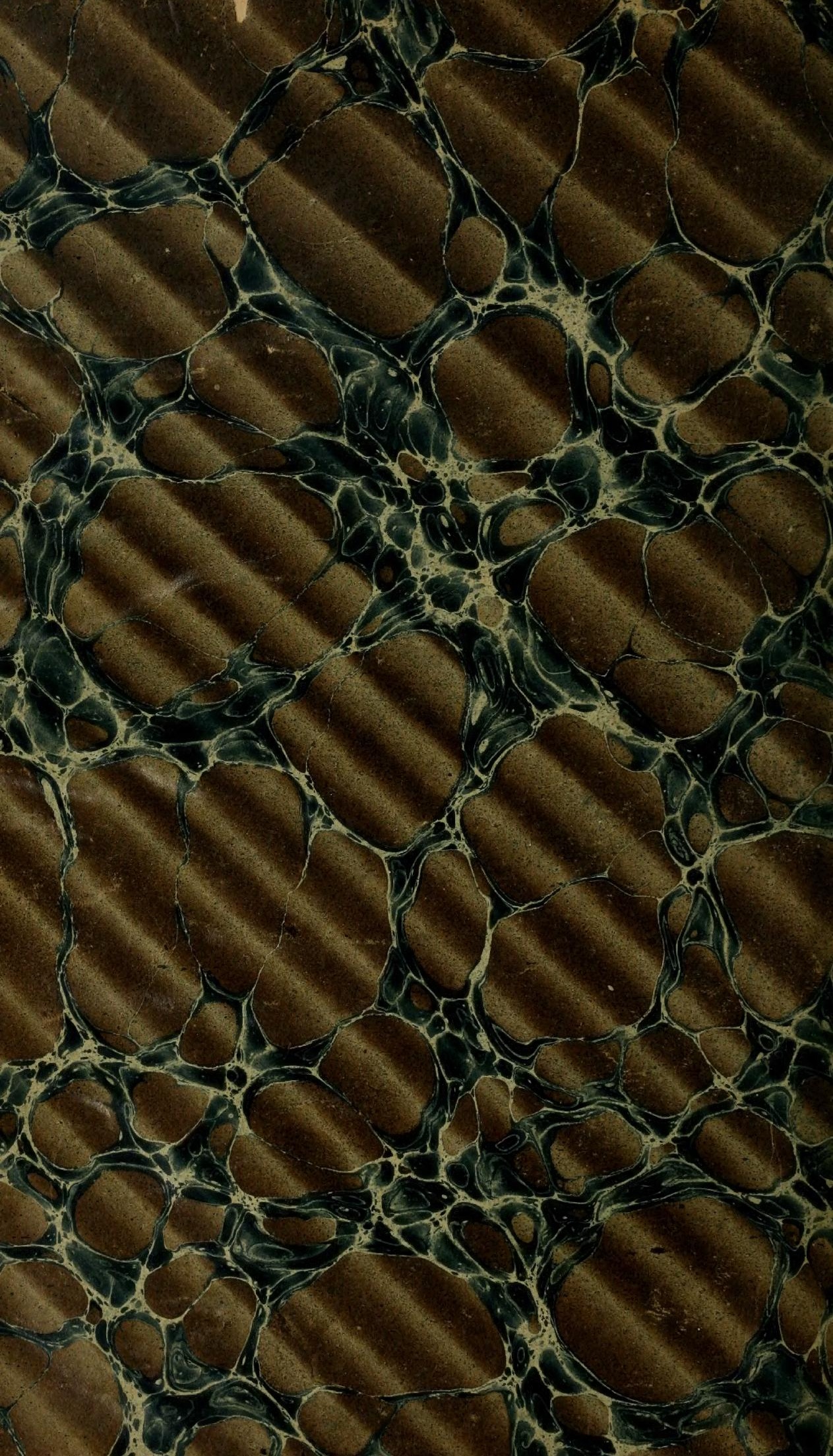


